\title{
ECC PERFORMANCE IN THE SEMISCALE GEOMETRY
}

\author{
D.J. Hanson \\ C.E. Cartmill \\ K.R. Perkins \\ C.J. Shaffer \\ D.M. Snider
}

\section{Aerojet nuclear Company NATIONAL REACTOR TESTING STATION Idaho Falls, Idaho -83401}

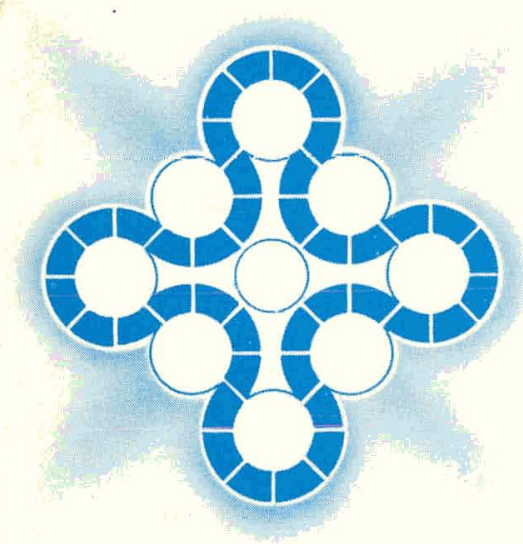

\section{U. S. ATOMIC ENERGY COMMISSION}




\section{DISCLAIMER}

This report was prepared as an account of work sponsored by an agency of the United States Government. Neither the United States Government nor any agency Thereof, nor any of their employees, makes any warranty, express or implied, or assumes any legal liability or responsibility for the accuracy, completeness, or usefulness of any information, apparatus, product, or process disclosed, or represents that its use would not infringe privately owned rights. Reference herein to any specific commercial product, process, or service by trade name, trademark, manufacturer, or otherwise does not necessarily constitute or imply its endorsement, recommendation, or favoring by the United States Government or any agency thereof. The views and opinions of authors expressed herein do not necessarily state or reflect those of the United States Government or any agency thereof. 


\section{DISCLAIMER}

Portions of this document may be illegible in electronic image products. Images are produced from the best available original document. 


\section{DISCLAIMER}

This report was prepared as an account of work sponsored by an agency of the United States Government. Neither the United States Government nor any agency Thereof, nor any of their employees, makes any warranty, express or implied, or assumes any legal liability or responsibility for the accuracy, completeness, or usefulness of any information, apparatus, product, or process disclosed, or represents that its use would not infringe privately owned rights. Reference herein to any specific commercial product, process, or service by trade name, trademark, manufacturer, or otherwise does not necessarily constitute or imply its endorsement, recommendation, or favoring by the United States Government or any agency thereof. The views and opinions of authors expressed herein do not necessarily state or reflect those of the United States Government or any agency thereof. 


\section{DISCLAIMER}

Portions of this document may be illegible in electronic image products. Images are produced from the best available original document. 


$$
\begin{gathered}
\text { Printed in the United States of America } \\
\text { Available from } \\
\text { National Technical Information Service } \\
\text { U. S. Department of Commerce } \\
5285 \text { Port Royal Road } \\
\text { Springfield, Virginia } 22151
\end{gathered}
$$

Price: Printed Copy $\$ 7.60 ;$ Microfiche $\$ 1.45$

\section{LEGAL NOTICE}

This report was prepared as an account of work sponsored by the United States Government. Neither the United States nor the United States Atomic Energy Commission, nor any of their employees, nor any of their contractors, subcontractors, or their employees, makes any warranty, express or implied. or assumes any legal liability or responsibility for the accuracy, completeness or usefulness of any information, apparatus, product or process disclosed, or represents that its use would not infringe privately owned rights. 


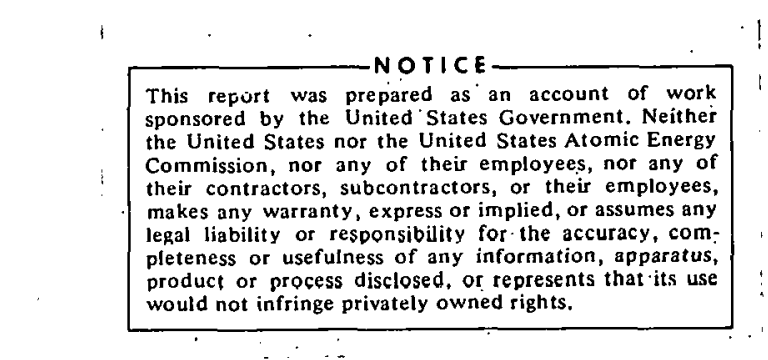

ECC PERFORMANCE IN THE SEMISCALE GEOMETRY

by

D. J. Hanson

C. E. Cartmill

K. R. Perkins

C. J. Shaffer

D. M. Snider

\section{AEROJET NUCLEAR COMPANY}

Date Published - June 1974

PREPARED FOR THE U. S. ATOMIC ENERGY COMMISSION IDAHO OPERATIONS OFFICE

UNDER CONTRACT NO. AT(10-1)-1375 


\section{AGKNOWLEDGMENTS}

The authors wish to express their thanks to the personnel of the Fluids Laboratory Division for their.efforts in conducting the tests and gathering the test data, to the personnel of the Test Integration and Coordination Section for verification and documentation of the data, to K. A. Dietz for her efforts in editing and improving the quality of the overall-report, to $\mathrm{L}$. K. Keller for her patience and persistence in typing and correcting this report, to D. C. Mecham and D. J. Barnum for their.work in setting up the RELAP4 computer model of the isothermal system and for supplying the computer calculations, and to R. W. Shumway for writing Appendix D to document the hot-wall data correlation method which he originally developed. 


\begin{abstract}
Selected experimental data from ECC investigations performed as part of the Semiscale Blowdown and Emergency Core Cooling (ECC) Project are analyzed. The analysis is confined to data that describe ECC-related phenomena in the cold leg, upper annulus, downcomer, and lower plenum because these components represent the path the ECC must follow to reach a position where cooling of a core could result. The semiscale project data and the analysis presented in this report are valuable for evaluating the adequacy and improving the predictive capability of analytical models developed to predict system response and ECC behavior during a postulated loss-of-coolant accident in a pressurized water reactor.
\end{abstract}




\section{SUMMARY}

An extensive water-cooled nuclear reactor research program is currently being carried out by Aerojet Nuclear Company under the sponsorship and direction of the Atomic Energy Commission. As part of this research program, the Semiscale Blowdown and Emergency Core Cooling (ECC) Project has progressively used more complex and better scaled experiments to investigate many of the complex and interrelated phenomena that occur during a loss-of-coolant accident (LOCA).

The most recent semiscale experimenlal program reprcsents the most comprehensive effort to date to investigate both the phenomena that occur during ECC injection and the interrelationship between these phenomena. This program was made up of three different test programs which were coordinated to initially provide a basic understanding of countercurrent flow phenomena with both air-water and steam-water mixtures in steady state experiments and then to progressively investigate these phenomena, as well as other ECC-related phenomena, in transient experiments using steam-water mixtures with energy transfer from the system boundaries.

Analysis of the data produced from the recent experiments has provided an understanding of the phenomena controlling ECC behavior in the semiscale geometry, and the system - response data are currently being used for evaluating the adequacy and improving the predictive capability of analytical models developed to predict both system response and ECC behavior during an LOCA. The semiscale experimental results, through comparison with data from similar experiments in larger geometries, provide a basis for evaluating the effects of physical scale. However, since the semiscale system is small compared to a pressurized water reactor (PWR) and compromises were necessary in scaling this smaller system from a larger system, the phenomena associated with ECC injection in the semiscale geometry cannot be related directly to the ECC associated phenomena in a PWR.

The three different recent test programs included the transparent vessel test program, the semiscale system countercurrent flow test program, and the isothermal test program.

The transparent vessel tests were steady state, air-water, separate effects tests that provided data on downcomer countercurrent flow and bypass phenomena. The transparent vessel test system consisted of a plexiglass vessel connected to an air and water supply system and to a drain system for the water. The plexiglass vessel allowed visual and photographic observations to be made of the phenomena occurring in the upper annulus (the area directly above the downcomer), the downcomer, and the lower plenum regions of the vessel. The design of the vessel allowed changes in the geometry of the upper annulus region and the downcomer region to be made such that the effect of the geometry of these regions on countercurrent flow could be investigated. 
The semiscale system countercurrent flow tests consisted of both steady state and transient separate effects tests which were aimed at investigating steam-water countercurrent flow behavior in the semiscale vessel. These tests were conducted to supply data on the effects of condensation and evaporation on the countercurrent flow phenomena. The semiscalé system countercurrent flow test apparatus consisted of the 1-1/2-loop semiscale pressure vessel, a phase separator, and a storage tank. The vessel was connected to a steam supply and to the storage tank which supplied the water. The phase separator was used to separate the two-phase fluid exiting the top of the vessel into components so that singlephase flow measurements could be made. The system configuration was varied slightly during the test program to meet the needs of each test.

The isothermal test program consisted of transient blowdown integral effects tests, a number of which were aimed at investigating the effects of different semiscale system configurations on ECC performance, and transient ECC delivery tests in the absence of blowdown but with the system metal walls hot. The transient hot-wall ECC delivery tests were performed following the completion of blowdown tests. The 1-1/2-loop isothermal semiscale system consisted of a pressure vessel with simulated reactor internals, an intact loop. with a steam generator, pump, and pressurizer; a blowdown loop with rupture assemblies, a simulated steam generator, and a simulated pump; a pressure suppression system with a suppression tank and header; and a coolant injection system.

Selected experimental data from the recent ECC investigations in the semiscale geometry are analyzed. The analysis has been confined to data that describe ECC-related phenomena in the cold leg, upper annulus, downcomer, and lower plenum. These components represent the path the ECC must follow in a PWR to reach a position where cooling of the core can result. Representative data from these parts of the system are presented together with calculated results and a comparison is made between the trends predicted by analytical tools, including the RELAP4 computer core, and the trends measured by the system instrumentation. The discussion of the analysis begins with the cold leg data analysis and proceeds with a subsequent discussion of each component along the ECC flow path to the lower plenum.

\section{Intact Loop Cold Leg}

The intact loop cold leg piping heat transfer, flow condensation, and mixing processes that occur during ECC injection affect the quality, velocity, and temperature of the fluid entering the upper annulus region of the vessel.

Cold leg piping surface heat fluxes and heat transfer coefficients near the ECC injection port were calculated from pipe wall temperature measurements using an inverse heat conduction method. The calculated wall heat fluxes and heat transfer coefficients were predicted well by single-phase heat transfer correlations indicating that boiling at the pipe walls was suppressed. The suppression of the boiling mechanism appears to result because the ECC flowing in the cold leg pipe retained a relatively large amount of subcooling. 
Measurements made near the pump discharge and near the vessel inlet were used to determine the distribution of the ECC in the cold leg pipe during and following blowdown. During blowdown the measurements near the vessel inlet showed single-phase subcooled water flow entering the vessel, whereas measurements near the pump discharge showed high quality fluid flowing toward the injection port. The momentum of the fluid in the cold leg pipe during blowdown appears to force the ECC toward the vessel. Near the end of blowdown and following the completion of blowdown, some ECC periodically flowed back to near the pump discharge but the active pump forced this flow away from the pump discharge.

The flow and density measurements near the pump discharge provided an indication of the amount of steam condensation occurring in the cold leg. Both condensation of the steam in the blowdown fluid and piping heat transfer influenced the temperature of the ECC flowing in the cold leg with condensation being the strongest influencc. Density measurements about 16 inches downstream of the injection port indicated that condensation was complete by the time the ECC reached this position. The amount of condensation that occurred in the cold leg was nearly the same over a range of ECC injection rates from a near volumetrically scaled injection rate to about 2.4 times the volumetrically scaled injection rate.

The injection of subcooled ECC into the high quality blowdown fluid flowing in the semiscale intact loop cold leg caused pressure fluctuations with an amplitude of about \pm 2 psi. These fluctuations during blowdown were of lower amplitude than the pressure fluctuations observed in the Combustion Engineering Inc. steady state steam-water mixing tests. Following the end of blowdown, the amplitude of the pressure fluctuations in the semiscale system increased but were seldom larger than 10 psi. Some of the Combustion Engineering Inc. data show similar pressure fluctuations whereas other data show much larger pressure fluctuations than those observed in semiscale following blowdown.

\section{Upper Anrulus}

The upper annulus region of the vessel acts as a water distributor for the downcomer during both normal operation and during ECC injection. Instrumentation was not included in the upper annulus region because of the upper annulus geometry and the complex flow patterns caused by this geometry. Therefore, for purposes of analysis, the upper annulus was treated as a lumped system having average properties.

An upper annulus mass balance, using instrumentation at the intact loop and broken loop cold legs, was used to calculate the mass flow at the downcomer entrance. This mass balance exhibited much later flow reversal than the downcomer turbine flowmeter velocity measurements, indicating the possibility of fluid draining down the sides of the downcomer after the flow in the center of the downcomer had reversed. A RELAP4 calculation showed earlier flow reversal at the downcomer entrance than the flow calculated from this mass balance. 
A simplitied energy balance on the upper annulus appears to be accurate enough to calculate an approximate upper annulus bulk fluid temperature. This energy balance indicated that a large perccntage of the energy transferred to the injected ECC came from condensation in the upper annulus region. The condensation occurring in the upper annulus appears to have caused pressure suppression in this region when the ECC injection rate was about 2.4 times the volumetrically scaled injection rate.

\section{Downcomer}

The complex phenomena that occur in the downcomer region can influence the time of delivery and the rate of delivery of ECC to the lower plenum. Downcomer countercurrent flow, bypass flow, and heat transfer phenomena were investigated in the semiscale geometry.

The effect of countercurrent flow on delivery of water to the lower plenum was investigated in the semiscale geometry. The form of the Wallis countercurrent flow correlation was shown to correlate the air-water countercurrent flow data in the semiscale geometry for individual downcomer gap sizes to a single line. The density term in the Wallis correlation correlated countercurrent flow data for pressures ranging from 20 to 42 psia. Removal of the geometric factor (the hydraulic diameter term) from the form of the Wallis correlation allowed the resulting dimensional parameters to correlate to a single line the data from downcomer gap sizes ranging from 0.49 to 1.58 inches. A dimensionless parameter was found which also correlated the air-water data and has the capability of correlating countercurrent flow data taken for different types of fluids.

Countercurrent flow in the semiscale size downcomer controlled the water delivery to the lower plenum for air flow rates above a volumetric flux of $\mathrm{J}_{\mathrm{g}}^{* 1 / 2}=0.33$. Below this value, whether countercurrent flow controlled or not depended upon the water flow rate. If the water flow rate was sufficiently large, the gas velocity was forced to be high enough to cause countercurrent flow and cause some restriction of the flow to the lower plenum. If the water flow was not high enough, buoyancy forces and flow sweeping in the semiscale upper annulus appeared to control the delivery to the lower plenum.

The effect on countercurrent flow in the semiscale geometry of upper annulus geometry, two-phase mixtures entering the upper annulus from the cold leg, and downcomer length were investigated in air-water tests. The effects of upper annulus geometry and of a two-phase mixture entering the upper annulus on the countercurrent flow in the semiscale downcomer were negligible. The effect on countercurrent flow of shortening the semiscale downcomer was negligible for all but the shortest length downcomer. For the shortest length downcomer investigated, the velocity of the fluid entering the cold leg appears to influence the delivery to the lower plenum. When the fluid velocity was low, asymmetric flow occurred with most of the water flowing down one side of the downcomer and most of the air flowing up the other side. When the fluid velocity was increased, the water was more evenly distributed around the downcomer and symmetric countercurrent flow in the downcomer occurred. 
Steam-water countercurrent flows investigated in the semiscale geometry were influenced strongly by condensation and evaporation. When the countercurrent, steam flow was not sufficiently high to raise the water that reached the entrance to the downcomer to saturation temperature, the downcomer countercurrent steam flow was completely condensed and all of the water entering the vessel fell to the lower plenum. Energy from the downcomer walls evaporated some of the water in the downcomer causing an increased countercurrent steam velocity in the downcomer and thereby caused less water to be delivered to the lower plenum.

Differential pressure and velocity measurements in the downcomer as well as flow and density measurements at the boundaries to the downcomer were used to aid in an interpretation of the phenomena occurring in the downcomer during blowdown. The differential pressure measurements provided an indication of the density of the fluid in the downcomer over the first 15 to 20 seconds of the blowdown period. This calculated density indicates the existence of axial density differences in the downcomer after about the first 7 seconds of the blowdown. The velocity measurements in the downcomer were uscd with saturation densities to calculate a countercurrent flow dimensional flux during blowdown. These calculated dimensional fluxes are sufficiently high during blowdown to restrict most countercurrent flow of water according to the steady state countercurrent flow correlations derived from air-water and steam-water data. The calculated downcomer densities indicate that the density in the downcomer remains low until the dimensioned volumetric flux drops below a threshold value. Therefore, little water had entered the semiscale downcomer until the completion of blowdown.

The effects of hot downcomer walls on the delivery of ECC to the lower plenum of the semiscale system are exaggerated when compared to the effects of hot downcomer walls on lower plenum delivery in a PWR, because the downcomer surface-area-to-volume ratio in the semiscale system is about a factor of ten higher than this ratio in a PWR. This large difference in downcomer surface-area-to-volume ratio results because of compromises necessary in scaling a small system from a much larger system. The large uninsulated downcomer surface area in the vessel used for the semiscale system countercurrent flow tests and the isothermal system tests allowed sufficient amounts of heat to be transferred to the downcomer fluid to restrict the water flow to the lower plenum for long periods of time. The restriction of water flows into the downcomer appears to result from steam generation at the downcomer walls raising the downcomer steam velocity sufficiently to cause countercurrent flow. The isothermal test results indicated that increasing the ECC injection rate or increasing the downcomer gap size decreased the delay in delivery to the lower plenum that resulted because of hot downcomer walls.

\section{$\underline{\text { Lower Plenum }}$}

The amount of mass remaining in the semiscale lower plenum was calculated from lower plenum density measurements. The mass that remained during blowdown was generally less than that which would have remained if only the mechanisms of flashing and lower plenum heat transfer had affected the lower plenum mass. The large reverse core flow 
that resulted when ECC was injected caused significant lower plenum mass loss over that which occurred during non-ECC tests. The postulated mechanisms of lower plenum water loss that occurred during ECC injection tests were level swell and liquid surface oscillations in the lower plenum which forced water into the downcomer when the downcomer flow velocity was high enough to result in entrainment and subsequent removal of water from the system.

ECC was injected directly into the lower plenum during one isothermal blowdown test. In contrast to the semiscale single-loop lower plenum ECC injection tests, the ECC injected directly into the lower plenum during the isothermal tests was not expelled but accumulated and remained in the lower plenum.

\section{$\underline{\text { Hot -Wall Predictive Method }}$}

A predictive method was developed for the semiscale system to predict the delay in delivery of water to the lower plenum that was caused by the hot downcomer walls. This method is based on the results from the coordinated test program to investigate the ECC performance in the semiscale geometry. The method predicts the delay in lower plenum delivery in the semiscale system with reasonable accuracy. 


\section{NOMENCLATURE}
$A=$ Area $\left(\mathrm{ft}^{2}\right)$
$A_{c}=$ Cross-sectional area $\left(\mathrm{ft}^{2}\right)$
C $=\cdot$ Constant
$C_{\mathrm{f}} \quad=\quad$ Fluid friction factor
$\mathrm{D}=$ Hydraulic diameter $(\mathrm{ft})$
$\mathrm{F}=$ Ratio of two-phase Reynolds number to liquid Reynolds number
$\mathrm{F}_{\mathrm{S}}=$ Control volume surface force
$\mathrm{g}=$ Gravitational constant $\left(\mathrm{ft} / \mathrm{sec}^{2}\right)$
$\mathrm{h} \quad=\quad$ Enthalpy $\left(\mathrm{Btu} / \mathrm{lb}_{\mathrm{m}}\right)$
$\mathrm{h}_{\mathrm{d}}=$ Downcomer wall heat transfer coefficient $\left(\mathrm{Btu} / \mathrm{lb}_{\mathrm{m}}\right)$
$\mathrm{h}_{\mathrm{fg}}=$ Latent heat of vaporization of water $\left(\mathrm{Btu} / \mathrm{lb}_{\mathrm{m}}\right)$
$\mathrm{h}_{\mathrm{in}}=$ Enthalpy of the incoming water $\left(\mathrm{Btu} / \mathrm{lb}_{\mathrm{m}}\right)$.
$\mathrm{h}_{\text {mac }}=$ Chcn macroconvective (forced convection) heat transfer coefficient $(\mathrm{Btu} / \mathrm{hr}-$ $\mathrm{ft}^{2: \mathrm{O}} \mathrm{F}$ )
$\mathrm{h}_{\mathrm{mic}}=$ Chen microconvective (boiling) heat transfer coefficient $\left(\mathrm{Btu} / \mathrm{hr}-\mathrm{ft}^{2}{ }^{\mathrm{o}} \mathrm{F}\right)$
$\mathrm{J}=$ Superficial velocity $(\mathrm{ft} / \mathrm{sec})$
$\mathrm{k}=$ Thermal conductivity (Btu/hr-ft $\left.{ }^{2}-\mathrm{o}_{\mathrm{F}}\right)$
$\mathrm{m}=$ Constant
$\mathrm{m}=$ Mass flow $\left(\mathrm{lb}_{\mathrm{m}} / \mathrm{sec}\right)$
$\mu \quad=\quad$ Viscosity $\left(\mathrm{lb}_{\mathrm{f}^{-}}-\sec / \mathrm{ft}^{2}\right)$
$\mathrm{P} \quad=\quad$ Pressure (psia)
$\Delta \mathrm{P}=\quad$ Pressure differential (psid) 


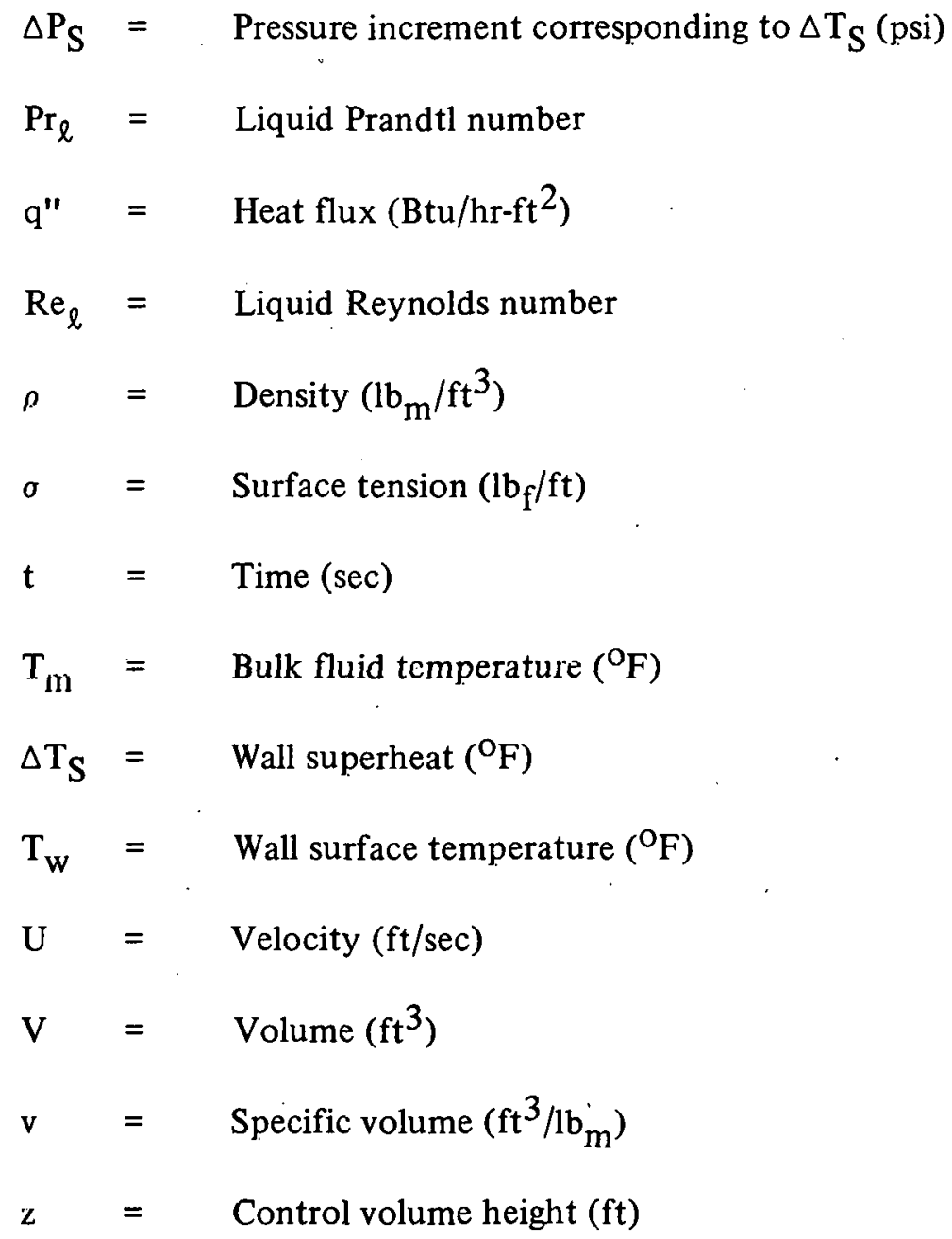

Subscripts

$$
\begin{array}{ll}
\mathrm{d} & =\text { Downcomer } \\
\mathrm{dg} & =\text { Downcomer steam } \\
\text { eff } & =\text { Effective downcomer gas flow } \\
\mathrm{f} & =\text { Saturated liquid } \\
\mathrm{g} & =\text { Gas or saturated steam } \\
\mathrm{i} & =\text { Referenced to either } \ell \text { or } \mathrm{g} \\
\text { in } & =\text { Into downcomer } \\
\ell & =\text { Liquid }
\end{array}
$$




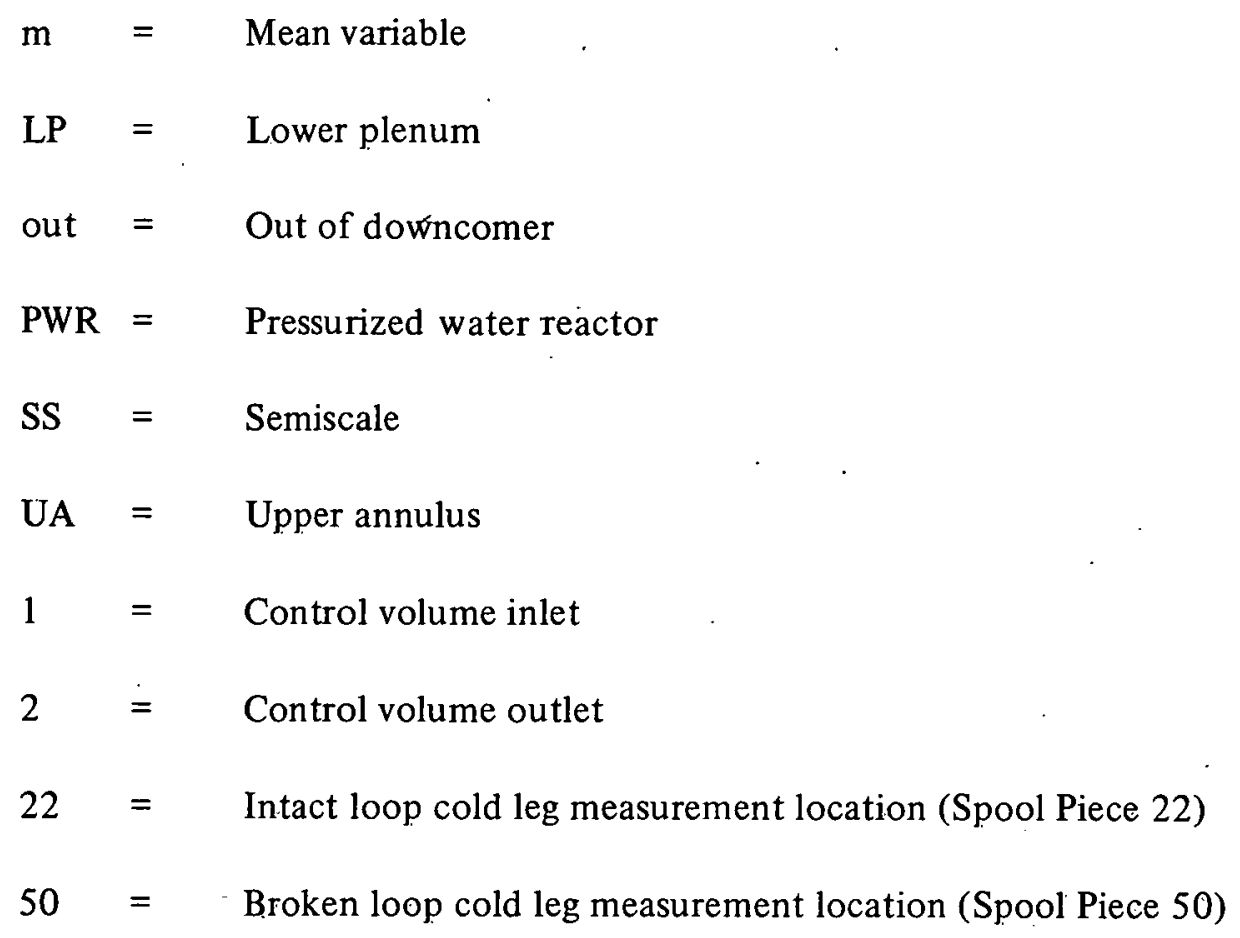




\section{CONTENTS}

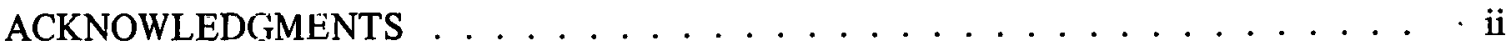

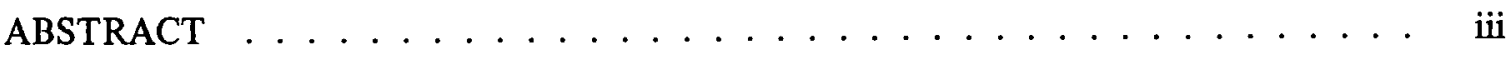

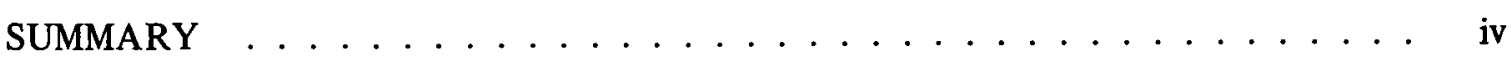

NOMENCLATURE ......................

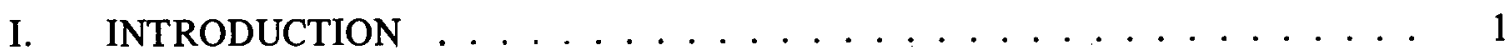

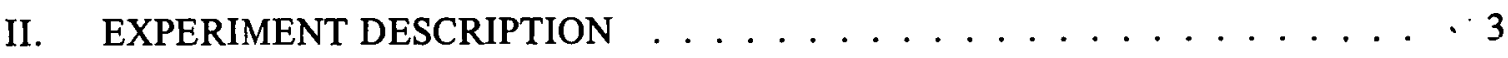

1. TRANSPARENT VESSEL TESTS .................. 3

2. SEMISCALE SYSTEM COUNTERCURRENT FLOW TESTS . . . . . . . 4

3. ISOTHERMAL SYSTEM TESTS ............... 8

III. RESULTS OF DATA ANALYSIS $\ldots \ldots \ldots \ldots$

1. INTACT LOOP COLD LEG PHENOMENA . . . . . . . . . . . 15

1.1 Piping Heat Transfer . . . . . . . . . . . . . . 15

1.2 Cold Leg Fluid Conditions During ECC Injection _. . . . . . . 25

1.3 Cold Leg Pressure and Injection Port Differential

Pressure Fluctuations . . . . . . . . . . . . . 32

2. UPPER ANNULUS PHENOMENA . . . . . . . . . . . . . 37

2.1 Upper Annulus Flow . . . . . . . . . . . . . . . 37

2.2 Upper Annulus Bulk Fluid Temperature . . . . . . . . . . . . . 40

3. DOWNCOMER PHENOMENA .................. 44

3.1 Steady State Countercurrent Flow and Bypass Flow

Phenomena ................... . . 45

3.2 Transient Countercurrent Flow Phenomena . . . . . . . . . 73

3.3 Downcomer Heat Transfer . . . . . . . . . . . . . 88

3.4 Hot-Wall Effects on ECC Delivery ... . . . . . . . . . . 98

4. LOWER PLENUM PHENOMENA . . . . . . . . . . . . . . . . 102

4.1 Effect on Lower Plenum Mass Due to Cold Leg ECC

Injection ....................... 103 
4.2 ECC Injection into the Lower Plenum _. . . . . . . . . 106

4.3 Hot-Wall Effects on Rate of Delivery to Lower

Plenum . . . . . . . . . . . . . . . 108

IV. HOT-WALL COUNTERCURRENT FLOW PREDICTIVE METHOD . . . . . . 111

1. PREDICTIVE METHOD FOR UPPER ANNULUS $\ldots \ldots \ldots \ldots \ldots$

2. PREDICTIVE METHOD FOR THE DOWNCOMER . . . . . . . 112

2.1 Countercurrent Flow . . . . . . . . . . . . 112

2.2 Downcomer Heat Transfer Modcl . . . . . . . . . . . . 114

2.3 Summary of Predictive Method Equations . . . . . . . . . 116

3. COMPARISON OF PREDICTIVE METHOD RESULTS WITH

TEST DATA . . . . . . . . . . . . . . . . . 117

4. SENSITIVITY STUDY $\ldots \ldots \ldots \ldots \ldots \ldots \ldots \ldots$

5. APPLICATION OF PREDICTIVE METHOD TO LARGER

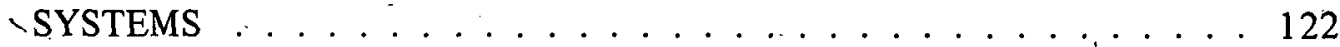

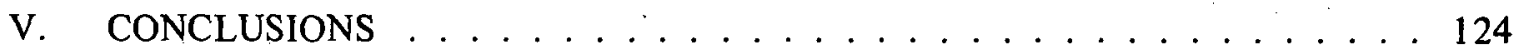

1. INTACT LOOP COLD LEG . . . . . . . . . . . . . . 124

2. UPPER ANNULUS $\ldots \ldots \ldots \ldots \ldots \ldots \ldots \ldots \ldots$

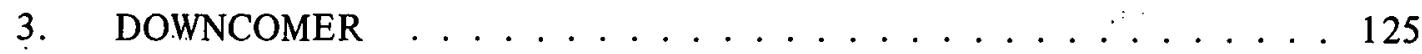

4. LOWER PLENUM . . . . . . . . . . . . . . . . . . . . . 127

5. HOT-WALL PREDICTIVE METHOD . . . . . . . . . . . . . . . . 127

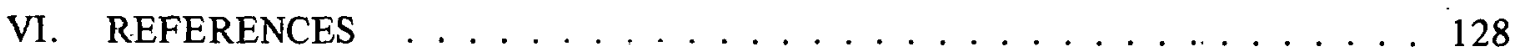

APPENDIX A -- ERROR ANALYSIS OF THE INVERS DATA REDUCTION

METHOD AS APPLIED TO SEMISCALE . . . . . . . . . . . . . . . 131

APPENDIX B - RELAP4 MODEL USED FOR THE INVESTIGATION OF

ECC PERFORMANCE IN THE SEMISCALE GEOMETRY . . . . . . . . . . . . . . 143

APPENDIX C - FILLER GAP FLOW ANALYSIS $\ldots \ldots \ldots$

APPENDIX D - DATA CORRELATION PREDICTIVE METHOD $\ldots \ldots \ldots$

APPENDIX E -- SOLUTION TO MATHEMA TICAL EQUATIONS EMPLOYED

IN THE HOT-WALL COUNTERCURRENT FLOW PREDICTIVE MODEL . . . . . . 165 
1. Simplified schematic of transparent vessel . . . . . . . . . . . 5 5

2. Piping and instrument diagram for semiscale countercurrent flow tests . . . 7

3. 1-1/2-loop semiscale isothermal blowdown test system - isometric . . . . . . 11

4. 1-1/2-loop isothermal pressure vessel - cross-sectional view $\ldots \ldots \ldots \ldots$

5. Piping heat fluxes for hot-wall Test $15.1-22$ gpm ECC injection rate . . . . 17

6. Piping heat fluxes for hot wall Test $15.2-52 \mathrm{gpm}$ ECC injection rate $\ldots \ldots$

7. Heat transfer coefficients for hot-wall Test $15.1 \ldots \ldots 20$

8. Heat transfer coefficients for hot wall Test $15.2 \ldots \ldots \ldots 21$

9. Calculated and experimental piping heat fluxes for isothermal blowdown Test 1010 without ECC injection . . . . . . . . . . . . . 22

10. Calculated and experimental heat transfer coefficients for isothermal blowdown Test 1010 without ECC injection . . . . . . . . . . . 23

11. Calculated piping heat fluxes for isothermal blowdown Test 1008 with ECC injection . . . . . . . . . . . . . . . . 24

12. Calculated and experimental heat transfer coefficients for isothermal blowdown Test 1008 with ECC injection . . . . . . . . . . . 25

13. Measured densities in the intact loop cold leg near the vessel inlet and near the pump discharge - Test $1006 \ldots \ldots \ldots$

14. Fluid velocity near the cold leg entrance to vessel - Test $1008 \ldots \ldots 27$

15. Volumetric flow rate near pump discharge for tcsts with and without ECC injection ...................... 30

16. Volumetric flow rate at core inlet for tests with and without ECC injection . . . . . . . . . . . . . . . . . 30

17. Volumetric flow rate near pump discharge for tests with different volumetrically scaled ECC injection rates . . . . . . . . . . . . .

18. Volumetric flow rate at core inlet for tests with different ECC

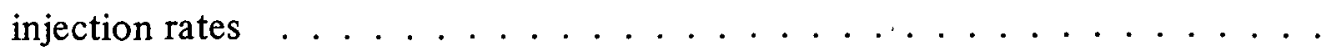


19. Depressurization of cold leg during test with near volumetrically scaled ECC injection rate and test without ECC injection . . . . . . . . . . 33

20. Deprcssurization of cold leg during test with about 2.4 times volumetrically scaled ECC injection rate and test without ECC injection . . . . 33

21. Cold leg pressure during isothermal Test $1008-14.5$ to 20 seconds after rupture . . . . . . . . . . . . . . . . . . 34

22. Cold leg pressure during isothermal Test $1008-19.5$ to 25 seconds after rupture . . . . . . . . . . . . . . . . . . . 34

23. Cold leg pressure during isothermal Test $1008-22.5$ to 50 seconds after rupture . . . . . . . . . . . . . . . . . . 35

24. Differential pressure across ECC injection port during isothermal Test $1008 \ldots \ldots \ldots \ldots$. . . . . . . . . . . . . . . . . . . . .

25. Control volume for upper annulus mass balance . . . . . . . . . . . . . 38

26. Mass flow rate at the downcomer inlet during isothermal Test $1008 \ldots . . . . \quad 39$

27. Typical hot-wall test densities at vessel inlet and pump discharge of intact loop cold leg

28. Wallis-type countercurrent flow correlation least squares fit to data for 0.35 -in. annular gap . . . . . . . . . . . . . .

29. Wallis-type countercurrent flow correlation least squares fit to data for 0.49 -in. annular gap . . . . . . . . . . . . . . 48

30. Wallis-type countercurrent flow correlation least squares fit to data for 0.70 -in. annular gap . . . . . . . . . . . . .

31. Wallis-type countercurrent flow correlation least squares fit to data for 1.58 -in. annular gap . . . . . . . . . . . . . . 50

32. Comparison of Wallis-type countercurrent flow correlation least squares fits to data for annular gaps considered . . . . . . . . . . . 51

33. Dimensioned fluxes for the range of gap sizes tested $\ldots \ldots \ldots 52$

34. Dimensionless one-tenth power fluxes for the range of gap sizes tested .......................... 53

3.5. Dimensioned fluxes for different system pressures $\because \ldots \ldots \ldots$

36. Typical results for ECC delivery to the lower plenum for various inlet air flows without countercurrent flow 
37. Water delivery to lower plenum for various air fluws -0.49 -in. annular gap . . . . . . . . . . . . . . . . . 56

38. Water delivery to lower plenum for various air flows -1.58 -in. annular gap

39. Dimensioned fluxes for tests with and without cold leg and bypass leg nozzles ........................ 58

40. Dimensioned fluxes exhibiting effect of two-phase mixture entering vessel ............................ 59

41. Simplified schematic of the uniform water distributor . . . . . . . . 60

42. Dimensionless fluxes exhibiting effect of uniform flow to downcomer

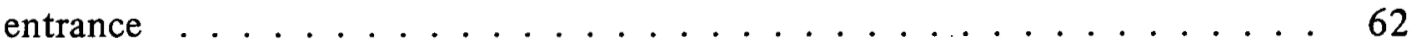

43. Dimensionless fluxes exhibiting effect of upper annulus length on water delivery to the lower plenum ................ 63

44. Dimensionless fluxes exhibiting effect of presence of hot leg simulators on water delivery to the lower plenum . . . . . . . . . . . . . 64

45. Dimensionless fluxes for different downcomer annulus lengths . . . . . . 65

46. Water delivery to lower plenum for the 0.49 -in. annular gap and short and long downcomers ................... 66

47. Dimensionless fluxes for air-water countercurrent tests in the transparent vessel and in the semiscale vessel with and without the filler gap . . . . . . .

48. Dimensioned fluxes for steady state semiscale system baseline tests with 0.5 - and 1.0-in. downcomer gaps . . . . . . . . . . . . . . 69

49. Dimensioned fluxes for steady state semiscale system flow bypass tests with 0.5 -in. downcomer gap . . . . . . . . . . . . . . .

50. Dimensioned fluxes for steady state semiscale system flow bypass tests with 1 -in. downcomer gap

51. Dimensioned fluxes for steady state semiscale system wall heating tests with 0.5 -in. downcomer gap . . . . . . . . . . . . . . . . .

52. Dimensioned fluxes for steady state semiscale system inlet water temperature tests with 0.5 -in. downcomer gap . . . . . . . . . . . . .

53. Dimensioned fluxes for steady state semiscale system cold leg steam injection tests with 1 -in. downcomer gap 
54. Dimensioned fluxes for steady state semiscale system tests in which the order of establishing the initial steam and water flows was reversed . . . . . 75

55. Location of instrumentation in the downcomer and lower plenum . . . . . 76

56. Control volume for section of downcomer . . . . . . . . . . . . 77

57. Comparison between measured densities and density calculated from lower

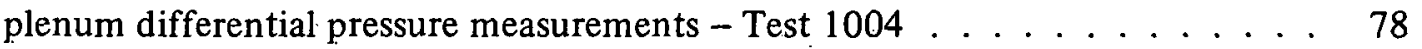

58. Comparison between calculated densities in upper annulus and downcomer Test $1004 \ldots \ldots \ldots$. . . . . . . . . . . . . . . 80

59. Comparison between calculated densities in upper annulus and downcomer - Test $1010 \ldots \ldots \ldots$. . . . . . . . . . 81

60. Comparison between calculated densities in upper annulus and downcomer - Test $1008 \ldots \ldots \ldots \ldots$. . . . . . . . . . . . . . .

61: Calculated densities in downcomer Sections 1 and 2. for Test $1010 \ldots \ldots$

62. Calculated flow rate at top of downcomer and measured core flow rate (bottom of downcomer) - Test $1010 \ldots \ldots$. . . . . . . . . 83

63. Calculated average velocity and measured local velocity near the top of the downcomer - Test $1010 \ldots \ldots \ldots$. . . . . . . . . 85

64. Transient dimensioned volumetric flux - Test $1008 \ldots \ldots$. . . . . . 87

65. Transient dimensioned volumetric flux - hot-wall Test $15.3 \ldots \ldots 8$. . . .

66. Densities in the downicomer during ECC injection for hot-wall Test $15.3 \ldots \ldots \ldots \ldots \ldots$. . . . . . . . . . . 89

67. Downcomer surface heat fluxes calculated by INVERS . . . . . . . . . 90

68. Calculated downcomer surface heat fluxes for Test $1011 \ldots \ldots$. . . . . 91

69. Calculated downcomer heat transfer coefficients for Tést $1011 \ldots \ldots 1$

70. Calculated downcomer surface heat fluxes for Test $1009 \ldots \ldots$. . . . . . 92

71. Calculated downcomer heat transfer coefficients for Test $1009 \ldots . \ldots 3$

72. Calculated surface heat fluxes from the intact loop side of the downcomer during hot-wall Test $15.1 \ldots \ldots \ldots . \ldots . \ldots 94$

73. Calculated surface heat fluxes from the broken loop side of the downcomer during hot-wall Test $15.1 \ldots \ldots \ldots \ldots$. . . . . . . . . 95 
74. Calculated surface heat fluxes for hot-wall test (Test 15.4) with the largest downcomer gap (1.69 in.) . . . . . . . . . . . . . . 96

75. Calculated surface heat fluxes near the axial center of the downcomer during hot-wall tests . . . . . . . . . . . . . . . 97

76. Calculated heat transfer coefficients near the axial center of the downcomer during hot-wall tests

77. Measured temperatures and density in lower plenum during ambient temperature test

78. Downcomer dimensioned volumetric flux resulting from steam generation during hot-wall Test 15.3

79. Fraction of initial lower plenum mass remaining in the lower plenum during isothermal Tests 1008 and $1010 \ldots \ldots \ldots$. . . . . . . . 104

80. Fraction of initial lower plenum mass remaining in the lower plenum during isothermal Tests 1006 and $1008 \ldots \ldots \ldots$. . . . . . . . 105

81. Fraction of lower plenum mass remaining in the lower plenum during isothermal Tests 1008 and 1009

82. Thermocouple response exhibiting progressive rise of subcooled water in lower plenum during lower plenum ECC injection - Test 1004

83. Horizontal density measurement in lower plenum during hot-wall Tests 15.1 and 15.2

84. Horizontal density measurement in lower plenum during hot-wall Tests 15.3 and 15.4

85. Diagonal density measurements in lower plenum exhibiting lower plenum mass changes during hot-wall tests

86. Comparison of predicted delay limes with data $\therefore \ldots \ldots \ldots$

A-1. Comparison of INVERS surface temperature solutions for two time-step

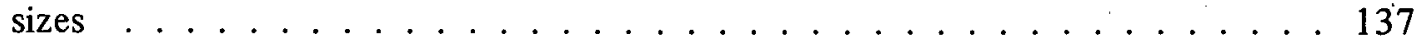

A-2. INVERS surface temperature solutions for three time advances compared to the internal temperature data . . . . . . . . . . . . . 138

A-3. Internal temperature calculated by INVERS compared to measured internal temperature ................... 140

A-4. Surface temperatures calculated by INVERS compared to measured internal temperatures input to INVERS fur Lwo radial locations 
B-1. RELAP4 model of the isothermal system . . . . . . . . . . . 146

D-1. Comparison between delay time calculated by the data correlation method and that obtained experimentally . . . . . . . . . . . . . 163

E-1. Model flow diagram ....................... 170

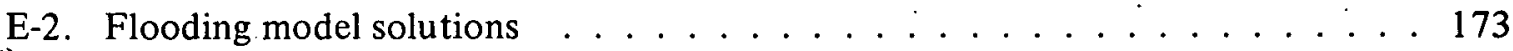

E-3. Flooding mode dependence on the integrated flux $\ldots \ldots \ldots$

\section{TABLES}

I. Possible Downcomer Gap Geometries for Transparent Vessel Tests . . . . . . 6

II. Conditions for Semiscale System Countercurrent Flow Tests . . . . . . . . 9

III. Summary of Semiscale System Configuration and Conditions for Isothermal Double-Ended Rupture Blowdown Tests . . . . . . . . . . . . . 12.

IV. Summary of Test Conditions for Hot-Wall Tests Performed Following Double-Ended Rupture Blowdown Tests . . . . . . . . . . . . . . . 13.

V. Maximum Temperature Increases of the ECC Fluid in the Cold Leg Resulting from Condensation and Piping Heat Transfer . . . . . . . . 29

VI. Calculation of Temperature of Injected Fluid Compared to Measured Temperature .......................... 43

VII. ECC Delay Times for Varying Injection Rates and Gap Sizes . . . . . . . . . . 99

VIII. Nominal System Variables for the Predictive Method Sensitivity Study . . . . . 119

IX. Results of Predictive Method Sensitivity Study . . . . . . . . . . . . 120

A-I. Error in INVERS Calculations Relative to Known Analytical Solution for Semi-Infinite Solid . . . . . . . . . . . . . . . . . . 135

A-II. INVERS Heat Flux Error for Various Radiation Node Sizes for Test 15.1,

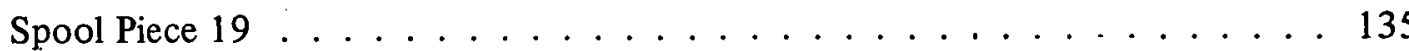




\section{ECC PERFORMANCE IN THE SEMISCALE GEOMETRY}

\section{INTRODUCTION}

An extensive water-cooled nuclear reactor safety research program is currently being carried out under the sponsorship and direction of the Atomic Energy Commission. A part of this research program is directed toward investigating the effectiveness of emergency core cooling (ECC) in mitigating the consequences of a loss-of-coolant accident (LOCA) in a water-cooled nuclear reactor. The Emergency Core Cooling Systems (ECCS) are standby auxiliary core cooling systems which inject subcooled water into either the cold leg piping or the upper annulus region during the LOCA. To reach the core, the injected water must proceed down the downcomer and into the lower plenum and either add to the lower plenum inventory if the plenum is not full or force water from the plenum into the core and downcomer regions if the plenum is full. The flow rate of ECC to the lower plenum is dependent on many complex, interrelated phenomena which occur in the cold leg piping, the upper annulus region, the downcomer, and the lower plenum.

The Semiscale Blowdown and Emergency Core Cooling (ECC) Project has progressively used more complex and better scaled experiments to investigate many of the complex and interrelated phenomena that occur during blowdown and ECC injection. The most recent semiscale experimental program represents the most comprehensive effort to date to investigate both the phenomena that occur during ECC injection and the interrelationship between these phenomena. This program was made up of three different test programs which were coordinated to initially provide a basic understanding of certain ECC-related phenomena and then to progressively investigate these phenomena as well as other ECC-related phenomena in greater detail. The transparent vessel test program was conducted initially to investigate countercurrent flow and flow bypass phenomena in a semiscale-sized downcomer and to determine whether these phenomena could be described in terms of existing countercurrent flow correlations. Air and water were used as the fluids for the transparent vessel tests because existing correlations were based on data limited almost exclusively to these fluids. The semiscale system countercurrent flow tests were subsequently conducted to investigate steady state and transient countercurrent flow phenomena in a steam-water medium where condensation and evaporation could affect the phenomena occurring. The concluding test program, the isothermal system test program, was conducted to investigate transient ECC-related phenomena and the interaction between these phenomena in addition to the phenomena that occur during the blowdown portion of a simulated LOCA.

The data from the most recent semiscale experimental program are valuable for evaluating the adequacy and improving the predictive capability of analytical models developed to predict both system response and ECC behavior during an LOCA. Data from the semiscale ECC investigations are also valuable for comparison with data from similar ECC investigations in larger geometries to aid in evaluating the effects of physical scale. 
However, since the semiscale system is small compared to a pressurized water reactor (PWR) and compromises were necessary in scaling this smaller system from a larger system, the phenomena associated with ECC injection in the semiscale geometry cannot be related directly to the ECC associated phenomena in a PWR.

This report presents the analysis of selected experimental data from the recent ECC investigations in the semiscale geometry. The analysis has been confined to data that describe ECC-related phenomena in the cold leg, upper annulus, downcomer, and lower plenum because these components represent the path the ECC must follow to reach a position where cooling of the core can result. Representative data from these parts of the system are presented to indicate the trends in the phenomena that are occurring. Wherc different trends are observed for similar tests, possible explanations of the differences are included. In a limited number of cases, results calculated by the RELAP4 ${ }^{[1]}$ computer code are shown with the analyzed isothermal system data. The data and the calculated results are shown together and a comparison is made between the trends predicted by an analytical tool and the trends measured by the system instrumentation. 


\section{EXPF.R.IMF,NT DF.SCRIPTION}

A coordinated experimental program has been conducted to investigate ECC-related phenomena in the semiscale system. The overall program was conducted as three separate test programs: the transparent vessel countercurrent flow tests, the semiscale system countercurrent flow tests, and the isothermal system tests. A brief description of each of these programs follows.

\section{TRANSPARENT VESSEL TESTS}

The transparent vessel tests were steady state, air-water, separate effects tests that were intended to provide data on downcomer countercurrent flow and bypass phenomena[a]. These tests were conducted in a transparent plexiglass vessel which allowed visual and photographic observations of the phenomena. The transparent vessel test program was initiated when a literature search indicated that the majority of the countercurrent flow data was limited to data taken in small diameter tubes or packed beds with inlet geometries that distribute the flow uniformly around the top of the test section. Since the semiscale vessel downcomer region is annular with a much larger diameter than most tubes tested and with an inlet geometry which may not distribute the fluid uniformly around the annulus, the applicability of prior countercurrent flow data to the semiscale downcomer was uncertain. Therefore, a test program was conducted to supply countercurrent flow test data in a geometry similar to the semiscale vessel. The objectives of the transparent vessel tests were to:

(1) Investigate the countercurrent flow phenomena that occur in an annulus with dimensions similar to the semiscale downcomer to determine whether commonly used countercurrent flow correlations describe the effect of the countercurrent air flow on the delivery of water (ECC) to the lower plenum.

(2) Investigate the relationship between flow bypassing the downcomer and countercurrent flow in the downcomer

(3) Investigate the effect on countercurrent flow and bypass flow of changing the geometry of the upper annulus

(4) Investigate the effect on countercurrent flow of changing the downcomer length by changing the length of the core barrel

(5) Provide data for establishing a relationship between the countercurrent flow tests in the transparent vessel and the metal semiscale vessel.

[a] The transparent vessel test data are to be published in the Experiment Data Report for Semiscale Transparent Vessel Countercurrent Flow Tests, ANCR-1163. 
.The transparent vessel test system consisted of a transparent plexiglass vessel connected to an air and water supply system and to a drain system for the water. A schematic drawing of the transparent vessel is shown in Figure 1 along with the nomenclature used to identify the different parts of the vessel. The vessel, as shown, is in its normal operating configuration. The design of the transparent vessel allowed changing the core barrels and filler pieces to obtain different downcomer gap widths. Table' I lists the radial downcomer gap width as a function of the core barrel outside diameter and the filler piece inside diameter. Since the inside diameter of the vessel was 8.4. inches, gaps using Filler D in Table I do not actually incorporate a filler piece. The upper annulus region was also designed to allow a change to be made in the diameter of the inlet pipe by removal of the nozzle liner and to allow changes to be made in the flow area of the upper:annulus by removal of the hot leg simulators or by extension upward of the baffle.. The air was supplied by a multistage compressor and water was supplied from the building water supply system.

\section{-2. SEMISCALE SYSTEM COUNTERCURRENT FLOW TESTS}

The semiscale system countercurrent flow tests consisted of both steady state and transient separate effects tests which were aimed at investigating steam-water countercurrent flow behavior in the semiscale vessel. These tests were conducted to supply data on the

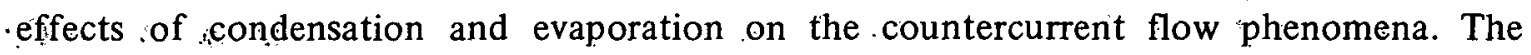
specific objectives of the semiscale system countercurrent flow tests were to:

(1.) Provide experimental data, which include the influence of condensation and evaporation, that will relate the rate at which water is delivered to the lower plenum to the superficial velocity of the steam in the downcomer

(2) Investigate the applicability of commonly used countercurrent flow correlations to steady state countercurrent flow data that include the effects of condensation and evaporation

(3) Provide an understanding of the transient hot-wall behavior of the semiscale system which will allow this behavior to be predicted.

The semiscale system countercurrent flow test-system, shown schematically in Figure 2 , consisted of the 1-1/2-loop semiscale pressure vessel, a phase separator, and a storage tank. The system configuration was varied slightly during the test program to meet the needs of each test. A brief description of the system components follows. 


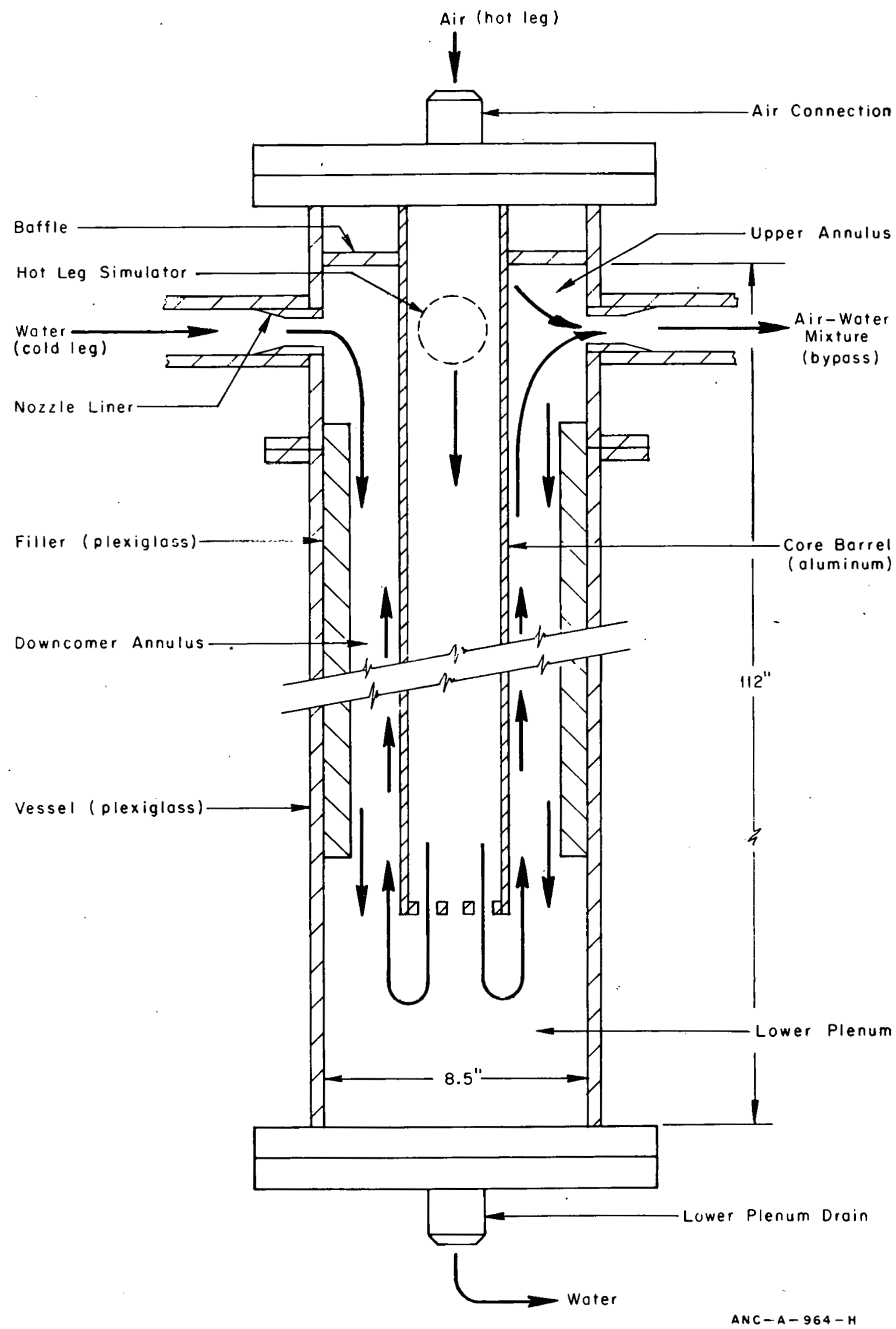

Fig. 1 Simplified schematic of transparent vessel. 
TABLE I

POSSIBLE DOWNCOMER GAP GEOMETRIES FOR TRANSPARENT VESSEL TESTS

\begin{tabular}{|c|c|c|c|c|c|}
\hline $\begin{array}{l}\text { Core } \\
\text { Filler } \\
\text { Piece }\end{array}$ & 1 & 2 & 3 & $\begin{array}{l}4 \\
\therefore\end{array}$ & - \\
\hline A & $\begin{array}{l}0.53 \\
9.57\end{array}$ & $\begin{array}{l}0.40 \\
7.31\end{array}$ & & & $\begin{array}{l}\text { Annular gap (in.) } \\
\text { Annulus flow area (in. }{ }^{2} \text { ) }\end{array}$ \\
\hline B & $\begin{array}{r}0.63 \\
11.53\end{array}$ & $\begin{array}{l}0.49 \\
9.27\end{array}$ & & & \\
\hline C & $\begin{array}{r}1.25 \\
25.43\end{array}$ & $\begin{array}{r}1.11 \\
23.17\end{array}$ & $\begin{array}{l}0.37 \\
8.48\end{array}$ & & \\
\hline D. & $\begin{array}{r}1.58 \\
33.87\end{array}$ & $\begin{array}{r}1.4 .5 \\
31.61\end{array}$ & $\begin{array}{r}0.70 \\
16.92\end{array}$ & $\begin{array}{l}0.35 \\
8.93\end{array}$ & \\
\hline
\end{tabular}

\section{Core Barrel Dimensions}

\section{Outside}

Diameter

(in.)

$1 \quad 5.24$

$2 \quad 5.51$

37.00 .

47.69 :
Associated

Cross-Sectional

Area (in.2)

21.55

23.81

38.50

46.49
Filler Piece Dimensions

Inside Associated

Diameter Cross-Sectional

(in.) Area (in.2)

A $6.30 \quad 31.12$

$\begin{array}{lll}\text { B } & 6.49 & 33.08\end{array}$

C $\quad 7.73$

46.98

D $8.40^{\circ}$

55.42 


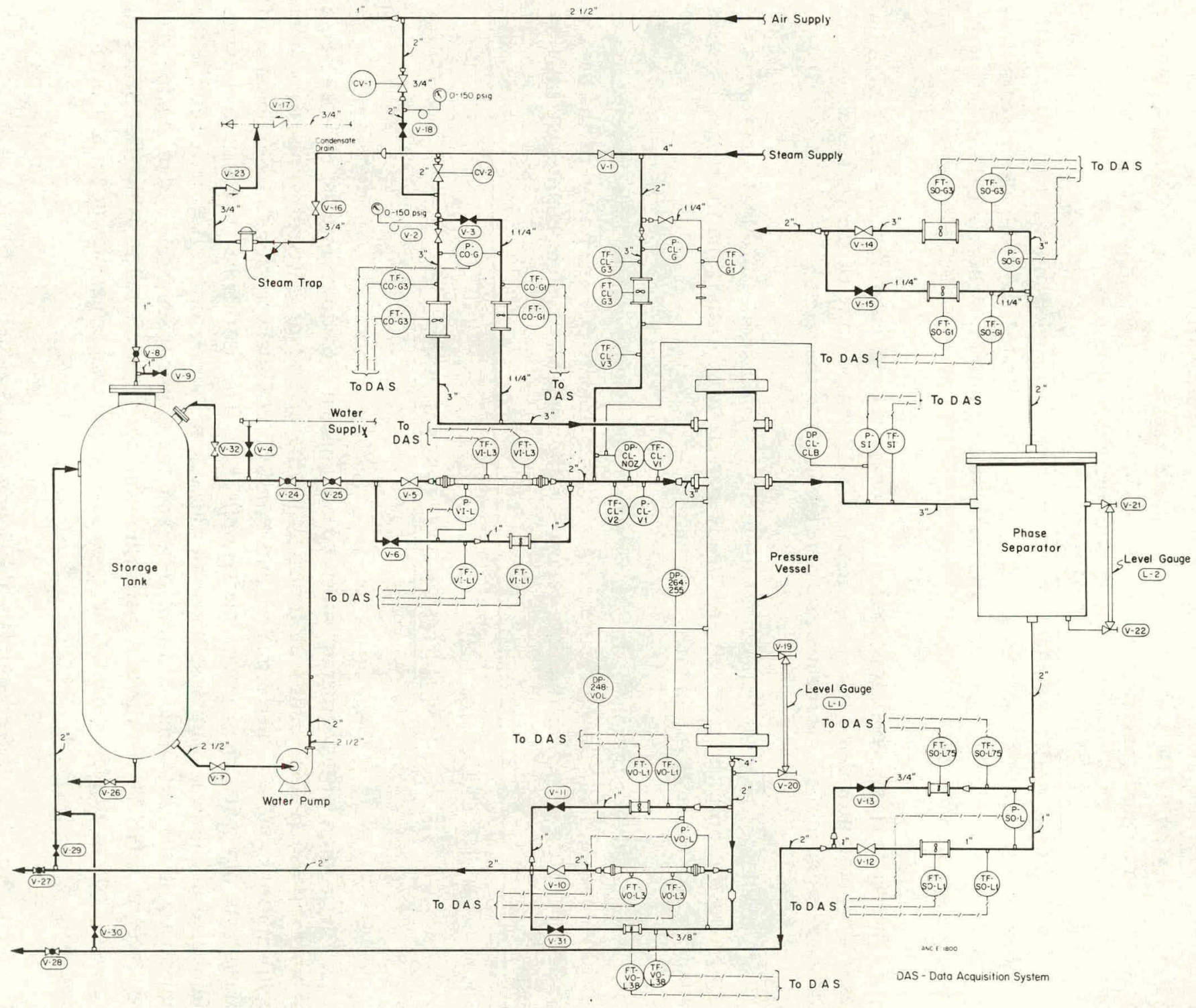

Fig. 2 Piping and instrument diagram for semiscale countercurrent flow tests. 
The 1-1/2-loop semiscale vessel is constructed of a 10-inch Schedule-160 carbon steel pipe about 12 feet in length. The vessel internals consisted of a core barrel assembly and two downcomer filler pieces. The filler pieces were used to provide radial downcomer gap widths of 0.5 and 1.0 inch and the vessel wall provided an additional gap of 1.69 inch. One of the cold leg nozzles was attached to the water supply system from the storage tank and the other cold leg nozzle was attached to the phase separator to allow the measurement of possible downcomer bypass flow. A penetration in the lower head allowed the lower plenum to be drained as needed to measure delivery to the lower plenum.

The phase separator was made from a tank with an angled internal perforated baffle installed to aid in the phase separation. This baffle separated the two-phase mixture that exited the vessel cold leg into steam and water so that measurements could be made on the single-phase components of the flow.

The water storage tank was used as a reservoir for recirculating the water used in the tests. This tank provided a means for regulating the temperature of the water delivered to the vessel while minimizing the necessary energy input to the water.

A number of tests were conducted using the system described. Table II summarizes the test groups for both the transient and steady state tests performed and the range of system conditions for the tests within these test groups.

A detailed description of the semiscale system countercurrent flow test apparatus, instrumentation, and test procedures, as well as a complete documentation of the data, is contained in the experimental data report for the semiscale system countercurrent flow tests ${ }^{[2]}$.

\section{ISOTHERMAL SYSTEM TESTS}

The isothermal test program consisted of transient blowdown integral effects tests, a number of which were aimed at investigating the effects of different semiscale system configurations on ECC performance, and transient ECC delivery tests in the absence of blowdown but with the system metal walls hot. The isothermal hot-wall tests were numbered in the same manner as the semiscale system countercurrent flow tests because the objectives of the isothermal hot-wall tests and the transient semiscale system heated wall tests were similar. The isothermal system hot-wall tests are referred to as the Test Series 15 hot-wall tests in this document. The objectives of the isothermal blowdown test program were to:

(1) Provide data for use in the development and evaluation of LOCA analytical models

(2) Provide a basis for determining the applicability of the steady state countercurrent flow results obtained from separate effects tests in the semiscale program for predicting blowdown behavior 
TABLE II

CONDITIONS FOR SEMISCALE SYSTEM COUNTERCURRENT FLOW TESTS

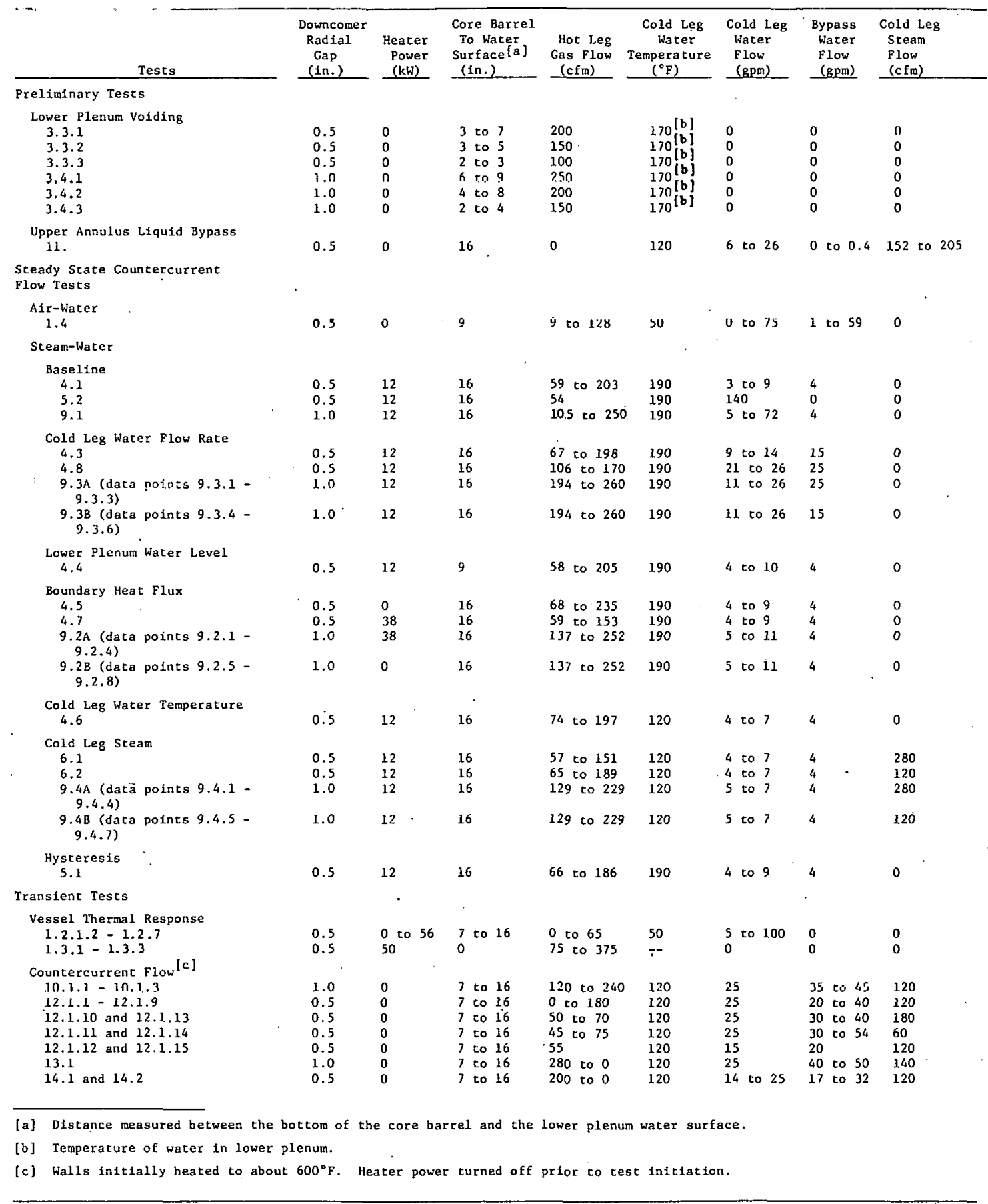


(3) Provide data for comparison with data from larger scale experiments to aid in establishing the effects of physical scale on system and ECC performance

(4) Provide an understanding of the transient hot-wall behavior of the semiscale system which will allow this behavior to be predicted.

The 1-1/2-loop isothermal semiscale system, shown isometrically in Figure 3, consisted of a pressure vessel with simulated reactor internals, an intact loop with a steam generator, pump, and pressurizer; a blowdown loop with rupture assemblies and a simulated steam generator and simulated pump; a pressure suppression system with a suppression tank and header; and a coolant injection system. The isothermal system blowdown test conditions are summarized in Table III and the hot-wall test conditions are summarized in Table IV.

The analysis presented in this report concentrates on data from isothermal tests with ECC injection (blowdown Tests 1004, 1006, and 1008), and the hot-wall tests (Tests 15.1, 15.2, 15.3, and 15.4); however, data from tests without ECC injection are analyzed for comparative purposes. Only limited analysis of isothermal blowdown Test 1009 is included in this report because this test was used as an AEC standard problem against which the calculations of computer codes could be evaluated. The data were restricted until computer analyses were completed and, therefore, were not available in time for a complete analysis to be performed in conjunction with the other isothermal tests.

A detailed description of the system test conditions, test apparatus, and test procedures, as well as a complete documentation of the data, is contained in the isothermal system description and experimental data reports ${ }^{[3-10]}$. A brief description of the system components follows.

The pressure vessel used for the isothermal tests, shown in Figure 4, was basically the same vessel that was used for the semiscale system countercurrent flow tests. The core barrel housed nine 5.5-foot-long electrical heater rods, six of which were used to heat the system to the initial test conditions. Electrical power to the heaters was shut off and isothermal conditions were established prior to blowdown. Lower plenums of two different lengths were used in the test series. The interior surfaces of the lower plenum were insulated for all tests except isothermal blowdown Test 1002.

The intact loop consisted of primary coolant piping,. a steam generator, a pressurizer, and a circulating pump. The intact loop piping was primarily 3 -inch Schedule-160 pipe. The steam generator was a tube-in-shell heat exchanger which was not active during the isothermal tests. The pressurizer operated in a manner that was similar to its counterpart in a PWR system. The circulating pump was a volute-type, heavy-duty, horizontal centrifugal pump rated for a nominal flow of $182 \mathrm{gpm}$ at a total head of 192 feet of water at $3560 \mathrm{rpm}$. 


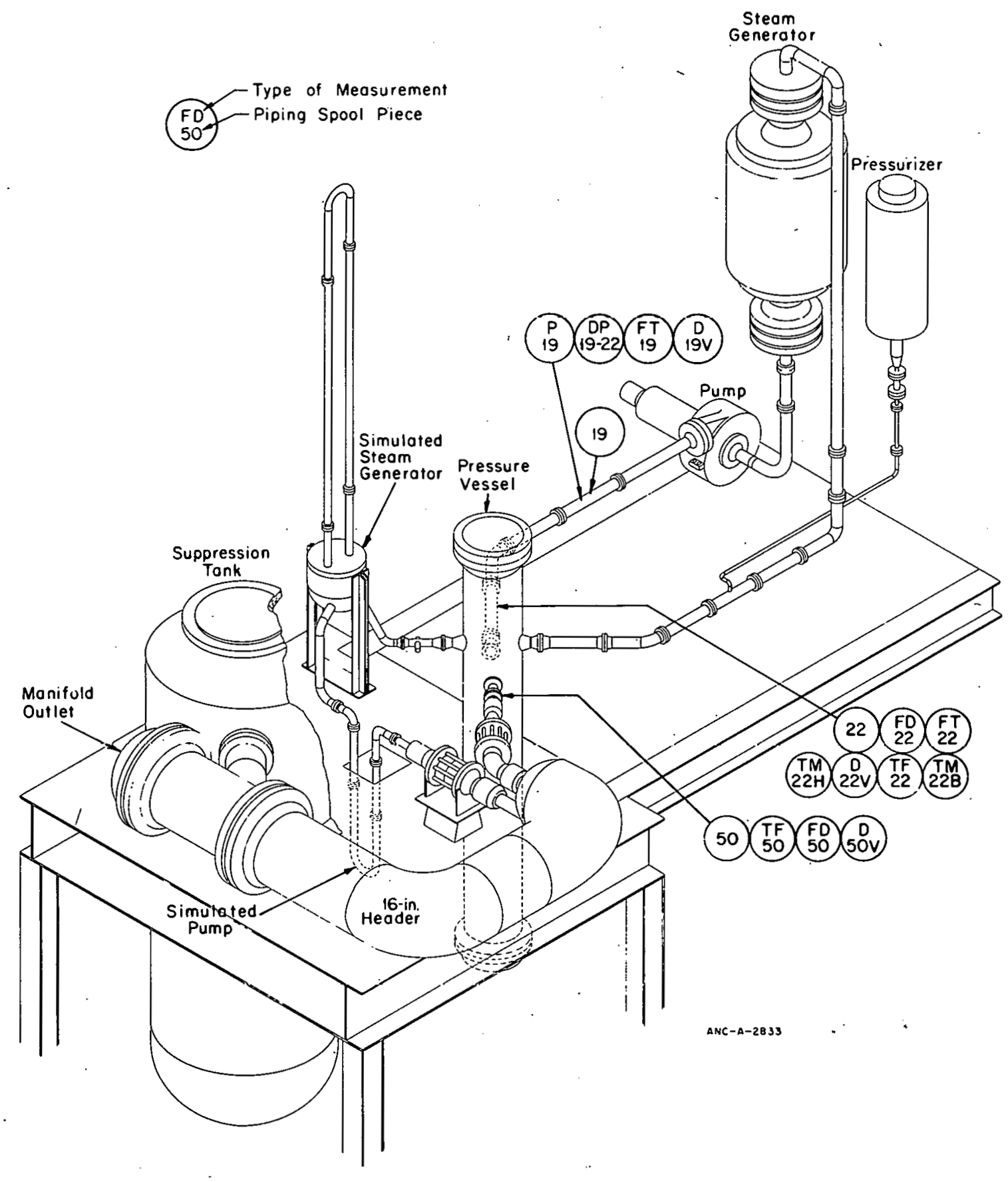

Fig. 3 1-1/2-loop semiscale isothermal blowdown test system - isometric. 
$\underline{\text { TABLE III }}$

SUMMARY OF SEMISCALE SYSTEM CONFIGURATION AND CONDITIONS FOR

ISOTHERMAL DOUBLE-ENDED RUPTURE BLOWDOWN TESTS

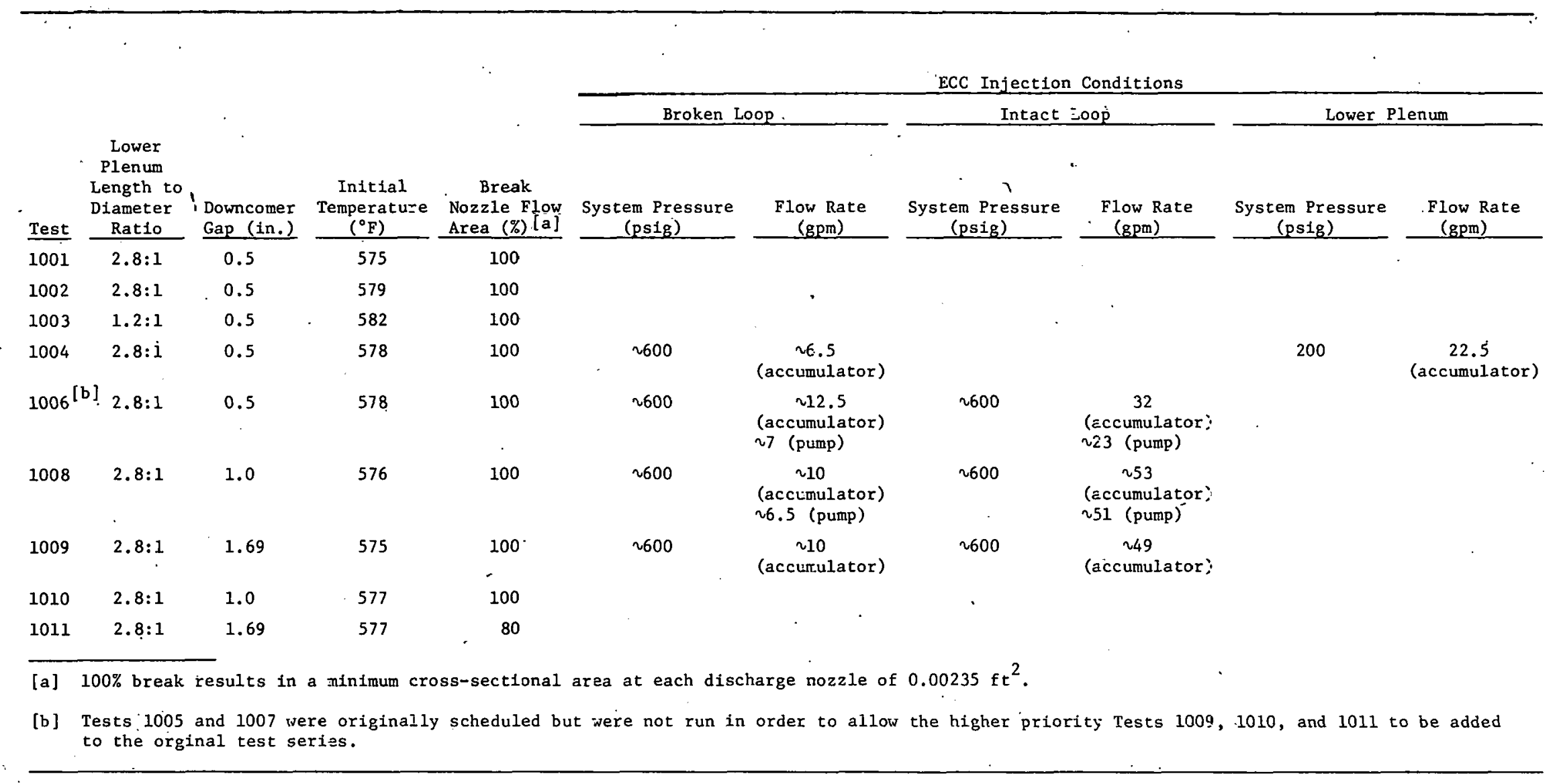


TABLE IV

SUMMARY OF TEST CONDITIONS FOR HOT-WALL TESTS PERFORMED

FOLLOWING DOUBLE-ENDED RUPTURE BLOWDOWN TESTS

\begin{tabular}{|c|c|c|c|c|c|}
\hline \multirow[b]{2}{*}{ Test } & \multirow[b]{2}{*}{$\begin{array}{l}\text { Followed } \\
\text { Blowdown } \\
\text { Test } \\
\end{array}$} & \multirow[b]{2}{*}{$\begin{array}{c}\text { System } \\
\text { Pressure } \\
\text { (psia) } \\
\end{array}$} & \multirow[b]{2}{*}{$\begin{array}{c}\text { Initial Average } \\
\text { Downcomer Wa11 } \\
\text { Temperature } \\
\left({ }^{\circ} \mathrm{F}\right) \\
\end{array}$} & \multicolumn{2}{|c|}{ ECC Injection Rate } \\
\hline & & & & $\begin{array}{c}\text { Intact Loop } \\
(\mathrm{gpm})\end{array}$ & $\begin{array}{c}\text { Broken Loop } \\
\quad(\mathrm{gpm}) \\
\end{array}$ \\
\hline 15.1 & 1001 & $\sim 54$ & $\sim 490$ & 21 & 7 \\
\hline 15.2 & 1004 & $\sim 50$ & $\sim 460$ & 52 & 7 \\
\hline 15.3 & 1010 & $\sim 62$ & $\checkmark 450$ & 51 & 7 \\
\hline 15.4 & 1011 & $\sim 65$ & 2,430 & $70^{[a]}$ & 7 \\
\hline [a] & raged o & the firs & 15 seconds of $t$ & test. & \\
\hline
\end{tabular}

The blowdown loop consisted of a simulated pump, a simulated steam generator, two rupture assemblies that provided a double-ended offset shear break, and associated piping. The piping was primarily 2-inch Schedule-160 carbon steel. The simulated steam generator and simulated pump consisted of piping with the necessary number of orifices needed to achieve the desired resistance to flow. The rupture assemblies consisted of a blowdown nozzle and two rupture discs.

The pressure suppression system consisted of a pressure tank with downcomer entrance and a 16-inch header. The purpose of the pressure suppression system was to provide a controlled backpressure near the end of the blowdown.

The ECC injection system consisted of four demineralized water injection subsystems, two accumulator systems, and two pump subsystems. This injection system interfaced with the vessel lower plenum and intact and blowdown loops through check valves.

The ECC injection rates for the isothermal tests were selected to fulfill the objectives of individual tests. For Test 1004, the ECC injection rate was volumetrically scaled to the ECC injection rate of a PWR. The volumetrically scaled ECC injection rate

$$
\dot{\mathrm{m}}_{\mathrm{SS}}=\dot{\mathrm{m}}_{\mathrm{PWR}} \frac{\mathrm{v}_{\mathrm{SS}}}{\mathrm{v}_{\mathrm{PWR}}}
$$

gives an average ECC injection rate into the isothermal system intact loop cold leg or into the lower plenum of about $3 \mathrm{lb} / \mathrm{sec}$, or $22 \mathrm{gpm}$. The intact loop accumulator ECC injection rate for Test 1006 was nearly volumetrically scaled and the rate for pumped ECC injection initiated following the accumulator ECC injection was volumetrically scaled. The ECC injection rate for Tests 1008 and 1009 were about 2.4 and 2.2 times the volumetrically scaled ECC' injection rate, rèspectively. 


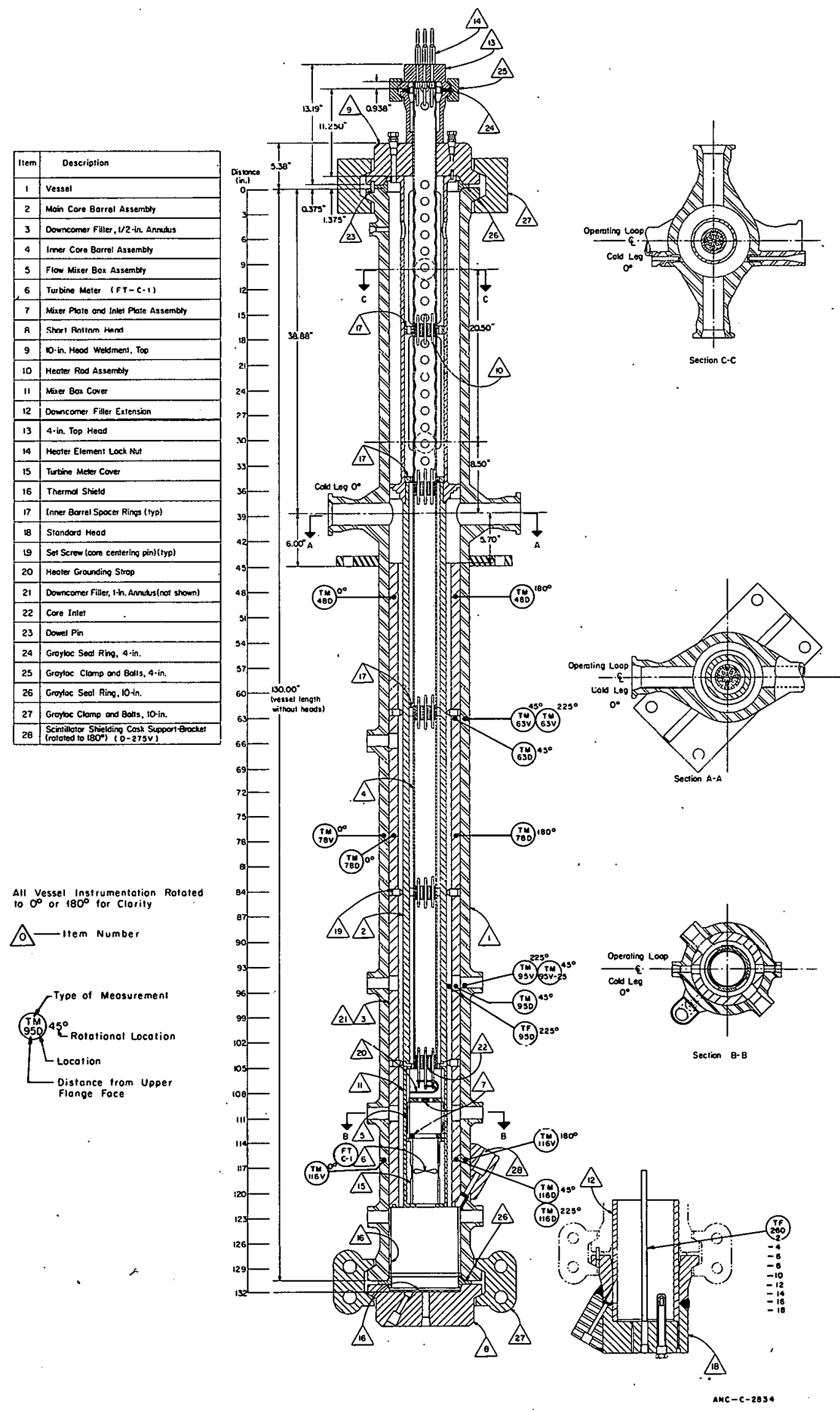

Fig. 4 1-1/2-loop isothermal pressure vessel -- cross-sectional view. 


\section{RESULTS OF DATA ANALYSIS}

The results from the analysis of selected, semiscale data are presented in this section. The data were selected such that trends in the phenomena which appear to be most significant are illustrated. For those cases in which different trends were observed in data from similar tests, an attempt has been made to show both the trends and to provide an explanation of the differences.

The analysis has been confined to data which describe ECC-related phenomena in the intact loop cold leg, upper annulus, downcomer, and lower plenum. These components represent the path the ECC must follow to reach a position where core cooling can result. The discussion of the analysis begins with the cold leg data analysis and proceeds with a subsequent discussion of each component along the ECC flow path to the lower plenum.

\section{INTACT LOOP COLD LEG PHENOMENA}

The intact loop cold leg piping heat transfer, flow, condensation, and mixing processes that occur during ECC injection affect the quality, velocity, and temperature of the fluid entering the upper annulus region of the vessel. Heat transfer from the pipe walls can increase the temperature of the cold leg fluid or increase the quality of the cold leg two-phase mixture through the generation of steam. depending on the extent of subcooling and the steam-water mixing processes that occur in the cold leg. Any increase in the cold leg fluid temperature would reduce the potential for condensation in the parts of the system affected by the cold leg fluid. Less condensation in the cold leg could result in higher cold leg fluid qualities. An increase in the quality of the cold leg fluid would result in an increase in the bulk fluid velocity at the entrance to the vessel upper annulus which could cause an increase of flow. directly across the upper annulus and consequently a decrease in flow to the downcomer.

\subsection{Piping Heat Transfer}

Wall heat fluxes were determined from the observed temperature history provided by thermocouples installed within the material of the cold leg pipe wall. These thermocouples were located on the side (TM-22H) and bottom (TM-22B) of the intact loop cold leg pipe at a position about 12 inches downstream of the ECC injection port toward the vessel. A computer program, INVERS, was used to solve the inverse conduction problem using the measured pipe metal temperatures to deduce both heat transfer rates and surface temperatures as functions of time. An error analysis of the INVERS program as applied to semiscale data is presented in Appendix A. This analysis provides estimates of the uncertainty in heat transfer rates and heat transfer coefficients which are shown as error bands on the appropriate figures in this section. 
The data from the Test Series 15 hot-wall tests were used to determine the heat transfer rates from the piping to the simulated ECC fluid without the complications of blowdown. The piping heat transfer rates which were determined near the injection point (Spool Piece 22 of the intact loop) for two hot-wall tests with different ECC injection rates are shown in Figures 5 and 6 . These heat fluxes are considered typical of the heat fluxes occurring over the cold leg from the injection port to the vessel. A calculation of the pipe wall heat fluxes was also made using empirical heat transfer correlations and the experimentally determined wall-to-bulk temperature difference (or the wall-to-saturated temperature difference for the boiling correlations). The Thom ${ }^{[11]}$ correlation,

$$
q^{\prime \prime}=\frac{\Delta T_{S}}{0.072} \cdot e^{(P / 1250)^{2}}
$$

where

$$
\begin{aligned}
& \mathrm{q}^{\prime \prime}=\text { the heat flux }\left(\mathrm{Btu} / \mathrm{hr}-\mathrm{ft}^{2}\right) \\
& \Delta \mathrm{T}_{\mathrm{S}}=\text { the wall superheat }\left({ }^{\mathrm{O}} \mathrm{F}\right) \\
& \mathrm{P}=\text { the pressure (psia) }
\end{aligned}
$$

is best suited for flow boiling heat transfer calculations.

Heat fluxes calculated using the Thom correlation as well as the heat fluxes calculated using experimental data and the widely used Dittus-Boelter ${ }^{[12]}$ correlation, which applies only to single-phase forced turbulent convection, are presented on Figures 5 and 6 . The Thom equation predicts heat fluxes considerably in excess of the experimentally determined values for the early portion of these tests, whereas the Dittus-Boelter relation gives a good prediction of the data for all but the first few seconds of the tests. The good agreement between the calculated heat fluxes and those predicted with a single-phase convective heat transfer correlation, such as the Dittus-Boelter correlation, indicates that the boiling heat transfer mechanism accounts for only a small portion of the total heat flux. A possible mechanism for the slight contribution due to boiling heat transfer has been discussed by Chen ${ }^{[13]}$. Chen suggests that the presence of a fluid temperature gradient, due to forced convection, effectively suppresses the boiling at the wall and he has correlated this suppression factor for a wide range of experimental conditions. By considering the additive effects of forced convection heat transfer (macroconvection) and boiling heat transfer (microconvection) as

$$
\mathrm{q}^{\prime \prime}=\mathrm{h}_{\operatorname{mac}}\left(\mathrm{T}_{\mathrm{w}}-\mathrm{T}_{\mathrm{m}}\right)+\mathrm{h}_{\mathrm{mic}} \Delta \mathrm{T}_{\mathrm{S}}
$$

where

$$
\begin{aligned}
& \mathrm{h}_{\mathrm{mac}}=\begin{array}{l}
\text { the macroconvective (forced convection) heat transfer coefficient } \\
\left(\mathrm{Btu} / \mathrm{hr}^{-} \mathrm{ft}^{2}{ }^{\circ} \mathrm{F}\right)
\end{array} \\
& \mathrm{T}_{\mathrm{w}}=\text { the wall surface temperature }\left({ }^{\circ} \mathrm{F}\right)
\end{aligned}
$$




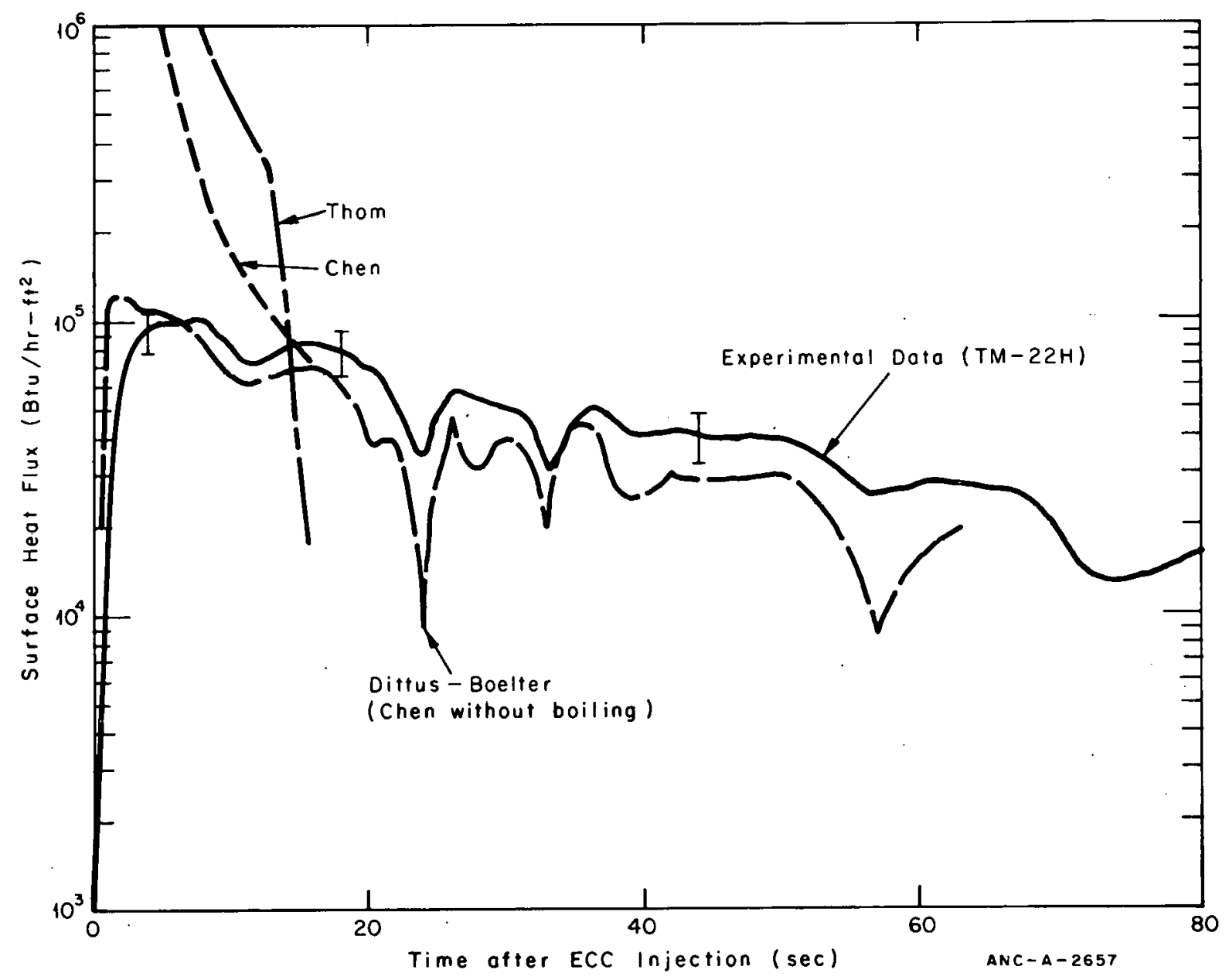

Fig. 5 Piping heat fluxes for hot-wall Test 15.1 - 22 gpm ECC injection rate.

$$
\begin{aligned}
& \mathrm{T}_{\mathrm{m}}=\text { the bulk fluid temperature }\left({ }^{\mathrm{O}} \mathrm{F}\right) \\
& \mathrm{h}_{\mathrm{mic}}=\text { the microconvective (boiling) heat transfer coefficient (Btu/hr-ft }{ }^{2}{ }^{\circ} \mathrm{F} \text { ) }
\end{aligned}
$$

Chen was able to closely correlate the existing flow boiling data. The microconvective heat transfer cocfficient is roughly equivalent to that provided hy Thom's equation except that it includes a suppression factor, $\mathrm{S}$, as a function of two-phase flow conditions. For the flow conditions and fluid properties of the hot-wall tests, the suppression factor varies from 0.3 to 0.5 and the Chen microconvective portion of the correlation can be approximated by

$$
\mathrm{h}_{\text {mic }} \stackrel{\cong}{=} 0.92\left(\Delta \mathrm{T}_{\mathrm{S}}\right)^{0.25}\left(\Delta \mathrm{P}_{\mathrm{S}}\right)^{0.75}
$$

where

$$
\begin{aligned}
& \Delta \mathrm{T}_{\mathrm{S}}=\text { the wall superheat }\left({ }^{\mathrm{O}} \mathrm{F}\right) \\
& \Delta \mathrm{P}_{\mathrm{S}}=\text { the pressure increment corresponding to } \Delta \mathrm{T}_{\mathrm{S}} \text { (psi). }
\end{aligned}
$$




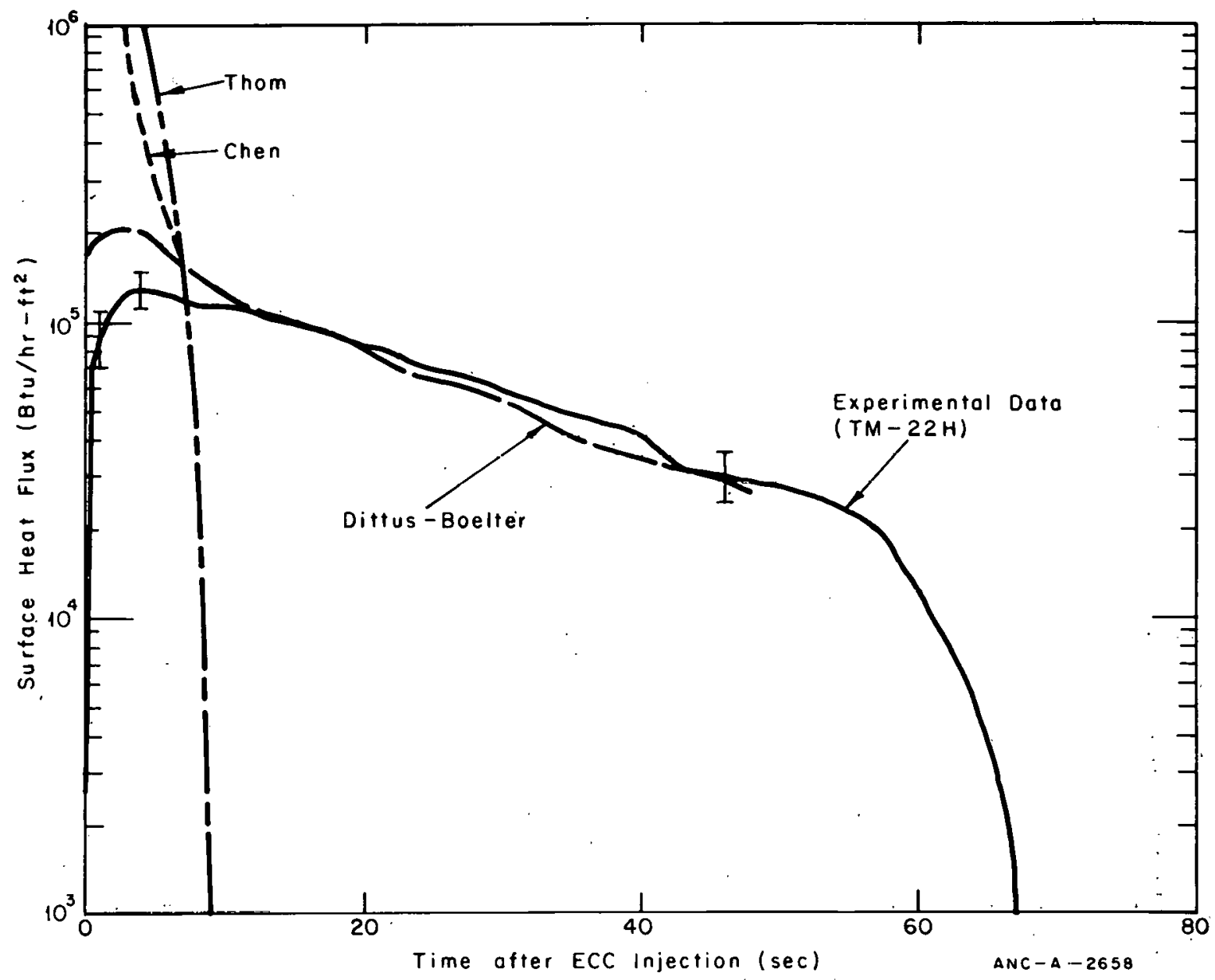

Fig. 6 Piping heat fluxes for hot wall Test 15.2 .. $52 \mathrm{gpm}$ ECC injection rate.

By using the Dittus-Boelter correlation and a two-phase multiplier, F, to predict the macroconvective component as recommended by Chen, the Chen correlation for the cold leg pipe condition can be written as

$$
\begin{aligned}
\mathrm{q}^{\prime \prime} & =0.023\left(\frac{\mathrm{k}}{\mathrm{D}}\right) \operatorname{Pr}_{\ell}^{0.4} \operatorname{Re}_{\ell}^{0.8}\left(\mathrm{~T}_{\mathrm{w}}-\dot{\mathrm{T}}_{\mathrm{m}}\right) \ddot{\mathrm{F}} \\
& +0.92\left(\Delta \mathrm{T}_{\mathrm{S}}\right)^{1.24}\left(\Delta \mathrm{P}_{\mathrm{S}}\right)^{0.75}
\end{aligned}
$$

where

$\mathrm{k}=$ thermal conductivity of the fluid

$\mathrm{D}=$ pipe diameter

$\operatorname{Pr}_{\ell}=$ liquid Prandtl number

$\mathrm{Re}_{\ell}=$ liquid Reynolds number

$\mathrm{F}=$ the ratio of the two-phase Reynolds number to the liquid Reynolds number (equal to unity for single-phase flow). 
The microconvective portion of the Chen correlation is not used in calculations for which the wall temperature falls below the saturation temperature because boiling does not occur. If boiling does not occur and if single-phase fluid is flowing in the pipe, the F-factor in the Chen correlation is equal to unity and the correlation reduces to the Dittus-Boelter correlation. Equation (5) was used in conjunction with the calculated wall temperature and experimental data to calculate the heat fluxes that are plotted on Figures 5 and 6 . During about the first 6 seconds, the microconvective portion of Equation (5) calculates heat fluxes larger than those calculated from the data, indicating additional suppression of the boiling mechanism over that calculated by the Chen correlation. This additional boiling suppression in the cold leg pipe may result because the flow at the measurement location, and throughout the cold leg pipe, is not fully developed. When the flow is not fully developed, larger temperature gradients can exist in the fluid near the wall causing additional suppression of the boiling. However, without more information on the effect of entrance velocity and temperature profiles on flow boiling, all that can be concluded is that the investigated boiling heat transfer correlations overestimate heat transfer coefficients for typical ECC injection conditions in the semiscale experiment and that the single-phase heat transfer coefficient correlation (Dittus-Boelter) gives a better estimate of the experimentally determincd heat transfer.

The calculated heat transfer coefficients for hot-wall Tests 15.1 and 15.2 are shown in Figures 7 and 8 . These heat transfer coefficients were determined using the difference between the calculated wall and measured bulk fluid temperatures together with the calculated heat fluxes. The dominant uncertainty in the heat transfer coefficients, as determined in Appendix A, is the uncertainty in wall-to-bulk temperature difference which is estimated to be $10^{\circ} \mathrm{F}$. When the difference between the calculated wall temperature and the measured bulk fluid temperature approaches $10^{\circ} \mathrm{F}$, the uncertainty in the calculated heat transfer coefficient becomes quite large. The Dittus-Boelter correlation for single-phase forced convection is shown on these figures and the close agreement again indicates that the nucleate boiling heat transfer mechanism can be neglected for conditions typical of simulated ECC injection in the semiscale system. Heat transfer coefficients from the boiling heat transfer correlations are not shown on these figures because they would be based on saturation temperature and would not be directly comparable.

In addition to the heat fluxes calculated for the hot-wall tests, cold leg wall heat fluxes were calculated for isothermal blowdown tests both with and without ECC injection. Figure 9 shows the calculated pipe wall heat fluxes at locations on the bottom and side of the cold leg pipe for isothermal Test 1010 which did not include ECC injection. During the first 10 seconds of depressurization, the heat transfer coefficient is sufficiently high that heat transfer is essentially conduction-limited; that is, the metal surface temperature closely follows the fluid temperature and the surface heat flux is essentially determined by the transient conduction of heat in the pipe wall. For purposes of comparison, a numerical solution was obtained using an infinite heat transfer coefficient (that is, the wall temperature was set equal to the fluid temperature), and this conduction-limited solution is also plotted on Figure 9. Since the heat transfer is essentially conduction-limited for the first 10 seconds of the test, the wall-to-bulk temperature difference is very small and any heat transfer correlation yielding large $\left(\mathrm{h}>1000 \mathrm{Btu} / \mathrm{hr}-\mathrm{ft}^{2}{ }^{\circ} \mathrm{F}\right)$ heat transfer coefficients 


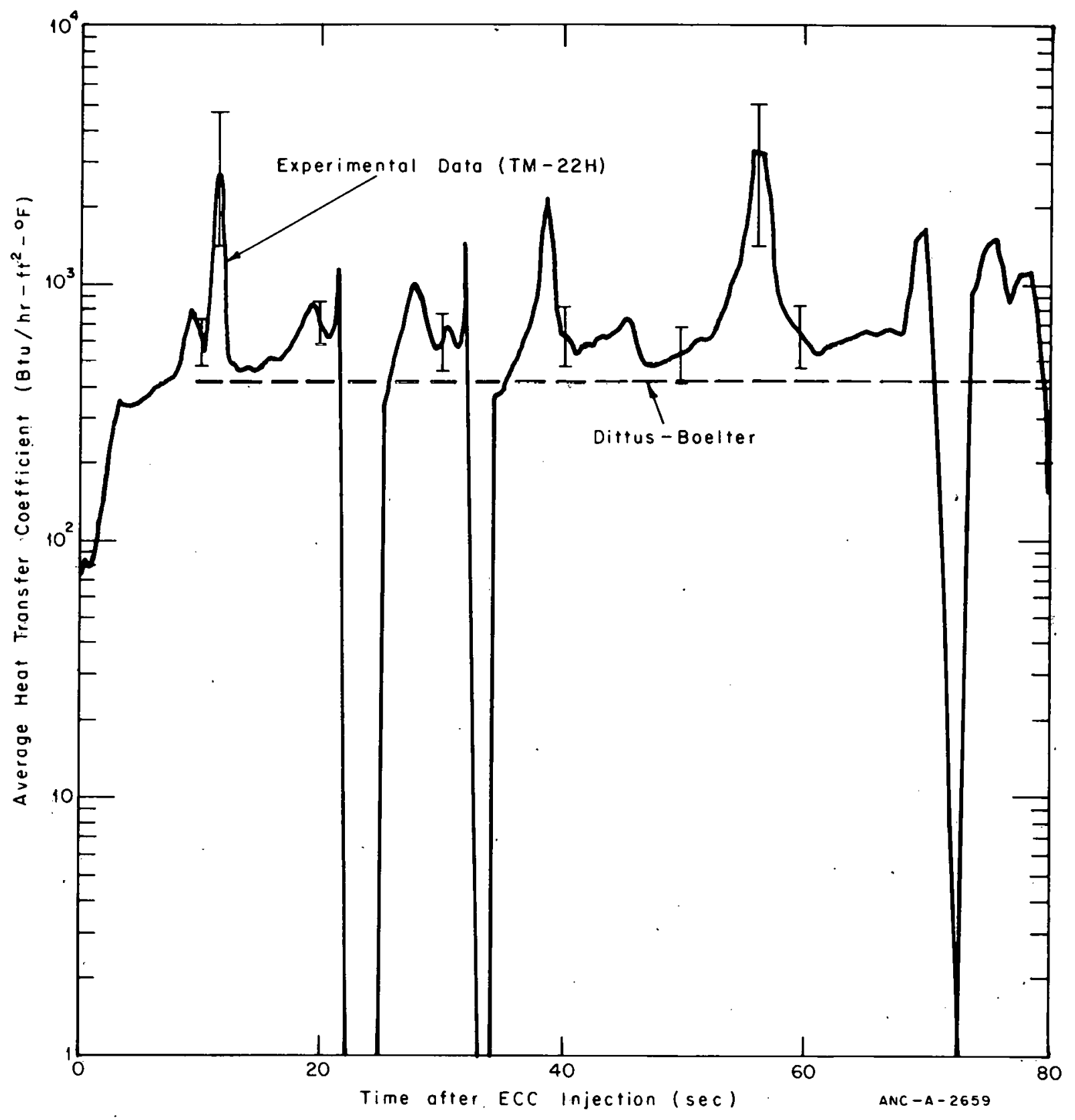

Fig. 7 Heat transfer coefficients for hot-wall Test 15.1.

will produce results which are in reasonable agreement with the data. Thus, both boiling heat transfer correlations and single-phase forced convection heat transfer correlations will adequately calculate the heat transfer rates. The heat fluxes calculated by RELAP4 ${ }^{[a]}$ are also shown on Figure 9. RELAP4, which uses the Thom heat transfer correlation during the initial part of blowdown, produced results that are in good agreement with the data over the period when the heat transfer is conduction-limited. For times greater than 10 seconds after rupture, the wall-to-bulk fluid temperature difference becomes sufficiently large that differences can be distinguished in the surface heat fluxes calculated with different heat transfer correlations.

[a] The RELAP4 model used in this report is described in Appendix B. The purpose of this model was to provide a best estimated calculation of the system response. 


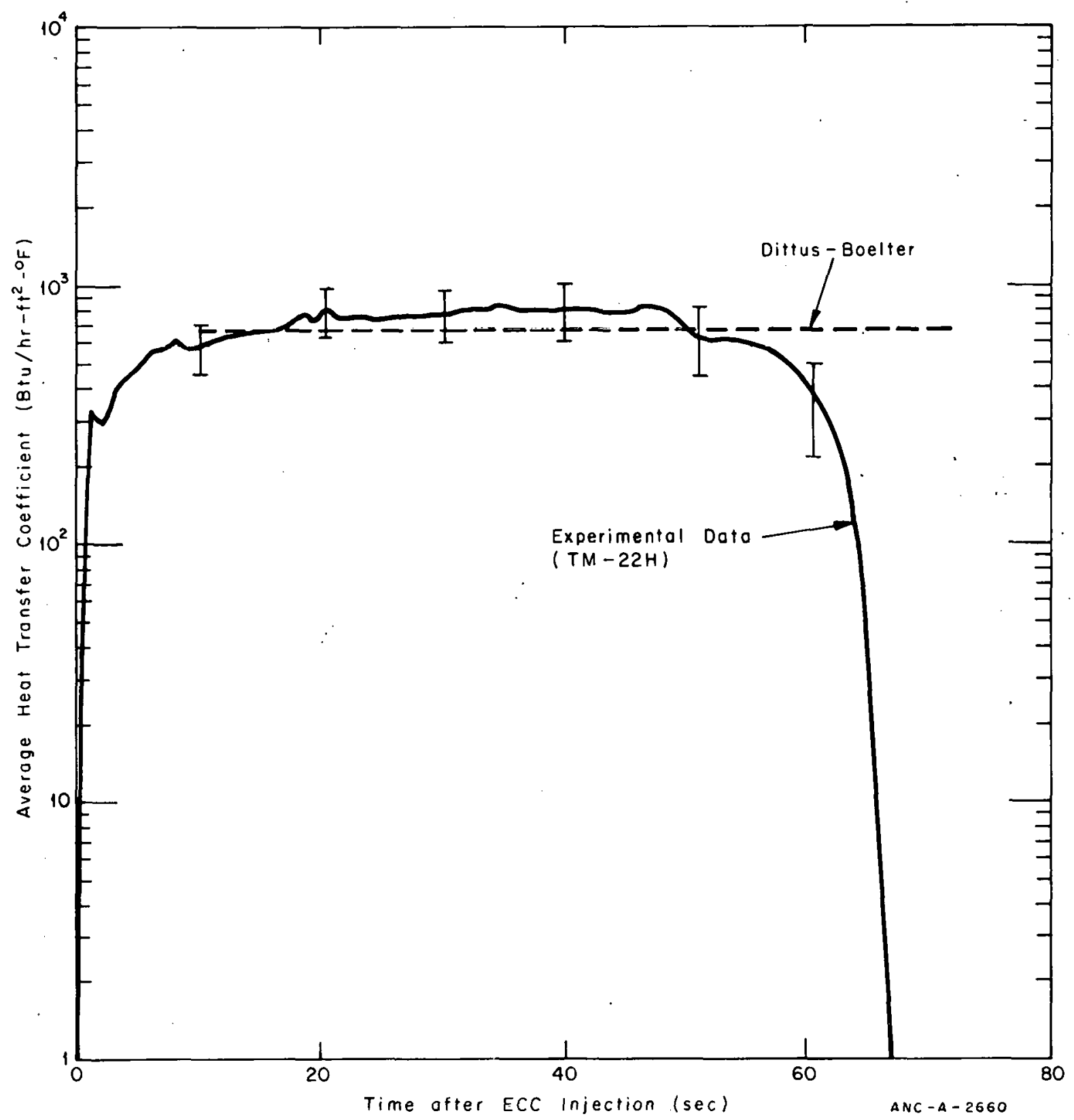

Fig. 8 Heat transfer coefficients for hot wall Test 15.2.

The heat transfer coefficients calculated for blowdown Test 1010 (without ECC injection) are shown in Figure 10. These coefficients were calculated using the same method described for the calculation of the heat transfer coefficients for the case without blowdown conditions. The small wall-to-bulk temperature difference that occurs during the early part of blowdown results in a large experimental uncertainty in the calculated heat transfer coefficients. However, since the heat transfer is conduction-limited for this portion of the test, the calculated heat fluxes are not very sensitive to the magnitude of the heat transfer coefficient as long as it is large, and the boiling correlations and single-phase convection correlations appear to give adequate calculations for the heat transfer. The experimental results presented in Figure 10 are calculated from two temperature measurements at the side and the bottom of the intact loop cold ieg pipe. The heat transfer coefficient for the bottom 


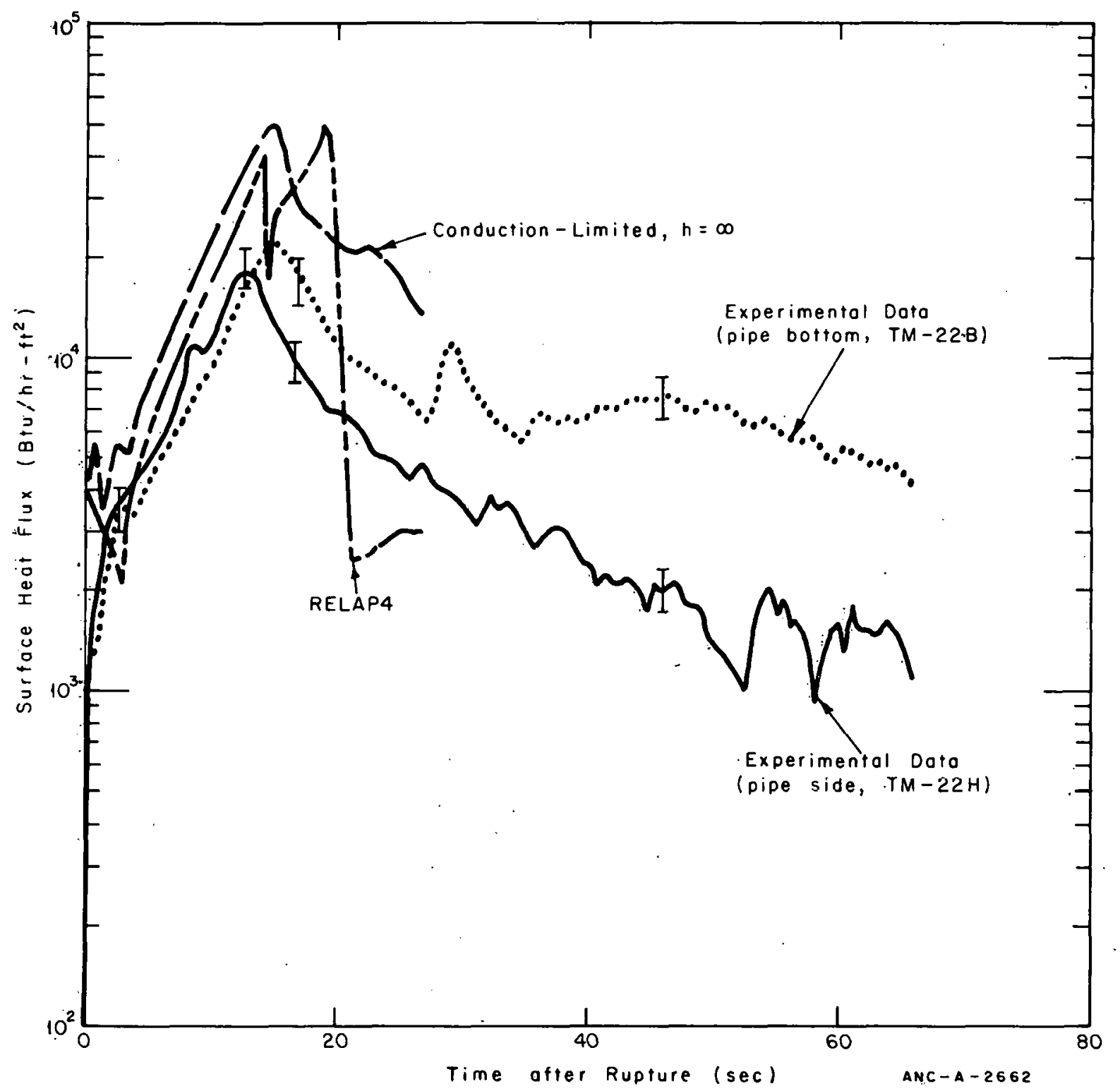

Fig. 9 Calculated and experimental piping heat fluxes for isothermal blowdown Test 1010 without ECC injection.

of the pipe is higher than that for the side. A possible.explanation for this difference in heat transfer coefficients is that the fluid stratifies as the blowdown progresses and the low quality fluid at the bottom of the pipe results in higher heat transfer coefficients and larger heat fluxes.

The heat transfer coefficients calculated by RELAP4 and those calculated using the Chen correlation are also included on Figure 10. The heat transfer coefficients calculated by RELAP4 are greater than those calculated from the data for about the first 22 seconds and less than those calculated from the data from 22 seconds until the end of blowdown. The heat transfer coefficients calculated using the Chen correlation follow the data well during the first. 20 seconds of the test. Toward the end of blowdown the fluid quality becomes high and the heat transfer coefficients calculated from the Chen correlation underestimates the heat transfer coefficients calculated from the data because the correlation is no longer applicable. 


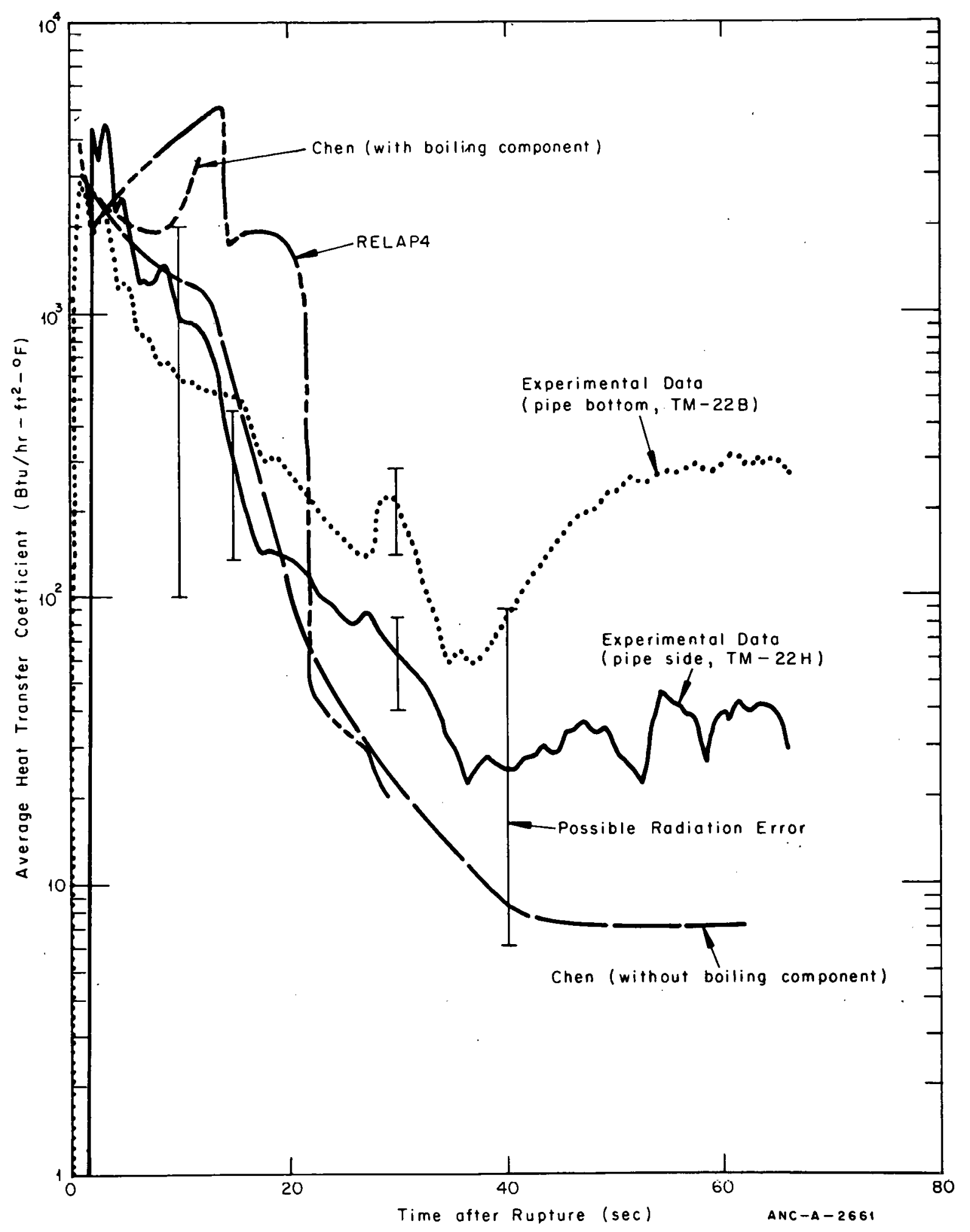

Fig. 10 Calculated and experimental heat transfer coefficients for isothermal blowdown Test 1010 without ECC injection. 
Figure 11 shows the calculated wall heat fluxes for the cold leg pipe for isothermal blowdown Test 1008 which included simulated ECC injection about 16 seconds after rupture. The heat fluxes calculated by RELAP4 are also shown along with the heat fluxes calculated from the single-phase forced convection correlation using the measured wall-to-bulk temperature difference. Both the RELAP4 heat fluxes and calculated pure convection heat fluxes are in good agreement with the heat fluxes calculated from the data. Comparison of the calculated heat fluxes for ECC and non-ECC blowdowns (Figures 9 and 11) indicates the heat flux in the cold leg increases by almost a factor of ten when the subcooled ECC is injected and remains much higher throughout the remainder of the blowdown period. Heat transfer coefficients for Test 1008 are presented in Figure 12. Even though the uncertainty in the data is fairly large for the early portion of the test, the single-phase forced convection correlation is seen to exhibit better agreement with the data

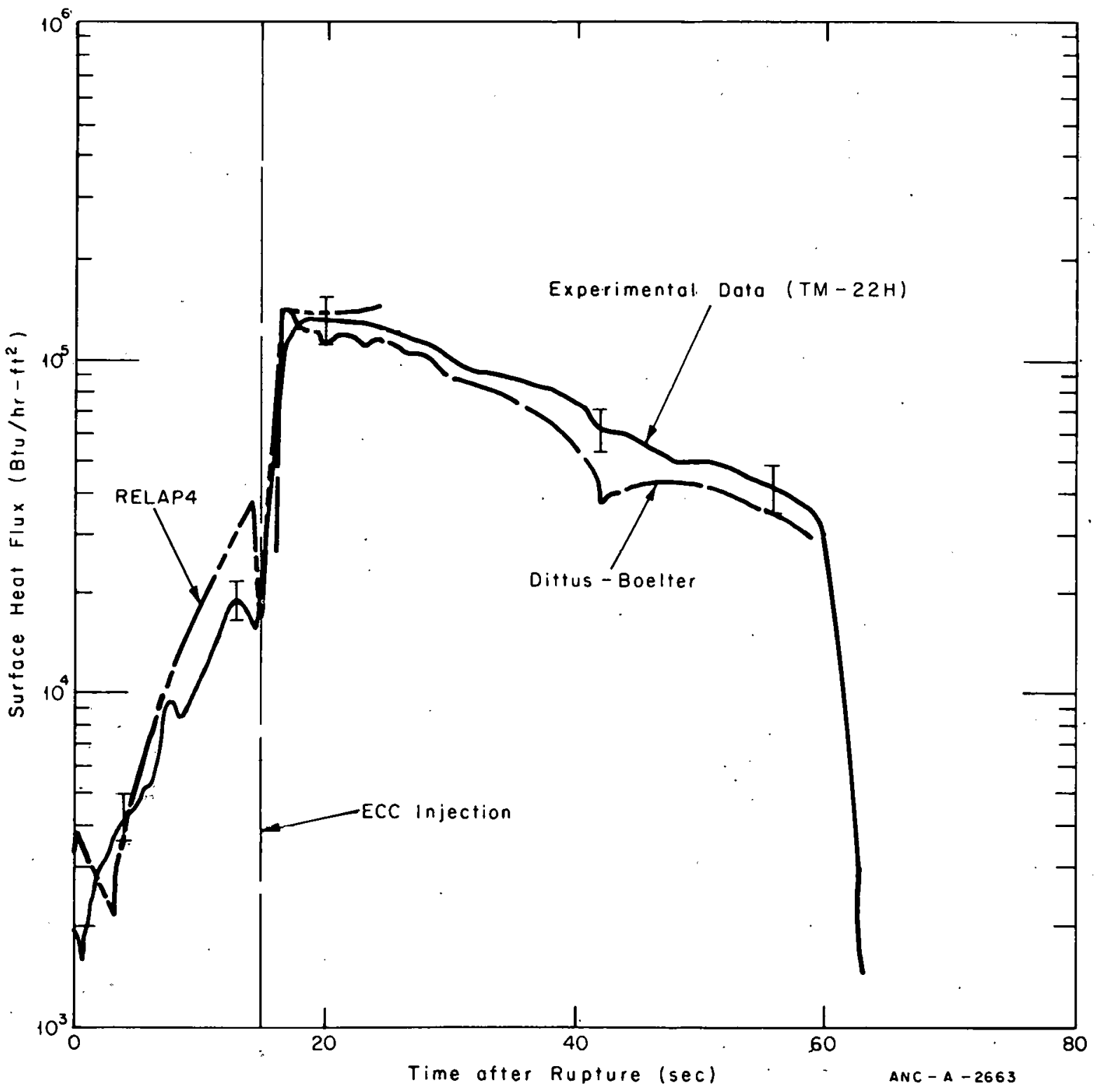

Fig. 11 Calculated piping heat fluxes for isothermal blowdown Test 1008 with ECC injection. 


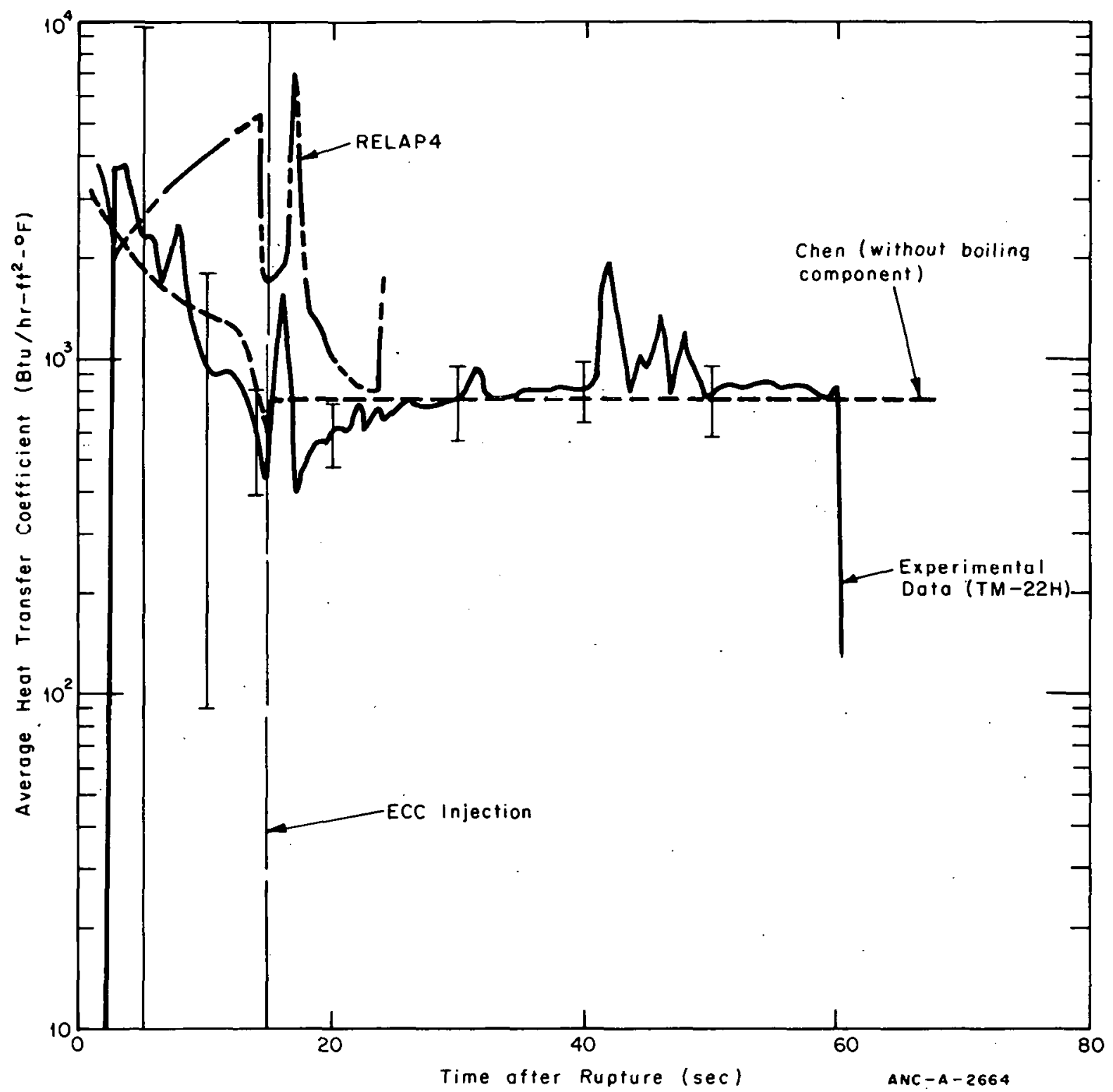

Fig. 12 Calculated and experimental heat transfer coefficients for isothermal blowdown Test 1008 with ECC injection.

than does the boiling correlation used by RELAP4. A possible explanation for the lack of a major contribution due to boiling may be the boiling suppression mechanism suggested by Chen, and discussed previously for the hot-wall tests without the influence of blowdown.

The heat fluxes and heat transfer coefficients calculated for Test 1008 are typical of heat fluxes calculated for other isothermal tests with ECC injection (Tests 1006 and 1009). Therefore, calculated results from these tests are not presented.

\subsection{Cold Leg Fluid Conditions During ECC Injection}

The fluid conditions in the intact loop cold leg were evaluated during ECC injection using measurements of density, flow, temperature, and pressure. Measurements in the cold leg near the vessel entrance and near the pump discharge and in the lower plenum at the inlet to the core were used to obtain this evaluation. 
Following ECC injection, the measured densities of the fluid in the cold leg can be used to indicate the position of the fluid in the cold leg pipe as well as to specify the density of the fluid. The measured densities near the vessel inlet and near the pump discharge for isothermal Test 1006 are shown in Figure 13. The measurement near the vessel inlet shows an increase in density to a value that is typical of the density of a subcooled fluid within two seconds of ECC injection. The density near the vessel varied only slightly over the ECC injection period indicating little or no steam was mixed with the injected fluid near the vessel entrance. The measured density near the pump discharge shows little variation from the time of ECC injection until after blowdown is complete. The fact that the density near the vessel shows ECC reached that position soon after ECC injection, whereas the density near the pump discharge shows no ECC fluid was present until after blowdown was over indicates that the blowdown fluid flowing in the cold leg forced the injected ECC toward the vessel and restricted flow of the ECC back toward the pump. After blowdown was complete the ECC began to fill the cold leg and some ECC alternately approached and was forced away from the pump discharge. The results presented in Figure 13 are typical of the results from other isothermal tests (Tests 1008 and 1009). The results of measurements of the fluid density in the cold leg for the Test Series 15 hot-wall tests showed a relatively constant density near the vessel and density variations near the pump discharge similar to the variations shown in Figure 13 after completion of blowdown.

The velocity of the fluid in the cold leg piping between the injection point and the vessel is dependent on the density of the fluid and the flow rate of the fluid. The density and flow drag disc measurements near the cold leg entrance to the vessel (Spool Piece 22) were combined to calculate this velocity; the results for Test 1008 are presented in. Figure 14. The large negative spike in velocity at the time of ECC injection was not indicated by the measurements obtained from the turbine flowmeter at this location and may be a spurious effect resulting from rapid cooling of the temperature sensitive drag disc. After completion of blowdown, the average velocity at the vessel inlet (Spool Piece 22) would be expected to approach the velocity of only the ECC flowing in the piping, which is about 3 $\mathrm{ft} / \mathrm{sec}$. The velocity of the fluid at the cold leg entrance to the vessel is higher by a factor of three than the velocity in the cold leg, shown in Figure 14, because a nozzle insert was utilized at the vessel inlet to attain vessel inlet fluid velocities that are typical of those in a PWR.

The possible major contributors to the temperature rise of the ECC water in the cold leg are mixing of the ECC with the water component of the two-phase blowdown fluid, condensation of part or all of the steam component of the two-phase blowdown fluid, and piping heat transfer. Since the quality of the two-phase blowdown fluid in the cold leg is about unity over the ECC injection time period, the temperature rise attributed to mixing of the ECC with the water component of the two-phase blowdown fluid is negligible. Since the measurements at the pump discharge show high quality fluid. flowing into the cold leg during ECC injection and since the measurements in the cold leg near the vessel indicate that complete condensation has occurred before the ECC has reached this location, the total rate of condensation of the blowdown fluid by the ECC was assumed to be equal to the flow rate measured near the pump discharge. 


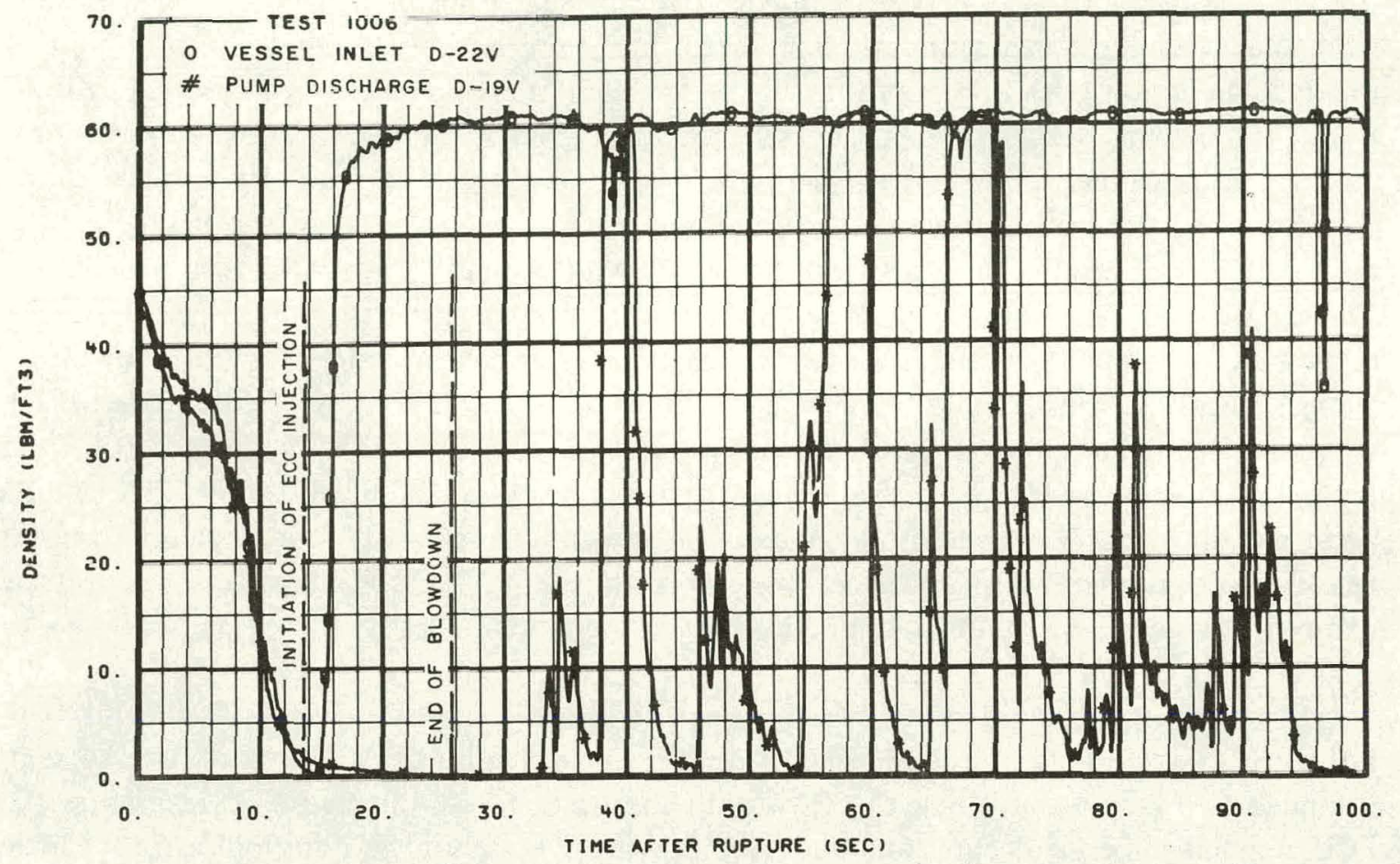

Fig. 13 Measured densities in the intact loop cold leg near the vessel inlet and near the pump discharge -- Test 1006.

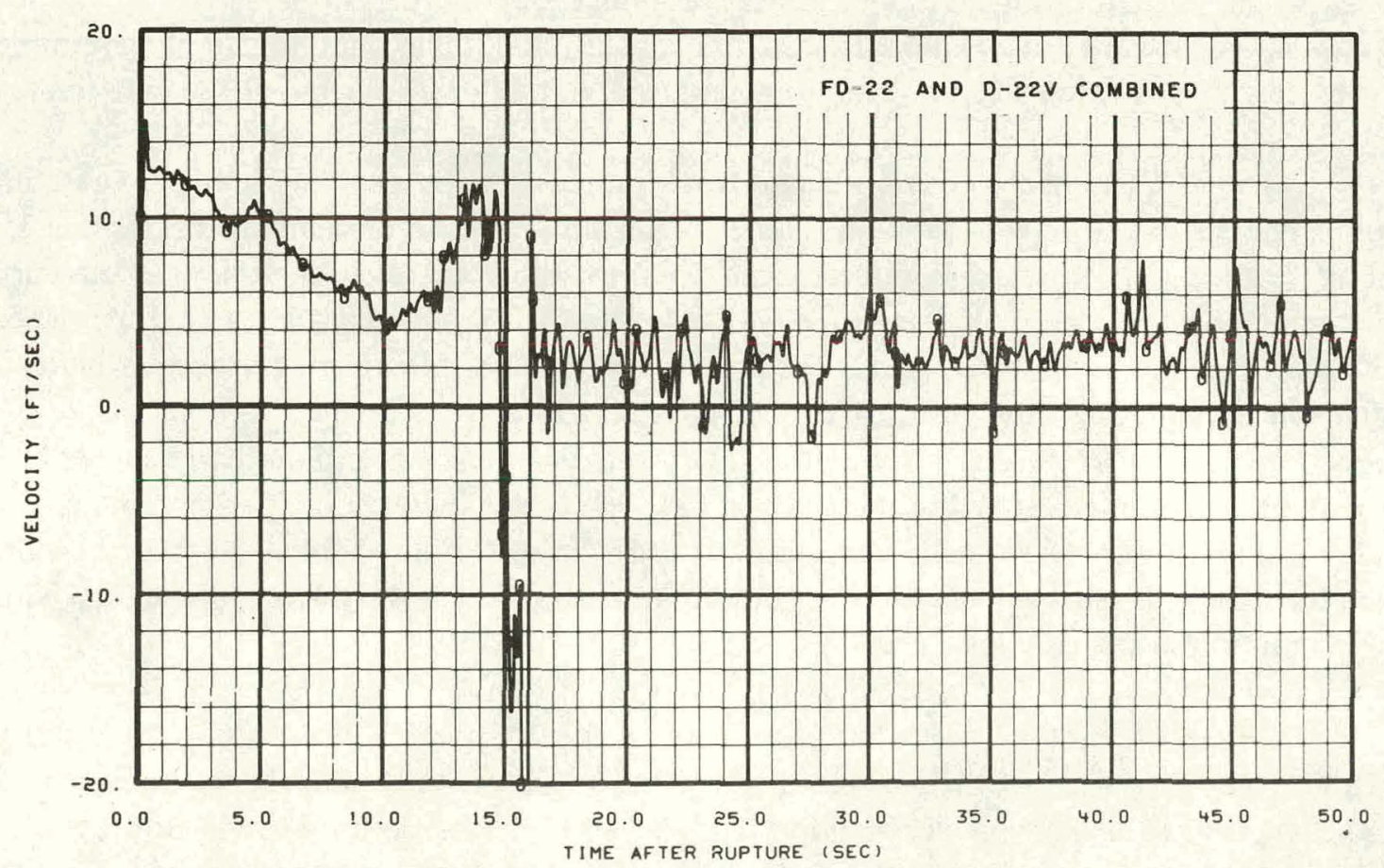

Fig. 14 Fluid velocity near the cold leg entrance to vessel -- Test 1008. 
Calculations have been performed to obtain an estimate of the temperature increase in the ECC fluid from the effects of condensation and heat transfer from the piping. Results from these calculations are presented in Table V. The amount of condensation varies during the ECC injection period; therefore, for these calculations a maximum rate of blowdown fluid condensation was established by selecting the largest flow rate at the pump discharge during the blowdown period of the isothermal tests. A similar approach was applied to the Test Series 15 hot-wall tests except that a maximum averaged value of flow was taken at the pump discharge because, in the absence of blowdown flows, the flow at this point oscillated. Through use of the wall heat fluxes determined previously, the piping heat flux was integrated over the injection leg area and used to determine an approximate temperature change resulting from piping heat transfer. Since the heat flux decreases with time, the maximum heat flux following ECC injection was used to estimate the maximum ECC fluid temperature increase resulting from heat transfer from the cold leg piping. The results presented in Table $\mathrm{V}$ represent the maximum increase in the ECC fluid temperature that results from condensation and heat transfer in the cold leg and, therefore, cannot be compared directly with cold leg temperature measurements.

The amount of condensation that occurs in the cold leg following ECC injection will influence the amount of condensation that can occur in other parts of the system. Condensation can occur along the flow path followed by the injected ECC as long as the ECC remains subcooled and some steam is present. The semiscale data indicate that little condensation occurs in the downcomer and lower plenum regions because the water entering these regions is near saturation temperature, and little condensation occurs in the broken loop cold leg because not much steam is present. Therefore, in the semiscale system, most of the condensation occurs in either the intact loop cold leg or in the upper annulus. The relative amounts of condensation in the cold leg and upper annulus can be determined from flow measurements at the pump discharge and in the lower plenum at the core inlet.

When ECC is injected during blowdown, condensation in the cold leg near the pump discharge causes the flow to increase, and condensation in the upper annulus causes the flow at the core inlet to reverse. Figures 15 and 16 show the volumetric flow rates at the pump discharge and the core inlet, respectively, for isothermal blowdown tests with and without ECC (isothermal Tests 1008 and 1010, respectively). Comparison of the results indicates that the volumetric flow at the core inlet is significantly increased, but in the reverse direction, by ECC injection, whereas the volumetric flow at the pump discharge due to ECC injection is increased by a lesser amount. The significant increase in the flow at the core inlet compared to the smaller increase in flow at the pump discharge indicates that condensation in the upper annulus has a greater effect on system flows than does condensation in the cold leg.

Comparison of the results of Tests 1006 and 1008, which had ECC injection rates nearly volumetrically scaled and about 2.4 times volumetrically scaled, respectively, also indicates that condensation in the upper annulus strongly affects the system flows. Figures 17 and 18 show the volumetric flow rates at the pump discharge and the core inlet for Tests 1006 and 1008. Comparison of the flow rates at the pump discharge for these two tests during ECC injection indicates the flow rates of fluid to the injection point are not 
TABLE V

MAXIMUM TEMPERATURE INCREASES OF THE ECC FLUID IN THE COLD LEG RESULTING FROM CONDENSATION AND PIPING HEAT TRANSFER

\begin{tabular}{|c|c|c|c|c|c|}
\hline & \multicolumn{5}{|c|}{ Test } \\
\hline & $\underline{1006}$ & $\underline{1008}$ & $\underline{15.1}$ & $\underline{15.2}$ & 15.3 \\
\hline ECC delivery rate (gpm) & 22 & 52 & 22 & 52 & 22 \\
\hline Initial ECC temperature $\left({ }^{\circ} \mathrm{F}\right)$ & 72 & 72 & 75 & 75 & 90 \\
\hline Assumed maximum steam condensation rate (gpm) & 400 & 400 & 200 & 300 & 370 \\
\hline $\begin{array}{l}\text { Maximum ECC fluid temperature increase due to } \\
\text { condensation in the cold } 1 \mathrm{eg}\left({ }^{\circ} \mathrm{F}\right)\end{array}$ & 260 & 130 & 47 & 24 & 33 \\
\hline $\begin{array}{l}\text { Maximum ECC fluid temperature increase due to } \\
\text { heat transfer from the cold leg piping }\left({ }^{\circ} \mathrm{F}\right)\end{array}$ & 17 & 8 & 9 & 9 & 8 \\
\hline $\begin{array}{l}\text { Calculated total increase in ECC fluid } \\
\text { temperature in the cold leg }\left({ }^{\circ} \mathrm{F}\right)\end{array}$ & 277 & 138 & 56 & 33 & 41 \\
\hline
\end{tabular}




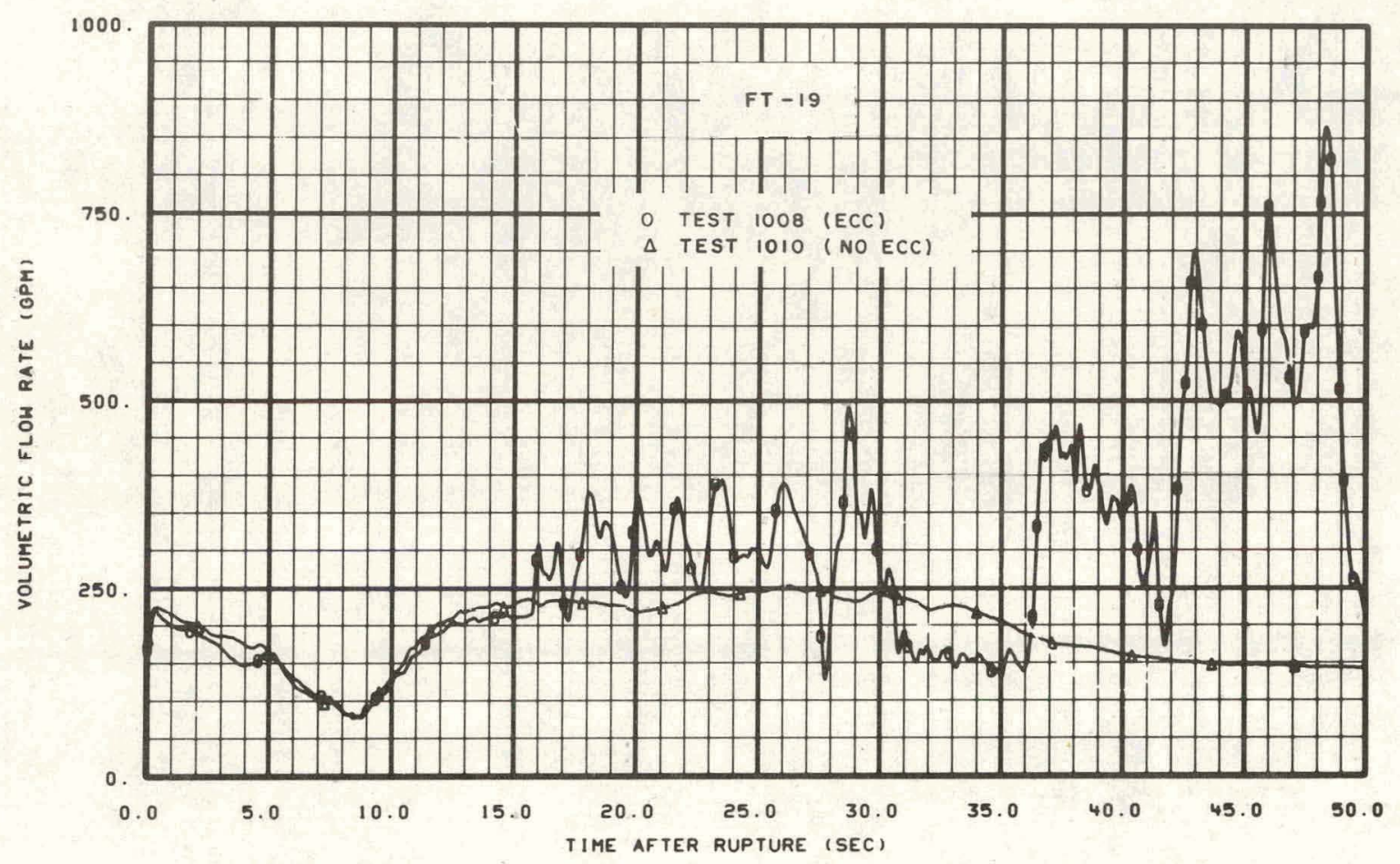

Fig. 15 Volumetric flow rate near pump discharge for tests with and without ECC injection.

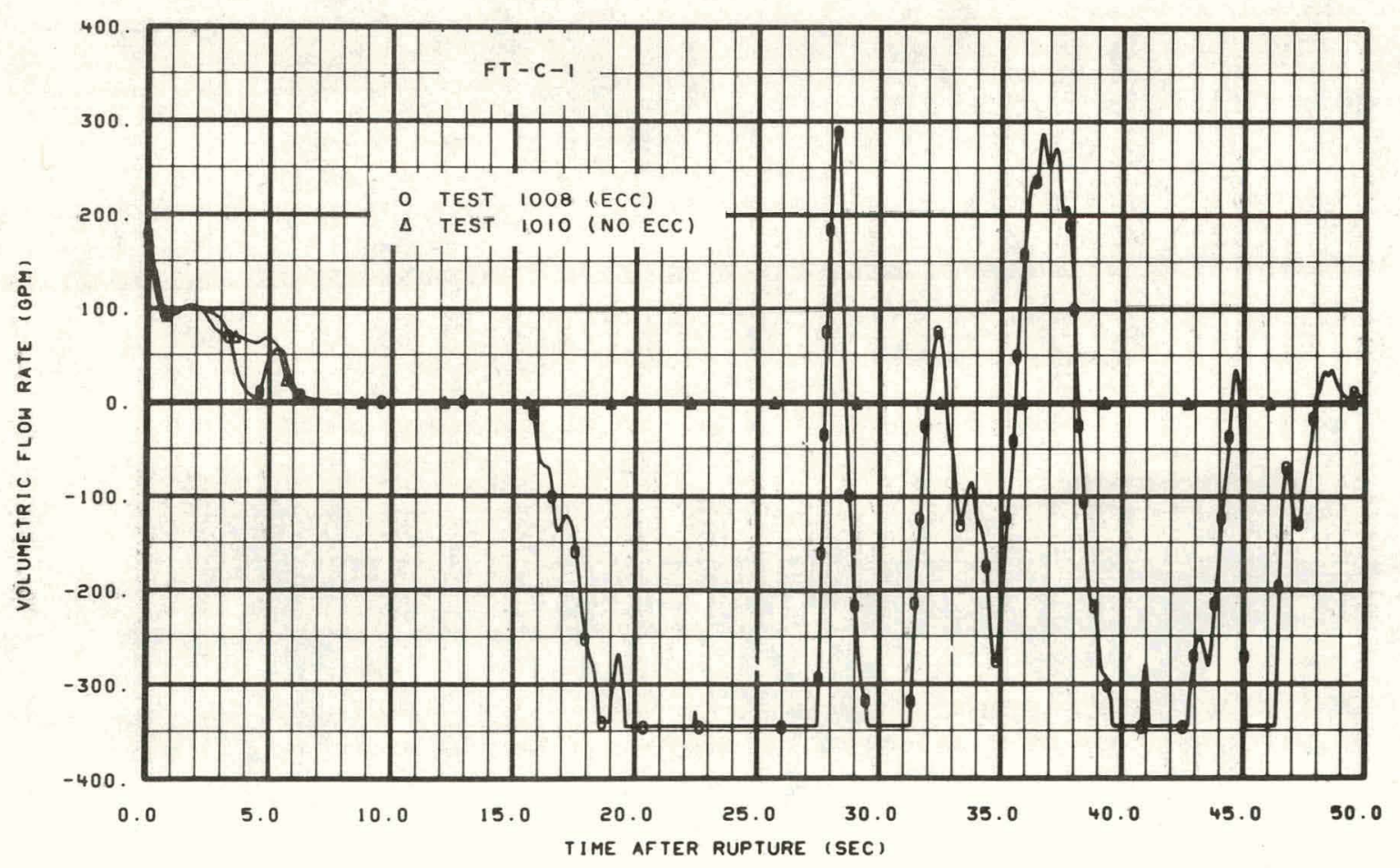

Fig. 16 Volumetric flow rate at core inlet for tests with and without ECC injection. 


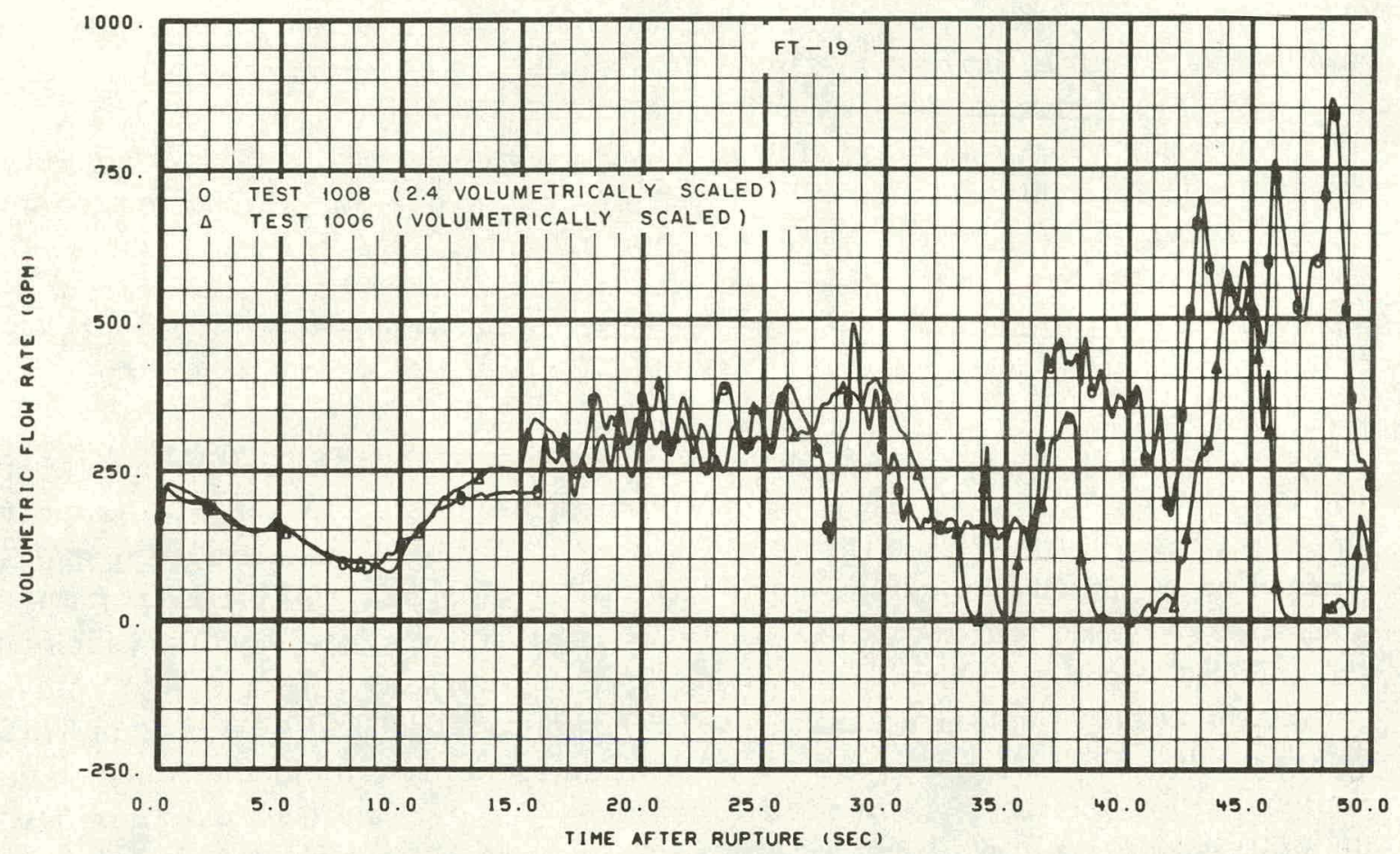

Fig. 17 Volumetric flow rate near pump discharge for tests with different volumetrically scaled ECC injection rates.

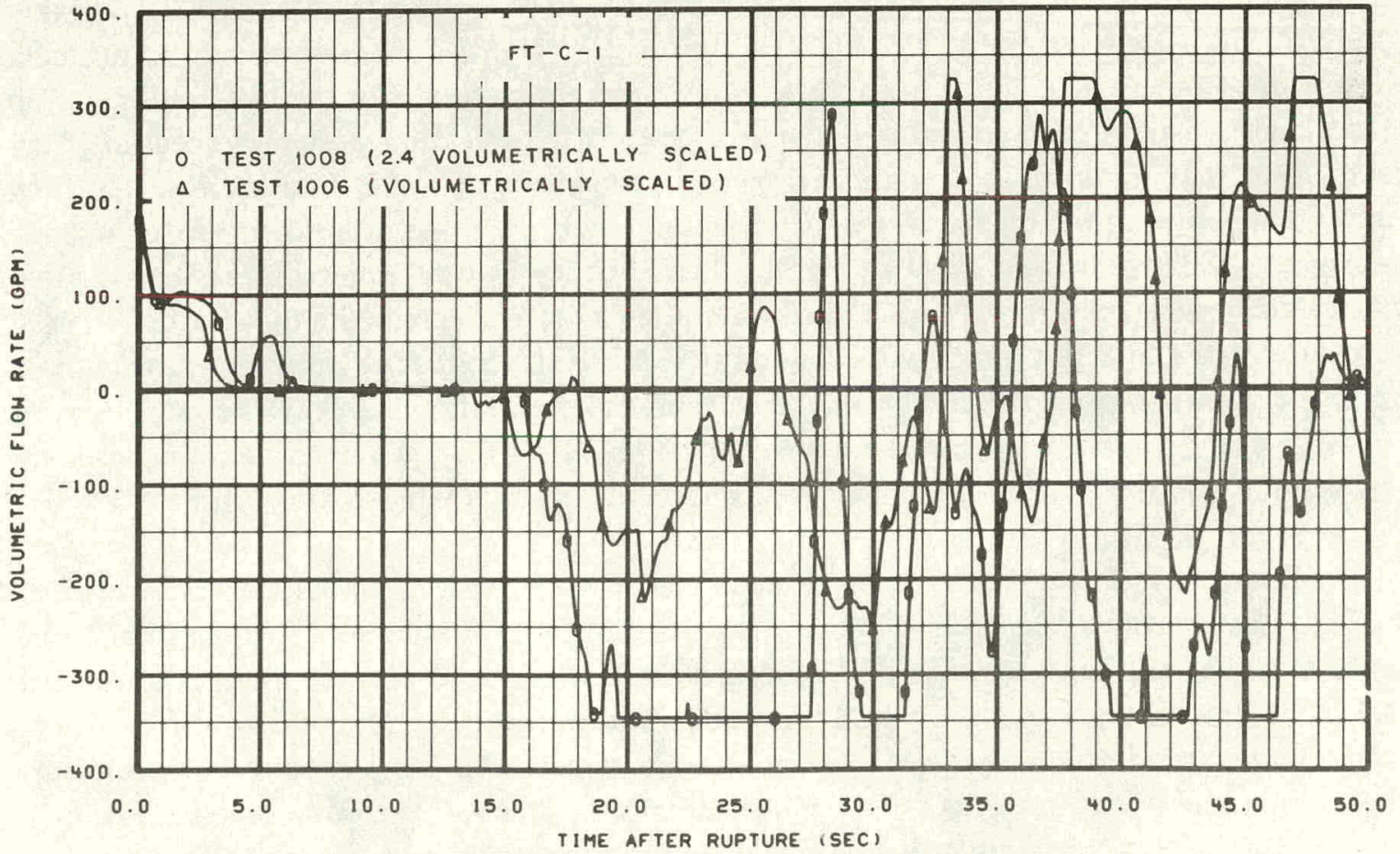

Fig. 18 Volumetric flow rate at core inlet for tests with different ECC injection rates. 
significantly different even though the injection rate for Test 1008 was about 2.4 times greater than the injection rate for Test 1006 . The flow at the core inlet exceeded the flow instrumentation range for Test 1008 at about $300 \mathrm{gpm}$, but the results still show that the flow toward the upper annulus is larger for Test 1008 than for Test 1006 . The difference in ECC flows and the corresponding difference in the subcooling of the water entering the upper annulus, as indicated in Table V, appears to cause the differences in the flow toward the upper annulus (as indicated by flow measurements at the bottom of the core). Comparison between the relative amounts of condensation that occur in the cold leg and the upper annulus at two different times for several tests is presented in Section III-2.2, Upper Annulus Bulk Fluid Temperature.

The effect of condensation in the cold leg and upper annulus regions on the rate of depressurization can be determined by comparing the pressures from tests with and without ECC injection. Figure 19 shows the cold leg pressures for Tests 1001 and 1006, and a comparison of the results indicates that the ECC injection rate of Test 1006 (nearly volumetrically scaled) did not cause a significant change in the rate of depressurization in the cold leg. Figure 20 shows the cold leg pressure from Tests 1010 and 1008, and a comparison of these results indicates that the ECC injection rate of Test 1008 (2.4 times the volumetrically scaled rate) increased the rate of cold leg depressurization over the rate of depressurization for the test without ECC injection. The increased depressurization rate during Test 1008 may have been caused by the larger amount of condensation in the upper annulus for Test 1008 .

\subsection{Cold Leg Pressure and Injection Port Differential Pressure Fluctuations}

Combustion Engineering, Inc. (CE) has performed separate effects steam-water mixing studies in $1 / 3$ - and $1 / 5$-PWR scale cold leg piping ${ }^{[14,15]}$ for a range of steady state steam and water flow rates and for different injection port geometries. For the different injection port angles tested, CE reported that the area around the injection port produced an effect similar to that produced by an undeveloped jet condenser. The $\mathrm{CE}$ data indicate the flow and condensation phenomena in the CE system caused the system pressure to fluctuate as much as \pm 20 psi at frequences as high as $2 \mathrm{~Hz}$. For a 90-degree injection angle, the same injection angle as used for the isothermal tests, the CE data also indicate that the differential pressure at the injection port oscillated and that the average pressure drop ranged from near zero to about $1 \mathrm{psid}$, depending on the steam and water flow rates. Other steam-water mixing tests ${ }^{[16]}$, although not conducted in a typical cold leg geometry, have also shown pressure oscillations occur when subcooled water and steam are injected together.

The semiscale cold leg pressure data have been examined to determine whether pressure fluctuations and oscillations occurred following ECC injection. Figures 21, 22, and 23 show the cold leg pressure for isothermal Test 1008 on expanded time and pressure scales. During blowdown (to about 26 seconds after rupture), the rate of depressurization is shown to vary, but no pressure oscillations are observed. The 30-psi spike in pressure beginning at about 27 seconds following rupture occurs at about the same time the injection mode switches from accumulator supplied injection to pumped injection and this increase in pressure is suspected to result from flow disturbances that accompany the change in 


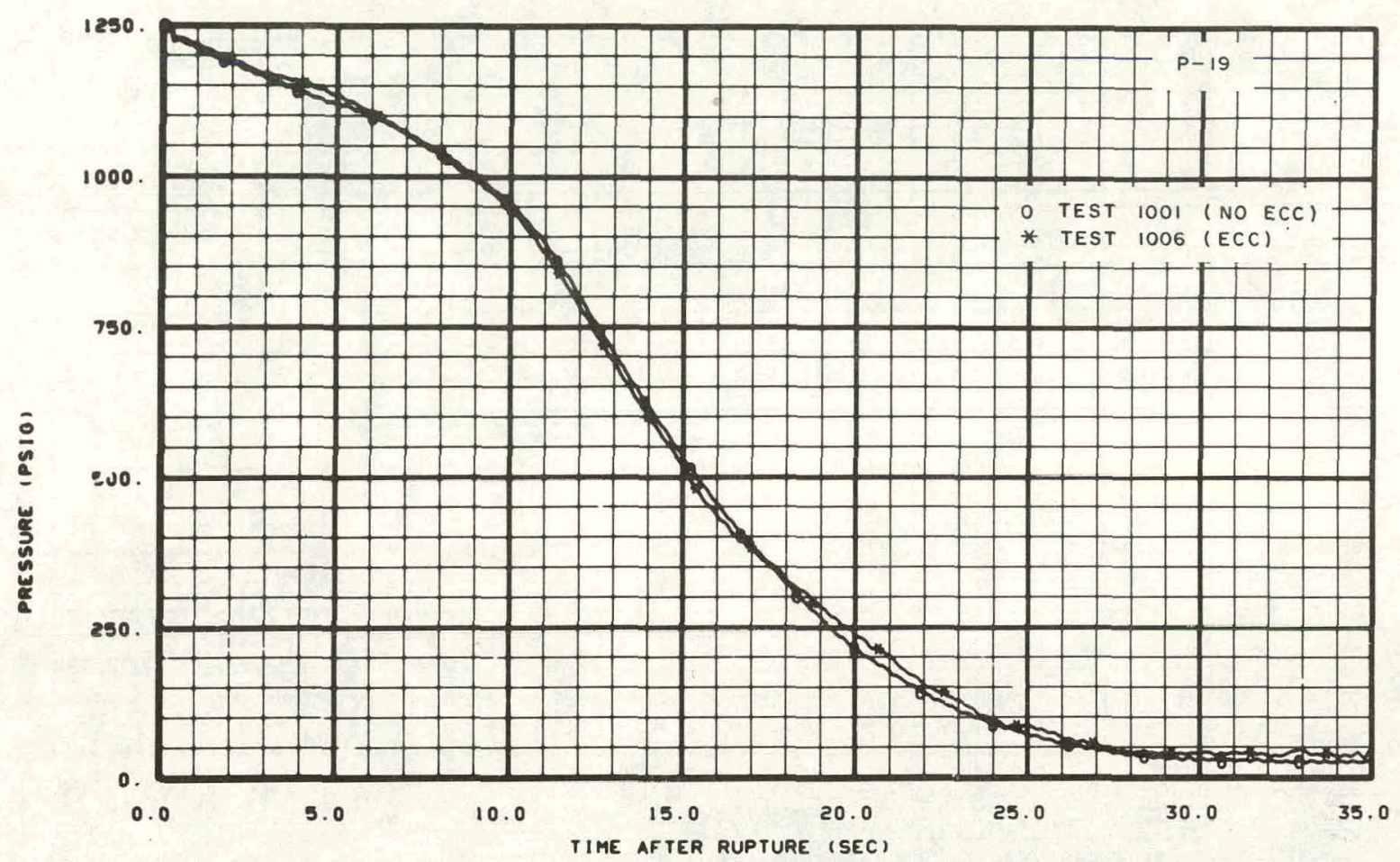

Fig. 19 Depressurization of cold leg during test with near volumetrically scaled ECC injection rate and test without ECC injection.

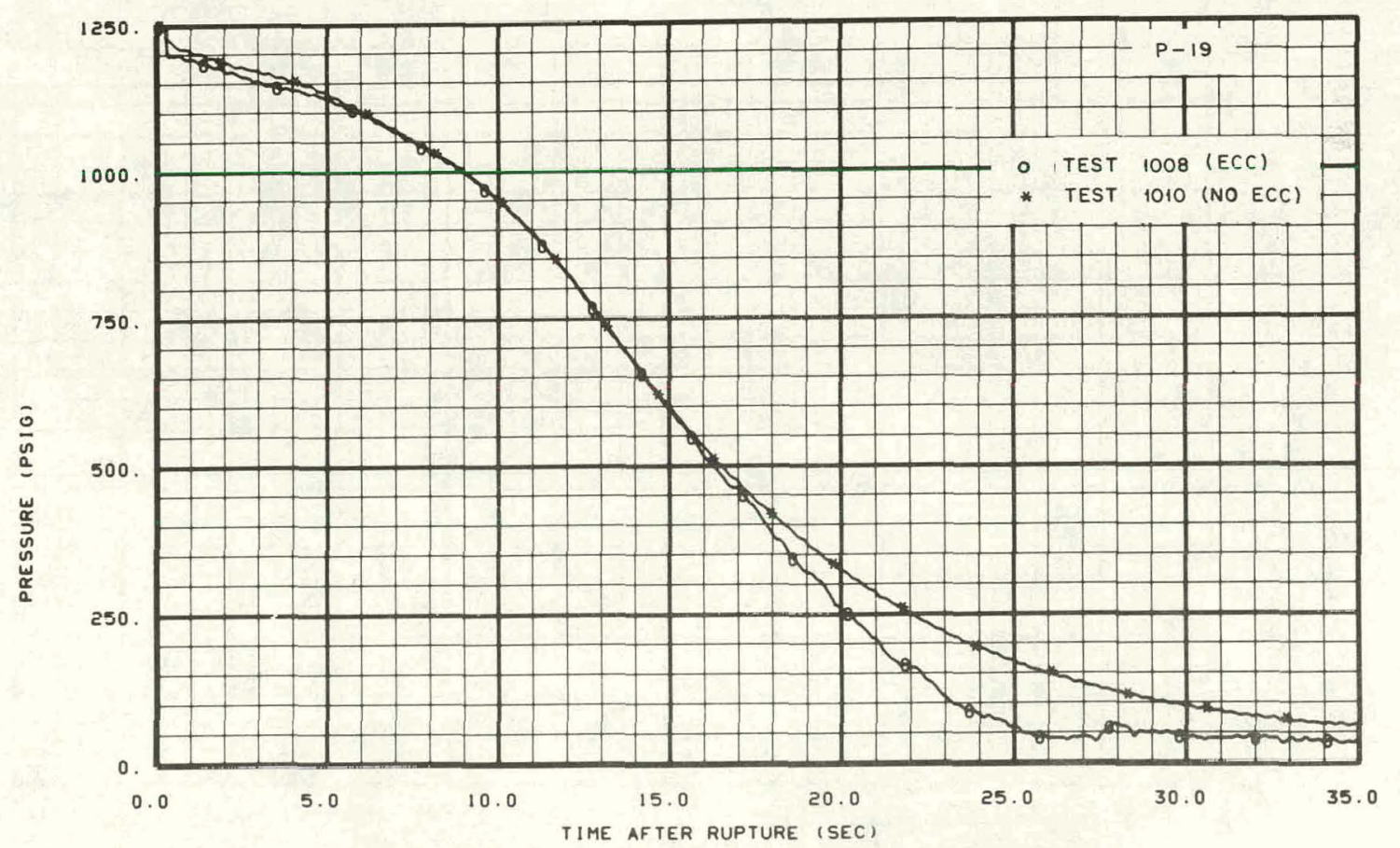

Fig. 20 Depressurization of cold leg during test with about 2.4 times volumetrically scaled ECC injection rate and test without ECC injection. 


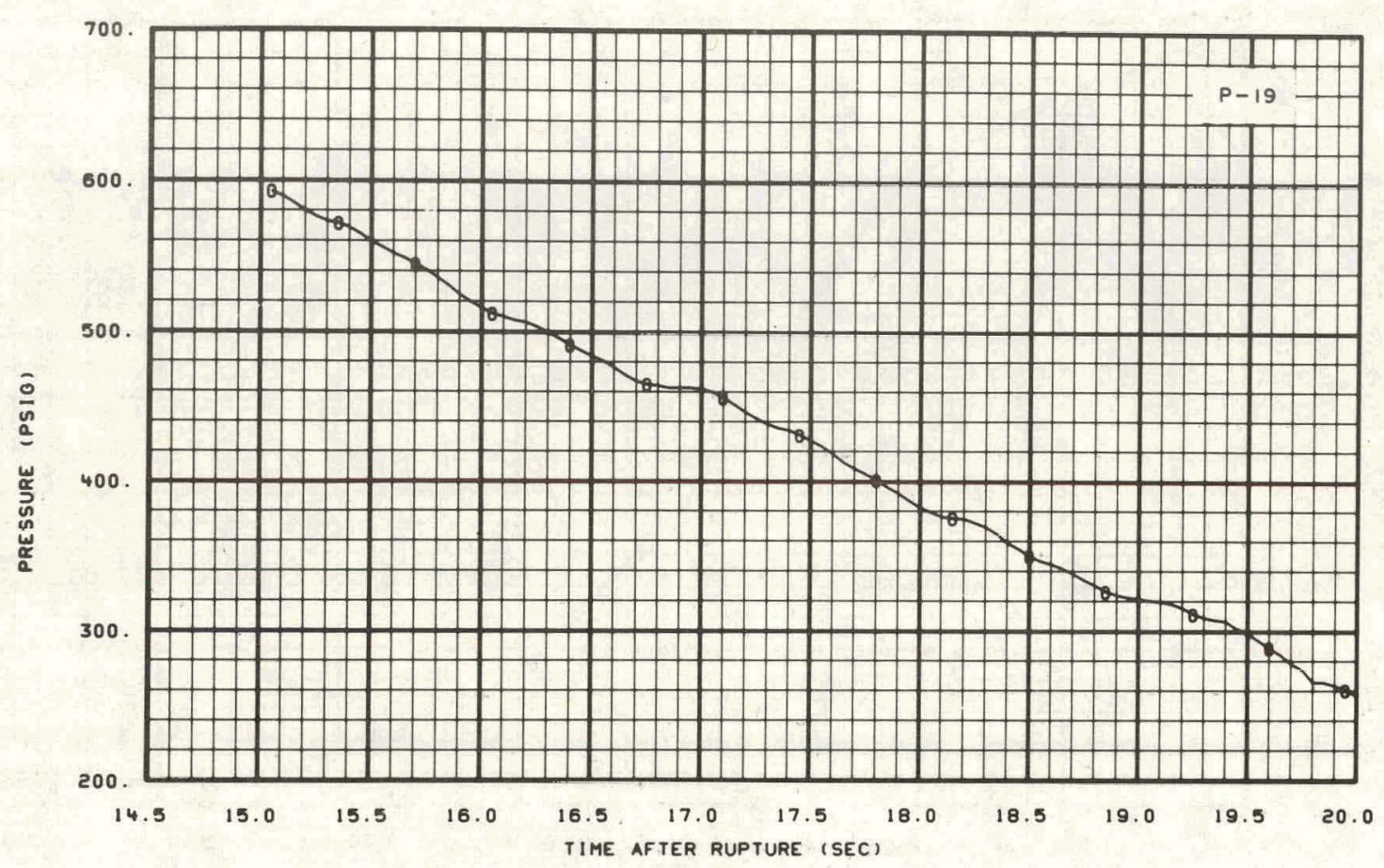

Fig. 21 Cold leg pressure during isothermal Test 1008 -- 14.5 to 20 seconds after rupture.

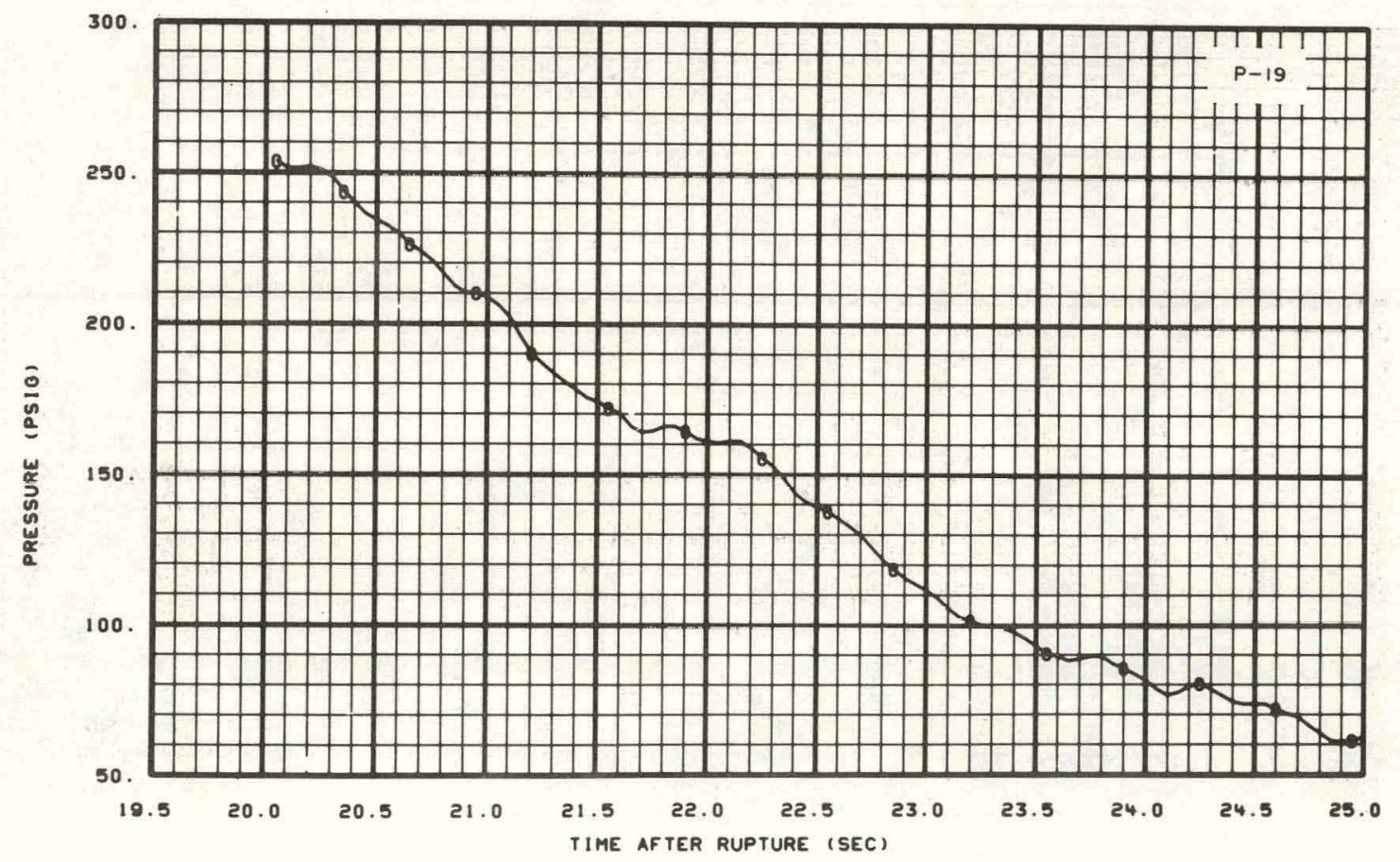

Fig. 22 Cold leg pressure during isothermal Test 1008 -- 19.5 to 25 seconds after rupture. 


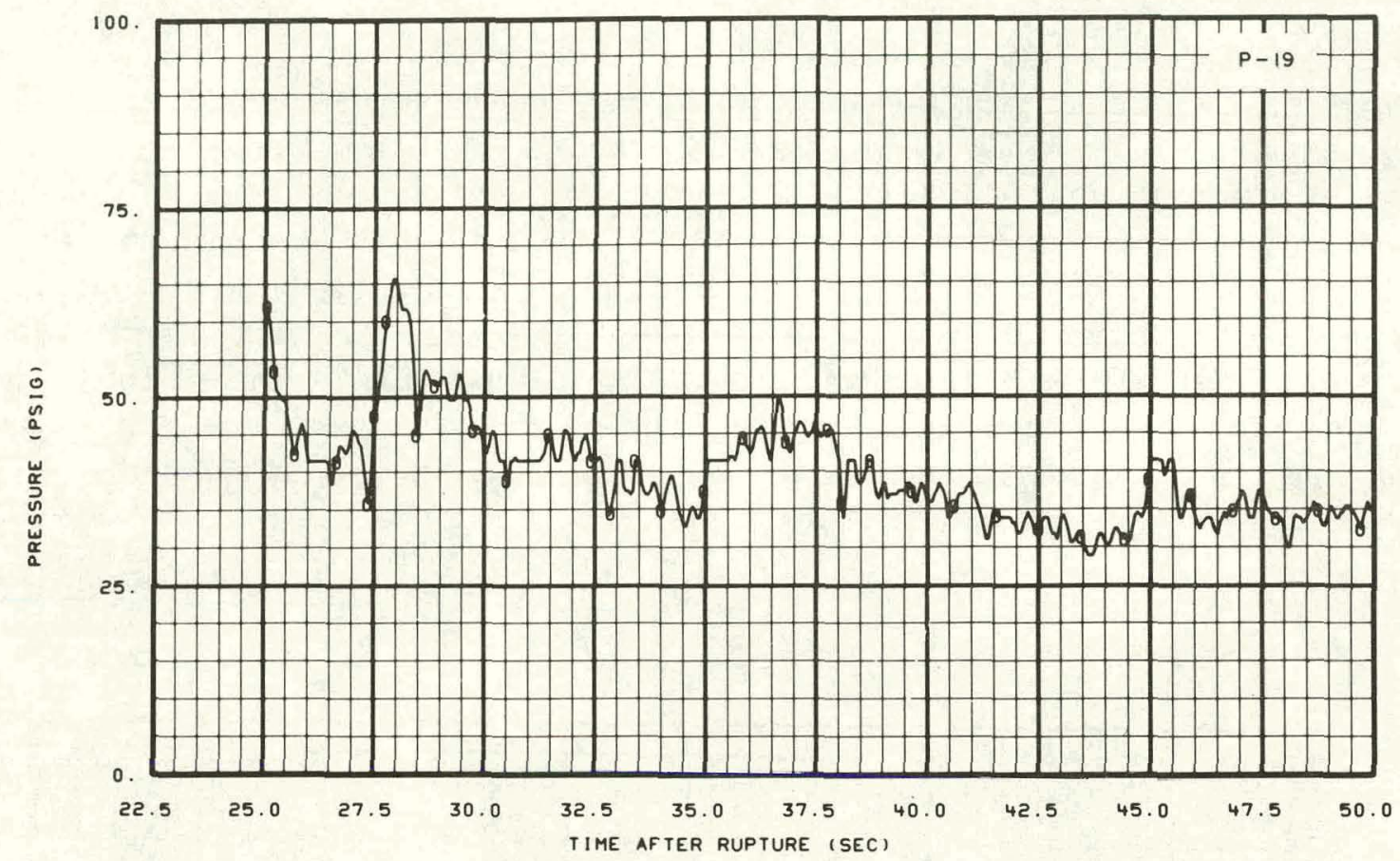

Fig. 23 Cold leg pressure during isothermal Test 1008 -- 22.5 to 50 seconds after rupture.

injection mode. With the exception of the 30-psi spike at about 27 seconds, the fluctuations in pressure are generally between 5 and 10 psi and are of low frequency. The pressure in the cold leg during isothermal Test 1006 exhibits trends similar to those exhibited by the Test 1008 pressure data with a pressure spike about the same time that the ECC injection pumps were actuated and with low frequency pressure fluctuations between 5 and 15 psi in amplitude.

Several different system parameters were investigated in an attempt to relate the CE separate effects pressure data to the semiscale system pressure data obtained in the cold leg. of the intact loop. These parameters included: (a) the ratio of water mass flow to steam mass flow; (b) the ratio of the energy of the steam flow that is available to raise the temperature of the water flow to the energy that would be needed to raise the water flow to saturation temperature; and (c) the steam momentum flux in the cold leg piping. During the blowdown portion of the semiscale tests, the semiscale cold leg pressure fluctuated only 2 or 3 psi, whereas the pressure fluctuations in the CE data were as large as 15 to 20 psi for all tests that could be related to the semiscale cold leg conditions by any of the investigated parameters. Following blowdown, the semiscale cold leg pressure fluctuations were generally less than 5 psi with few pressure spikes larger than 10 psi. Some CE separate effects data related to the postblowdown semiscale data by the investigated paramters produce pressure traces smoother than the semiscale data whereas other related separate effects data show high-frequency, large-amplitude pressure fluctuations. 
The differential pressure across the injection port for isothermal Test 1008 is shown in Figure 24. Following initiation of ECC injection at about 16 seconds, the fluctuations in differential pressure are seen to increase in frequency and amplitude. The large amplitude differential pressure spikes at about 28 and 38 seconds correspond to times at which water flowed back to the pump and the pump forced some of this water back through the cold leg pipe. The average pressure drop across the injection port for Test 1008 ranges from 0.10 to 0.50 psid which is consistent with the range of the 90 -degree injection port average pressure drops measured in the $\mathrm{CE}$ tests. The differential pressure across the injection port during isothermal Test 1006 behaved similarly to that presented in Figure 24 for Test 1008 with nominal pressure fluctuations of about \pm 1 -psi amplitude and with pressure spikes to \pm 4 -psi amplitude. The pressure fluctuations for Test 1006 appear to exhibit about the same frequency as the pressure fluctuations for Test 1008 .

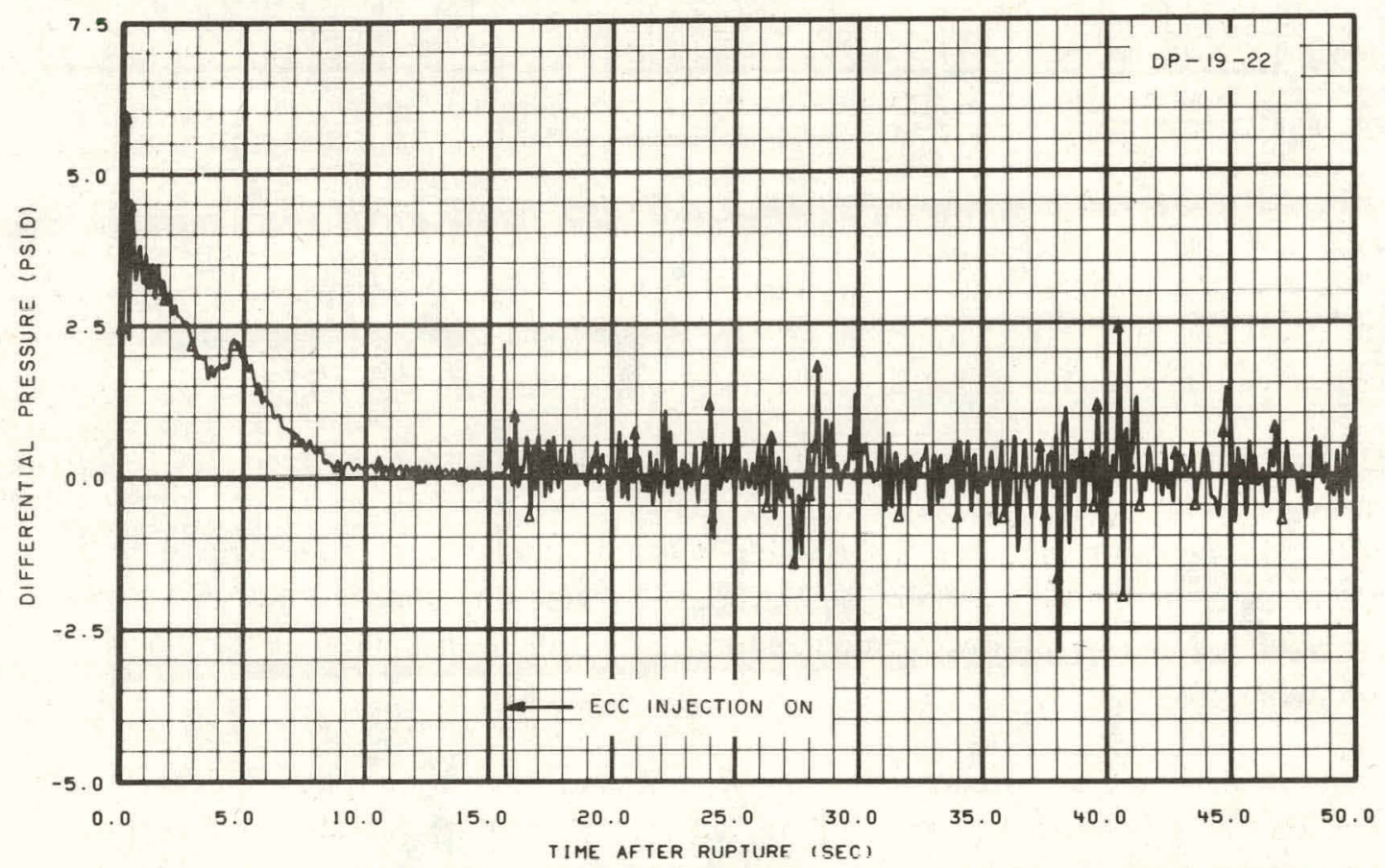

Fig. 24 Differential pressure across ECC injection port during isothermal Test 1008. 


\section{UPPER ANNULUS PHENOMENA}

The upper annulus region acts as a water distributor for the downcomer during both normal operation and during ECC injection. When a pipe rupture is simulated, the ECC entering the upper annulus from the cold leg may either flow down the downcomer or bypass the downcomer and flow out the broken leg piping. The temperature of the ECC at the entrance of the downcomer depends upon the amount of mixing and condensation in the upper annulus, the temperature of the ECC entering from the cold leg, and the heat transferred from the metal in the upper annulus region.

Instrumentation was not included in the upper annulus region of the semiscale vessel because the complexity of the upper annulus geometry and the complex flow patterns within it would have made valid interpretation of measured results virtually impossible. Therefore, the upper annulus is treated as a lumped system having average properties for the analysis presented in this section.

\subsection{Upper Annulus Flow}

Flow can enter or leave the upper annulus at the intact loop cold leg, the broken loop cold leg, and the downcomer entrance. Measurements of flow rate and direction were made near the upper annulus in both the intact loop and broken loop cold legs but similar measurements at the downcomer entrance were not made because of the complex geometry. The flow rate and direction at the entrance to the downcomer were estimated by performing a transient mass balance on the upper annulus region during blowdown. Through use of the control volume shown in Figure 25, the mass flow rates calculated from the data provided by instrumentation in the cold legs of the intact and broken loops were used in solving for the flow across the control surface between the upper annulus and the downcomer. The conservation of mass equation applied to the control volume is written as:

$$
\dot{\mathrm{m}}_{\mathrm{d}}=\dot{\mathrm{m}}_{50}-\dot{\mathrm{m}}_{22}+\frac{\mathrm{d}}{\mathrm{dt}} \int_{C V} \rho \mathrm{dV}
$$

where

$$
\begin{aligned}
\dot{\mathrm{m}} & =\text { mass flow }\left(\mathrm{lb}_{\mathrm{m}} / \mathrm{sec}\right) \\
\rho & =\text { density }\left(\mathrm{lb}_{\mathrm{m}} / \mathrm{ft}^{3}\right) \\
\mathrm{V} & =\text { total volume of control volume }\left(\mathrm{ft}^{3}\right)
\end{aligned}
$$

and subscripts d, 50, 22, and CV refer to the downcomer, broken loop cold leg measurement location (Spool Piece 50), intact loop cold leg measurement location (Spool Piece 22), and the integration over the control volume.

The time rate of change of mass in the control volume, represented by the last term in Equation (6), was calculated from the data by dividing the original control volume into the 


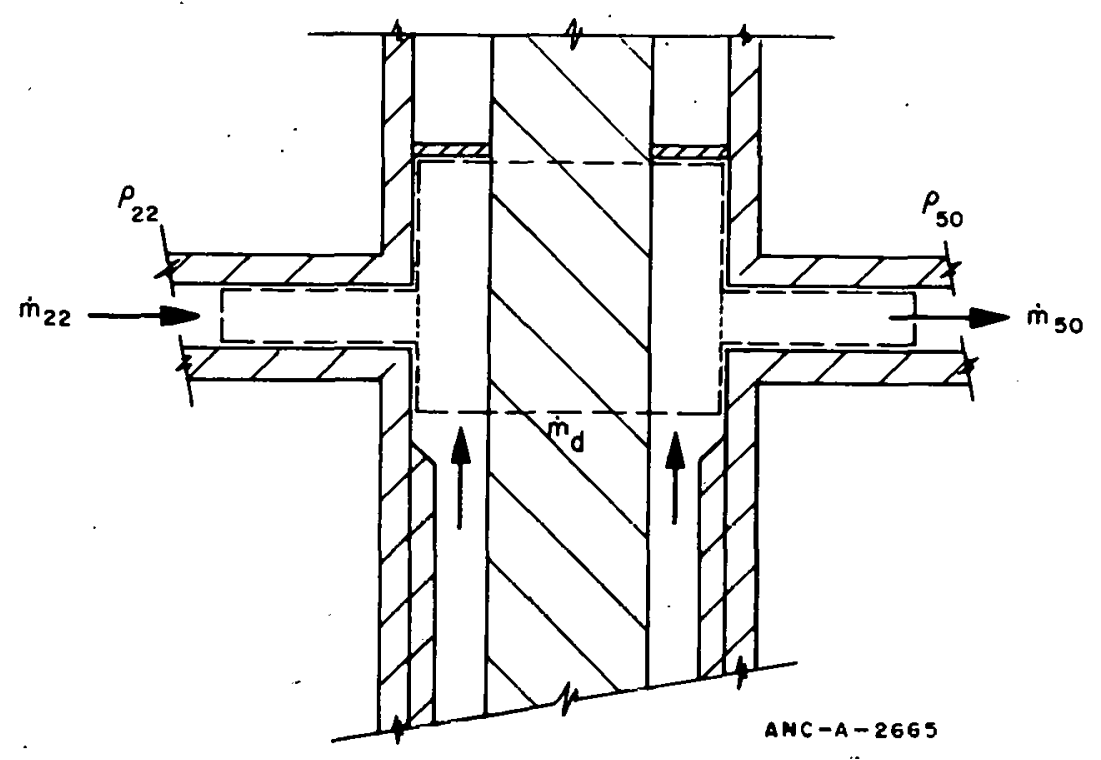

Fig. 25 Control volumc for upper annulus mass balance.

three smaller control volumes shown in Figure 25. The equation for this calculation is expressed as:

$$
\frac{d}{d t} \int_{C V} \rho d V=v_{22} \frac{d \rho_{22}}{d t}+v_{50} \frac{d \rho_{50}}{d t}+v_{U A} \frac{d \rho_{m}}{d t}
$$

where the subscript UA refers to the upper annulus. The mean density in the upper annulus, $\rho_{m}$, is the adjusted average of the densities measured at locations in the cold legs of the intact and broken loops. The measured densities were adjusted by accounting for the transit time of the fluid from the upper annulus to the measurement location assuming the density does not change between these two locations.

Figure 26 shows the downcomer inlet mass flow rate calculated for isothermal Test 1008 through use of the experimental data in Equations (6) and (7). Also included on this figure is the mass flow rate at the top of the downcomer as calculated by RELAP4. The flow rate calculated by RELAP4 reverses about 4 seconds earlier than the flow rate calculated from the data. Apparently the differences between the RELAP4 flow rate and the flow rate calculated from the data result from use of a homogeneous flow model in RELAP4 which does not accurately model the downcomer flow behavior during the full blowdown period.

During ECC injection, the amplitude of the downcomer flow oscillations calculated from the data shown in Figure 25 is expected to be larger than the amplitude of the actual flow oscillations. The large amplitudes of the calculated oscillations appear to result from sharp variations in the measured density which, when averaged and then differentiated in Equation (7), does not properly represent the mean density in the upper annulus region.

An accurate determination of the mass flow rate at the downcomer entrance is difficult to obtain for the Test Series 15 hot-wall tests because the upper annulus inlet and outlet flow instrumentation was ranged for blowdown and, therefore, the ranges were much 


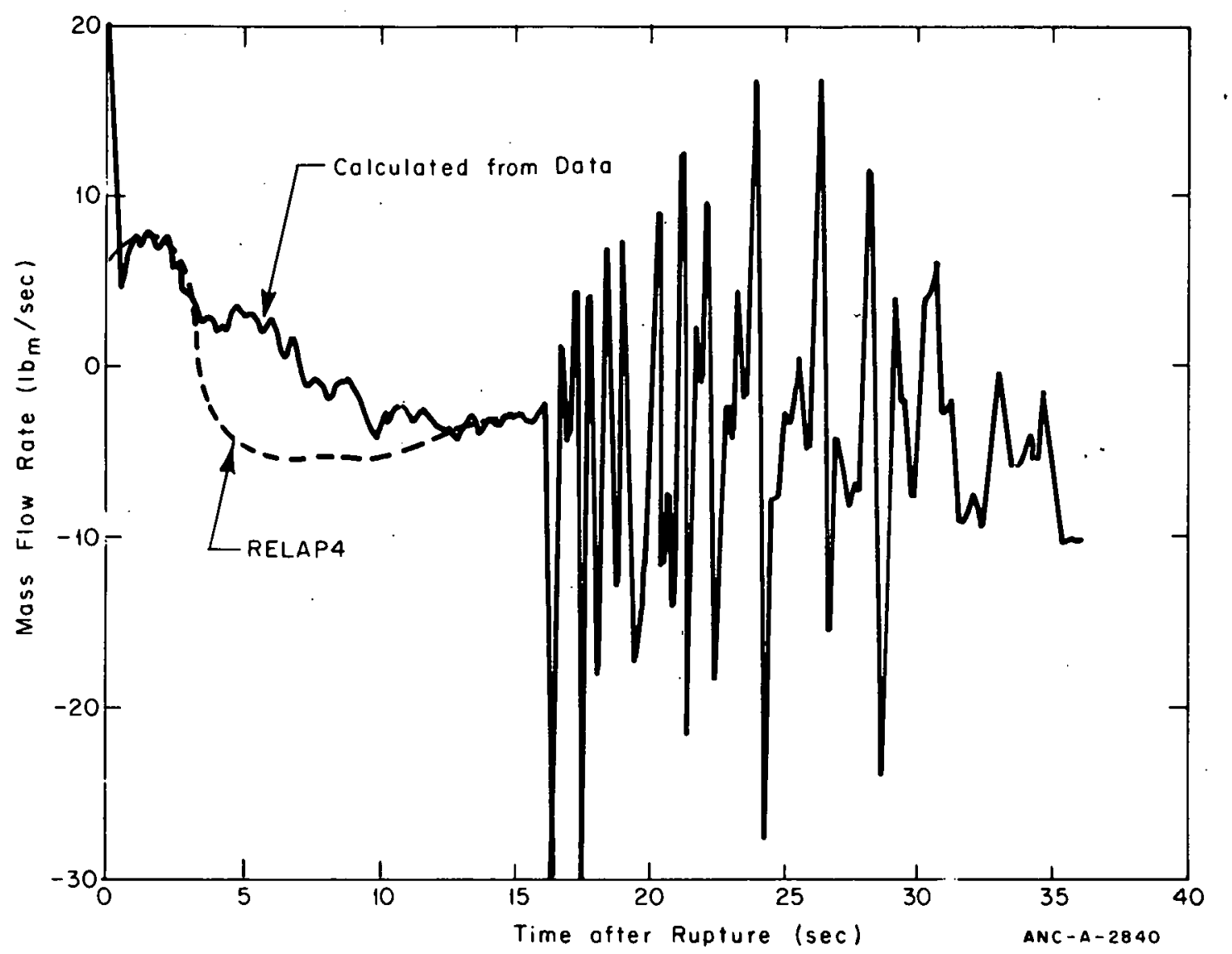

Fig. 26 Mass flow rate at the downcomer inlet during isothermal Test 1008.

above the flow rates for the hot-wall tests. The density measurements indicate that the initial ECC flow is pushed toward the vessel by the primary coolant pump, but after injection has been occurring for a short time, the injected fluid alternately backs up to the pump entrance and then is forced away from the pump entrance. Figure 27 shows a typical density measurement near the vessel inlet and at the pump discharge to illustrate this flow behavior. The density measurement at the vessel inlet indicates that the fluid entering the vessel is totally water for all tests with the exception of Test 15.1 for which the injection rate was low (22 gpm). For Test 15.1 the density measurement indicates the flow was predominantly water with occasional slugs of steam.

The momentum of the ECC at the vessel inlet for the Test Series 15 hot-wall tests is not sufficiently high to allow the ECC to be carried completely across the upper annulus. Since no steam initially flows from the downcomer, for the first several seconds; the injected flow will both begin to fill the upper annulus volume and flow into the downcomer. As the ECC flows into the downcomer, the steam generated on the hot walls causes countercurrent flow and restricts further water flow down the downcomer. The upper annulus then fills more rapidly and water begins to flow into the broken leg as the upper annulus becomes full. 


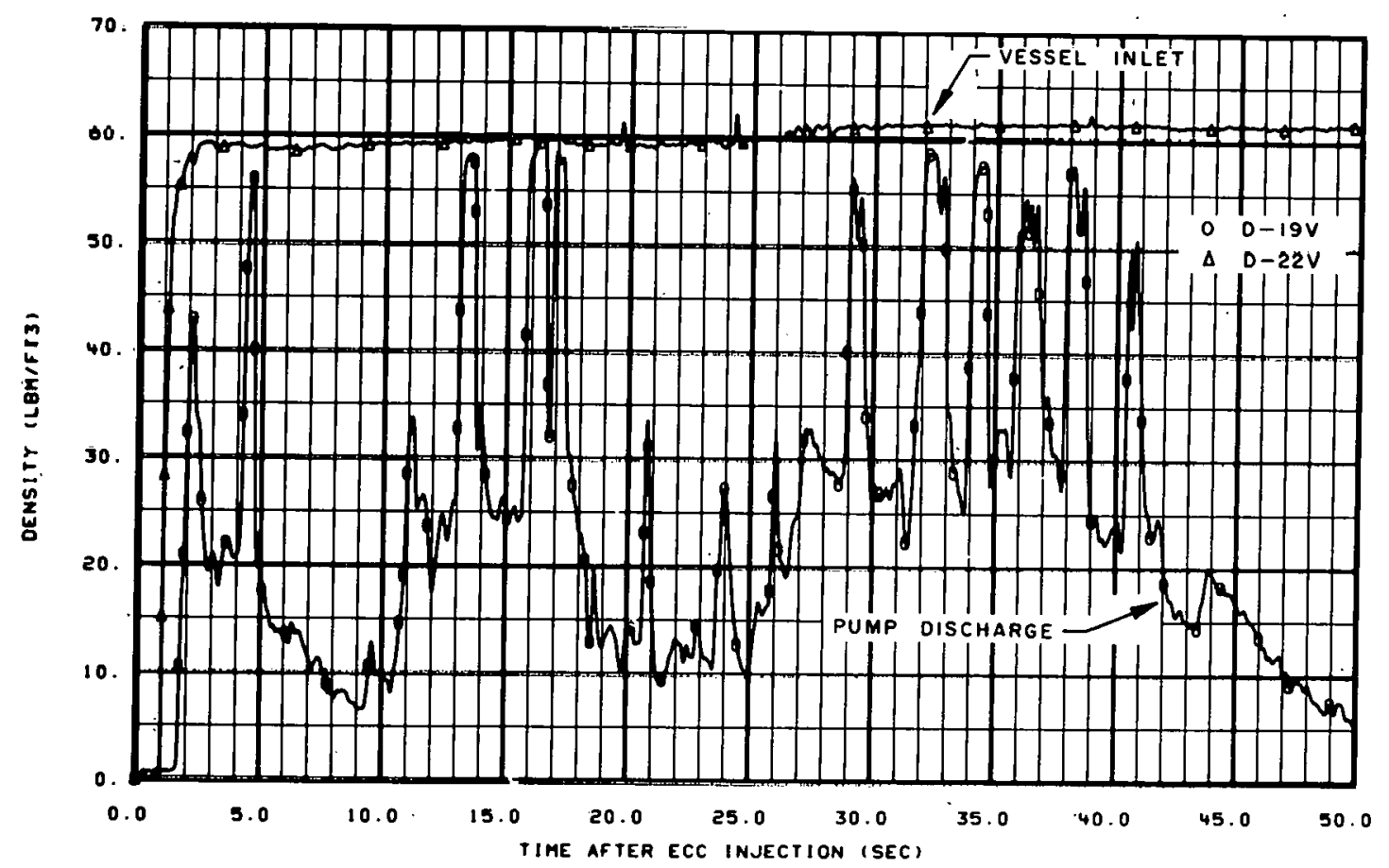

Fig. 27 Typical hot-wall test densities at vessel inlet and pump discharge of intact loop cold leg.

\subsection{Upper Annulus Bulk Fluid Temperature}

The bulk (average) temperature of the fluid in the upper annulus region was calculated using a gross energy balance on the upper annulus which accounted for the transport of - energy associated with the mass flows into and out of the upper annulus and the heat transfer from upper annulus metal walls. The calculations presented in this section have been restricted to an energy balance either during ECC injection for a blowdown test or during a Test Series 15 hot-wall test.

Four mass flows carry energy into or out of the upper annulus. In general, energy is transported into the upper annulus both from the intact loop cold leg flow and the

' $=$ downcomer flow, and energy is transported out of the upper annulus into the downcomer and the broken loop cold leg. The energy entering from the cold leg depends on the temperature of the injected ECC and the flow rate and on the condensation, mixing, and fieat transfer that occur in the intact loop cold leg. The energy entering from the downcomer depends on the mass flow rate and the temperature and density of the fluid at the downcomer entrance. The temperature of the fluid entering the downcomer and the broken cold leg was assumed to be equal to the upper annulus temperature. Since the "quality of the fluid flowing up the downcomer is high during ECC injection and during the

- Test Series 15 hot-wall tests, a simplifying assumption was made that the flow from the $\because$ downcomer was saturated steam. The data taken at the broken loop cold leg indicate that the assumption that all steam entering the upper annulus from the downcomer was condensed is reasonable. 
A steady state energy balance on the upper annulus was made using the discussed assumptions to provide a means of estimating the upper annulus bulk enthalpy. The energy balance was solved to obtain the following expression for the upper annulus bulk fluid enthalpy;

$$
\mathrm{h}_{U A}=\frac{\dot{\mathrm{m}}_{22} \mathrm{~h}_{22}+\dot{\mathrm{m}}_{\mathrm{dg}} \mathrm{h}_{\mathrm{g}}+\mathrm{Q}_{\mathrm{UA}}}{\dot{\mathrm{m}}_{50}+\dot{\mathrm{m}}_{\mathrm{d}}}
$$

where

$$
\begin{aligned}
& \mathrm{h}=\text { enthalpy }(\mathrm{Btu} / \mathrm{lb}) \\
& \mathrm{Q}=\begin{array}{l}
\text { total amount of heat entering the upper annulus fluid from the metal walls } \\
(\mathrm{Btu} / \mathrm{sec})
\end{array}
\end{aligned}
$$

and subscripts UA, 22, dg, g, 50, d, refer to the upper annulus, the intact loop cold leg measurement location (Spool Piece 22), downcomer steam flow, saturated steam properties, broken loop cold leg measurement location (Spool Piece 50) and a downcomer variable, respectively.

Further simplification of Equation (8) was necessary to perform calculations because data were not available for the $\dot{\mathrm{m}}_{\mathrm{dg}}$ and $\dot{\mathrm{m}}_{\mathrm{d}}$ terms during ECC injection. The mass flow rate of steam coming from'the downcomer $\left(\dot{\mathrm{m}}_{\mathrm{dg}}\right)$ was assumed to be approximately equal to the steam flow rate that would completely stop flow of water down the downcomer. This assumption would only be correct when the effect of hot downcomer walls dominates the other downcomer phenomena. The mass flow from the upper annulus to the downcomer $\left(\dot{\mathrm{m}}_{\mathrm{d}}\right)$ was assumed to be equal to the steam mass flow from the downcomer to the annulus. This assumption would be correct if the countercurrent steam flow was high enough to restrict most of the water flow to the downcomer and the heat transfer from the downcomer walls was high enough to vaporize all the entering water. Since the rate of liquid flow entering the downcomer is assumed to be equal to the steam flow rate leaving the downcomer, the flow to the broken cold leg must equal the flow from the intact loop cold leg.

By using the assumptions discussed, Equation (8) can be written as

$$
\mathrm{h}_{\mathrm{UA}}=\frac{\dot{\mathrm{m}}_{22} \mathrm{~h}_{22}+\dot{\mathrm{m}}_{\mathrm{d}} \mathrm{h}_{\mathrm{g}}+\mathrm{Q}_{\mathrm{UA}}}{\dot{\mathrm{m}}_{22}+\dot{\mathrm{m}}_{\mathrm{d}}} .
$$

Mass flow rate and temperature data from the intact loop cold leg (Spool Piece 22) were input into Equation (9) along with the steam saturation enthalpy determined from the pressure and the downcomer mass flow rate calculated from the countercurrent flow characteristics of the downcomer. For the Test Series 15 hot-wall tests, the ECC injection flow rate was assumed to be the flow rate at Spool Piece 22. The upper annulus heat transfer was calculated by assuming a very high heat transfer coefficient; that is, that the heat transfer from the metal surfaces in the upper annulus was conduction limited. 
Calculated results from the gross energy balance are presented in Table VI in the form of temperatures. Through use of Equation (9) the bulk fluid temperature in the upper annulus was calculated at two separate times for isothermal blowdown Tests 1006, 1008, and 1009 for Test Series 15 hot-wall tests. The first time, $t_{i}$, was the time at which the upper annulus became filled with injected coolant and the second time, $t_{i+10}$, was ten seconds after filling, when flow rates and heat transfer coefficients had stabilized. These results are shown in Table VI. The measured fluid temperatures at the broken cold leg (Spool Piece 50) and a position two inches into the downcomer (Spool Piece 48) are included for comparison.

The calculated ECC temperature increase includes the contributions of condensation and wall heat transfer in both the cold leg and the upper annulus. The percent of the total calculated temperature increase that results from each of these energy contributions is also presented. The calculated upper annulus bulk temperature is the temperature corresponding to the upper annulus bulk enthalpy calculated from Equation (9) and is equal to the calculated ECC temperature increase plus the initial ECC injection temperature.

A comparison of the measured temperatures with the calculated upper annulus temperatures shows reasonable agreement between the calculated upper annulus temperature and the measured broken loop cold leg temperature considering the simplicity of the analysis and the fluctuations that occurred in the measured temperatures, but poor agreement between the calculated temperature and the measured temperature three inches from the downcomer entrance. Since the calculated upper annulus temperature is a bulk temperature, it would tend to agree with the outlet temperature which is more representative of a bulk temperature. The temperature just inside the downcomer entrance is higher than either the calculated or the measured broken loop cold leg temperatures. The higher downcomer fluid inlet temperature is considered to result from condensation of the countercurrent fluid as the upper annulus fluid flows toward the downcomer and from heat. transfer from the downcomer walls.

Comparison of the percent of the calculated ECC temperature increase that results from condensation or heat transfer indicates that condensation in both the cold leg and the upper annulus region accounts for most of the ECC fluid temperature increase. The relative amounts of condensation occurring in these two regions appear to be dependent on the ECC injection rate and the time elapsed from the initiation of ECC injection. For Test 1008 (which: had about 2.4 times the volumetrically scaled injection rate), condensation in the upper: annulus region contributed more than $60 \%$ of the temperature increase of the ECC early in time and about $74 \%$ of the ECC temperature increase later in the blowdown. These results can be compared with the results from Test 1006 (which had a near volumetrically scaled ECC injection rate) to show that on a percentage basis the condensation in the upper annulus increased the ECC temperature by a greater amount during Test 1008 . The amount of condensation in the upper annulus increased with increasing ECC injection rate because the condensation rate in the cold leg pipe remained about constant and, therefore, the amount of subcooling of the ECC entering the upper annulus decreased. The results from Test 1009, which was performed with about the same ECC injection rate as Test 1008, show that on a percentage basis the condensation in the upper annulus was greater for. Test 1009 
TABLE VI

CALCULATION OF TEMPERATURE OF INJECTED FLUID COMPARED TO MEASURED TEMPERATURE

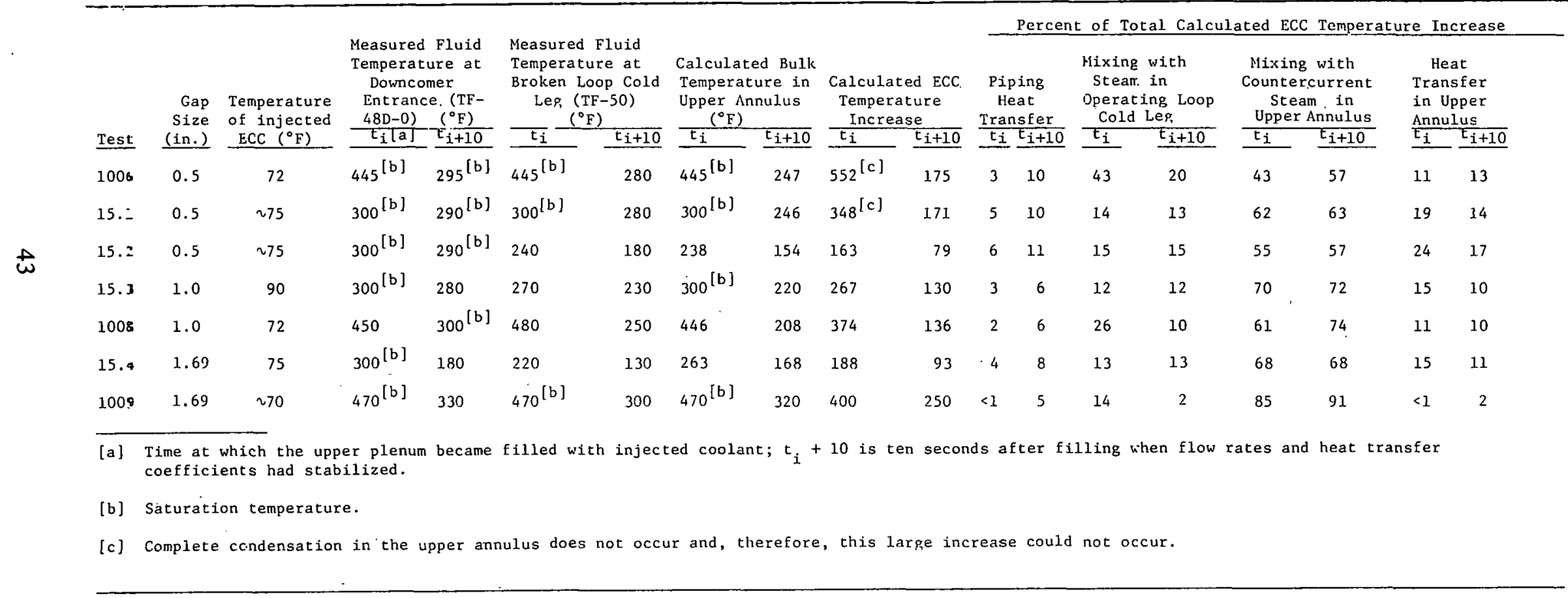


than for Test 1008. The amount of condensation was greater for Test 1009 because the larger downcomer gap for this test required larger amounts of steam to be generated to cause countercurrent flow.

\section{DOWNCOMER PHENOMENA}

The geometric relationship between the downcomer and the upper annulus and the asymmetry of the flow entering and leaving the upper annulus causes complex axial and azimuthal variations in the two-phase fluid flow in the downcomer. The transient nature of the two-phase flow and the influence of ECC injection on the downcomer conditions further complicates the flow conditions. During the period of ECC injection for a simulated cold leg break, the flow in the downcomer is upward or countercurrent to the flow of the ECC fluid down the downcomer. The forces exerted on the ECC by this countercurrent downcomer flow may be large enough to partially or fully negate the gravitational force which tends to pull the injected fluid into the downcomer area and thereby restrict the amount of water entering the downcomer and consequently the amount of water that reaches the lower plenum.

The circumferential distance between the intact loop cold leg entrance to the upper annulus and the broken loop cold leg exit from the upper annulus in the semiscale vessel is small compared to the corresponding distance in a PWR. If the momentum of the incoming ECC is high enough and if flow entering the upper annulus from the downcomer forces the ECC toward the break, some of the injected ECC may flow directly across the semiscale upper annulus and bypass the downcomer. This possible flow bypass of the downcomer could limit the flow to the downcomer to the extent that the bypass flow would cause a greater reduction in downward water flow than would the downward countercurrent flow process. If this situation existed the bypass flow would control the amount of ECC that reaches the lower plenum.

As ECC enters the downcomer, heat transfer from the downcomer wall will cause steam to be generated: As long as the ECC entering the downcomer is saturated, most of the heat transfer from the downcomer walls will generate steam and the resulting upward steam flow, when combined with the steam entering the downcomer from the lower plenum, may limit the amount of ECC that enters the downcomer. However, once the fluid entering the downcomer becomes subcooled, the energy exchange processes become complex with subcooled heat transfer, vaporization, and condensation occurring in close proximity. The net effect of subcooled water entering the downcomer is an increase in the ECC tlow into the downcomer and in the total heat transfer from the downcomer walls which subsequently decreases the time of ECC delivery to the lower plenum.

The effects of hot downcomer walls in the semiscale geometry are exaggerated when compared to the effects of hot downcomer walls in a PWR because the downcomer surface area to volume ratio in the semiscale system is about a factor of ten higher than this ratio in a PWR. This large difference in downcomer surface area to volume ratios results because of compromises necessary in scaling a small system from a much larger system. The large uninsulated downcomer surface area in the vessel used for the semiscale system countercurrent flow tests and the isothermal system tests will allow proportionately more 
heat to pass from the downcomer walls over the blowdown period than would pass from the walls of a PWR. As discussed previously, the high heat fluxes from the semiscale downcomer walls generate steam which increases the velocity of upward flow in the downcomer which can restrict the amount of water delivered to the lower plenum.

\subsection{Steady State Countercurrent Flow and Bypass Flow Phenomena}

Steady state countercurrent and bypass flow phenomena were investigated using air and water during the transparent vessel tests and using steam and water during the semiscale system countercurrent flow tests. Initially, tests were performed with air and water to investigate the effect of system geometry and inlet flow conditions on the countercurrent flow and bypass flow behavior of the semiscale downcomer. Next, steady state tests were performed with steam and water to aid in understanding countercurrent flow behavior when condensation and evaporation can occur.

The air-water countercurrent flow tests in the transparent vessel investigated countercurrent flow phenomena that occurred in an annulus with dimensions similar to those of the semiscale system downcomer to determine whether commonly used countercurrent flow correlations describe the effects of countercurrent flow on the delivery of water (ECC) to the lower plenum. These tests also investigated the relationship between flow bypassing the downcomer and countercurrent flow in the downcomer. Specifically, the effect on countercurrent flow and bypass flow of changing the geometry of the upper annulus was investigated. The effect on countercurrent flow of changing the length of the downcomer was also investigated by changing the length of the core barrel.

The steam-water countercurrent flow tests in the semiscale system investigated the influence of condensation and evaporation on the delivery of water to the lower plenum. These tests investigated the effects of downcomer gap size, the potential for condensation of steam by the inlet flow, heat addition to the fluid from the downcomer walls, and a two-phase mix ture entering from the cold leg.

3.11 Air-Water Countercurrent Flow in a Semiscale-Size Annulus. One of the main goals of the air-water countercurrent flow tests in the transparent vessel was to establish the relationship between the commonly used countercurrent flow correlations, which are derived from small tube or packed bed data, and the countercurrent flow data from an annular geometry whose size and inlet conditions are typical of the semiscale system, and subsequently to aid in establishing a relationship between the countercurrent flow tests in the transparent vessel and the metal semiscale vessel. An established relationship between the commonly used countercurrent flow correlations and the semiscale data was desired for simplifying the analysis of the semiscale data and for aiding in predicting the behavior of the semiscale system over a range of countercurrent flow conditions.

The most universally used countercurrent flow correlation is the Wallis [17] correlation. The form of the Wallis correlation, 


$$
\mathrm{J}_{\mathrm{g}}^{*}+\mathrm{m}_{\ell}^{*^{1 / 2}}=\mathrm{C}
$$

where

$$
\begin{aligned}
& \mathrm{J}_{\mathrm{g}}^{*}=\frac{\mathrm{J}_{\mathrm{g}}}{\sqrt{\mathrm{gD}}} \quad\left(\frac{\rho_{\mathrm{g}}}{\rho_{\ell}-\rho_{\mathrm{g}}}\right)^{1 / 2} \\
& \mathrm{~J}_{\ell}^{*}=\frac{\mathrm{J}_{\ell}}{\sqrt{\mathrm{gD}}} \cdot\left(\frac{\rho_{\ell}}{\rho_{\ell}^{-\rho_{\mathrm{g}}}}\right)^{1 / 2}
\end{aligned}
$$

allows countercurrent flow data to be presented as a straight line with slope $\mathrm{m}$ and ordinate intercept $\mathrm{C}$. The parameters used in the correlation are dimensionless volumetric fluxes where $\mathrm{J}_{\mathrm{g}}$ and $\mathrm{J}_{\ell}$ are respectively the superficial gas and liquid phase velocities which are based on the volumetric flow of the phase divided by the total cross-sectional flow area and $\mathrm{D}$ is the hydraulic diameter. The value of $\mathrm{C}$ is shown by Wallis to depend on the design of the ends of the tube or annulus and the way in which the gas and liquid are added and extracted from the system.

The form of the Wallis correlation has been applied to typical semiscale data and the results are shown in Figures 28 through 31 for radial downcomer gap widths ranging from 0.35 to 1.58 inch. These figures show that the form of the Wallis correlation fits the semiscale countercurrent flow data in a linear fashion, with the ordinate intercept representing the condition of no water reaching the lower plenum. These trends of the data are similar to other countercurrent flow data except that the constants $\mathrm{m}$ and $\mathrm{C}$ have different values than the constants from circular tube countercurrent flow data. Figure 32 is a composite plot of the least squares fit for the data presented in Figures 28 through 31 . Two trends in the data can be observed from Figure 32. The data for the 0.49-inch annular gap has a different slope than the other data. This difference in slope is attributed to differences in the downcomer entrance conditions. The 0.35-, 0.70-, and 1.58-inch annular gaps had a direct entrance, as illustrated in Figure 32, whereas the 0.49-inch gap had a filler piece placed on the inside diameter of the plexiglass vessel. For those tests in which filler pieces were used on the inside diameter of the vessel, the test results more closely resemble circular tube data because of the steeper slope and a larger ordinate intercept. Since most circular tube data were obtained by using a reservoir as the water supply at the top of the tube, the filler piece apparently causes the upper annulus to act similarly to a reservioir. When a filler piece is not used this reservoir is eliminated and the resulting data plot has a smaller slope and a lower ordinate intercept.

The second trend observed in the data on Figure 32 is that for tests with similar inlet geometries, the ordinate intercepts, or constants $\mathrm{C}$, decrease with increasing annular gap width. This trend in the data indicates that the hydraulic diameter term in the dimensionless volumetric flux is overcorrecting the data. If the diameter term is removed from the Wallis dimensionless volumetric flux, the resulting parameter can be represented by $\mathrm{J}^{* 1 / 2} \mathrm{D}^{1 / 4}$ which is independent of the gap size. The form of the dimensioned volumetric fluxes can then be written as 


\section{ERRATUM for ANCR-1161}

Page 47, Equation (11) should read:

$$
\mathrm{J}_{\mathrm{g}}^{* 1 / 2} \mathrm{D}^{1 / 4}+\mathrm{m} \mathrm{J}_{\ell}^{* 1 / 2} \mathrm{D}^{1 / 4}=\mathrm{C}
$$

where

$$
\mathrm{J}_{\mathrm{g}}^{* 1 / 2} \mathrm{D}^{1 / 4}=\mathrm{J}_{\mathrm{g}}^{1 / 2}\left[\frac{\rho_{\mathrm{g}}}{\mathrm{g}\left(\rho_{\ell}-\rho_{\mathrm{g}}\right)}\right] 1 / 4
$$

and

$$
\mathrm{J}_{\ell}^{* 1 / 2} \mathrm{D}^{1 / 4}=\mathrm{J}_{\ell}^{1 / 2}\left[\frac{\rho_{\ell}}{\mathrm{g}\left(\rho_{\ell}-\rho_{g}\right)}\right]^{1 / 4}
$$

Please Insert corrected equation in your copy of report. 


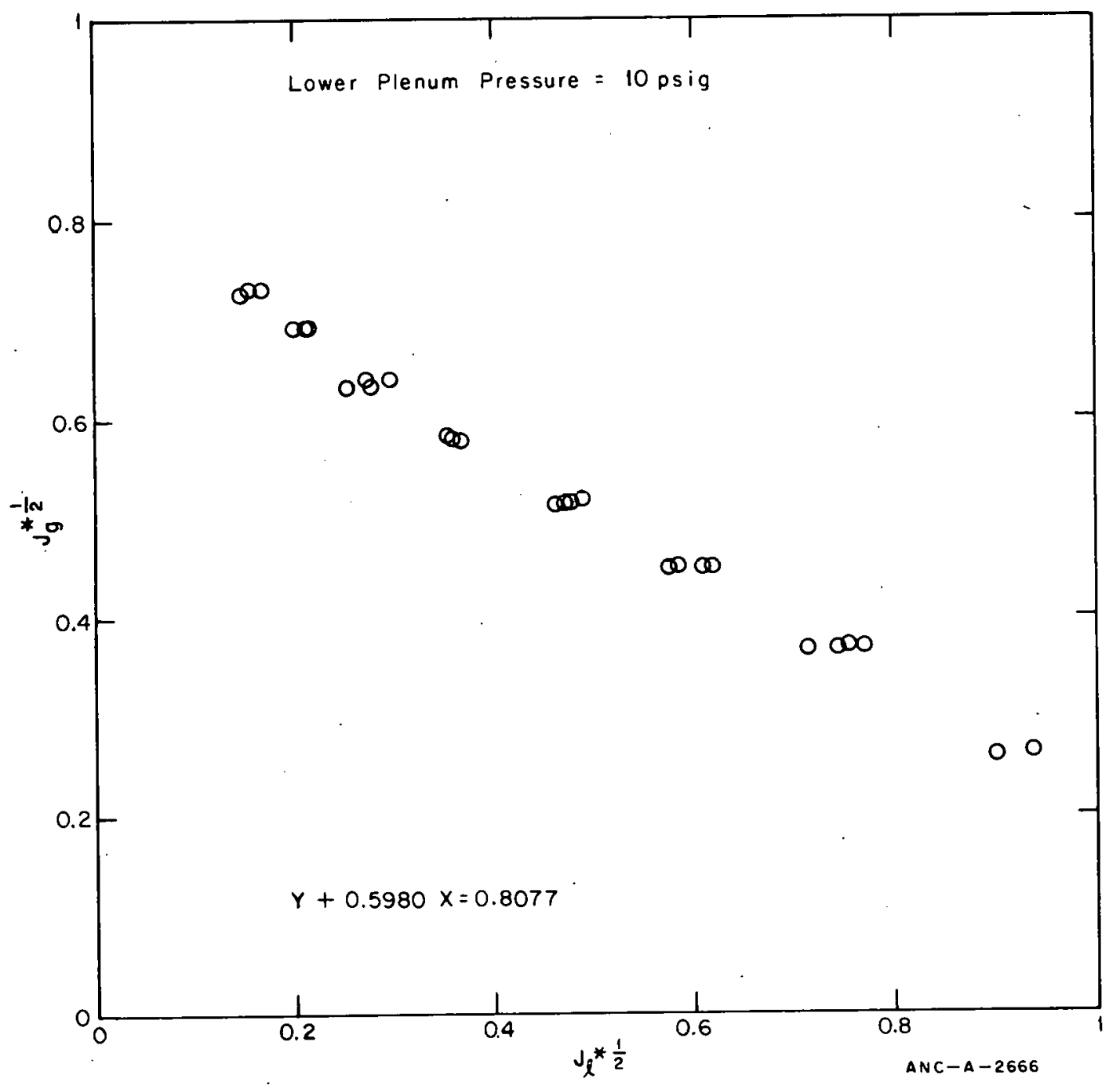

Fig. 28 Wallis-type countercurrent flow correlation least squares fit to data for 0.35 -in. annular gap.

$$
\mathrm{J}_{\mathrm{g}}^{*} \mathrm{D}^{1 / 2}+\mathrm{m} \mathrm{J} *^{1 / 2} \mathrm{D}^{1 / 4}=\mathrm{C}
$$

where

$$
\underset{\mathrm{g}}{\mathrm{J}} \cdot 1 / 2 \mathrm{D}^{1 / 4}=\mathrm{J}_{\mathrm{g}}\left[\frac{\rho_{\mathrm{g}}}{\mathrm{g}\left(\rho_{\ell}-\rho_{\mathrm{g}}\right)}\right]^{1 / 2}
$$

and

$$
\mathrm{J}_{\ell}^{*} \mathrm{D}^{1 / 4}=\mathrm{J}_{\ell}\left[\frac{\rho_{\ell}}{\mathrm{g}\left(\rho_{\ell}-\rho_{\mathrm{g}}\right)}\right]^{1 / 2} .
$$




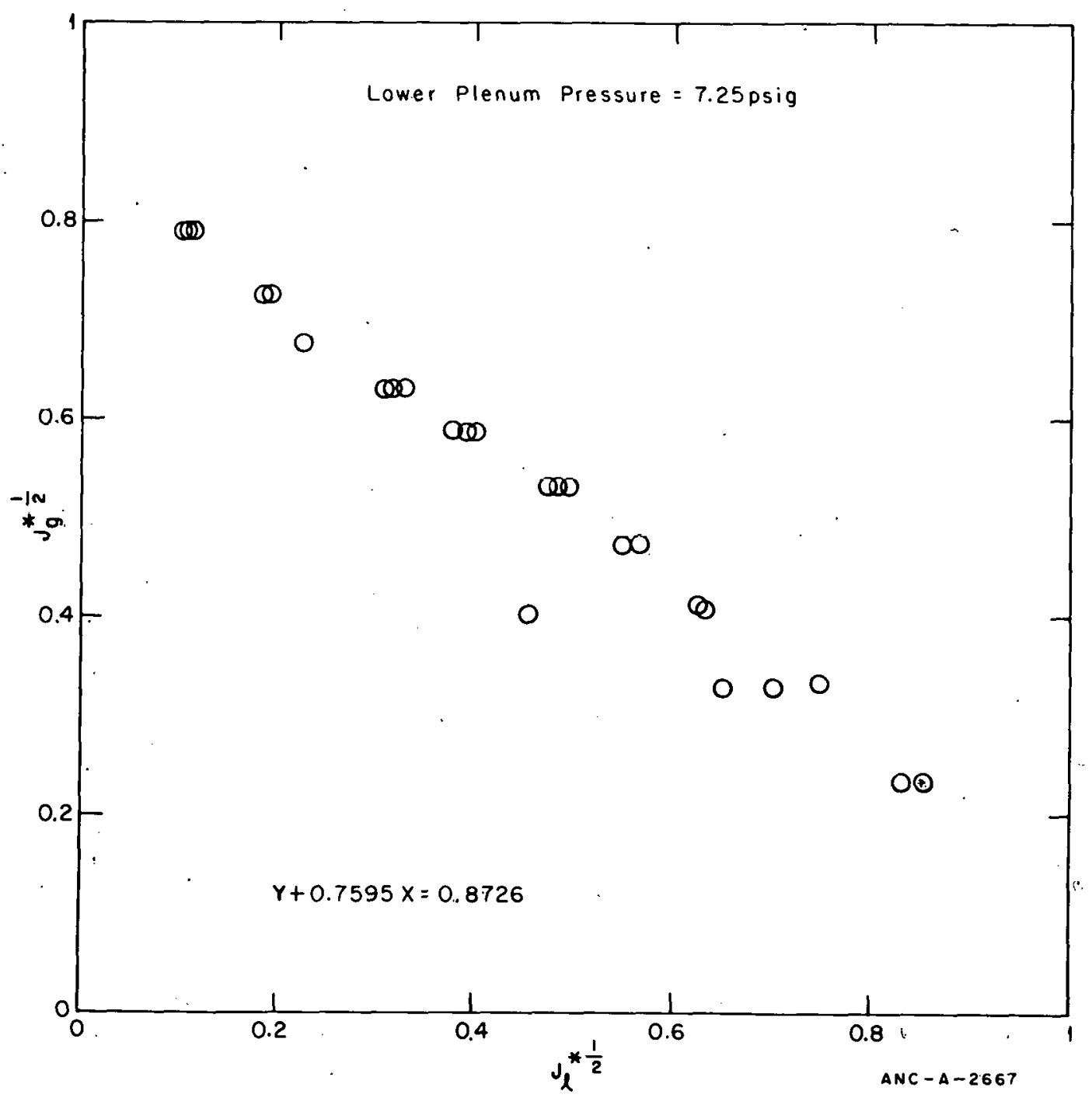

Fig. 29 Wallis-type countercurrent flow correlation least squares fit to data for 0.49 -in. annular.gap.

When these dimensioned parameters are applied to the data, the curves for gap sizes of 0.49 inch and greater plot together in a curve as shown in Figure 33, even though the downcomer inlet causes the data for the 0.49-inch gap to have a slightly different slope. Included in. Figure 33 are the results of countercurrent flow tests with the 0:35-inch gap which fall just enough below the other data to indicate that below: a certain gap size the hydraulic diameter must be included in the countercurrent flow correlation to properly correlate the data.:The maximum gap size for which the hydraulic. diameter appears to influence the correlation of . the data is in the range of 0.35 to 0.49 inch for the semiscale annulus. The slope $(\mathrm{m})$ and ordinate intercept $(C)$ that correlate the range of gap size from 0.49 to 1.58 inch are 0.70 and 0.47 , respectively.

Although $\mathrm{J}^{* 1 / 2} \mathrm{D}^{1 / 4}$ correlates the data well, a disadvantage of this form of parameter is that it is not dimensionless. To overcome this disadvantage, a dimensionless parameter, $\mathrm{J}^{+}$, was developed through use of the techniques of dimensional analysis. This dimensionless parameter is independent of diameter, but does take into account the fluid surface tension and viscosity. The resulting correlation: 


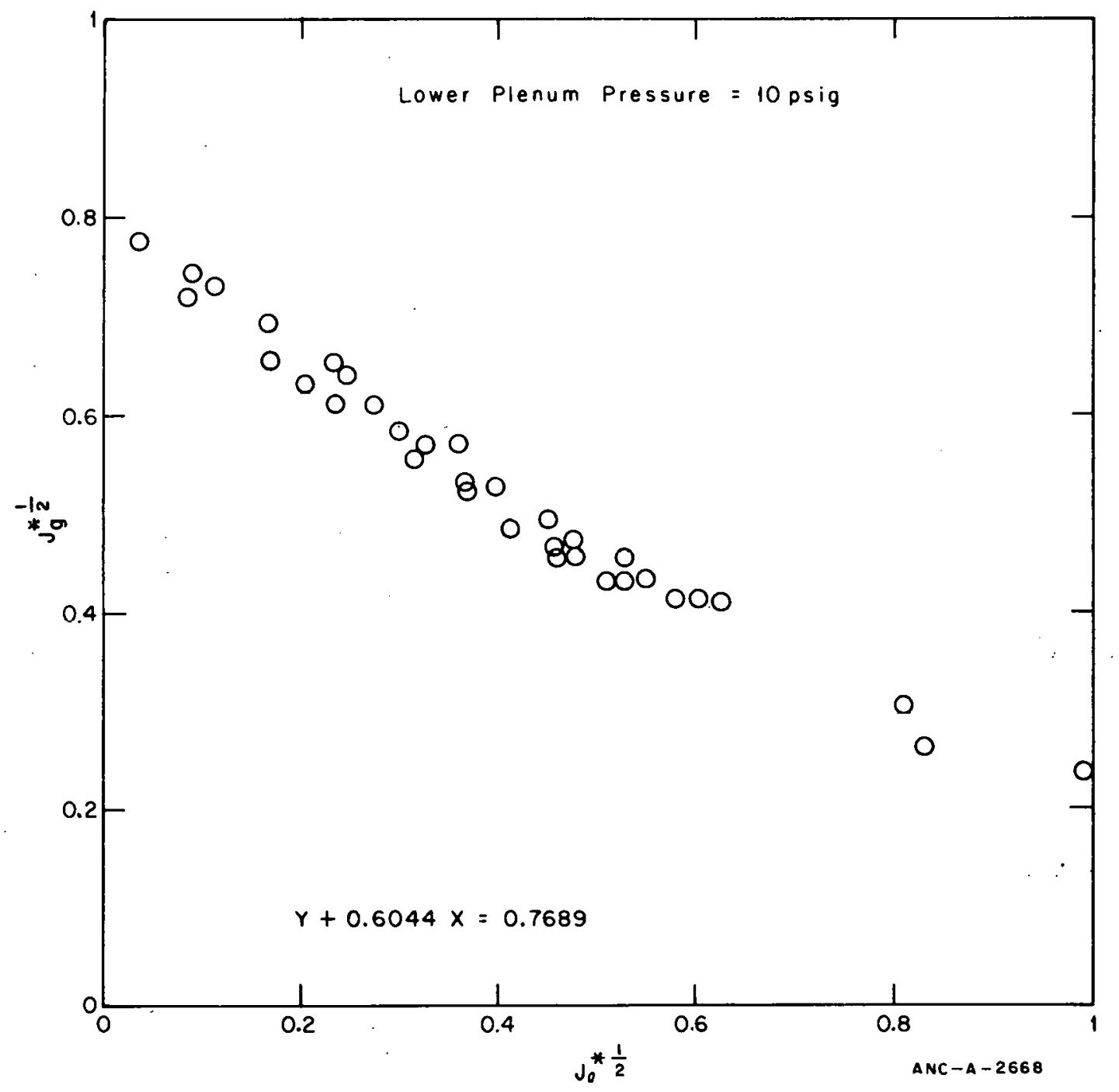

Fig. 30 Wallis-type countercurrent flow correlation least squares fit to data for 0.70 -in. annular gap.

where

$$
\mathrm{J}_{\mathrm{g}}^{+1 / 2}+\mathrm{m} \mathrm{J}_{\ell}^{+1 / 2}=\mathrm{C}
$$

$$
\mathrm{J}_{i}^{+}=\mathrm{J}_{i}\left[\frac{\rho_{\ell}{ }^{\mu} \ell}{\mathrm{g}^{2} \sigma_{\ell}^{2}}\right]^{1 / 5}\left(\frac{\rho_{i}}{\rho_{\ell}-\rho_{g}}\right)^{1 / 2}
$$

$\mathrm{J}=$ superficial phase velocity $(\mathrm{ft} / \mathrm{sec})$

$\mu \quad=\quad$ viscosity $\left(\mathrm{lb}_{\mathrm{f}} / \mathrm{sec}-\mathrm{ft}^{2}\right)$

$\sigma \quad=\quad$ surface tension $\left(\mathrm{lb}_{\mathrm{f}} / \mathrm{ft}\right)$

reduces the individual curves for gap sizes of 0.49 inch and greater to a single curve as shown in Figure 34. The form of the correlation was suggested by Wallis, but the coordinates are now independent of the geometry. The dimensionless parameter, $\mathrm{J}^{+} 1 / 2$, includes fluid properties to the one-tenth power, a correlation already found in some of the 


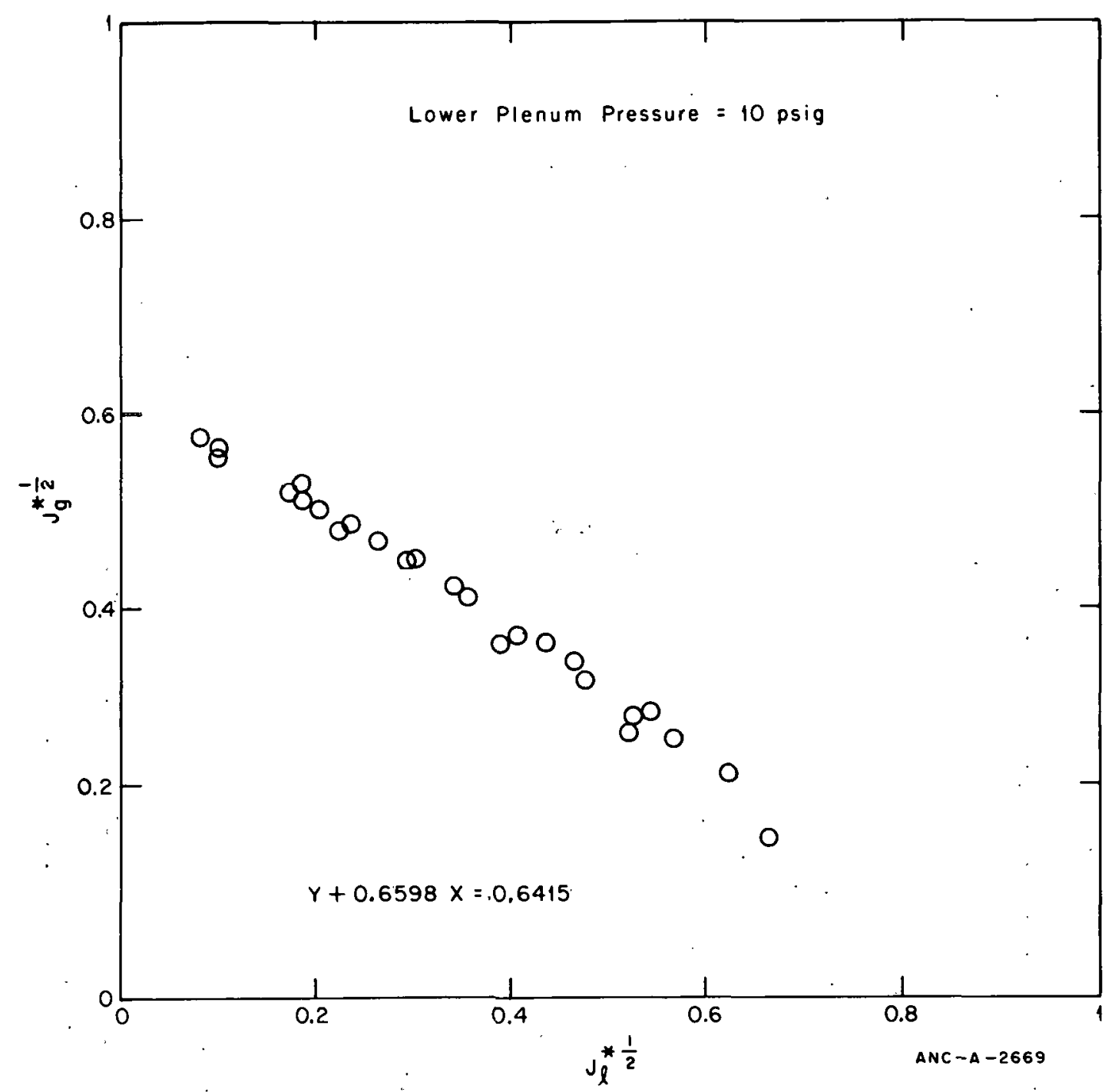

Fig. 31. Wallis-type countercurrent flow correlation least squares fit to data for 1.58-in. annular gap.

literature, but obtained independently by dimensional analysis ${ }^{[17]}$. Some circular tube data documented in the literature ${ }^{[17]}$ were taken at different viscosities and surface tensions and have been correlated with Equation (12) although the results are still preliminary.

Both the dimensionless correlation presented in Equation (12) and the Wallis correlation include the same density ratio which is supposed to correlate the countercurrent flow data taken at different pressures. A series of tests was conducted at different system pressures to determine whether this density ratio does properly correlate the data. Typical results from tests at different pressures are shown in Figure 35. A comparison of the data indicates that the density ratio properly correlates the data for a pressure range of 20 to 45 psia.

The remainder of the countercurrent flow data presented in this report is plotted in either the form of the nondimensional Wallis volumetric fluxes or the form of the dimensioned Wallis volumetric fluxes rather than in the form shown in Equation (12). Plotting in this form is done for greater ease in comparing the semiscale countercurrent flow results with countercurrent flow results presented in the literature. 


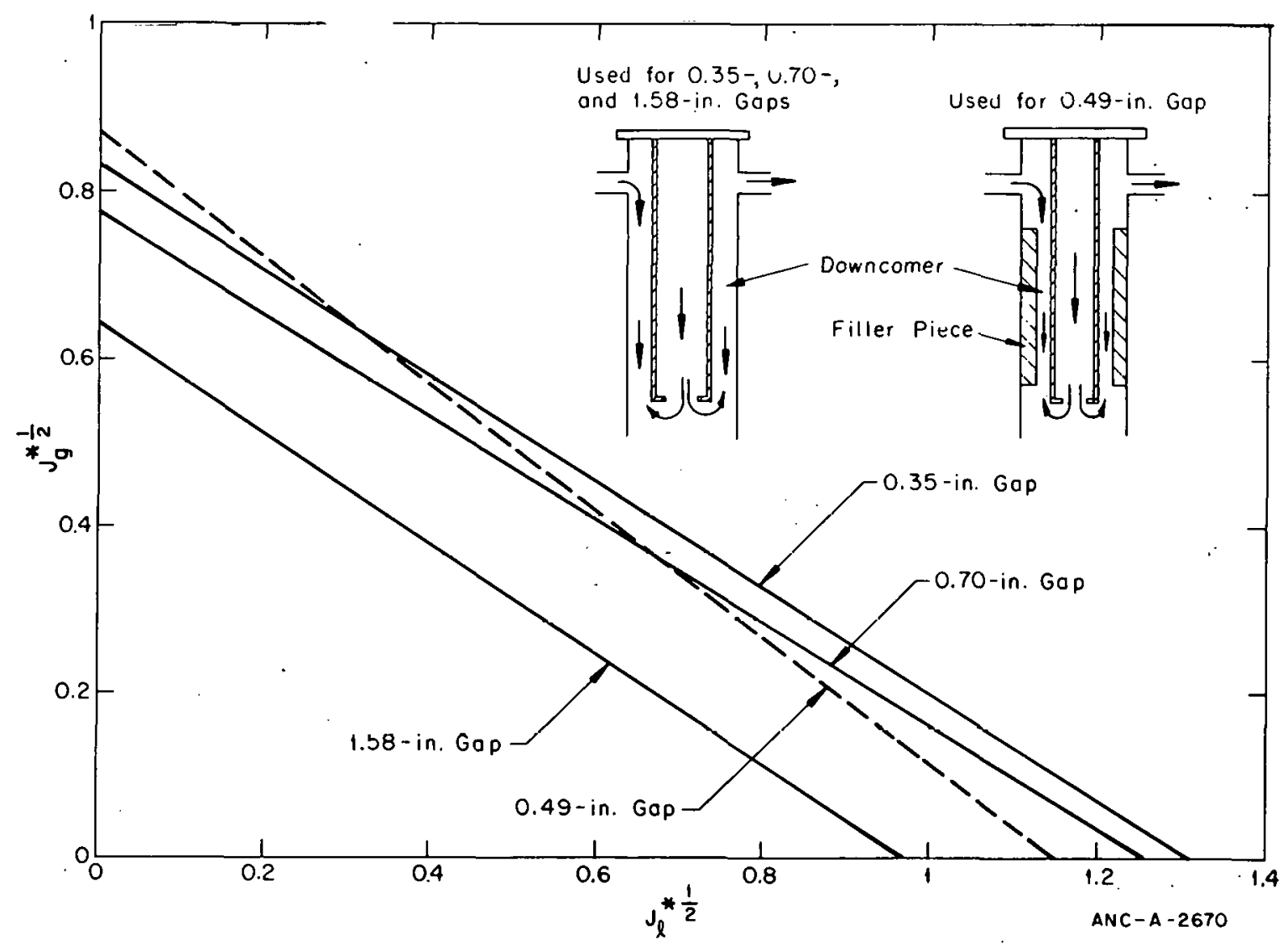

Fig. 32 Comparison of Wallis-type countercurrent flow correlation least squares fits to data for annular gaps considered.

3.12 Air-Water Bypass Flow. Some of the fluid entering the upper annulus can bypass the downcomer and flow directly out the broken cold leg. This bypass flow could be caused either by the initial horizontal momentum of the flow which causes the fluid to be carried completely across the small-diameter upper annulus to the simulated break or the bypass flow could be caused by the countercurrent flow from the downcomer sweeping the upper annulus fluid to the simulated break. Tests were conducted in the transparent vessel to determine whether the bypass flow in the upper annulus region significantly limits the amount of water reaching the downcomer and thereby controls the countercurrent flow phenomena and the amount of water reaching the lower plenum or whether the countercurrent flow phenomena restricts the lower plenum water delivery and the bypass flow is a result of this restriction. Tests were conducted to investigate the following downcomer bypass flow and countercurrent flow phenomena:

(1) The amount of ECC delivered to the lower plenum and the amount of bypass flow that occurs without countercurrent flow

(2) The effect of countercurrent air flow on bypass flow and ECC delivery to the lower plenum

(3) The effect on countercurrent flow and bypass flow of changes in the vessel inlet fluid velocity 


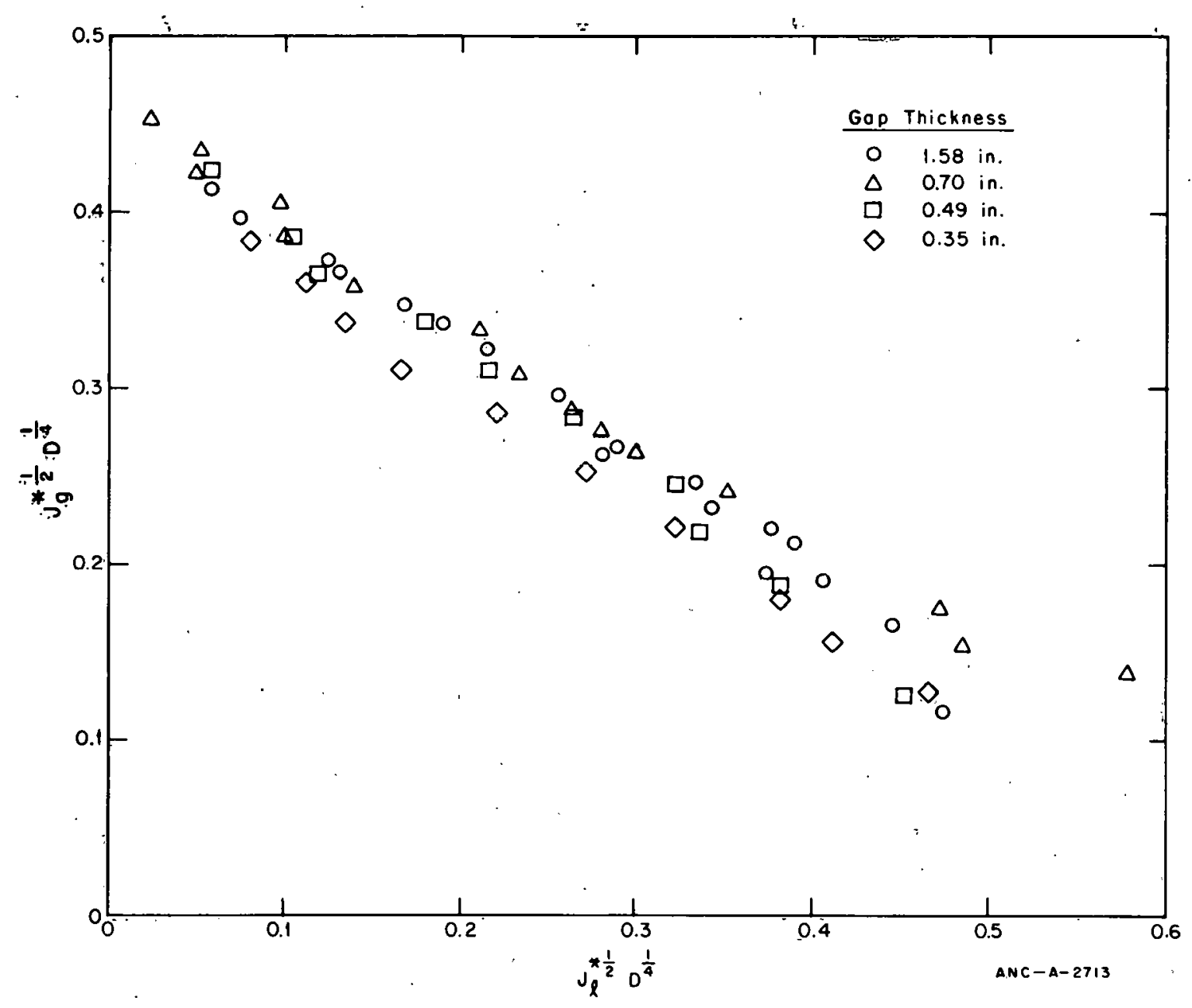

Fig. 33 Dimensioned fluxes for the range of gap sizes tested.

(4) The effect on bypass flow and countercurrent flow of a two-phase mixture flowing in from the cold leg.

A series of tests was conducted to determine the fraction of the entering flow that reaches the lower plenum in the absence of downcomer countercurrent flow. Initially, tests were conducted with water only entering the upper annulus from the cold leg. Results from these tests show that all water entering the vessel goes to the lower plenum for cold leg water flow rates less than $66 \mathrm{gpm}$ (inlet momentum about $747 \mathrm{lb} \mathrm{m} / \mathrm{ft}^{2}-\mathrm{sec}$ ). Further tests were then conducted to determine the fraction of the entering flow that reaches the lower plenum when a two-phase mixture enters the vessel from the cold leg. Typical results from tests without countercurrent flow are presented in Figure 36. These results show that more than $80 \%$ of the inlet flow is delivered to the lower plenum when the fluid momentum at the vessel inlet is less than about $350 \mathrm{lb}_{\mathrm{m}} / \mathrm{ft}^{2}$-sec [water inlet flow rates less than $30 \mathrm{gpm}$, with cold leg air flow rates up to $0.188 \mathrm{lb} / \mathrm{sec}(150 \mathrm{scfm})]$. For the three test points that were taken at a momentum of about $350 \mathrm{db}_{\mathrm{m}} / \mathrm{ft}^{2}-\mathrm{sec}$ the mixture velocity ranged from 46 to $116 \mathrm{ft} / \mathrm{sec}$. 


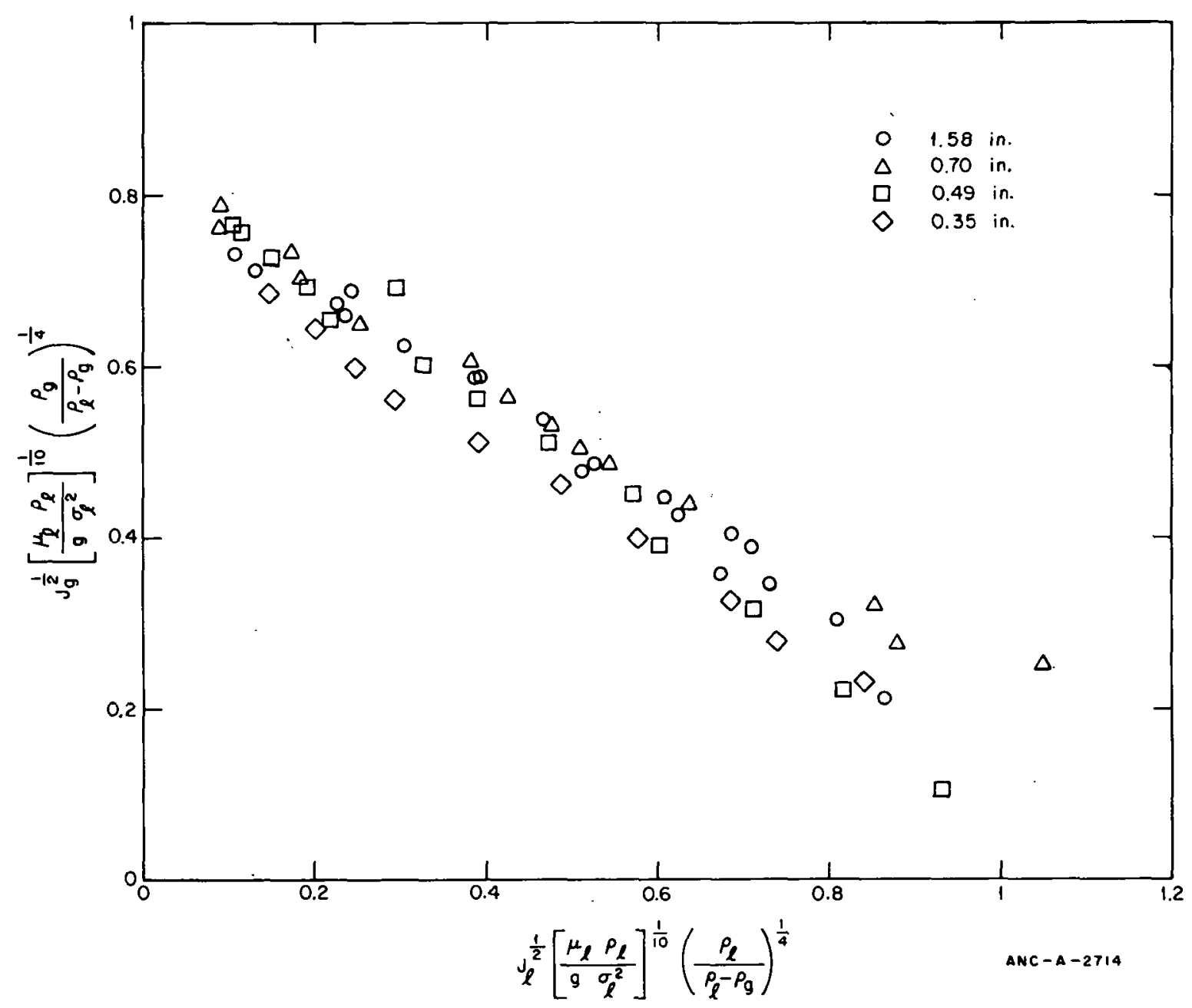

Fig. 34 Dimensionless one-tenth power fluxes for the range of gap sizes tested.

The differences between the percent of inlet flow delivered to the lower plenum with and without air mixed with the water are attributed to the increased velocities of the air-water mixture compared to the velocity for pure water and to flow sweeping or entrainment of some water by the air as the air was forced to exit the vessel through the bypass leg. The large spread in percent delivery for mixture momentums of greater than 400 $\mathrm{lb}_{\mathrm{m}} / \mathrm{ft}^{2}$-sec cannot be fully explained. However, several different flow patterns were observed in the upper annulus flow and a large and distinct change in lower plenum ECC delivery and flow bypass could result from a change in these flow patterns.

Several countercurrent flow test series were conducted with the same downcomer air flow rate but with several different vessel inlet water flow rates. The results of these tests can be used to investigate the effect of countercurrent air flow on the water delivery to the lower plenum and consequently the flow bypassing the downcomer. The results from one of the test series conducted in a downcomer with a 0.49-inch gap width are presented in Figure 37 where the water flow rate into the lower plenum is plotted against the water flow rate into the vessel.for a range of downcomer air flow rates. The results indicate that the amount of water reaching the lower plenum is independent of the water flow rate into the vessel for air flow rates greater than $24 \mathrm{scfm}\left(\mathrm{J}_{\mathrm{g}}^{* 1 / 2}=0.33\right)$. For air flow rates less than $24 \mathrm{scfm}$, the 


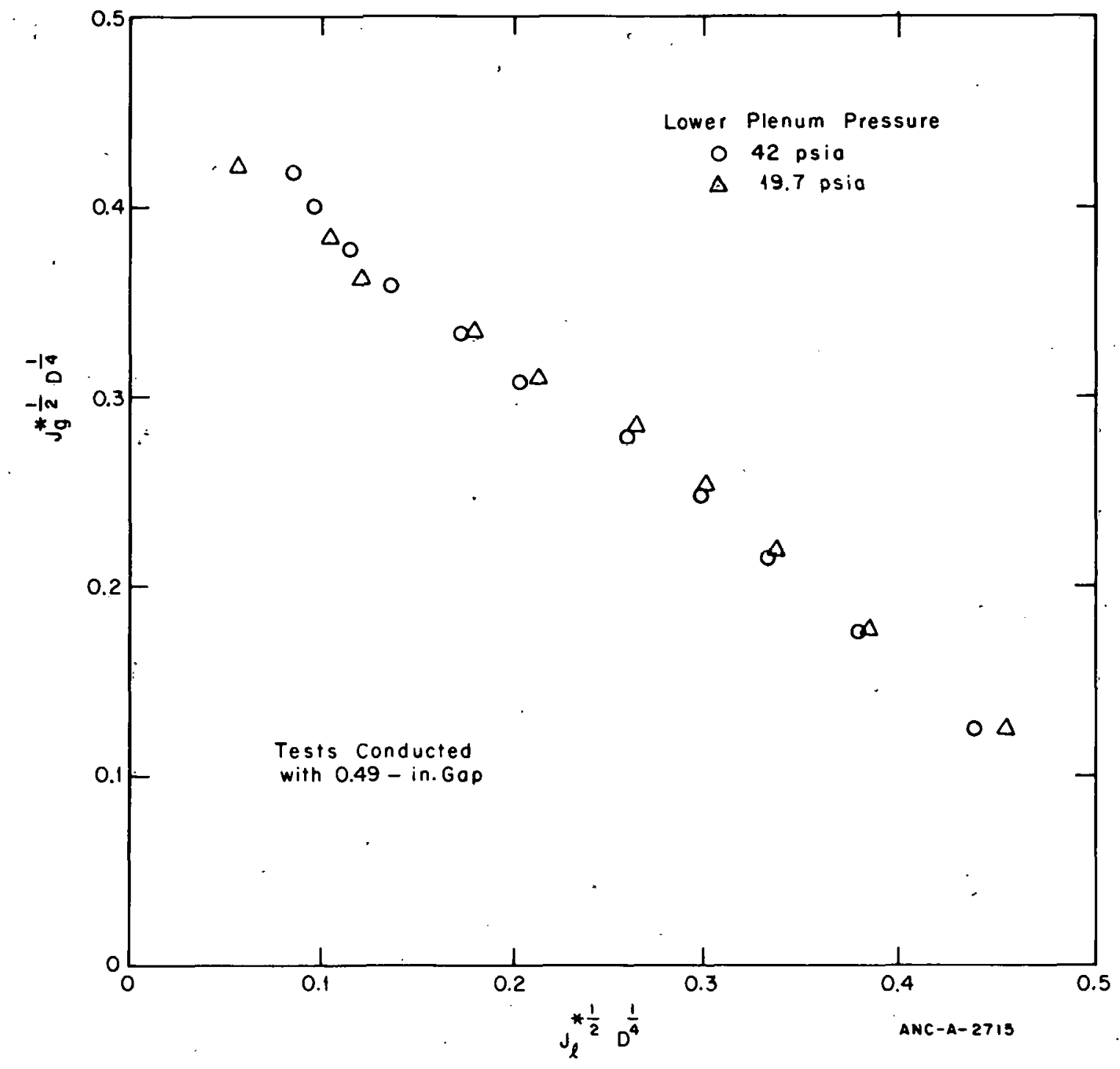

Fig. 35 Dimensioned fluxes for different system pressures.

water delivery to the lower plenum shows some dependence on the water flow rate into the vessel. The results of a second series of tests conducted with a 1.58-inch downcomer gap are shown in Figure 38. The effect of the water flow into the vessel on the water delivery to the lower plenum shows the same trends as observed for the 0.49-inch gap: At air flows above $200 \mathrm{scfm}\left(\mathrm{J}_{\mathrm{g}}^{*^{1 / 2}}=0.33\right)$ the water delivery to the lower plenum shows a weak dependence on the water flow rate into the vessel. At air flow rates less than $200 \mathrm{scfm}$ the amount of water delivery to the lower plenum shows a relatively strong dependence on the vessel inlet flow.

The amount of flow bypassing the downcomer is the difference between the amount of water flowing into the vessel and the amount of water that flows to the lower plenum. Therefore, at high air flow rates (greater than $\mathrm{J}_{\mathrm{g}}^{*} 1 / 2=0.33$ ), the amount of bypass is controlled by the restriction in delivery of water to the lower plenum that results from countercurrent flow in the downcomer. At lower air flow rates (less than $\mathrm{J}_{\mathrm{g}}^{*} 1 / 2=0.33$ ), visual observations indicate that countercurrent flow may not be occurring in the downcomer at all inlet water flow rates. The change in slope of the 200- and 140-scfm lower 


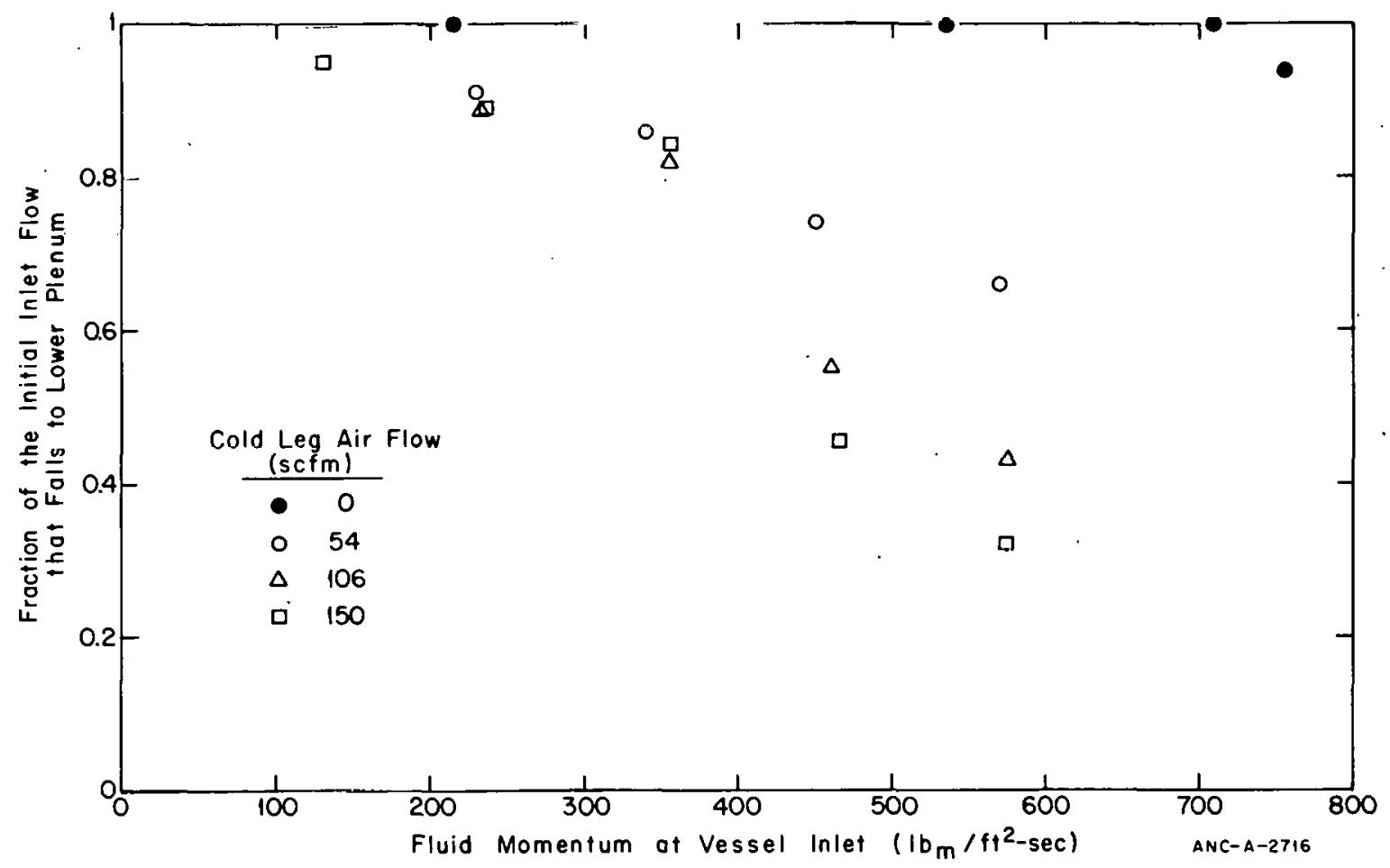

Fig. 36 Typical results for ECC delivery to the lower plenum for various inlet air flows without countercurrent flow.

plenum water delivery curves appears to indicate that countercurrent flow begins to restrict the water flow to the lower plenum when the water flow to the lower plenum becomes greater than some minimum value. A possible explanation for this behavior is that as the water flow in the downcomer becomes larger than this minimum value, the downcomer area occupied by the air decreased which causes increased air velocities. When the downcomer water flow becomes large, the air velocity is forced high enough to cause countercurrent flow which restricts delivery of water to the lower plenum.

When the countercurrent flow in the downcomer is not controlling the bypass flow, the downcomer bypass flow appears to result from the buoyancy effect of the air flowing through the upper annulus water combined with the flow sweeping effect as the air flows to the bypass leg. The buoyancy effect that occurs in the upper annulus appears to be caused by the rising air carrying some water upward with it. The combination of the buoyancy and the flow sweeping effect appears to directly affect the amount of water reaching the lower plenum until enough water is flowing in the downcomer to increase the air velocity sufficiently to cause countercurrent flow.

The investigation of flow to the lower plenum in the absence of countercurrent flow and with single-phase flow at the vessel inlet presented earlier in this section indicated that for inlet water flows less than $66 \mathrm{gpm}$, all the water would flow to the lower plenum; that is, no bypass flow would occur. The results presented in Figure 37 for a 0.49 -inch downcomer gap imply that the countercurrent air flow would have to be practically zero to attain a flow of $66 \mathrm{gpm}$ to the lower plenum, and the results presented in Figure 38 for a 1.58-inch downcomer gap indicate that the countercurrent air flow would have to be about $200 \mathrm{scfm}$ 


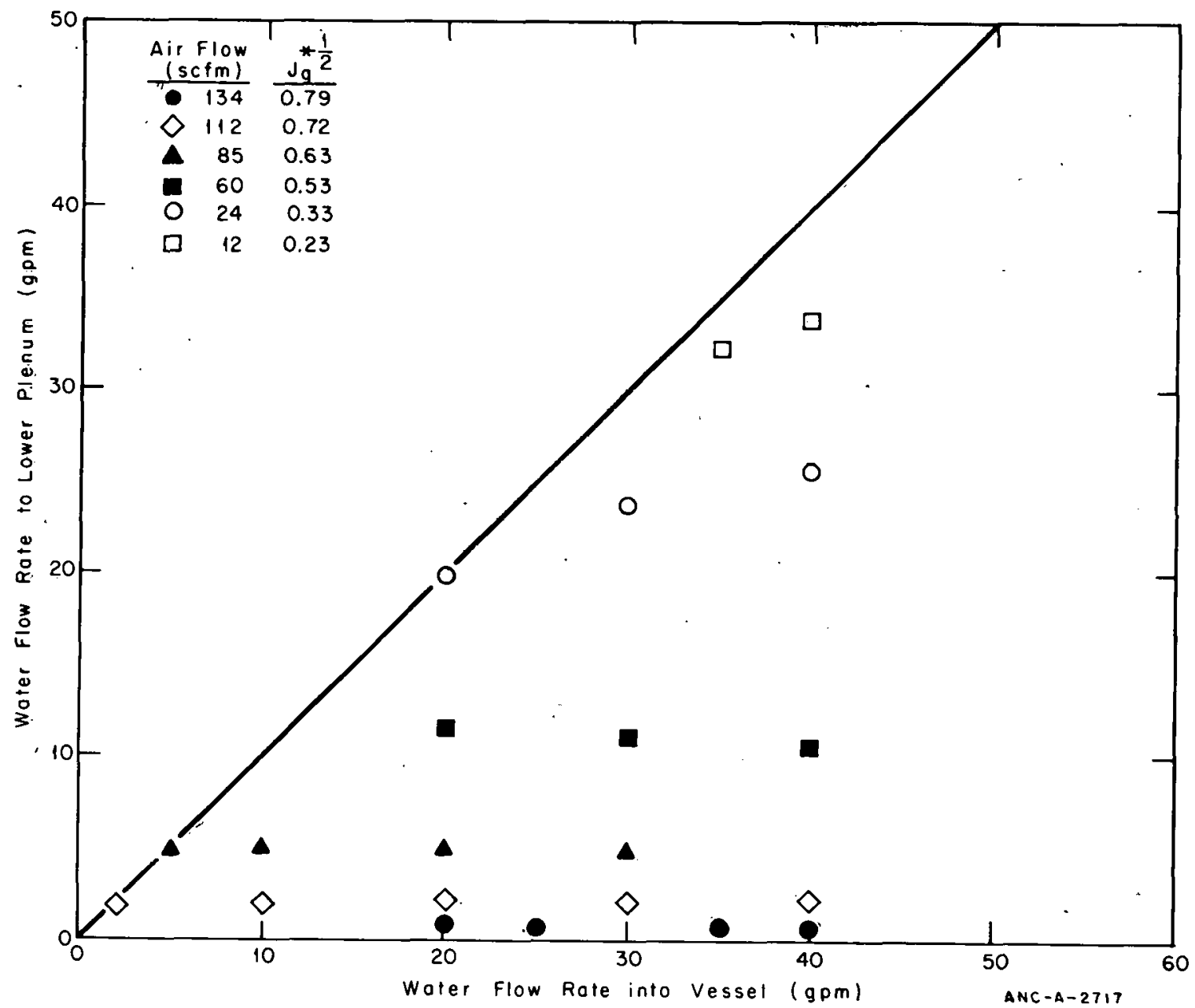

Fig. 37 Water delivery to lower plenum for various air flows .- 0.49-in. annular gap.

or less before $66 \mathrm{gpm}$ could reach the lower plenum. This comparison of results tends to confirm the conclusion that when countercurrent flow does exist in the downcomer, this countercurrent flow, rather than the momentum of the fluid at the vessel inlet, limits the flow to the lower plenum and thereby controls the amount of bypass.

A limited number of countercurrent flow tests werc conducted without the nozzles at the vessel cold leg inlet and bypass outlet. The nozzles were removed to increase the vessel inlet and bypass flow area by a factor of three and thereby allow a reduction in horizontal velocity in the upper annulus region. The purpose of these tests was to investigate the influence of velocity on the countercurrent and bypass flow phenomenon while maintaining a reasonable range of flow rates. Results from these tests can be compared with results of tests with nozzles to determine whether the velocity at the inlet influences delivery to the lower plenum. The results from the countercurrent flow tests with and without nozzles are plotted in Figure 39 using the dimensioned form of the Wallis correlation. A comparison of the data shows that the decrease in inlet velocity resulting from removing the nozzles does not appreciably change the rate of water delivery to the lower plenum. 


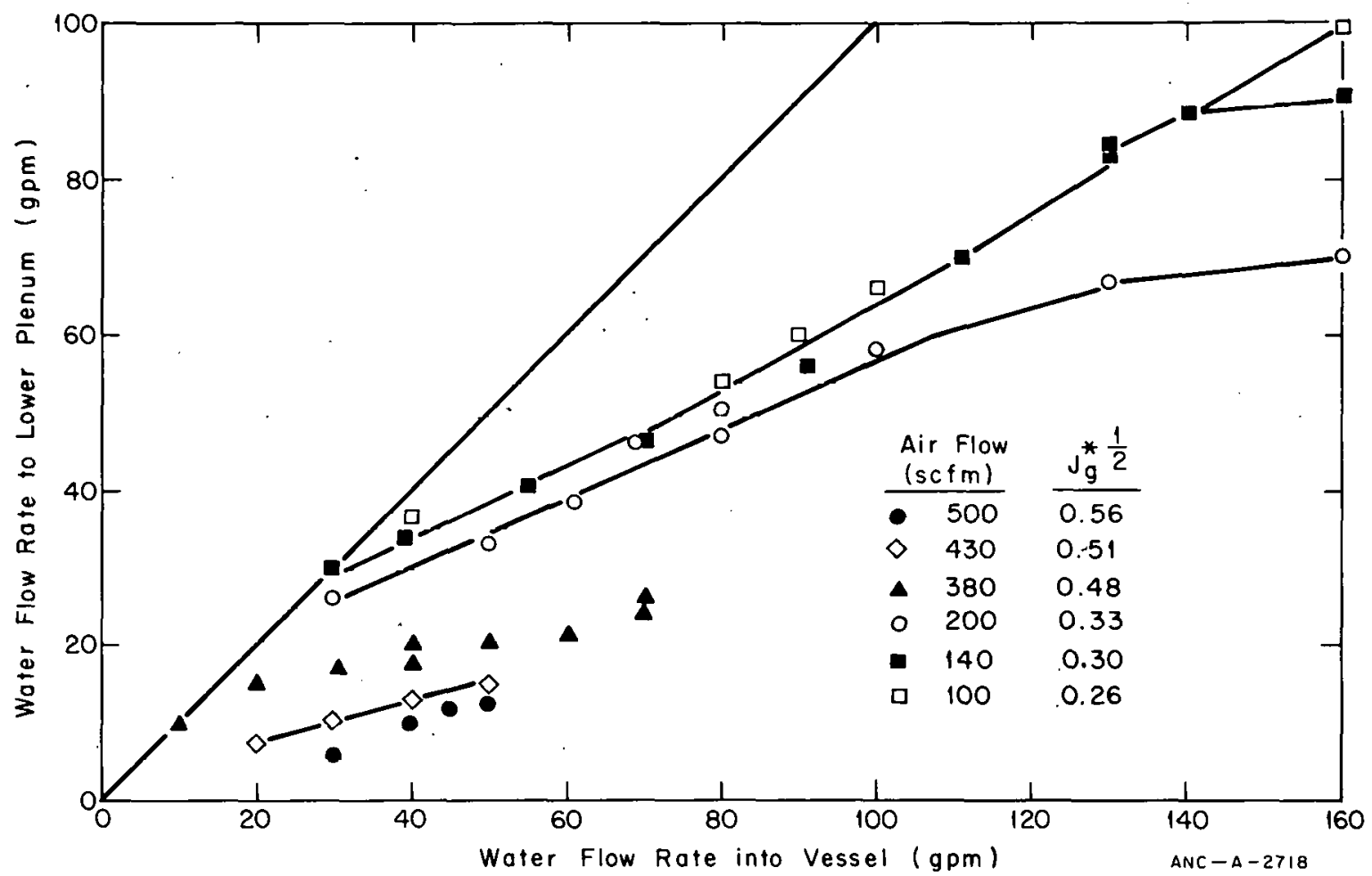

Fig. 38 Water delivery to lower plenum for various air flows -- 1.58-in. annular gap.

Countercurrent flow tests were conducted to determine the effect that a two-phase mixture entering the upper annulus has on the countercurrent flow and upper annulus bypass characteristics of the semiscale vessel. For one group of tests, the cold leg water flow, countercurrent air flow, and pressure conditions for each data point with no cold leg air flow were repeated with a cold leg air flow of $0.067 \mathrm{lb} / \mathrm{sec}(50 \mathrm{scfm})$. Results from these tests are presented in Figure 40 together with the results from tests with water only entering from the cold leg. The velocities of the two-phase mixture entering the vessel for these tests ranged from 10 to $20 \mathrm{ft} / \mathrm{sec}$ which was up to a factor of two higher than the corresponding velocities for tests with water only flowing in the cold leg. A comparison of the data presented in Figure 40 indicates that no change in the lower plenum delivery results from a. two-phase mixture entering at the cold leg.

Tests with a two-phase mixture entering the vessel were also conducted with cold leg air flow rates of about $0.24 \mathrm{lb}_{\mathrm{m}} / \mathrm{sec}(200 \mathrm{scfm})$. The velocity of the two-phase mixture entering the vessel for these tests ranged from about 20 to $30 \mathrm{ft} / \mathrm{sec}$ which was from about a factor of two to about a factor of seven higher than for the corresponding tests with water only entering the vessel. The results from these tests indicate about the same lower plenum delivery rate at high and intermediate countercurrent air flow rates, but a reduced (about $20 \%$ ) lower plenum delivery rate at low countercurrent air flow rates. Since at low countercurrent air flow rates, the countercurrent flow processes and consequently the water delivery to the lower plenum have been shown to be sensitive to the inlet water flow rate, the reduction in the flow to the lower plenum for these tests appears to be caused by a limitation on delivery to the lower plenum that could occur from either the higher velocities 


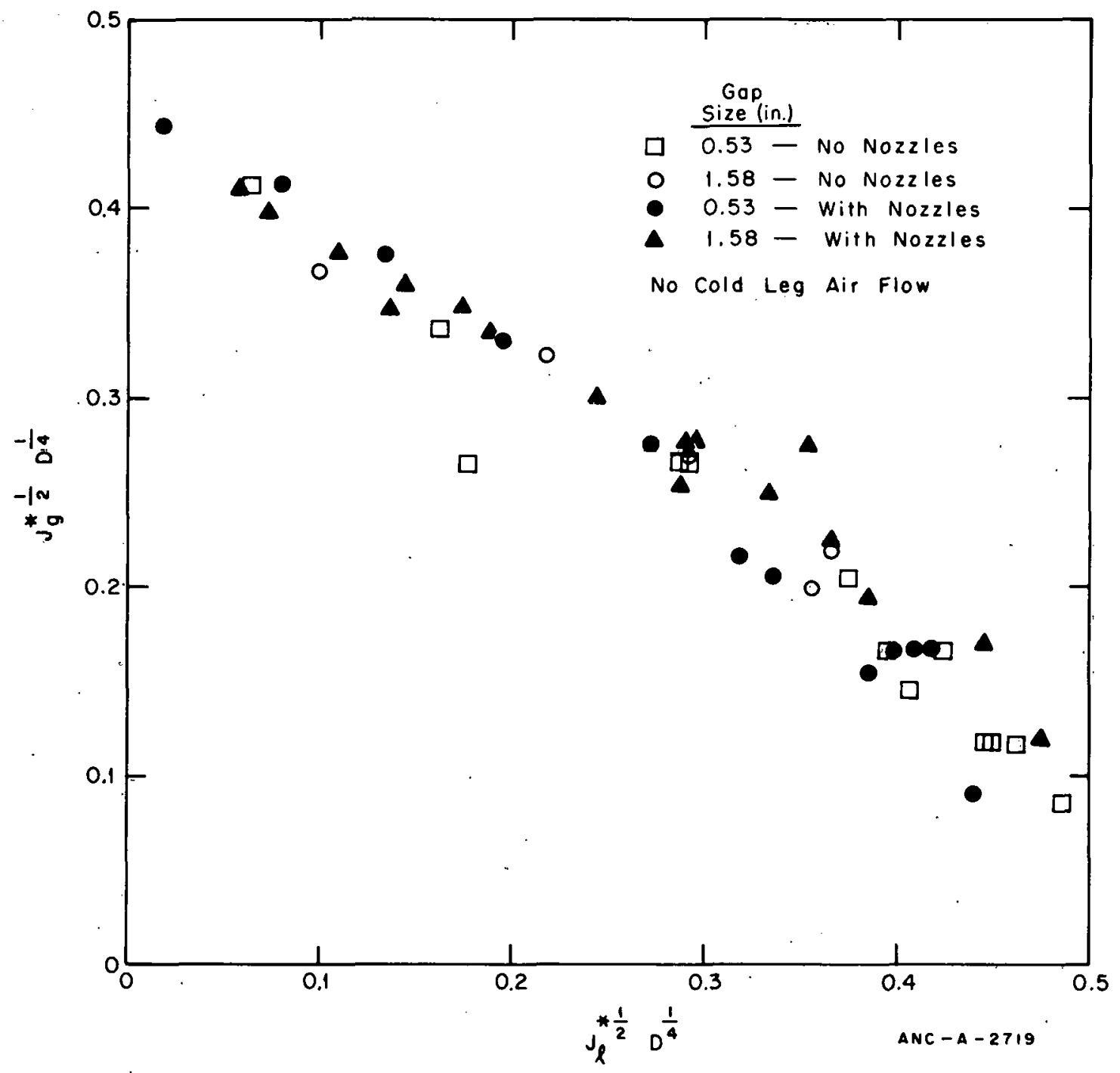

Fig. 39 Dimensioned fluxes for tests with and without cold leg and bypass leg nozzles.

at the vessel inlet or the entrainment of some water in the cold leg air as the air flowed from the cold leg to the bypass leg. Since the cold leg vessel inlet velocity for these tests did not vary significantly, the entrainment of the water by the cold leg air appears to be the best explanation of the reduction in delivery.

3.13 Effect of Upper Annulus Geometry Changes. Tests were conducted in the transparent vessel system to investigate the effect of changes in the upper annulus geometry on the downcomer countercurrent flow. The upper annulus geometry changes included: (a) replacing the upper annulus with a flow distributor that induces flow parallel to the downcomer axis with a uniform flow around the downcomer entrance; (b) increasing the height, and consequently the vertical cross-sectional area, of the upper annulus; and (c) removing the hot-leg simulators to provide a more direct flow path from the vessel cold leg inlet to the vessel outlet (bypass leg). 


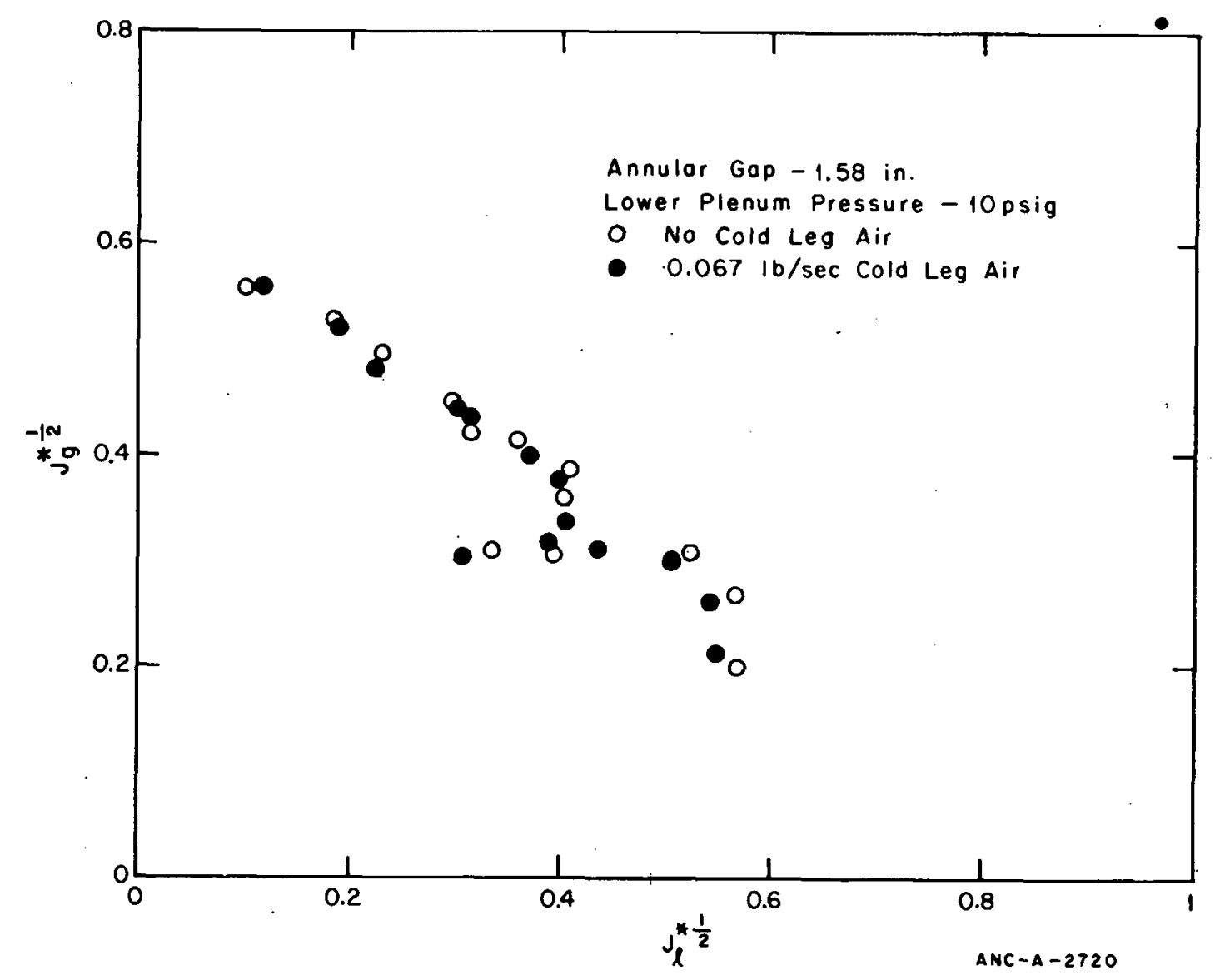

Fig. 40 Dimensioned fluxes exhibiting effect of two-phase mixture entering vessel.

A limited number of countercurrent flow tests were performed with the upper annulus portion of the transparent vessel, including the cold leg and bypass leg, removed and replaced with an inlet water distributor that was designed to induce flow parallel to the downcomer axis and to distribute the water uniformly around the top of the downcomer. The purpose of these tests was to provide uniform inlet flow distribution, countercurrent flow data that could be compared to the normal inlet countercurrent flow data to indicate the effect on countercurrent flow of the nonuniform distribution of water to the downcomer entrance that results from injection normal to the downcomer.

A schematic of the flow distributor is shown in Figure 41. The water entered the bottom of the apparatus and was distributed by a perforated plate. The entrance to the downcomer was similar to a weir. For all tests performed, the water level was maintained above the top of the weir-type entrance to assure water flow down both walls of the downcomer. 

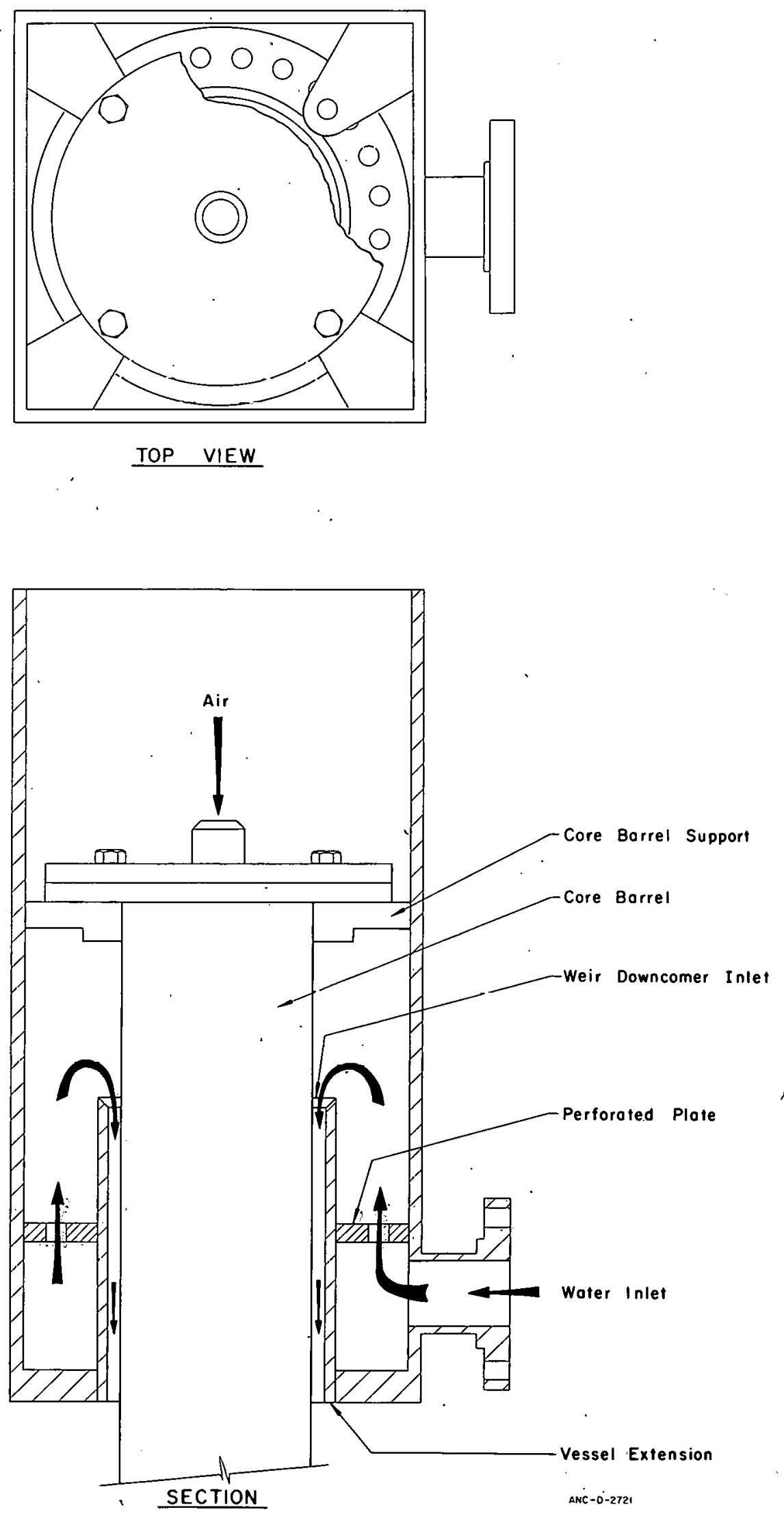

Fig.41 Simplified schematic of the uniform water distributor. 
Four countercurrent flow data points were taken with the uniform inlet flow distributor and a 0.49-inch-downcomer gap. These four data points are shown plotted in the form of the Wallis correlation in Figure 42 along with data points taken with the normal inlet configuration and a 0.49 -inch-downcomer gap. The transparent vessel uniform inlet data have a slope that would be similar to that for the countercurrent flow data taken with circular tubes with a similar inlet geometry, but the ordinate intercept of the uniform inlet data would be much higher than the ordinate intercept derived from circular tube data. A comparison of the data from the uniform and normal inlet distributors indicates that nonuniform distribution of water to the downcomer entrance causes slightly less water delivery to the lower plenum at the higher downcomer air flow rates.

Countercurrent flow tests were conducted in which an extension was placed on top of the normal transparent vessel upper annulus and the entire core barrel was raised 10 inches to lengthen the upper annulus region and effectively shorten the downcomer. The hot leg simulators were appropriately moved to maintain their position in line with the inlet cold leg and the bypass leg. Lengthening the upper annulus provided a larger upper annulus vertical cross-sectional area in which the water entering from the cold leg could flow more easily over the top of the hot leg simulator and thereby reach the bypass leg more easily than with the shorter length upper annulus. The purpose of these tests was to determine whether the potential for an increased flow through the upper annulus region would affect the downcomer countercurrent flow.

The results from tests with the upper annulus lengthened are presented in the form of the Wallis correlation together with results from tests with normal inlet geometries in Figure 43. A comparison of the data shown on this figure indicates that no change in the lower plenum delivery results from lengthening the upper annulus; therefore, the conclusion. reached was that lengthening the upper annulus does not affect the downcomer countercurrent flow.

Additional countercurrent flow tests were conducted to investigate the effect on countercurrent flow of changing the upper annulus geometry. For these tests, the hot leg simulators were removed from the upper annulus to provide a more direct flow path from the cold leg vessel inlet to the vessel outlet (bypass leg). The purpose of these tests was to determine whether this unrestricted flow path allowed water to bypass the entrance to the downcomer an thereby affect the countercurrent flow. The results from tests with the hot leg simulators removed are presented in the form of the Wallis correlation in Figure 44 together with results from tests performed with the hot leg simulators in place. A comparison of the presented data indicates no significant change in lower plenum water delivery results from removing the hot leg simulators; therefore, the conclusion reached is that removing the hot leg simulators does not affect the downcomer countercurrent flow.

3.14. Effect of Changing the Downcomer Length. Several series of tests were conducted to investigate the effect on countercurrent flow of changes in the downcomer length. The nominal length of the downcomer was about 68 inches. The downcomer length was varied by shortening the length of the core barrel. For those tests with the shortened 


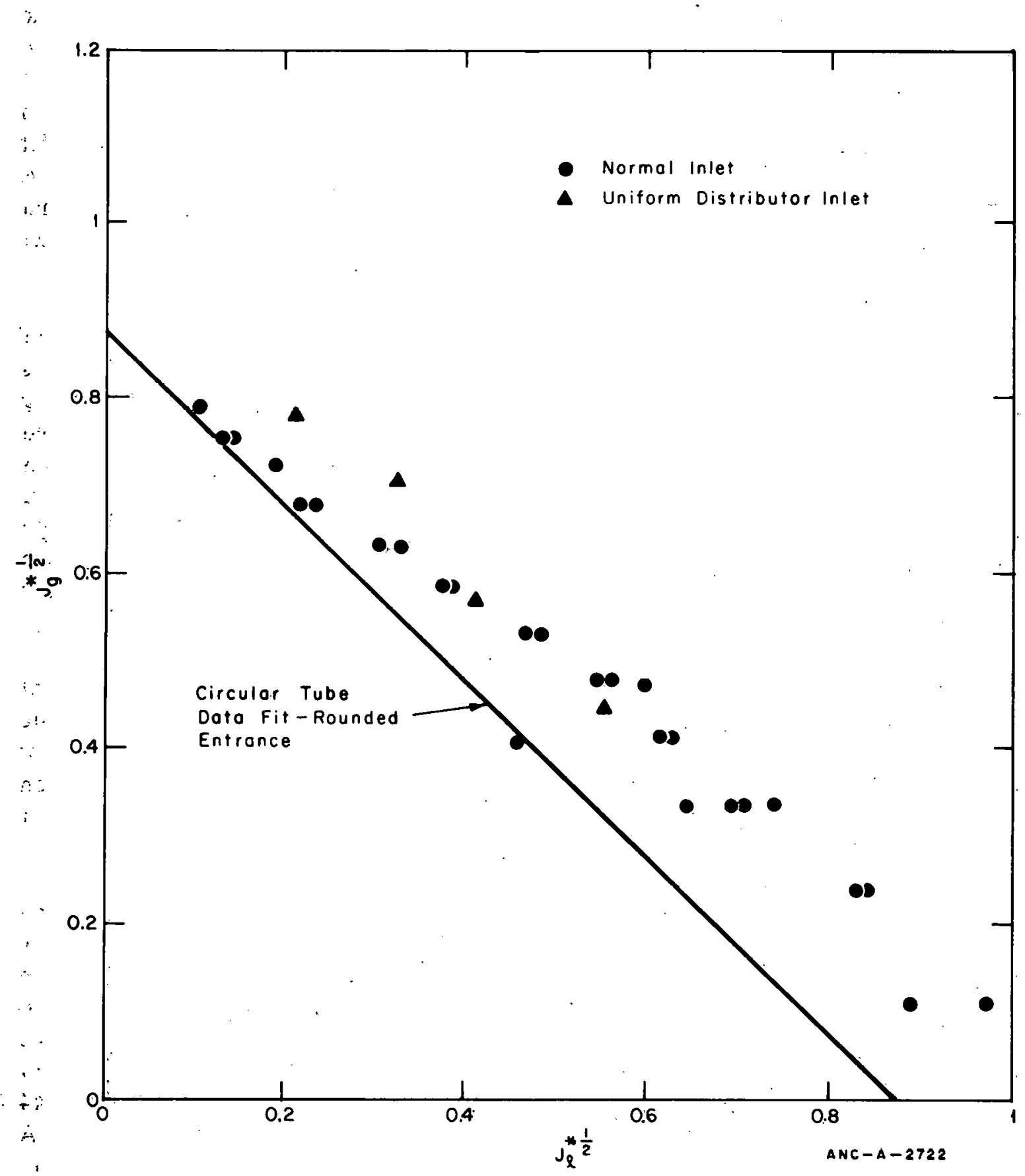

Fig. 42 Dimensionless fluxes exhibiting effect of uniform flow to downcomer entrance.

ذ... 


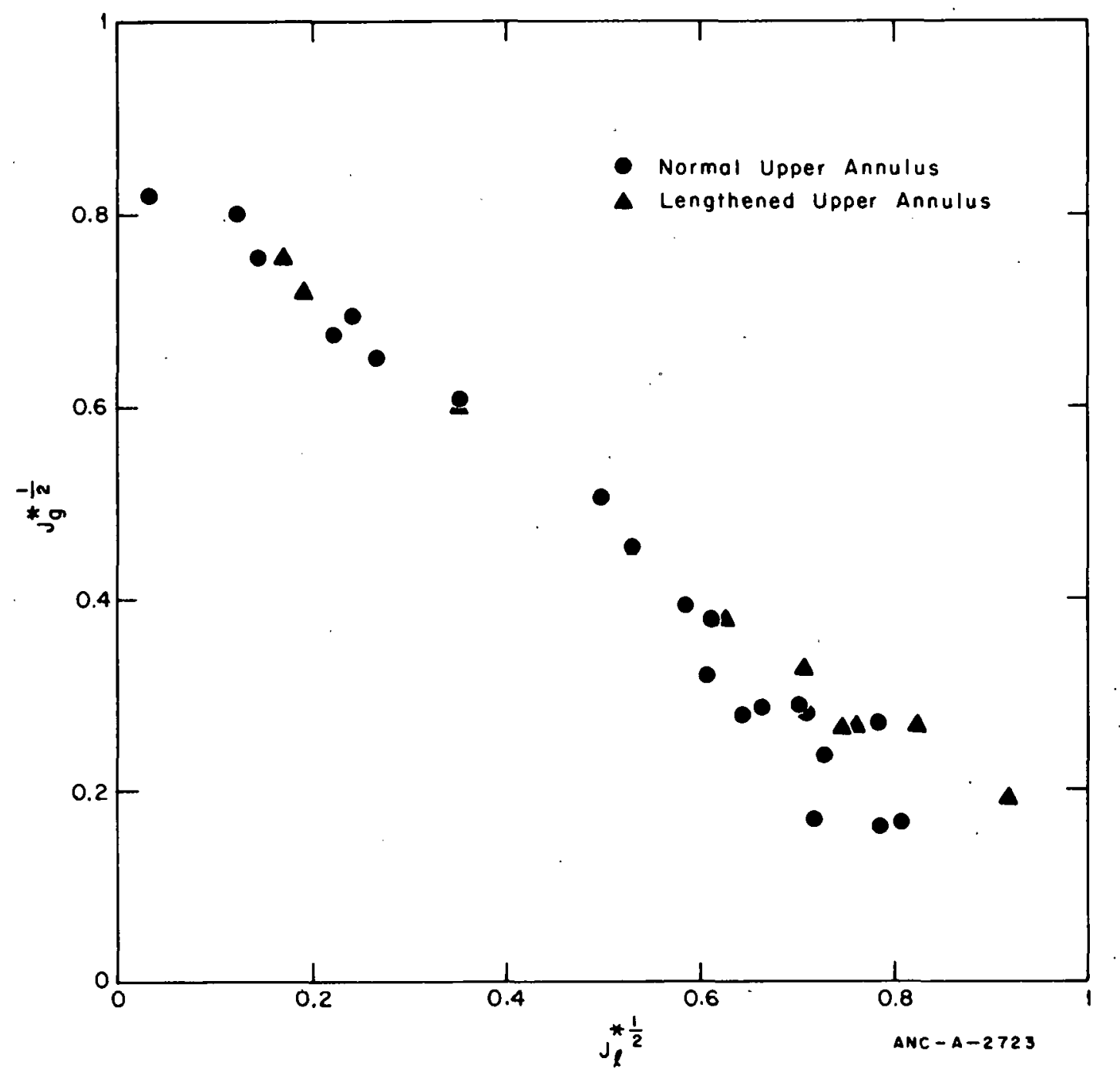

Fig. 43 Dimensionless fluxes exhibiting effect of upper annulus length on water delivery to the lower plenum.

core barrel, the length of the downcomer was defined as the distance from the top of the downcomer filler piece to the bottom of the core barrel; or, if a filler piece was not used as part of the downcomer, the length was defined as the distance from the centerline of the cold leg pipe to the bottom of the core barrel. The shortened downcomers which used a filler piece were 34,24 , and 6 inches in length. For tests in which a filler piece was not used the length of the downcomer was about 12 inches.

The data from countercurrent flow tests performed in a system with a 0.49 -inch-downcomer gap and downcomer lengths of $68,34,24$, and 6 inches are presented in the form of the Wallis correlation in Figure 45 to illustrate the effect of downcomer length on the delivery of water to the lower plenum. For a large range of countercurrent air flow rates, the water delivery to the lower plenum is about the same for the 68-, 34-, and 24-inch-length downcomers. However, for some tests, the data from the 6-inch-length downcomer exhibits considerable scatter from the data of the other downcomer lengths. 


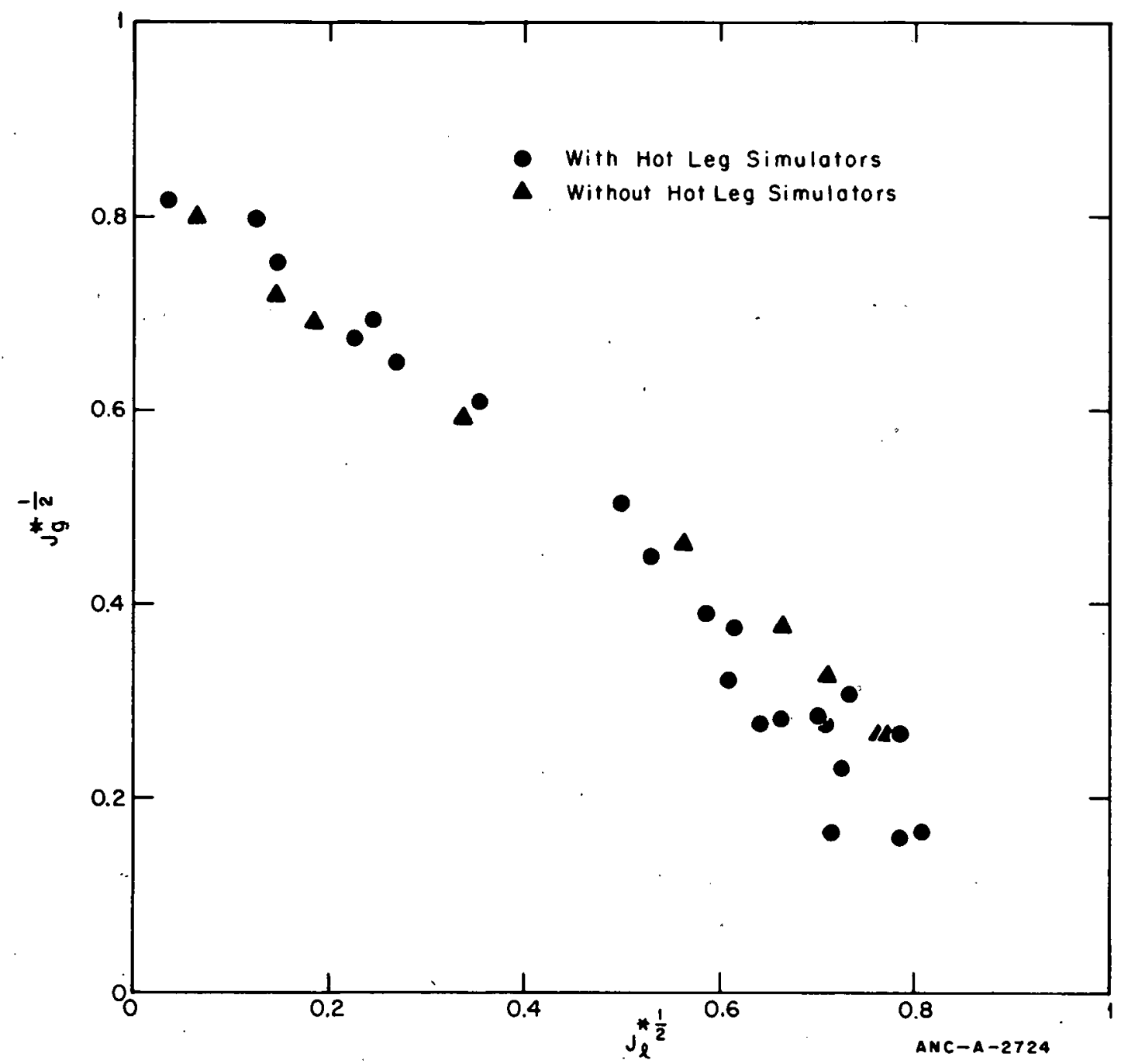

Fig. 44 Dimensionless fluxes exhibiting effect of presence of hot leg simulators on water delivery to the lower plenum.

Data from tests with a 0.49 -inch-downcomer gap and the 6- and 68-inch-length downcomers are presented in Figure 46 where the water flow rate into the lower plenum is plotted against the water flow rate into the vessel for a range of countercurrent air flow rates. This figure is basically Figure 37 with the data for the short downcomer added. The data from the 68-inch downcomer indicate that, for a given countercurrent air flow, the flow to the lower plenum is relatively independent of inlet flow whereas for a given air flow the data from the short (6-inch) downcomer exhibit large variations in the flow to the lower. plenum for inlet flows less than about 16 gpm (inlet velocity less than about $3 \mathrm{ft} / \mathrm{sec}$ ). These large variations in the flow to the lower plenum for a given countercurrent air flow account for the scatter in the data for the 6-inch downcomer shown in Figure 45. Observations of the flow in the shortest downcomer showed that at relatively low water flows into the vessel, most of the water tended to flow down the cold leg inlet side of the downcomer while most of the air escaped up the opposite side of the downcomer. These observations are in direct contrast to the observations made in the longer downcomers where flow was uniform around the circumference of the downcomer. 


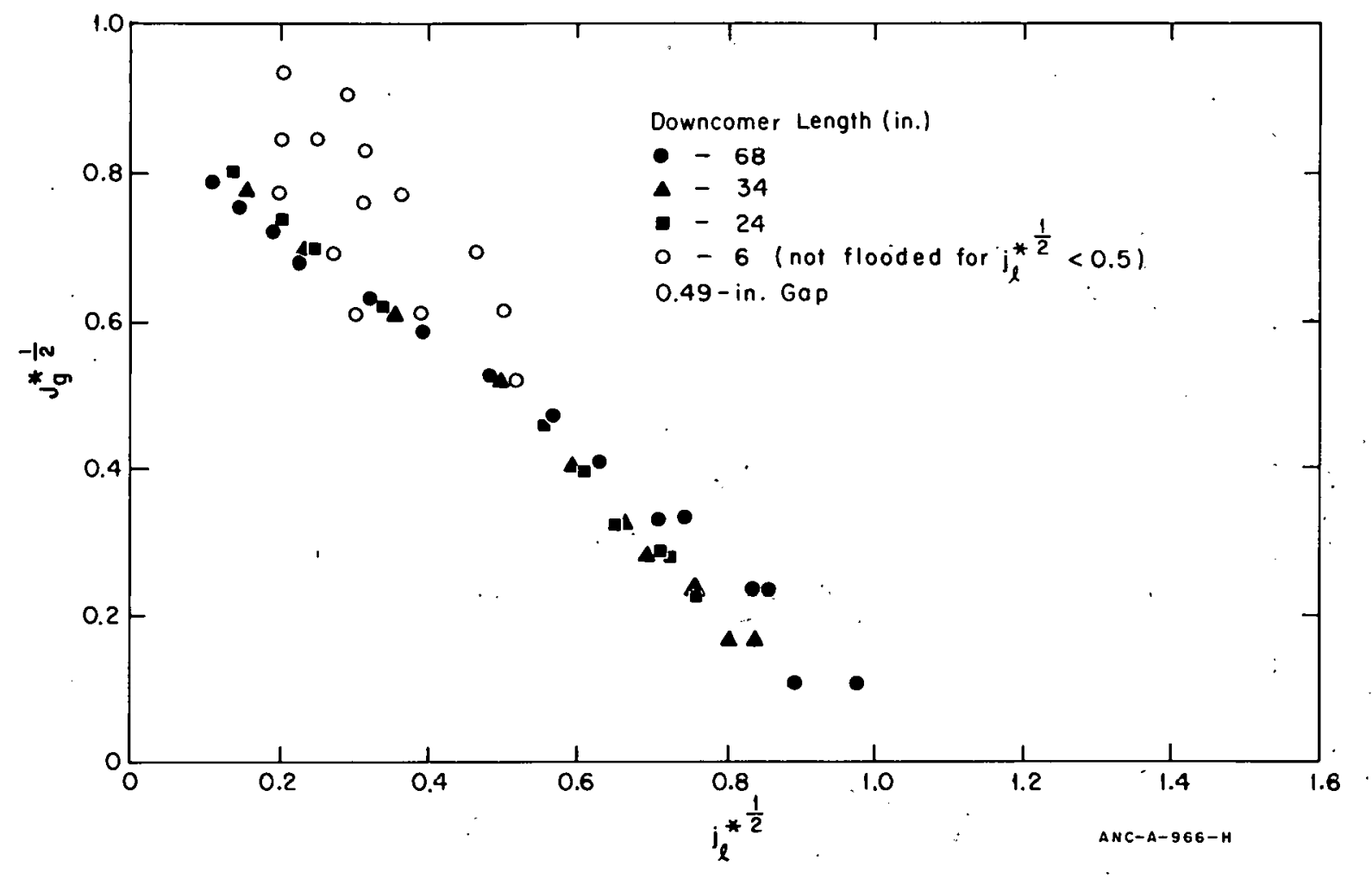

Fig. 45 Dimensionless fluxes for different downcomer annulus lengths.

Further countercurrent flow tests were conducted with the 6-inch downcomer length and a 0.40 -inch downcomer gap. The results of these tests were similar to those presented in Figures 45 and 46 in that nearly all of the variations in lower plenum flow occurred at inlet flow rates less than $16 \mathrm{gpm}$. Countercurrent flow tests were also conducted in a system with a 1.45-inch downcomer gap and a downcomer length of 12 inches (downcomer with no filler). These tests did not exhibit data scatter in the lower plenum flow and the data were similar to those from other tests performed with longer downcomers. However, the inlet flows for these tests were generally above the maximum inlet flow at which the variation in lower plenum delivery rate occurred $(16 \mathrm{gpm})$ for other tests because countercurrent flow would not have occurred in the larger downcomer gap for water flows less than $16 \mathrm{gpm}$ and countercurrent air flows over the'range tested.

Countercurrent flow tests with a two-phase mixture entering the cold leg were performed with the 0.49- and 0.40-inch gaps and a 6-inch downcomer. These tests did not show a variation in the lower plenum delivery flow. rate over the range of inlet flow rates even with inlet flows less than $16 \mathrm{gpm}$. However, the velocity of the two-phase vessel inlet flow was much greater than the single-phase flow velocity at inlet flows of $16 \mathrm{gpm}$. Apparently the asymmetric flow and the resulting changes in water delivery to the lower plenum are affected by the velocity at the vessel inlet. A possible explanation for the variation in flow to the lower plenum and for the asymmetric flow is that below $16 \mathrm{gpm}$ the inlet water velocity was not high enough to carry the water completely around the core barrel and into the downcomer gap on the opposite side of the inlet before the water had fallen below the end of the short core barrel. The fact that nearly all variation in lower plenum flow occurred below a constant value of inlet flow (16 gpm) supports the preceding explanation. 


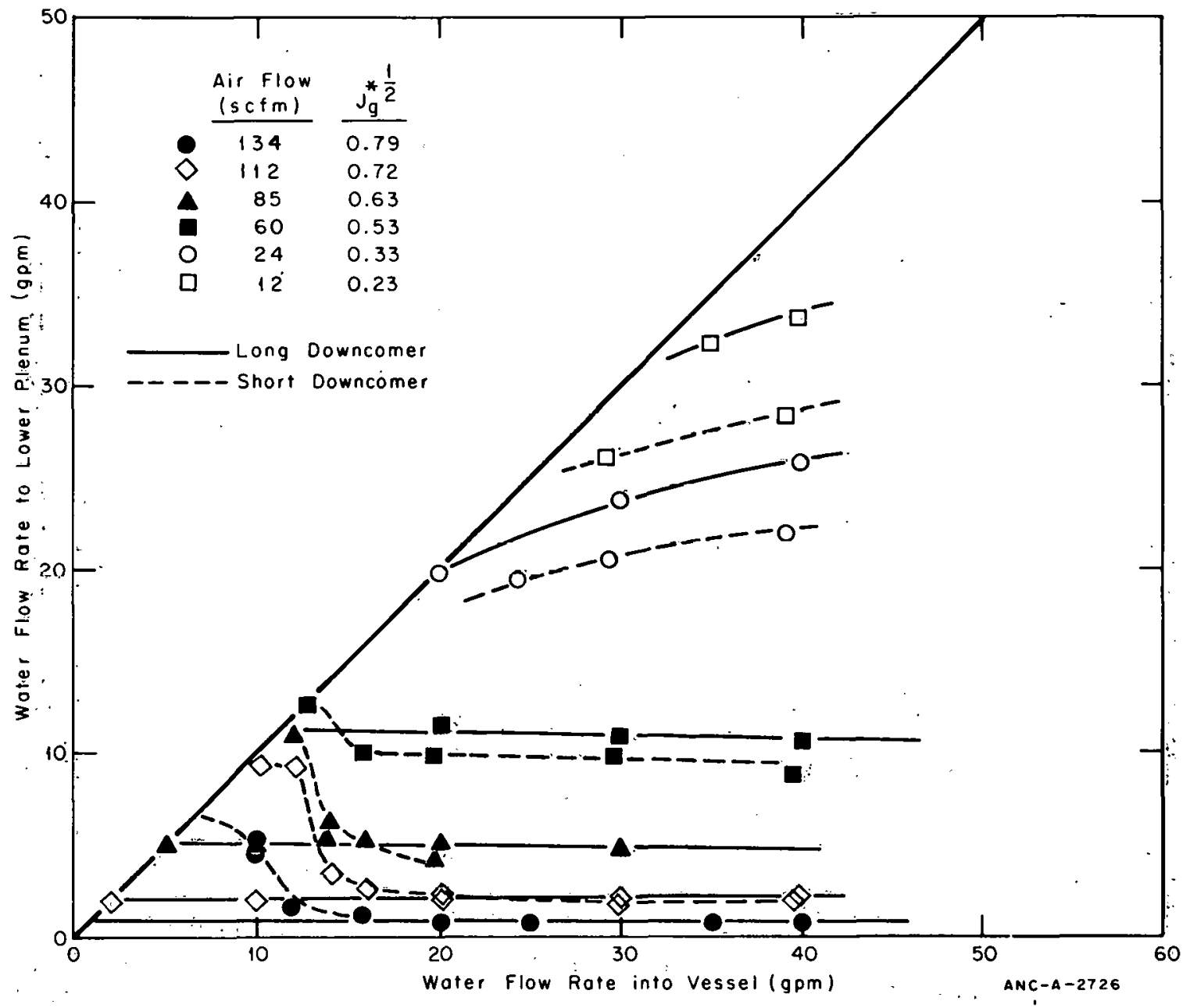

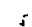

Fig. 46 Water delivery to lower plenum for the 0.49-in. annular gap and short and long downcomers.

3.15 Relätionship Between Air-Water and Steam-Water Tests. In order to correlate the results of the steady state countercurrent flow tests in the semiscale system with the transparent vessel data, air-water tests were conducted. in the metal semiscale vessel. Test data from both systems are shown plotted in the form of dimensioned fluxes in Figure 47. The data presented are from tests with similar entrance conditions and downcomer annular gap̣ sizes of approximately $0.50 \mathrm{inch}$. The fact that the data from the two systems did not agree resulted in an investigation into possible differences between the two tests.

$\therefore$ The investigation into the differences between the transparent vessel and semiscale system test results led to the conclusion that an additional gap of approximately 0.05 inch "filler gap" influenced the amount of water delivered to the lower plenum. The small second gap resulted in two flow paths to the lower plenum within the semiscale vessel. Two flow paths to the lower plenum did not exist in the transparent vessel geometry because 0 -rings were used between the filler piece and vessel inside diameter to seal the second possible flow path. By analysis, individual countercurrent flow curves for the two flow paths or "downcomers" were developed for the semiscale system vessel, which satisfied an overall mass balance, and which represented the assumed countercurrent flow conditions. The details of this analysis are presented in Appendix C. 


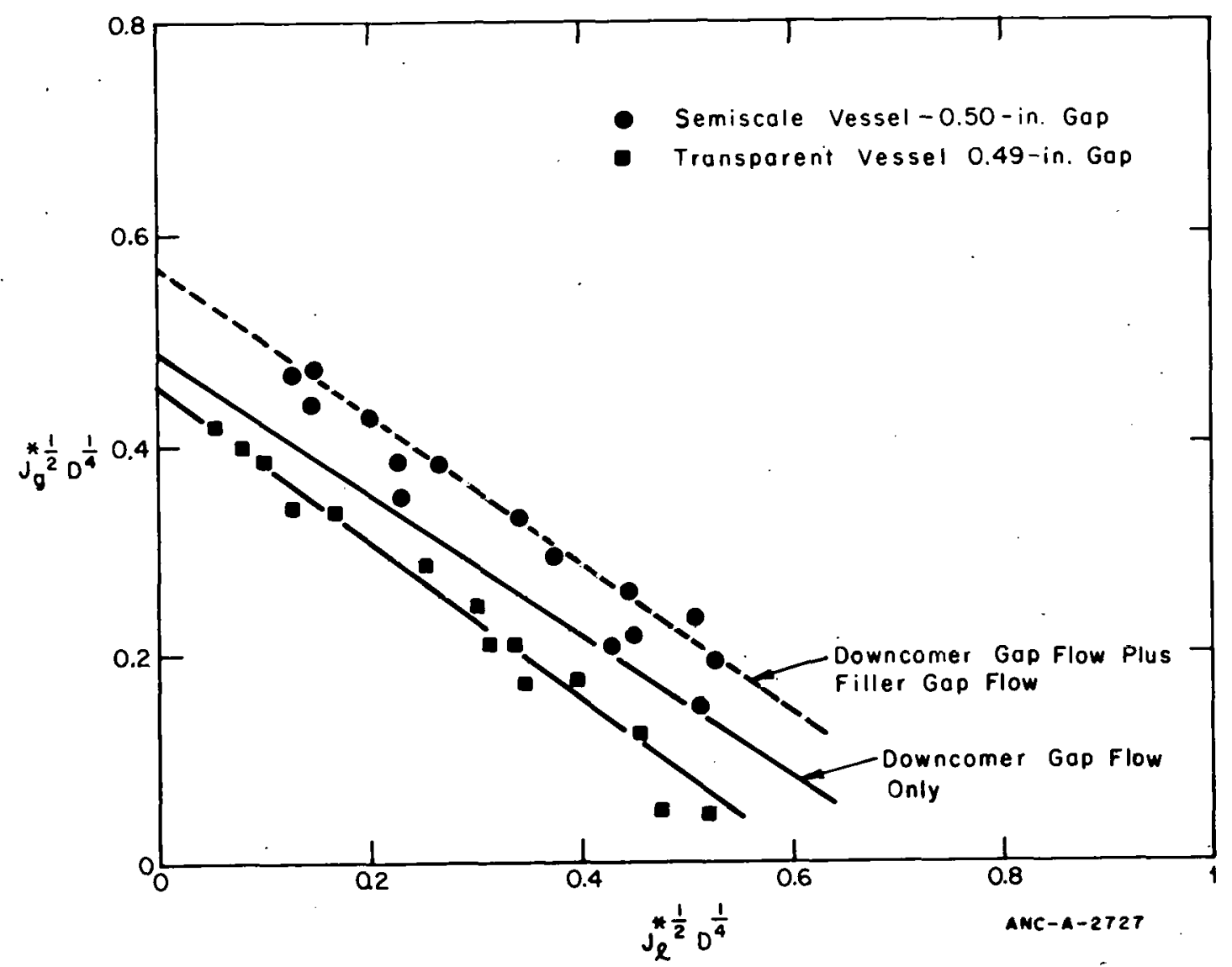

Fig. 47 Dimensionless fluxes for air-water countercurrent tests in the transparent vessel and in the semiscale vessel with and without the filler gap.

When the amount of water calculated to be flowing in the filler gap was subtracted from the measured flow to the lower plenum the semiscale system vessel downcomer countercurrent flow results compared favorably with those of the transparent vessel, as shown in Figure 47. A likely cause of the difference between the transparent vessel curve and the downcomer gap flow curve is the lack of an accurate representation of the countercurrent flow curve for the small filler gap. Some of the differences between the two curves could also be caused by the difference in surface conditions between the plexiglass and the carbon steel metal vessels (that is, between differences in the wettability of plexiglass versus carbon steel). However, the magnitude of this effect cannot be determined because no investigations on the effect of wettability on countercurrent flow have been reported in the literature. Even though the air-water data from the semiscale metal vessel which have been adjusted for the effect of the filler gap are slightly different than the transparent vessel data, the results are sufficiently similar to conclude that the transparent vessel test results provide a good representation of the countercurrent air-water phenomena occurring in the semiscale system vessel when both vessels have similar entrance conditions and gap sizes. 
3.16 Steam-Water Countercurrent Flow. The steady state semiscale system countercurrent flow tests were conducted to supply data on the effects of condensation and evaporation on countercurrent flow in the semiscale downcomer. Steam and water were used as the fluids in these tests for determining a relationship between the velocity of the steam in the downcomer annulus and the water delivery rate to the lower plenum. The effect on water delivery to the lower plenum of varying several system parameters downcomer gap size, cold leg water flow rate, wall heat flux, cold leg water temperature, and cold leg steam flow mixing with the cold leg water - and of changing the method of initiating the tests was studied.

An overview of the steady state steam-water data indicates that countercurrent steam-water flow could not be established if subcooled water reached the entrance to the downcomer. Even small amounts of subcooling at the downcomer entrance appeared to cause progressively larger amounts of steam condensation until the steam velocity at the top of the downcomer was low enough to allow a significant amount of water to flow into the downcomer. At this point complete condensation of the dowcomer steam flow appeared to occur and all the water entering the vessel fell to the lower plenum. The data also indicate a departure from the trends of the air-water data for values of $J_{\ell}^{* 1 / 2} \mathrm{D}^{1 / 4}$ less than 0.11 for the 0.5-inch downcomer gap as illustrated in Figure 48. This same departure from the air-water trends was shown to exist for the 1-inch gap studies, but not as strongly. A hypothesis was developed which attributed the unexpected hump in the data at high countercurrent gas flows to phenomena occurring in the small gap between the filler piece and the vessel (filler gap). Analytical calculations indicate that a maximum water flow of 18 gpm is possible down the filler gap when no countercurrent gas flow exists. A value of $\mathbf{J}_{\ell}^{*} 1 / 2 \mathrm{D}^{1 / 4}=0.11$ with the 0.5 -inch gap corresponds to a water flow rate of about $2 \mathrm{gpm}$ which would flow down the filler gap. Analysis of the relative resistances between the filler gap and downcomer gap leads to the conclusion that for a given gas flow rate, complete stoppage of water flow resulting from the countercurrent flow of steam could have occurred in the downcomer without complete stoppage of water flow in the filler gap. Therefore, all water reaching the lower plenum at $\mathrm{J}_{\ell}^{*} 1 / 2 \mathrm{D}^{1 / 4}$ values of less than 0.11 could have done so by flowing down the filler gap while countercurrent flow in the downcomer gap restricted all water from flowing to the lower plenum through the downcomer. Possible eccentricity of the filler gap and the instrumentation lead channels machined in the outside diameter of the filler piece may have channeled the flow in the filler gap and have caused significant delivery to the lower plenum even though high velocity steam flow was occurring in the filler gap. Although completely quantifying the effect the filler gap had on countercurrent flow in the downcomer over the complete range of steam flows is extremely difficult, the analysis indicates that the test results at the low liquid flows which resulted from high steam flows may have been altered sufficiently by the filler gap that the data reported for downcomer liquid flow rates less than $\mathrm{J}_{\mathrm{g}}^{*} \cdot 1 / 2 \mathrm{D}^{1 / 4}$ of about 0.1 should be considered questionable as to their significance.

The data for the 0.5- and 1.0-inch gaps presented in Figure 48 have been used in this report as "standard" or baseline data against which other test data with parameter variations can be compared. Various conclusions can be drawn from analysis of these data. The most 


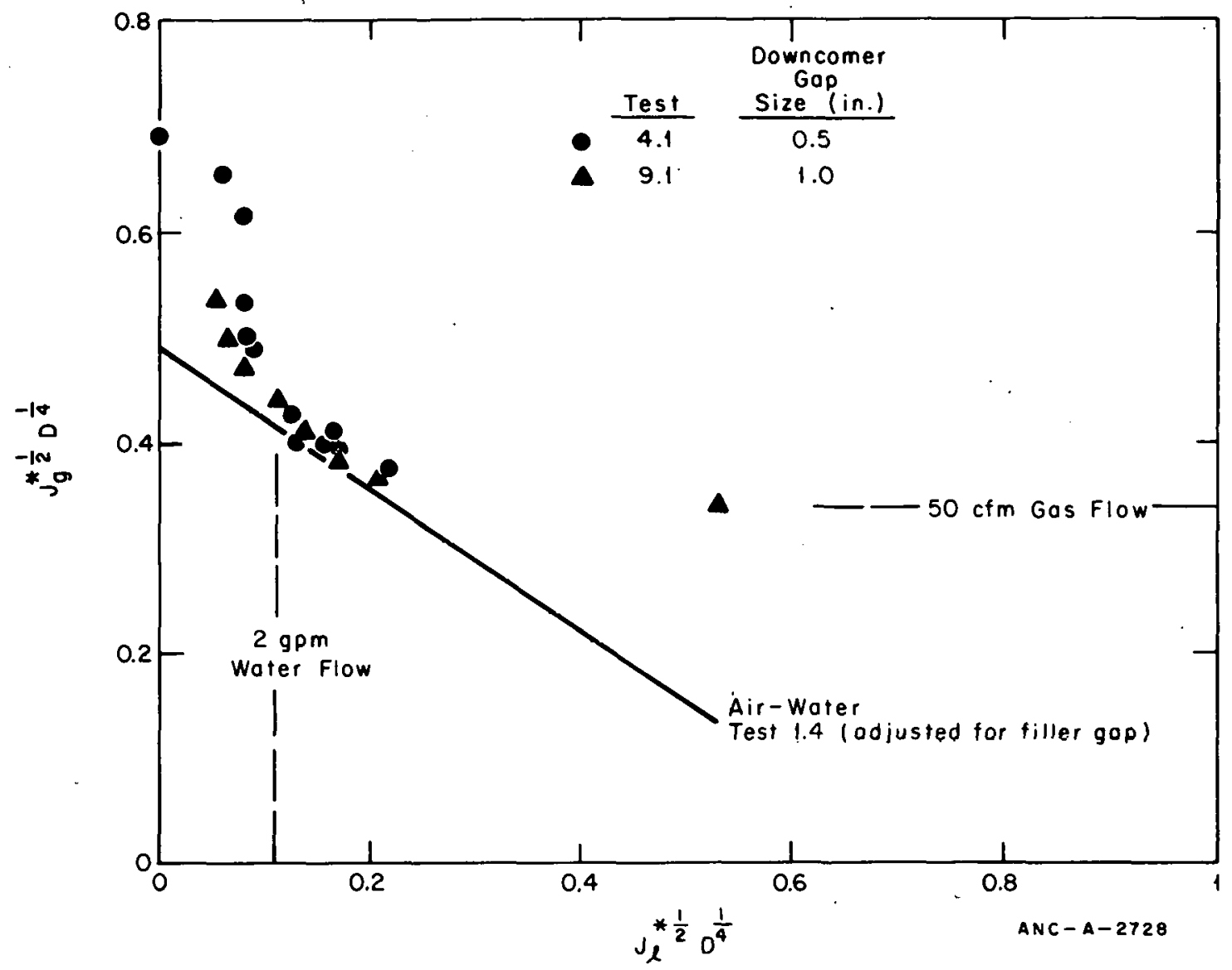

Fig. 48 Dimensioned fluxes for steady state semiscale system baseline tests with 0.5 - and 1.0 -in. downcomer gaps.

important conclusion is that a countercurrent flow condition could not be obtained in the 0.5 -inch downcomer gap for superficial stcam velocities below about $15 \mathrm{ft} / \mathrm{sec}\left(\mathrm{J}_{\mathrm{g}}^{*} 1 / 2 \mathrm{D}^{1 / 4}\right.$ $=0.36$ ). The steam at smaller flow rates was completely condensed, allowing all liquid that entered the vessel inlet to reach the lower plenum. This result is of interest because it indicates that condensation can overwhelm the countercurrent flow processes when the liquid entering the downcomer becomes sufficiently subcooled. For the dimensioned liquid volumetric fluxes greater than 0.11 , the data from the two gap sizes represented in Figure 48 correlate to essentially the same countercurrent flow curve. The correlation of data from different gap sizes is consistent with the results of the transparent vessel tests which showed the data from gap sizes greater than about 0.5 inch could be represented by a single line when correlated by the dimensioned form of the Wallis correlation.

A series of steam-water tests was conducted to determine the effect of bypass flow on the amount of water reaching the lower plenum. For these tests the bypass flow was held constant over a range of steam flows. The results of these tests for the 0.5 -inch gap and 1-inch gap are included in Figures 49 and 50, respectively. The results in both figures show a definite trend toward greater delivcry to the lower plenum with increased bypass flow. The 1 -inch gap results show a stronger trend toward more delivery at high bypass flow than the 0.5 -inch gap results, especially at 25 -gpm bypass flow. The trend toward more delivery to the lower plenum with increasing bypass flow appears to be similar to the trends in bypass flow that occurred during countercurrent flow for the larger gaps in the transparent vessel tests. 


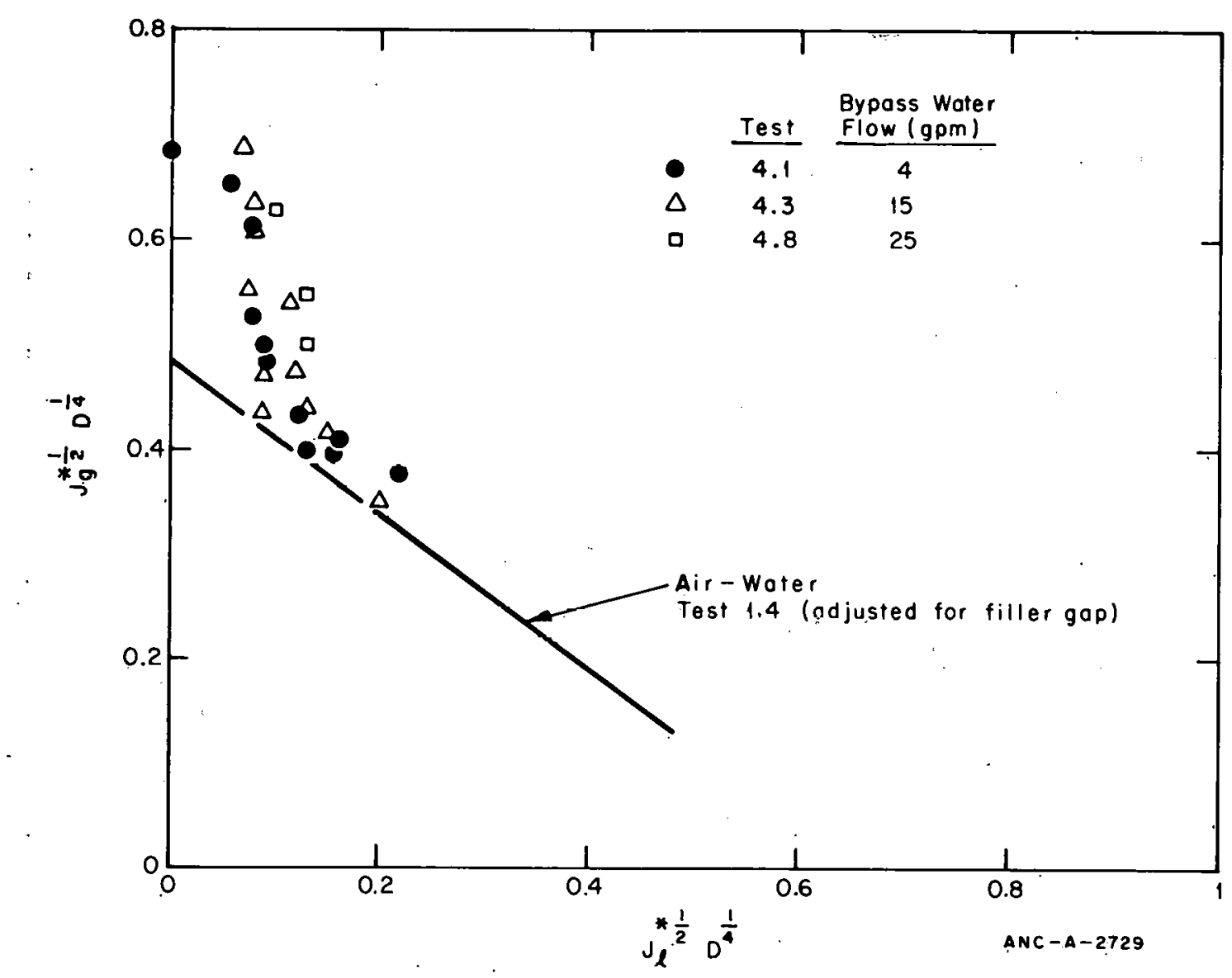

Fig. 49 Dimensioned fluxes for steady state semiscale system flow bypass tests with 0.5 -in. downcomer gap.

Figure 51 shows the results of steam-water tests conducted with a 0.5 -inch gap in which various heating rates were applied to the semiscale vessel to determine the effect of heating the vessel walls on the amount of water reaching the lower plenum. Heating rates of 0,11 , and $34 \mathrm{Btu} / \mathrm{sec}$ were utilized in three separate series of tests. The gap size for these tests was 0.5 -inch. The general results indicate that the water reaching the lower plenum is decreased, for a given inlet gas flow rate, as the hcating rate is increased. This trend appears to be caused by the increase in both downcomer and filler gap steam generation as the heating rate is increased. The increase in countercurrent steam velocity due to steam generation on the walls results in less water entering the downcomer which, together with the mass loss due to steam generation, results in less water reaching the lower plenum.

An analytical determination of the effect of heating the vessel walls on the downcomer flooding characteristics is very difficult to obtain, due to the influence of the filler gap. In the $11-\mathrm{Btu} / \mathrm{sec}$ heating cases, for example, $0.0123 \mathrm{lb} / \mathrm{mec}$ of water could be converted to steam. A given amount of the heat input to the vessel walls will go into producing steam in the filler gap, with the excess heat being eventually transferred into the downcomer itself. Sufficient information is not available to determine the exact amount of water that was converted to steam within each gap. 


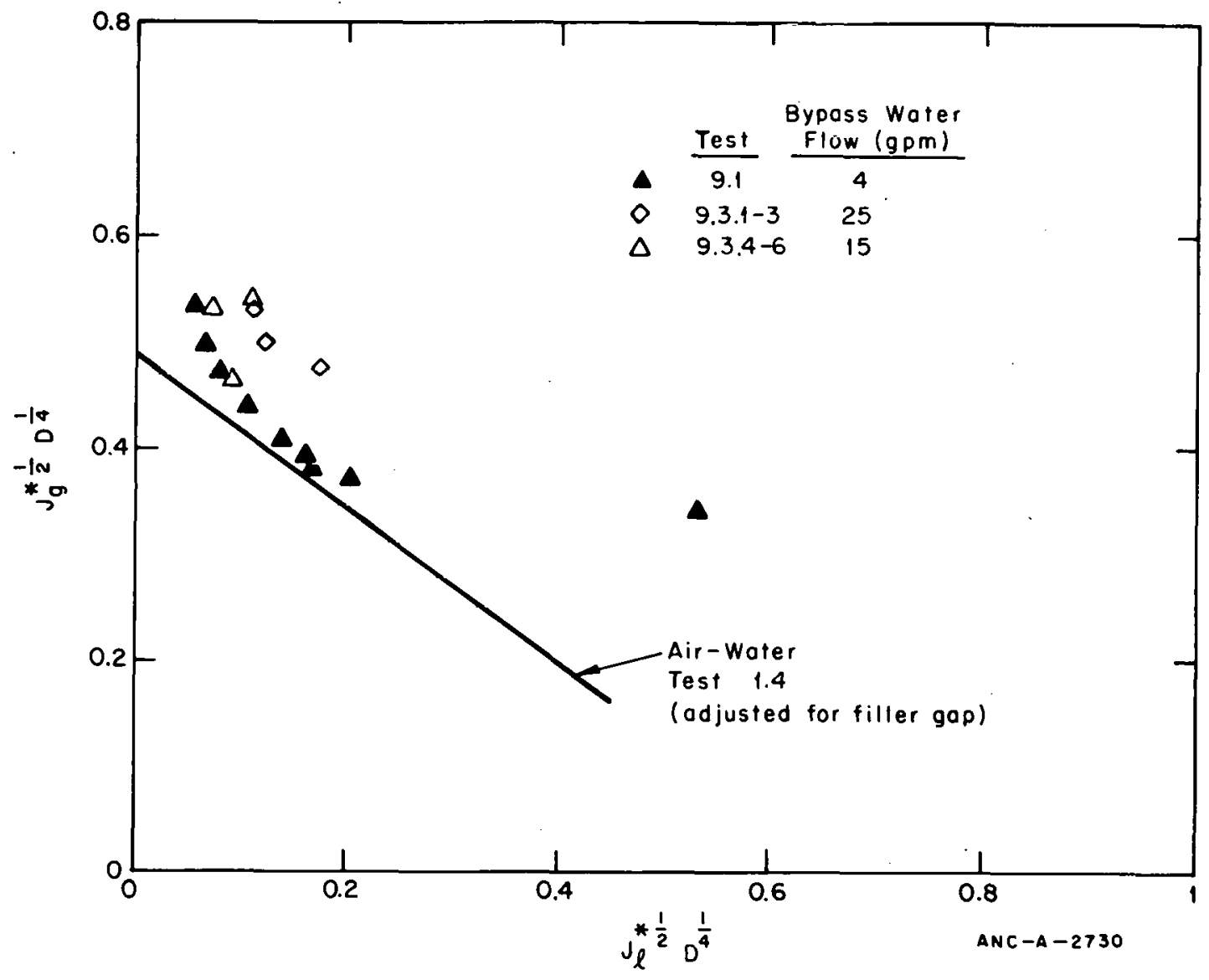

Fig. 50 Dimensioned fluxes for steady state semiscale system flow bypass tests with 1 -in. downcomer gap.

One series of tests was conducted to determine whether different cold leg inlet water temperatures had any appreciable effect on the flooding characteristics. Figure 52 shows results for inlet water temperatures of 120 and $190^{\circ} \mathrm{F}$. Analysis of the data indicates that the condensation of the steam flow in the upper annulus region brought the inlet water flow to saturation temperature for both groups of tests before the water flow reached the downcomer. Since the water entering the downcomer was saturated for both groups of tests, little difference is observed in the countercurrent flow results.

Steam was added to the cold leg inlet fluid for a series of steady state tests to determine the effect of two-phase flow at the vessel inlet on the amount of water reaching the lower plenum. The various rates of steam flow injected into the water flowing in the cold leg resulted in mixture velocities at the vessel inlet of $0.5,60$, and $180 \mathrm{ft} / \mathrm{sec}$. The fluid mixture at the vessel inlet was in the saturated state for these two-phase tests. The results shown in Figure 53 indicate that slightly less liquid reached the lower plenum during the tests for a mixture velocity of $180-\mathrm{ft} / \mathrm{sec}$, as compared lo data obtained at lower velocities. These results are consistent with those obtained in the transparent vessel for cold leg air injection in which the countercurrent flow characteristics were not significantly altered by a two-phase mixture at the vessel entrance as along as the downcomer air flow rate was high. 


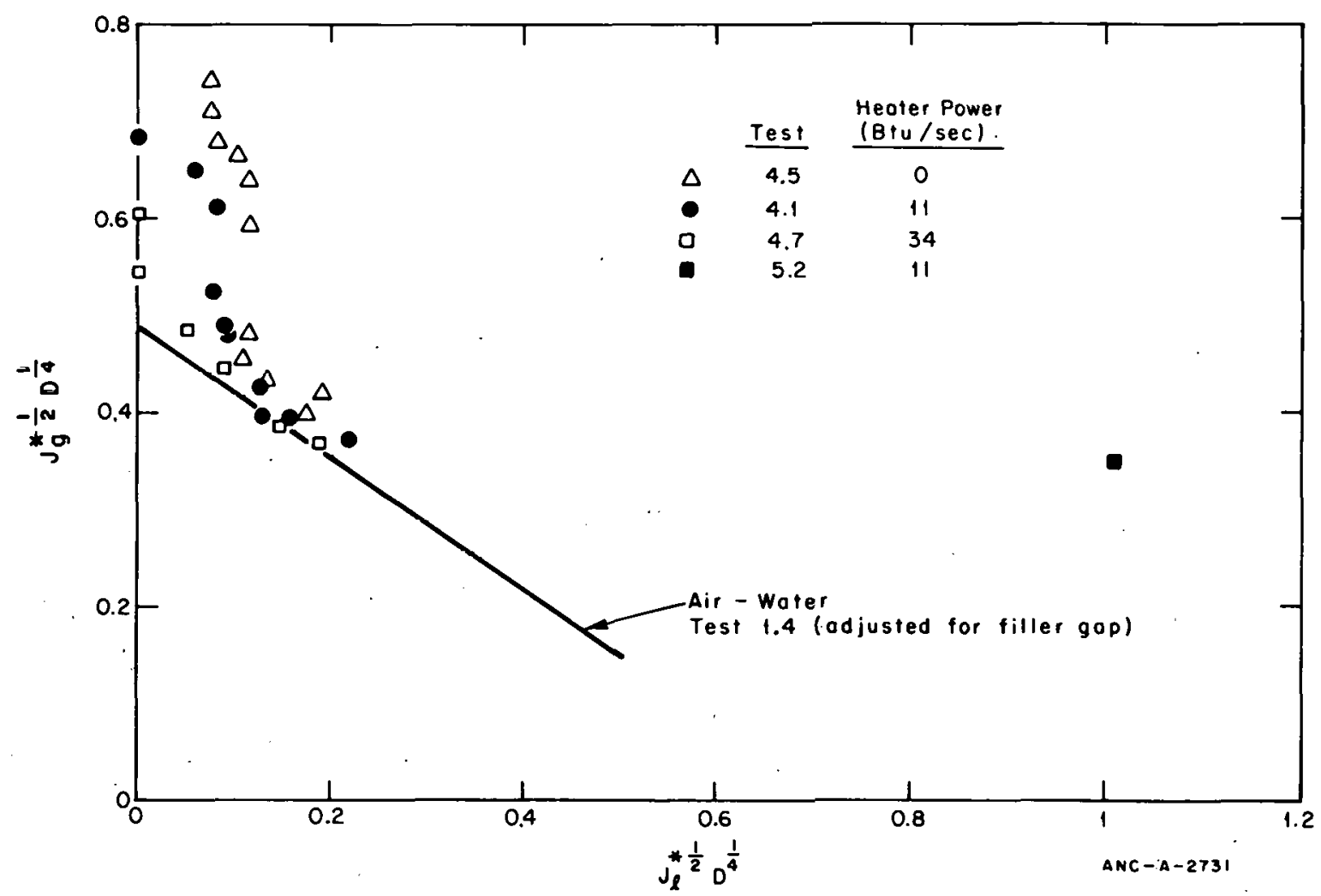

Fig. 51 Dimensioned fluxes for steady state semiscale system wall heating tests with 0.5 -in. downcomer gap.

The conclusion is thus drawn that the countercurrent flow characteristics are not altered by cold leg steam injection for mixture velocities below $180 \mathrm{ft} / \mathrm{sec}$ for the 0.5 -inch gap annulus configuration. Essentially, the same conclusion can be drawn from the test results for the 1-inch gap as from those indicated for the 0.5-inch gap.

A series of tests was conducted to determine whether the order in which the steam and water flows were established had any effect on the countercurrent flow characteristics. Tests were conducted in which steam flow in the downcomer was established followed by the initiation of water flow (Test 4.1). Further tests were conducted in which the water flow was first established, followed by the establishment of the steam flow (Test 5.1). The results of both types of tests are presented in terms of dimensioned volumetric fluxes in Figure 54. Comparison of the data from both types of tests indicates no appreciable differences exist between the results of both types of tests indicating that the method of establishment of the countercurrent flow conditions does not affect the countercurrent flow test results. 


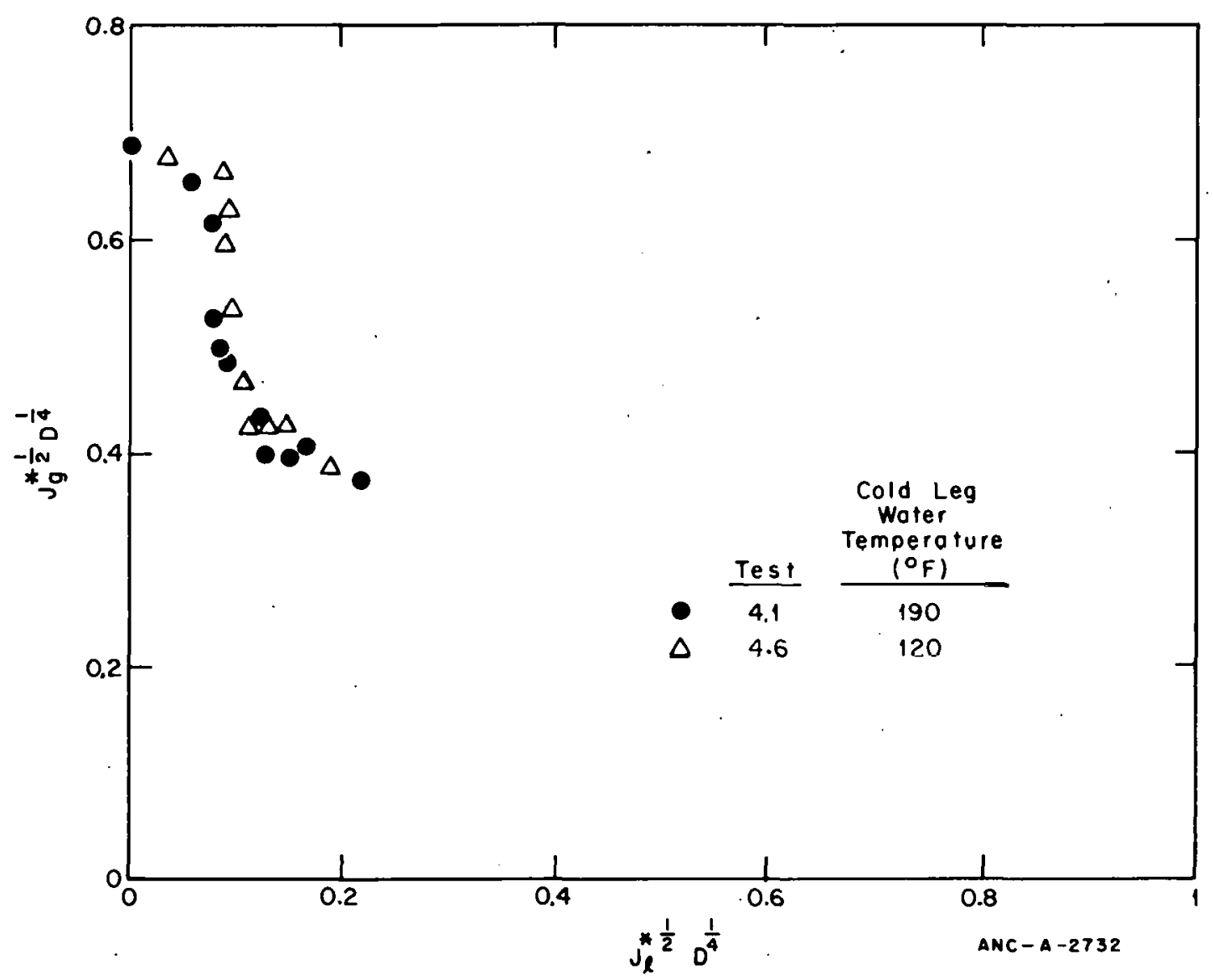

Fig. 52 Dimensioned fluxes for steady state semiscale system inlet water temperature tests with 0.5 -in. downcomer gap.

\subsection{Transient Countercurrent Flow Phenomena}

The interaction in the downcomer region between the ECC and the steam causes complex flow phenomena to occur in the downcomer region. Determination of downcomer fluid density, mass flow, and velocity is essential in gaining an understanding of the complex phenomena occurring in the downcomer. Knowledge of the density variation is necessary to provide an indication of the time at which ECC enters the downcomer and the amount of ECC that is in this region and to aid in understanding the heat transfer processes occurring in the downcomer. The velocity measurements provide a means of calculating downcomer volumetric fluxes that can be used to provide a comparison between the steady state and the transient countercurrent-flow characteristics.

3.21 Downcomer Density Evaluation. In many parts of the semiscale system, direct measurement of the average mixture density can be made with a gamma densitometer. However, the narrow annular region of the downcomer limits the type and amount of instrumentation that can be used and, therefore, no direct measurement of density is available. To obtain the mixture density and thus properties of the fluid in the downcomer, calculations were made using axial differential pressure measurements and a flow model for 


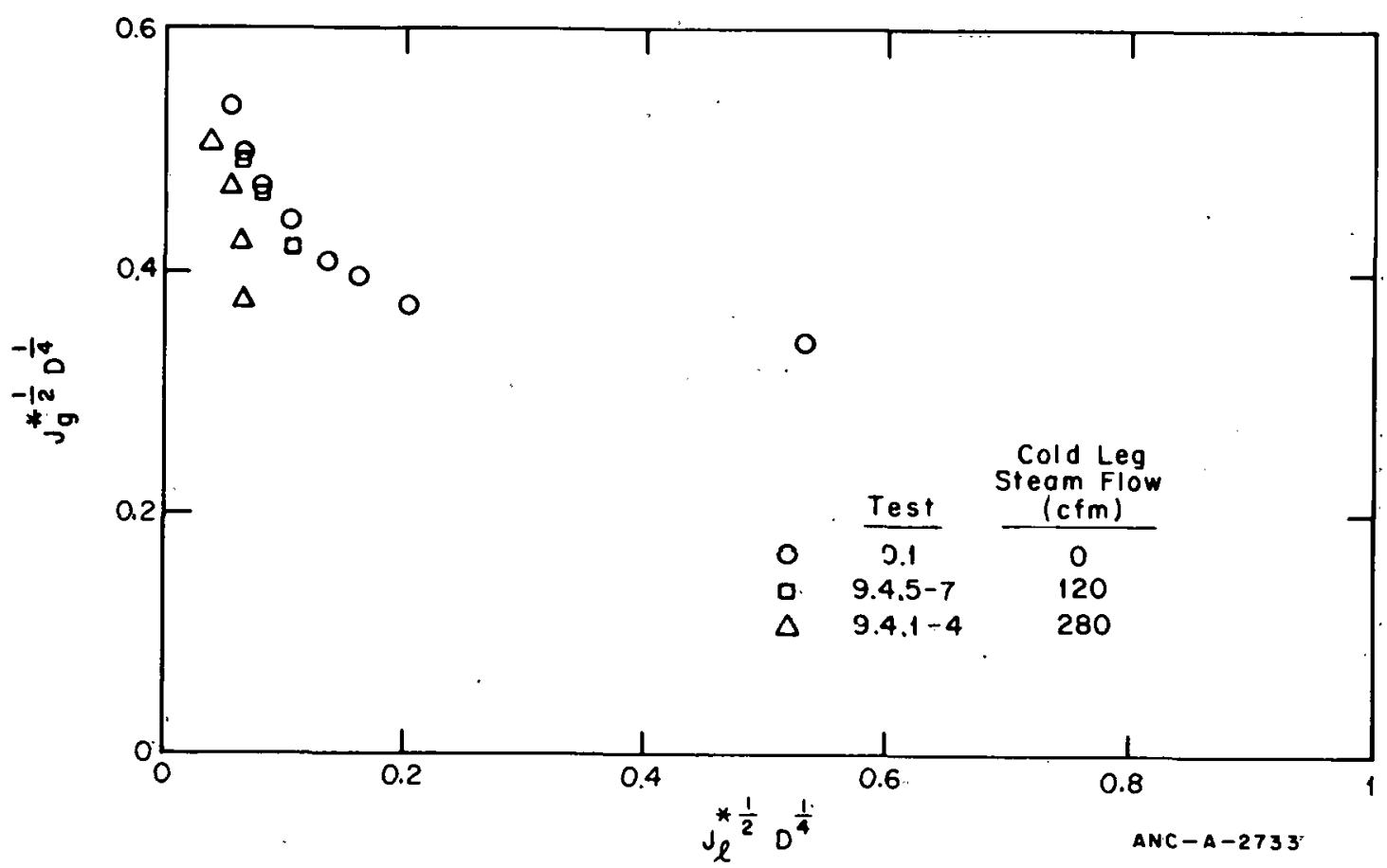

Fig. 53 Dimensioned fluxes for steady state semiscale system cold leg steam injection tests. with 1 -in. downcomer gap.

the hydraulic characteristics of the downcomer. The locations of instrumentation in the downcomer and lower plenum are shown in Figure 55. The control volume for a section of the annulus spanned by a differential pressure measurement is illustrated in Figure 56.

In the following analyses, thermodynamic equilibrium is assumed even though nonequilibrium conditions may occur during portions of the blowdown and ECC injection. The conservation of momentum equation considering one-dimensional flow and uniform density and velocity at the control surfaces (that is, homogeneous flow) is:

$-\left(P_{2}-P_{1}\right) A_{C}=-F_{S}+g \int_{C V} \rho d V+\left(\rho_{2} \dot{U}_{2}^{2}-\rho_{1} U_{1}^{2}\right) A_{c}+\frac{\partial}{\partial t} \int_{C V} U \rho d V$

where

$$
\begin{aligned}
& \mathrm{P}=\text { pressure } \\
& \mathrm{A}_{\mathrm{C}}=\text { cross-sectional area of the control volume } \\
& \mathrm{F}_{\mathrm{S}}=\text { control volume surface force } \\
& \mathrm{g}=\text { gravitational acceleration } \\
& \rho \quad=\text { density }
\end{aligned}
$$




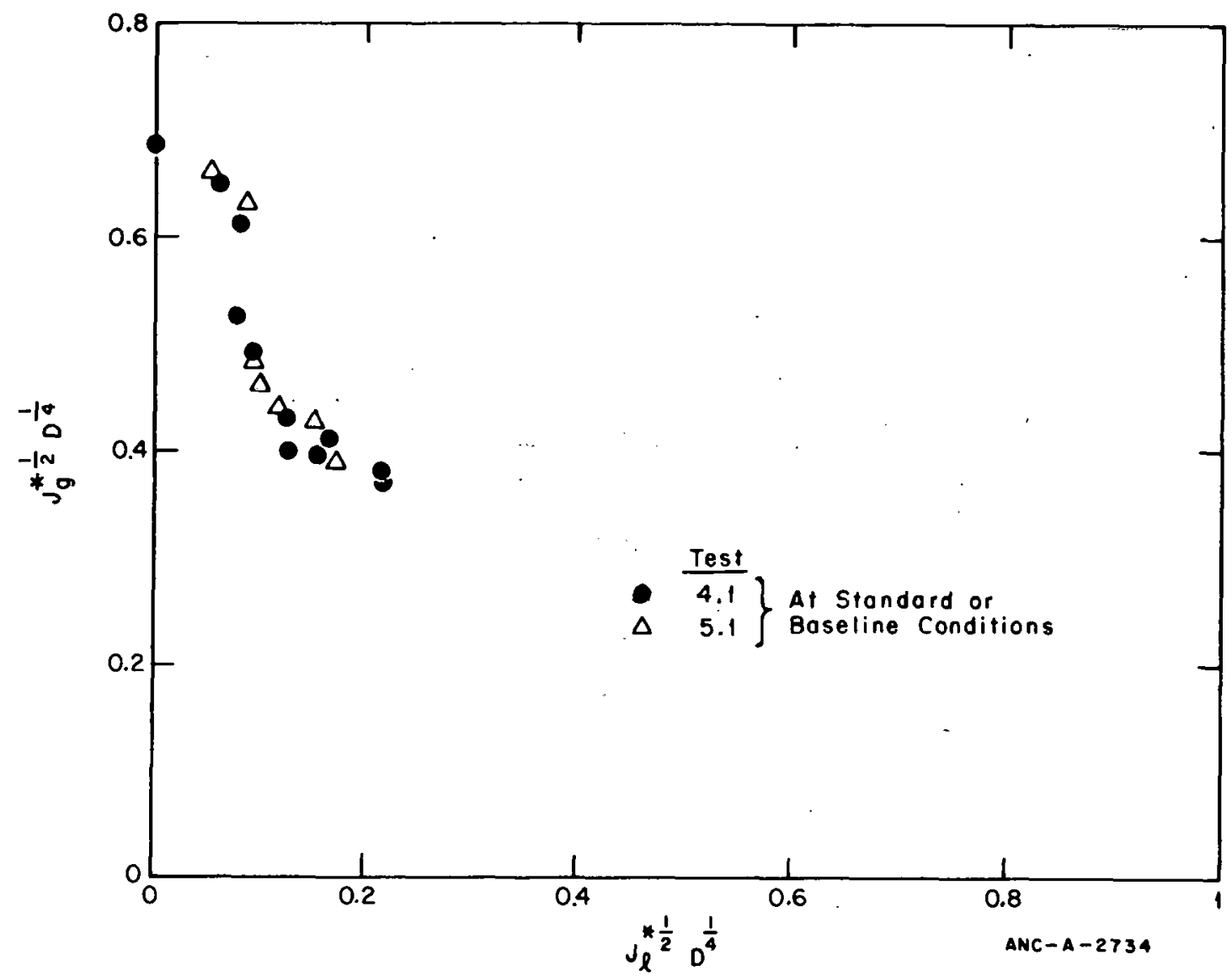

Fig. 54. Dimensioned fluxes for steady state semiscale system tests in which the order of establishing the initial steam and water flows was reversed.

$$
\begin{aligned}
& \mathrm{V}=\text { volume of the control volume } \\
& \mathrm{U}=\text { velocity of the fluid } \\
& \int_{C V}=\text { in tegration over the volume of the control volume }
\end{aligned}
$$

and subscripts 1 and 2 refer to the inlet and outlet of the control volume, respectively. Simplification of Equation (13) is necessary in order for the measured data to be used in evaluating the density of the fluid in the control volume. The velocity within the control volume is assumed to be uniform and the same for both the steam and the water. The average density for the control volume can be defined as

$$
\rho_{\mathrm{m}}=\frac{\int_{\mathrm{CV}} \rho \mathrm{dV}}{\mathrm{V}}
$$

The momentum equation becomes

$$
-\left(\mathrm{P}_{2}-\mathrm{P}_{1}\right)=\frac{2 \mathrm{C}_{\mathrm{f}} \rho_{\mathrm{m}} \mathrm{U}_{\mathrm{m}}{ }^{2} \mathrm{z}}{\mathrm{D}}+\mathrm{g} \mathrm{\rho}_{\mathrm{m}} z+\left(\rho_{2} \mathrm{U}_{2}{ }^{2}-\rho_{\mathrm{I}} \mathrm{U}_{\mathrm{I}}{ }^{2}\right)+\frac{\mathrm{d}}{\mathrm{dt}}\left(\mathrm{U}_{\mathrm{m}} \rho_{\mathrm{m}}\right) \mathrm{z}
$$




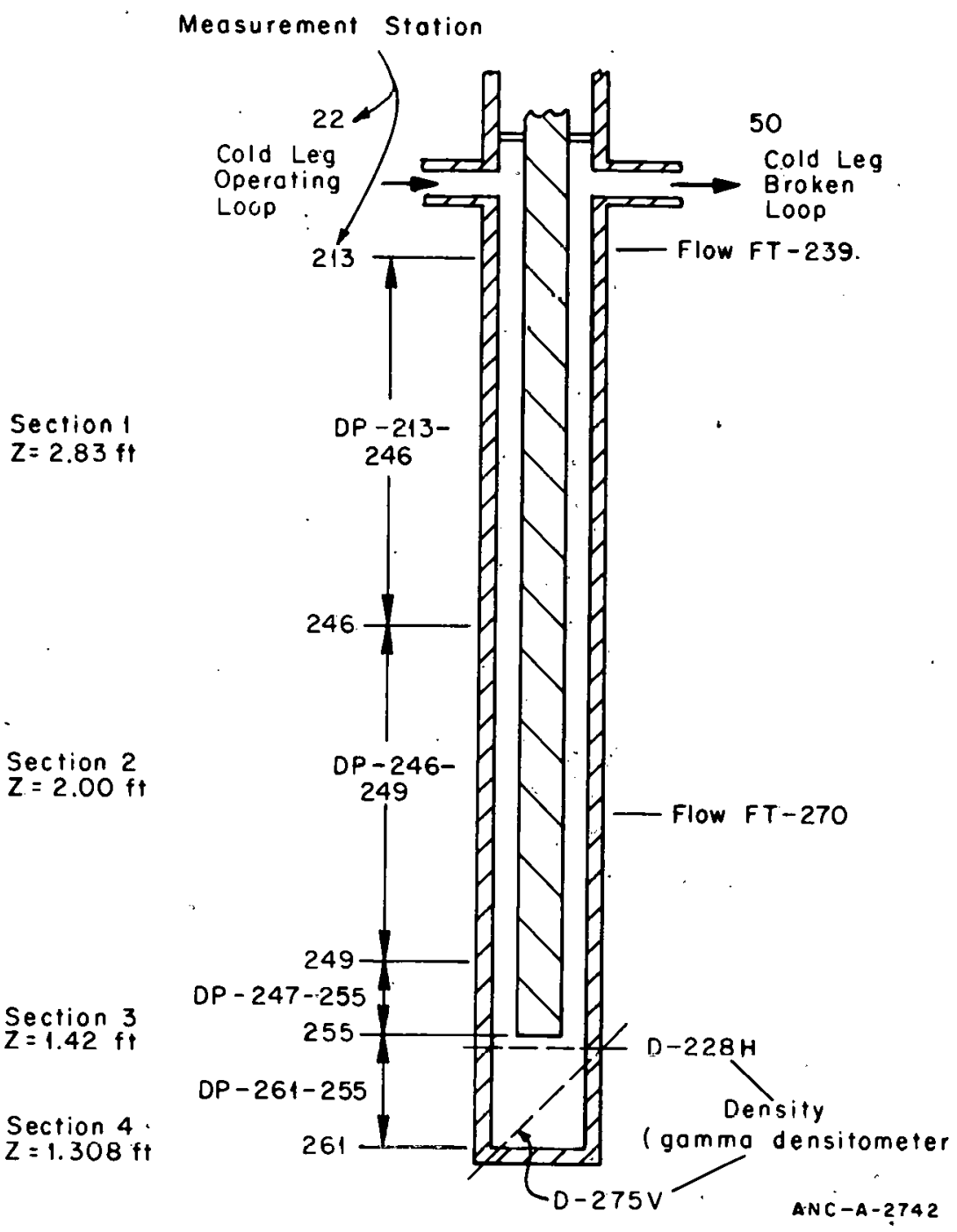

Fig. 55 Location of instrumentation in the downcomer and lower plenum. 
where

$$
\begin{aligned}
\mathrm{C}_{\mathrm{f}} & =\text { fluid friction factor } \\
\mathrm{D} & =\text { hydraulic diameter } \\
\mathrm{z} & =\text { control volume height }
\end{aligned}
$$

and the subscript $m$ denotes mean or average values. The difference between the momentum entering the control volume and that leaving the control volume $\left(\rho_{2} \mathrm{U}_{2}^{2}-\rho_{1} \mathrm{U}_{1}^{2}\right)$ is difficult to evaluate because local conditions are needed to evaluate the terms properly. However, since the difference between the momentum entering the control volume and that leaving the control volume is significant only when velocities become large and the average density is small, this term can be neglected in the calculation of the average

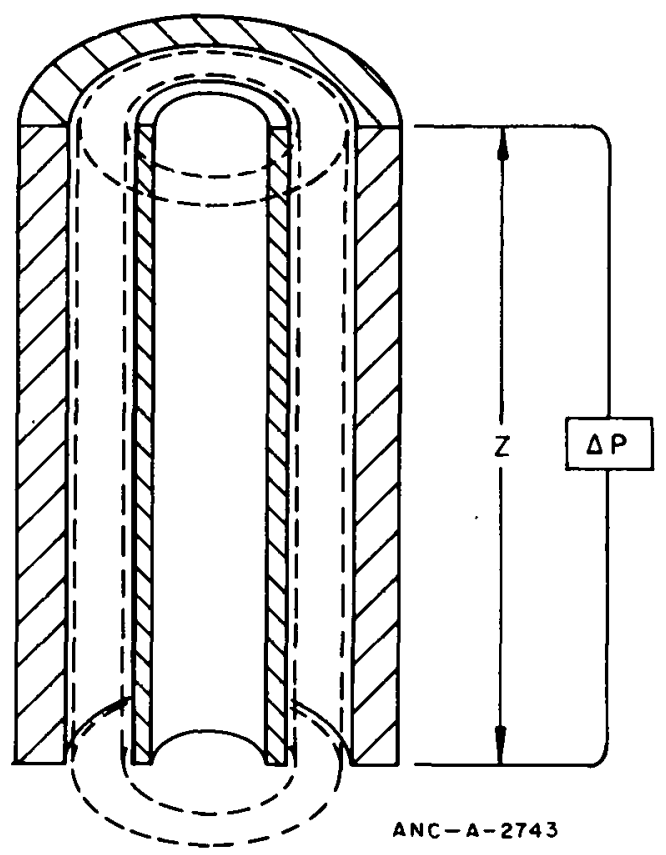

Fig. 56 Control volume for section of downcomer. density during the early portion of the blow-

down test and the later portion of the hot-wall tests. By assuming the time rate of change of momentum in the volume results from velocity variations rather than density changes, Equation (15) can be rearranged as

$$
\rho_{\mathrm{m}}=\frac{-\Delta \mathrm{P}}{2 \mathrm{C}_{\mathrm{f}} \mathrm{U}_{\mathrm{m}}^{2} z+g z+\frac{\mathrm{dU}}{\mathrm{dt}} z}
$$

The terms in the denominator of Equation (16), respectively, represent the contributions of the frictional forces, the gravitational forces, and the accelerational forces.

During the initial portion of a blowdown when the fluid velocity in the downcomer is low and the initial fluid accelerational forces have become small, Equation (16) reduces to the same solution as the basic momentum equation and, therefore, the calculated densities would be accurate. However, later in blowdown when velocities are high and the density is low, the density calculated from Equation (16) would not be accurate. The velocity and the measured density data indicate that the calculated density is accurate for about the first 15 seconds of a blowdown.

The average density was calculated from Equation (16) through use of experimental pressure and velocity data. Turbine flowmeters in the downcomer provided the characteristic velocities for the control volume. Once the average density was calculated, an average quality for the control volume could be defined on the basis of the known pressure or mixture temperature: 


$$
X=\left(\frac{\frac{1}{\rho_{m}}-v_{f}}{v_{g}-v_{f}}\right) \text {. }
$$

To evaluate the densities calculated from differential pressure measurements, the calculated densities in the lower plenum were compared with data obtained from density measurements in the lower plenum. Good agreement between calculated and measured densities would be expected in the lower plenum where the fluid dynamic forces are small compared to the gravitational forces. Figure 57 shows good agreement between calculated and measured lower plenum densities during Test. 1004 until ECC injection into the lower plenum at 22 seconds caused the mixture in the lower plenum to stratify as indicated by the rapid drop in the density at the top of the lower plenum as measured by the horizontal density measurement. The diagonal density measurement and the density calculated from the differential pressure both provide an average density over the control volume and are not capable of showing stratification of the steam-water mixture. The relatively poor agreement between these densities after 24 seconds is considered to result from an improperly installed differential pressure line which partially drained when stratification occurred.

Direct comparison of the calculated downcomer fluid densities with the measured downcomer fluid densities is not possible because density data are not available for the

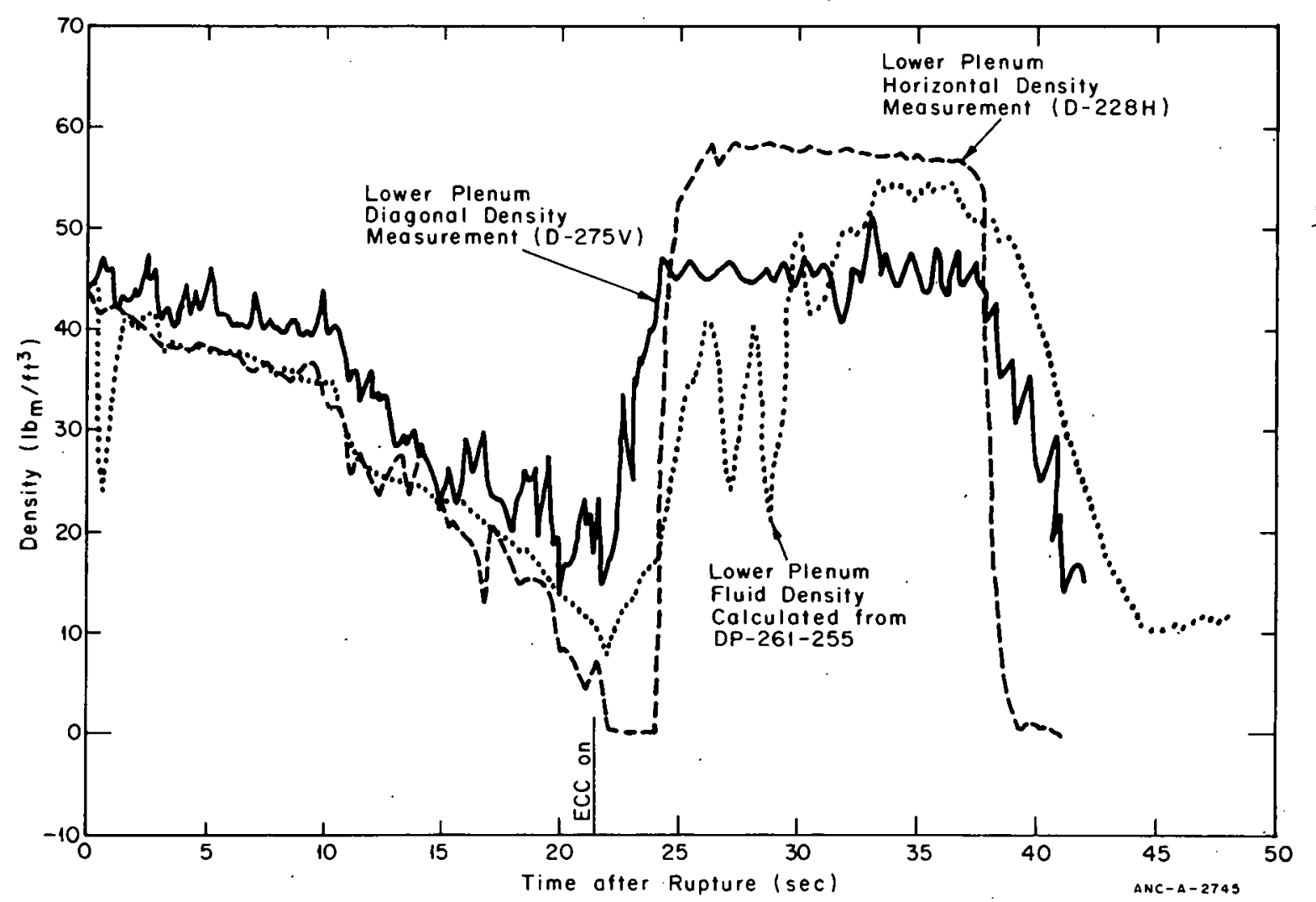

Fig. 57 Comparison between measured densities and density calculated from lower plenum differential pressure measurements -- Test 1004. 
downcomer, but a comparison with the calculated average upper annulus density is possible. The average density in the upper annulus was obtained by using the measured density and velocity data for the fluid near the vessel in the two cold legs by the method of calculating the mean density of the fluid in the upper annulus which was described in Section III-2.1. Plots of the typical calculated average density in the upper annulus and the density calculated by Equation (16) for downcomer Sections 1 and 2, shown in Figures 58 and 59, are for Test 1004 with ECC injection into the lower plenum and for Test 1010 without ECC injection. Figure 59 also shows the downcomer density as calculated by RELAP4. Figure 60 presents the densities of the downcomer fluid calculated from the differential pressure data and calculated by RELAP4 and the average density. of the fluid in the upper annulus calculated from the data for an isothermal test that included ECC injection, Test 1008.

An understanding of the behavior of the downcomer densities can be gained by examining the mass flows at the boundaries of the downcomer. A gross mass balance on the downcomer shows the rate of change in the average downcomer density to be proportional to the difference between the mass flow at the boundaries of the downcomer; that is,

$$
\frac{\mathrm{d} \rho_{\mathrm{d}}}{\mathrm{dt}}=\frac{\dot{\mathrm{m}}_{\text {in }}-\dot{\mathrm{m}}_{\text {out }}}{\mathrm{v}_{\mathrm{d}}} \text {. }
$$

An estimation of the flow at the top of the downcomer was made from a mass balance at the top of the downcomer (Section III-2.1). The flow at the bottom of the downcomer was not calculated directly but, for purposes of comparison, was assumed to be equal to the flow in the lower plenum at the bottom of the core barrel. This assumption is not entirely correct as a result of changes in the amount of mass stored in the lower plenum, but is considered to be sufficiently correct for demonstrating the behavior of the density in the downcomer.

The densities calculated using Equation (16) for downcomer Sections 1 and 2 are shown in Figure 61 and the calculated flow rate at the top of the downcomer and the measured' core mass flow rate which is the assumed flow rate at the bottom of the downcomer are shown in Figure 62. For the first 6 seconds of blowdown, the mass flow rate out the core is larger than the mass flow into the upper downcomer, and the mass loss is reflected in the negative slope of the time varying density curves. At about 6 seconds, however, the upper downcomer and core mass flow rate curves cross, indicating a net inflow within the downcomer. At about this same time, the slope of the density curves goes positive as a result of net inflow in to the downcomer. The mass flow rate curves cross again at about 10 seconds indicating a net outflow out of the downcomer has again begun, and this change is also reflected by the transient density slope again becoming negative. The phenomenon of the downcomer filling during the period in which the downcomer mass flow rate reverses direction was noted in all isothermal tests evaluated.

Comparison of the densities calculated using Equation (16) and the densities calculated from measurements near the upper annulus indicates that Equation (16) provides a reasonable calculation of the average downcomer density during the initial portion of the blowdown. Deviation of the densities calculated by Equation (16) from the actual average 


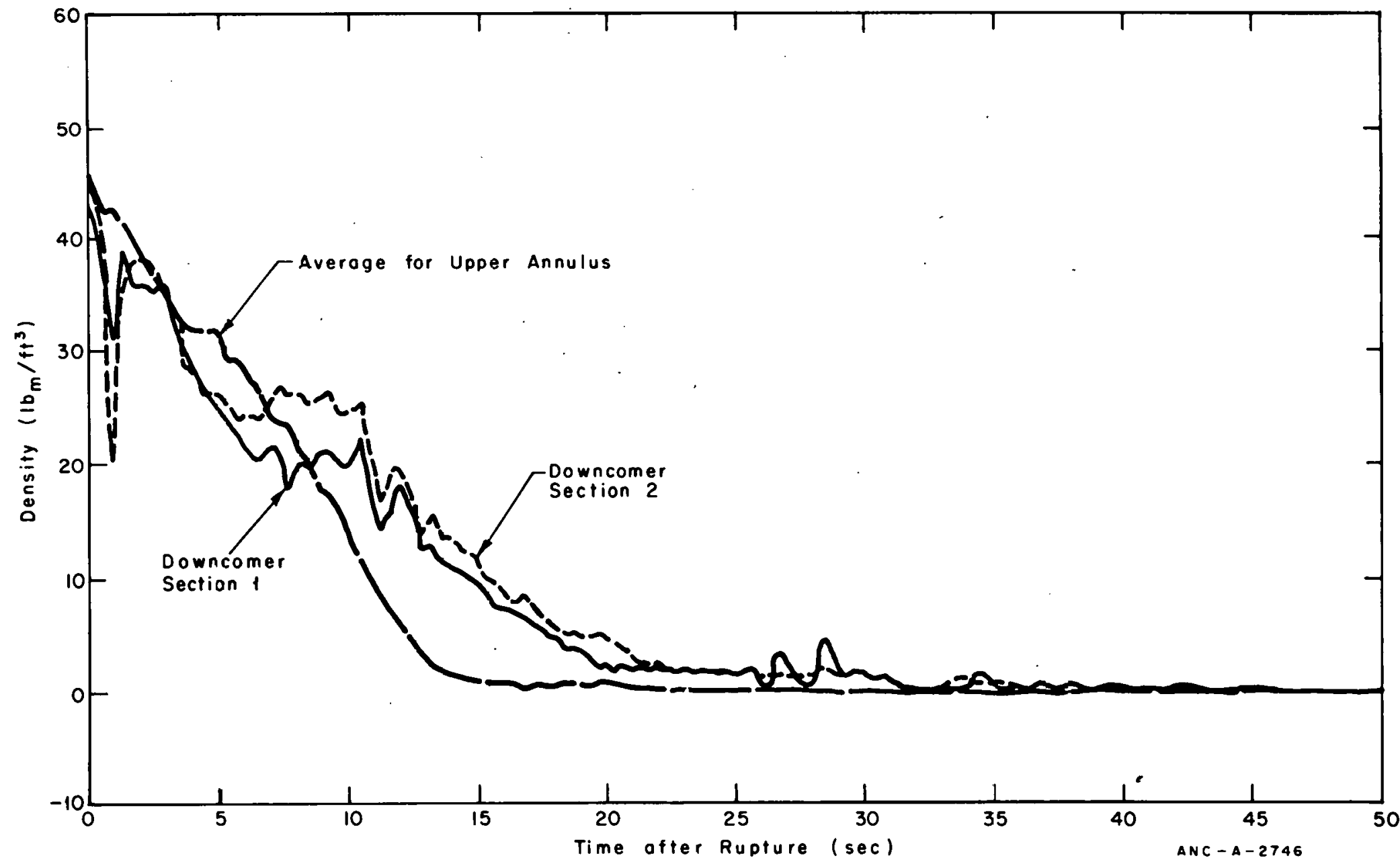

Fig. 58 Comparison between calculated densities in upper annulus and downcomer -- Test 1(104. 


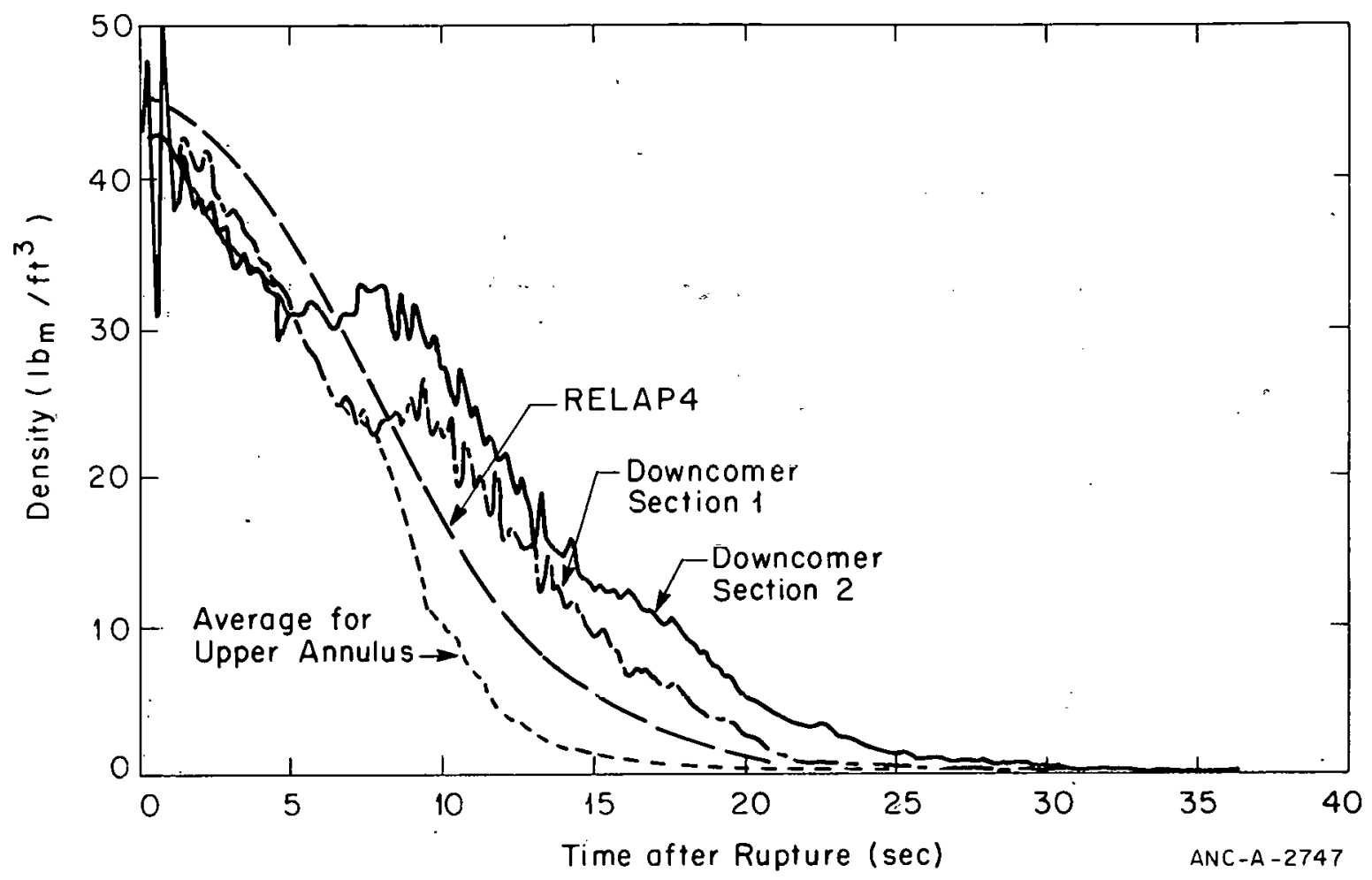

Fig. 59 Comparison between calculated densities in upper annulus and downcomer -- Test 1010.

downcomer density will occur when the dynamic forces become significant compared to the gravitational force - normally toward the end of blowdown when the mixture quality is high.

The axial variation in downcomer density can be estimated by comparing the densities calculated from the differential pressure measurements in Sections 1 and 2 of the downcomer. Relatively good agreement exists between the calculated densities for the two axial sections prior to downcomer flow reversal (about 6 seconds after rupture). After the downcomer flow reversal, the lower section (Section 2) densities are greater than the upper section densities indicating the presence of more water in the lower section. Figure 60 indicates good agreement between the densities in the axial sections prior to ECC injection, but a wide variation in the results after injection. After blowdown has ended, about 28 seconds after rupture, the upper section (Section 1) appears to alternately fill and void as a result of the countercurrent steam flow and the effects of the hot downcomer walls. Further discussion of the effects of hot downcomer walls is included in Sections III-3.3 and -3.4.

The densities in the downcomer calculated by RELAP4, as shown in Figures 59 and 60 , are in good agreement with the data for about the first 7 seconds of the blowdown period. After about 7 seconds, the densities calculated by RELAP4 are less than the 


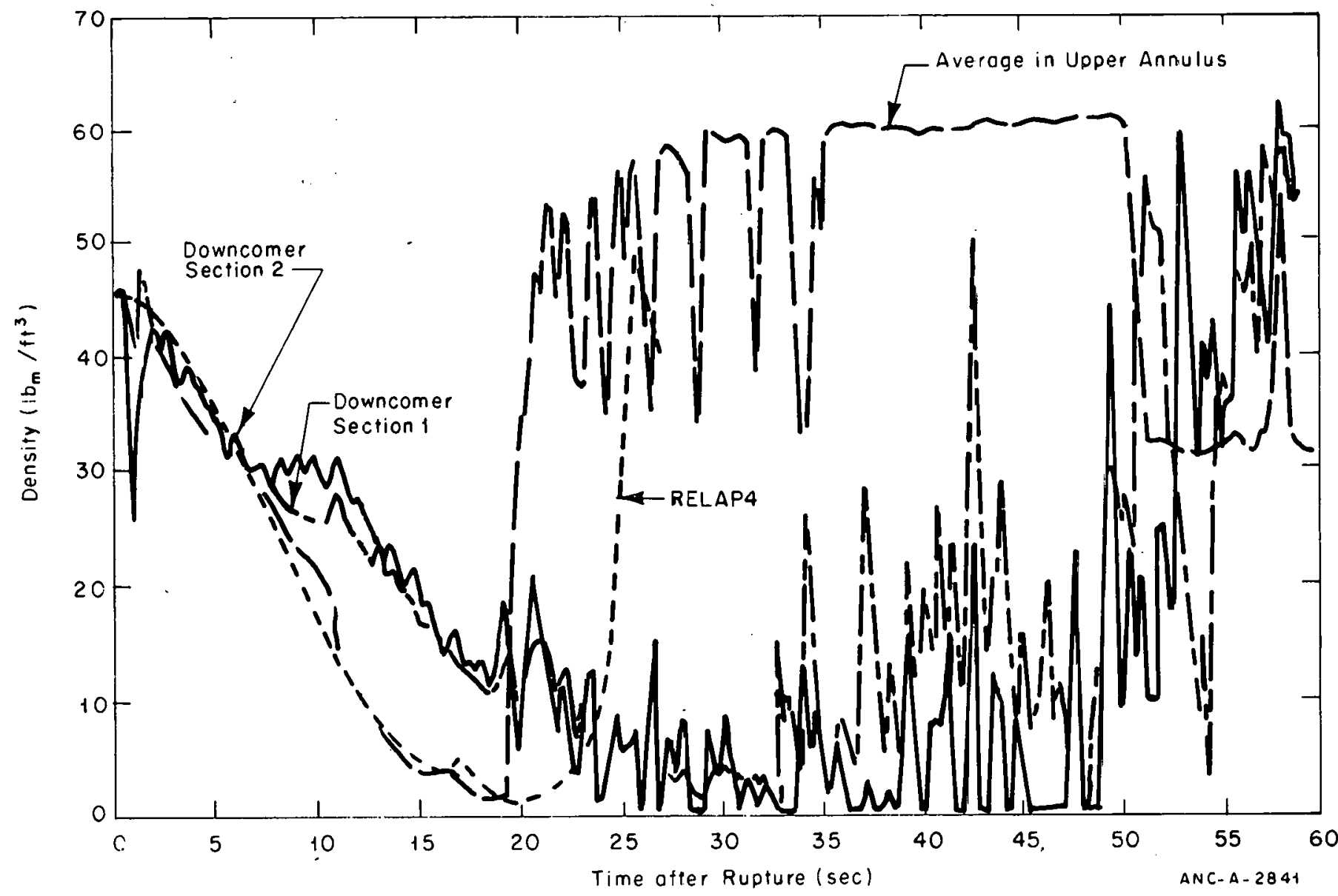

Fig. 60 Comparison between calculated densities in upper annulus and downcomer .. Test 1008. 


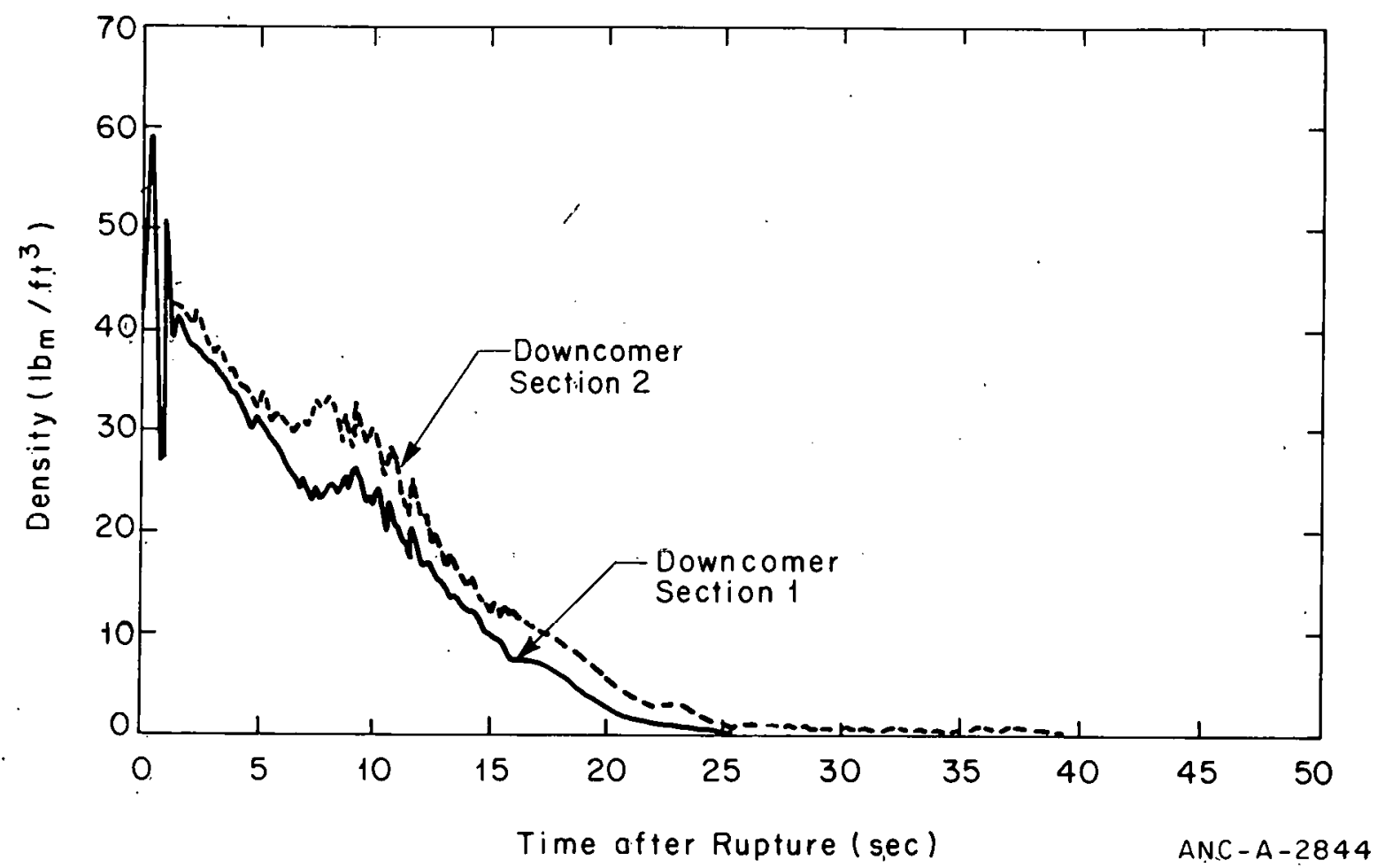

Fig. 61 Calculated densities in downcomer Sections 1 and 2 for Test 1010.

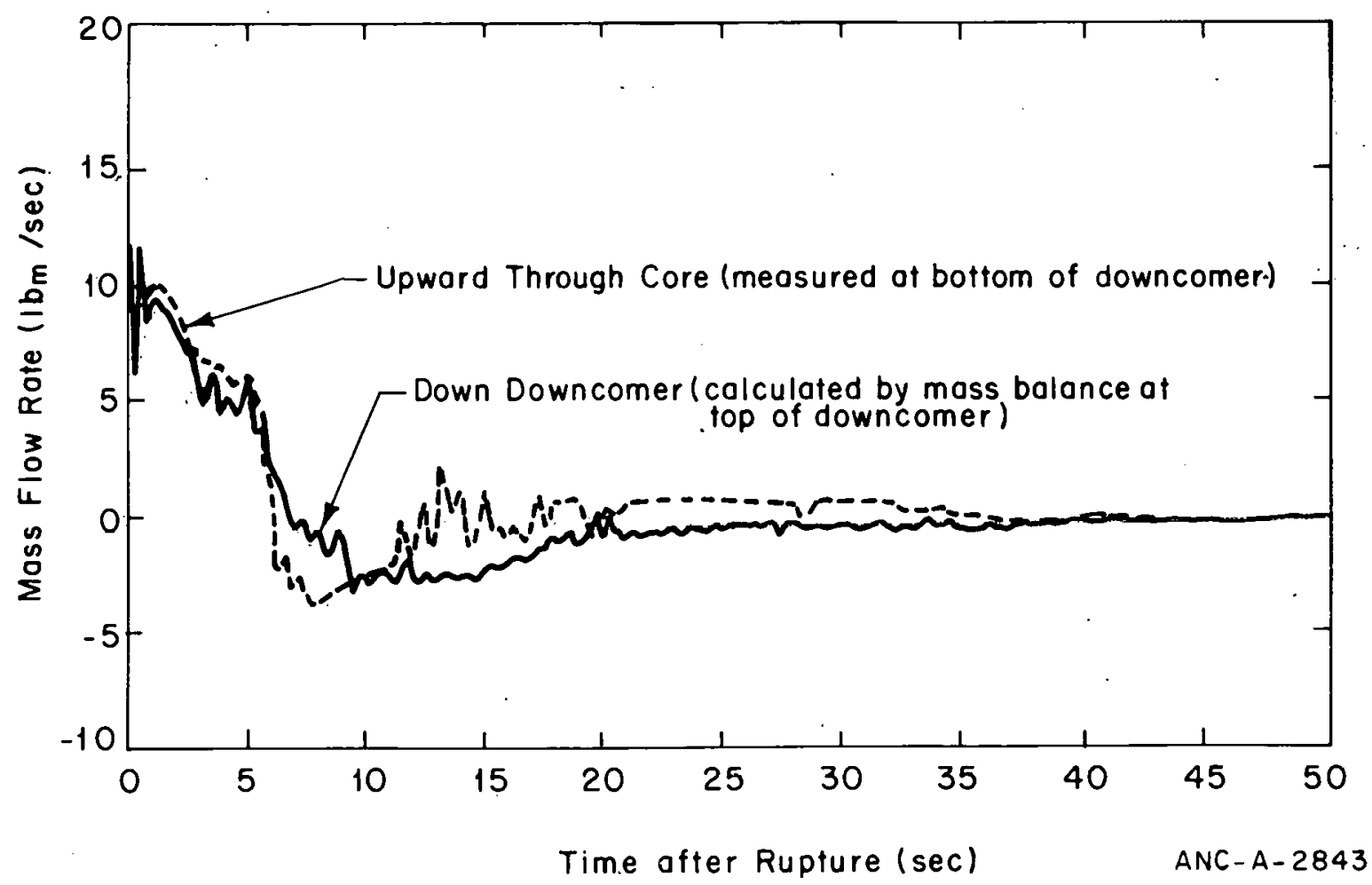

Fig. 62 Calculated flow rate at top of downcomer and measured core flow rate (bottom of downcomer) - Test 1010. 
densities calculated from the differential pressure data. The underestimation by RELAP4 of the downcomer density appears to result from the use of a homogeneous flow model of the downcomer and is discussed further in Section III-3.22. The sharp rise at about 25 seconds in the downcomer fluid density calculated by RELAP4 in Figure 60 indicates that RELAP4 is predicting that the downcomer is filling with water. The downcomer densities calculated by Equation (16) from the data do not show this large increase and indicates that RELAP4 is not properly simulating the effects in semiscale of countercurrent flow and hot downcomer walls.

3.22 Downcomer Velocity and Volumetric Flux. The velocity, at distinct points in the downcomer was measured by turbine flowmeters during some of the isothermal system blowdown and hot-wall tests. Since these turbine flowmeter data represent a local velocity measurement, for purposes of comparison, the average velocity was determined from the calculated mass flow rate at the top of the downcomer and the appropriate calculated density.

The countercurrent flow dimensioned volumetric fluxes were shown in Section III-3.1 to provide a means of correlating, for steady state conditions, the amount of water that reached the lower plenum as a function of the downcomer superficial gas velocity and density as well as the liquid density. The dimensioned fluxes for the transient isothermal blowdown and hot wall tests were calculated from the downcomer turbine flowmeter velocity data and the steam and liquid densities to provide a means of determining whether a relationship exists between the transient and the steady state countercurrent flow processes.

An average velocity at the top of the downcomer, $\mathrm{U}_{\mathrm{d}}$, can be determined from the calculated mass flow rate and the density at this position:

$$
\mathrm{U}_{\mathrm{d}}=\frac{\dot{\mathrm{m}}_{\mathrm{d}}}{\rho \mathrm{A}_{\mathrm{d}}}
$$

The calculated downcomer mass flow rate, presented in Section III-2.1, was used in Equation (19) along with either the calculated upper annulus density or the calculated downcomer density, depending on the direction of the flow. The average velocity for isothermal Test 1010, calculated by Equation (19) and the local velocity measured by a turbine flowmeter near the top of the downcomer, are presented on Figure 63. The turbine flowmeter did not indicate flow direction, but the initial velocity is shown negative because the initial flow is known to be negative. The turbine flowmeter indicates a possible change in flow direction when the measured velocity goes to zero. Since a flow reversal is known to occur in the early portion of the blowdown, the velocity reversal is shown to occur when the velocity is zero at about 7 seconds after rupture.

Agreement between the calculated average and measured local velocities does not appear to be good. An important discrepancy between the two velocities is the time difference indicated for flow reversal. For Test 1010, this difference is about 5 seconds and for other tests evaluated (isothermal Tests 1001, 1004, and 1008), the time difference is from 3 to 6 seconds. 


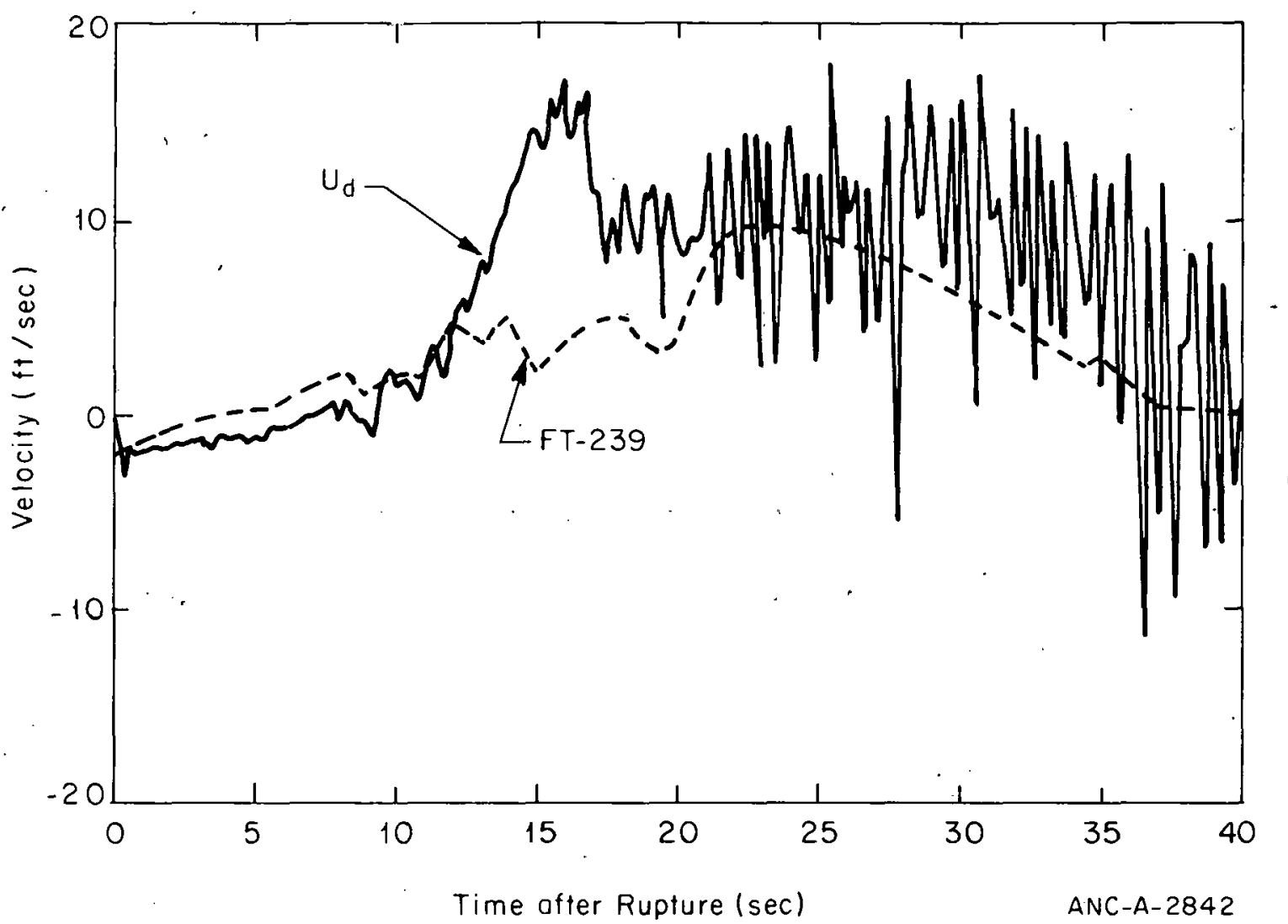

Fig. 63 Calculated average velocity and measured local velocity near the top of the downcomer .. Test 1010.

The velocity determined from the turbine flowmeter data and that calculated on the basis of mass continuity represent a locil velocity and an average velocity, respectively. The diameter of the downcomer turbine flowmeter is $3 / 8$ inch and the flowmeter was centered within the annular gap. It was therefore sensitive to the flow in the center of the downcomer and insensitive to flow near the downcomer walls. The sensitivity to flow in the center of the gap would be greater for the larger downcomer gap sizes. The net mass flow rate calculated from an overall mass balance, on the other hand, is not sensitive to variations of flow across the downcomer gap and is strongly weighed by the denser water flow. If the steam flows primarily in the center of the downcomer gap during blowdown, the measured velocity will be more representative of the high quality steam-water mixture, whereas the mass continuity analysis will be more representative of the net mass transfer rate. The time difference between the flow reversals may, therefore, represent a difference in the time at which the mixture in the center of the downcomer gap reverses directions compared to the time at which the net mass flow (steam plus water) reverses. For this situation, a countercurrent type flow would exist in the downcomer early in the blowdown period with a high density fluid near the walls continuing to flow downward for 3 to 5 seconds after the fluid in the center of the downcomer reverses direction and flows upward. The high density fluid near the walls would continue falling toward the lower plenum until the flow and pressure gradients in the downcomer cause this flow to reverse. This behavior is consistent 
with the rise of the measured density in the lower portion of the downcomer above the measured density in the upper section after downcomer flow reversal has occurred.

The RELAP4 calculation of densities in the downcomer were shown in Figures 59 and 60 to slightly overestimate the density during the first 7 seconds of blowdown and to underestimate the density for times later than 7 seconds. The homogeneous model of the fluid in the downcomer used by RELAP4 is not appropriate for the apparent nonhomogeneous flows observed from the downcomer data. The high density fluid flowing down the walls early in blowdown and the countercurrent flow following ECC injection cause the homogeneous densities calculated by RELAP4 to be in error.

The transient dimensioned volumetric flux in the downcomer both during the isothermal system blowdown and hot-wall tests was calculated using data from the downcomer turbine flowmeters and the saturated steam and water densities. The lurbine flowmeters, as discussed previously, appear to respond to the flow in the center of the annular gap and, therefore, the velocities measured by the turbine flowmeters were taken as the gas velocities. The saturated water and steam properties used in the calculations were evaluated from the measured pressure. The turbine flowmeter nearest the top of the downcomer was about 4 inches down into the downcomer. Therefore, the velocity at the top of the downcomer can be somewhat different from the measured velocity. For example, if the flow is upward and if steam is being generated at a rate greater than it is being condensed, the velocity measured from the turbine flowmeter will be slightly lower than the -velocity at the top of the downcomer.

A comparison between the magnitude of the transient dimensioned volumetric flux and the downcomer density can be used to indicate the magnitude of the volumetric flux that will keep water from entering the downcomer or that will expel water from the downcomer. The steady state countercurrent flow data indicated that the dimensioned volumetric flux needed to be less than 0.47 to 0.50 for water to begin flowing to the lower plenum.

Figure 64 shows the transient volumetric flux for isothermal Test 1008 during which ECC injection was initiated about 16 seconds following rupture. The calculated downcomer densities derived from differential pressure measurements are shown in Figure 60. At the start of ECC injection ( $t=15$ seconds) the downcomer flow increased sharply, possibly due to a lowering of pressure in the upper annulus produced by condensing of steam by the subcooled ECC. The density curves do not reflect any significant amount of mass being delivered to the downcomer at the beginning of $\mathrm{ECC}$ injection, but indicate a continual voiding. At 23 seconds, the density data indicate the downcomer emptied and the volumetric flux reached its maximum. The volumetric flux then began to decrease and apparently decreased sufficiently to allow water to penetrate the annulus from 27 to 29 seconds. Apparently water began entering the downcomer when the volumetric flux dropped below about 0.40 to 0.44 . Steam generation from the influx of water caused the volumetric flux to increase above about 0.40 , which was sufficient to eject the remaining water from the annulus. The volumetric fluxes indicate that chugging began at about 29 


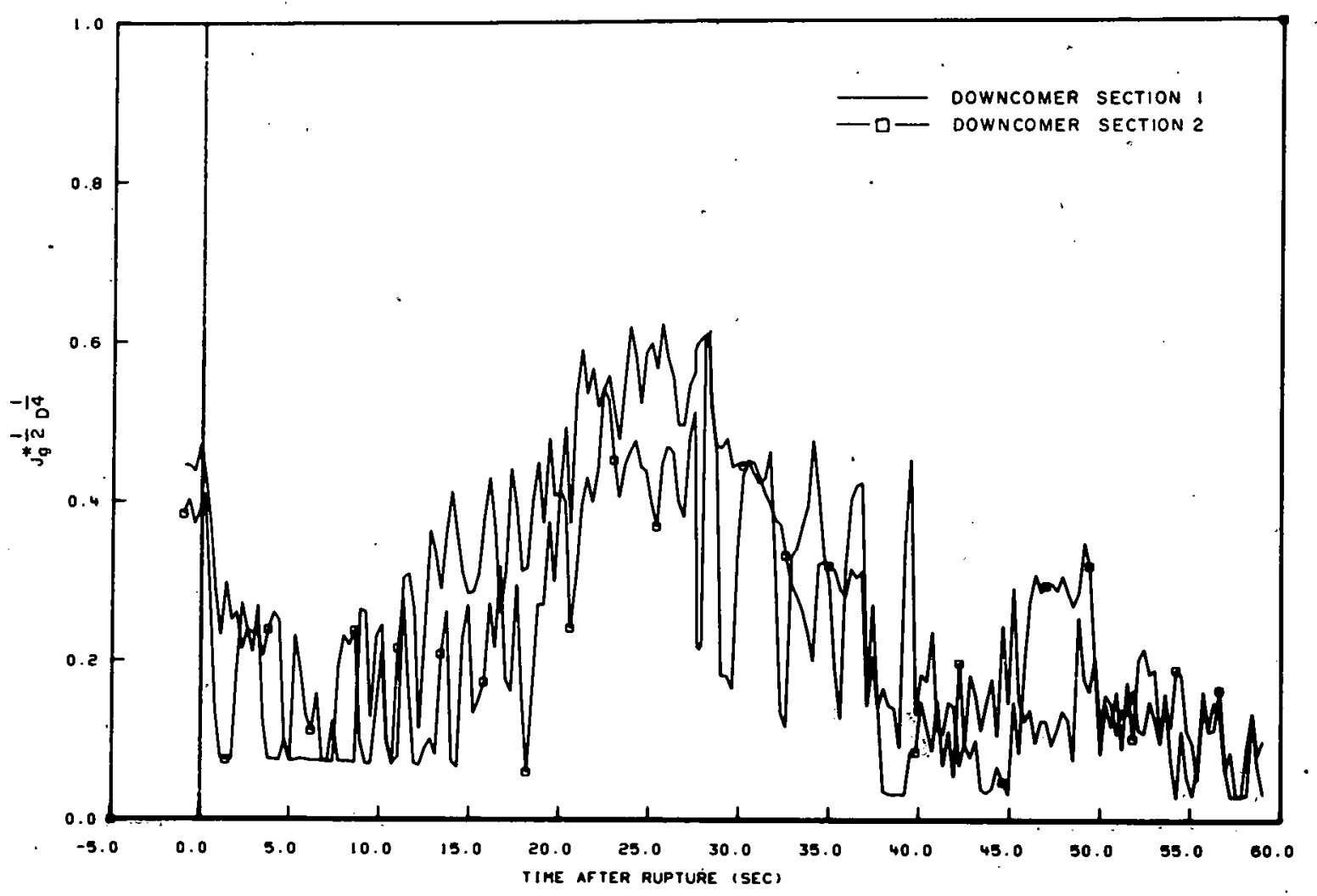

Fig. 64 Transient dimensioned volumetric flux -- Test 1008.

seconds with water alternately entering and being blown from the downcomer. The downcomer was completely filled at about 49 seconds. Since the downcomer turbine flowmeters would not indicate gas velocities after water had reached the flowmeter, the water would decrease the measured velocities and would, therefore, make the calculated volumetric fluxes incorrect. The effect of the water on the volumetric fluxes was probably greatest after about 30 seconds for the volumetric fluxes shown on Figure 64. The trends of the results presented in Figure 64 are similar to the trends observed for Test 1006 which was also a test with ECC injection.

The volumetric fluxes and downcomer densities calculated from hot-wall Test 15.3 data are presented in Figures 65 and 66, respectively. Comparison of the results presented on the two figures indicates that water alternately entered and was blown from the downcomer. The amount of chugging that occurred during the hot-wall tests is difficult to determine because the turbine flowmeters would not respond to the gas velocity once large quantities of water entered the downcomer and the calculated volumetric fluxes would not be accurate. As was exhibited by the results of Test 1008, nearly all the water appears to be blown from the downcomer when the calculated volumetric flux exceeds about 0.40 to 0.44 . These results were typical of those from the other hot-wall tests.

The steady state air-water countercurrent flow test results presented in Section III-3.1 indicated that no water would penetrate the downcomer when the dimensioned volumetric 


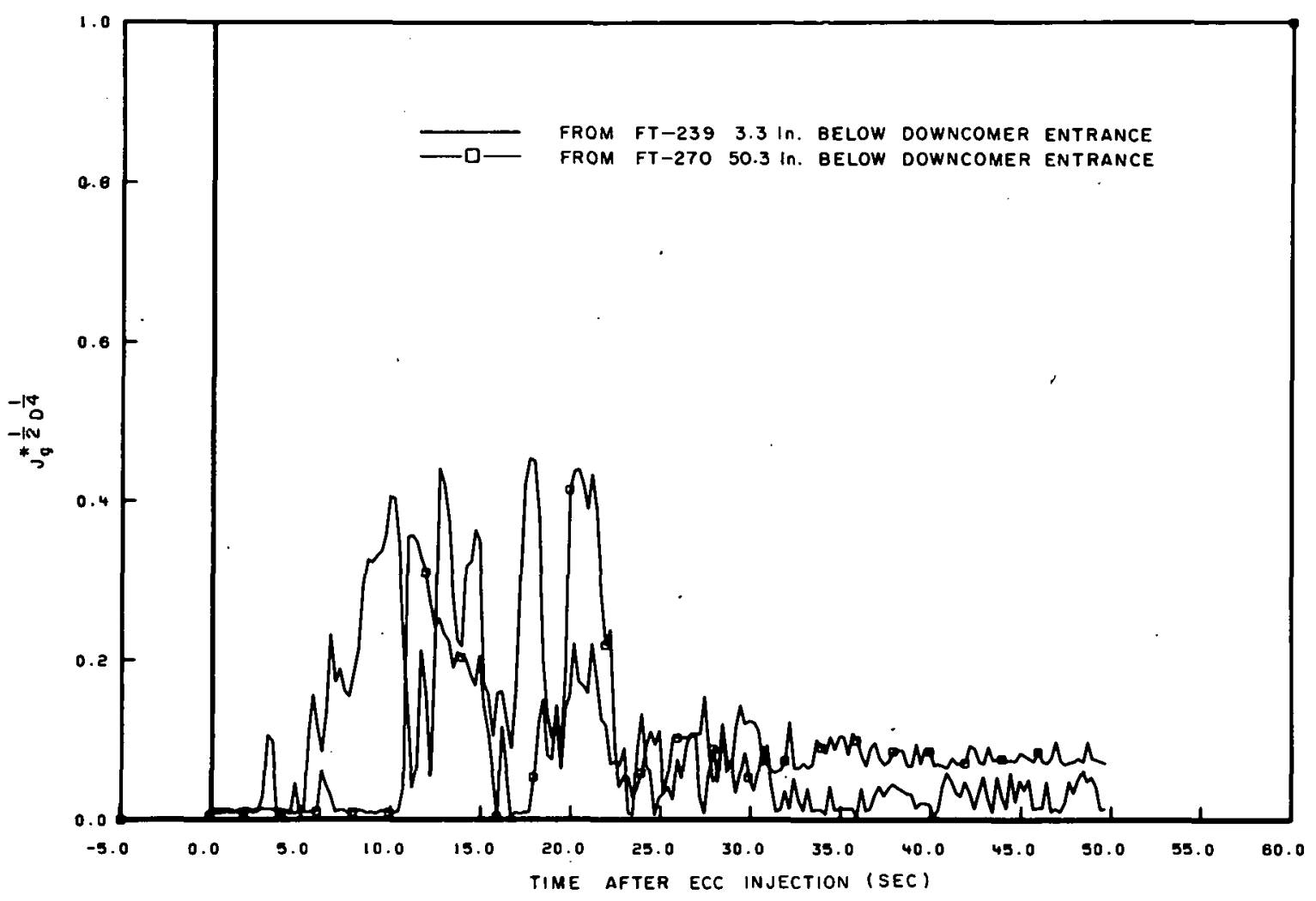

Fig. 65 Transient dimensioned volumetric flux .. hot-wall Test 15.3.

flux exceeded 0.47 to 0.50 (the ordinate intercept of the countercurrent flow curve). The calculated downcomer volumetric fluxes and the calculated densities presented for transient Tests 1008 and 15.3 indicate that all water is expelled or blown from the downcomer when the dimensioned volumetric fluxes exceed about 0.40 to 0.44 . Since the magnitude of the dimensioned volumetric flux at which water would begin to enter the downcomer is about the same for the steady state and transient tests, the steady state air-water countercurrent flow test results appear to provide a reasonable representation of the transient countercurrent flow data.

\subsection{Downcomer Heat Transfer}

The heat transfer rates in the isothermal and hot-wall test series were determined from an inverse heat conduction computer code, INVERS. INVERS calculated the surface heat flux and the wall surface temperature from the transicnt behavior of one of several temperature measurements at known locations in the vessel wall, filler piece, or core barrel by means of the inverse one-dimensional heat conduction solution. Heat transfer coefficients were calculated by using the calculated heat flux and the difference between the calculated surface temperature and the measured bulk fluid temperature. A brief discussion of the inverse conduction method used to calculate the heat fluxes and heat transfer coefficients is presented in Appendix A. 


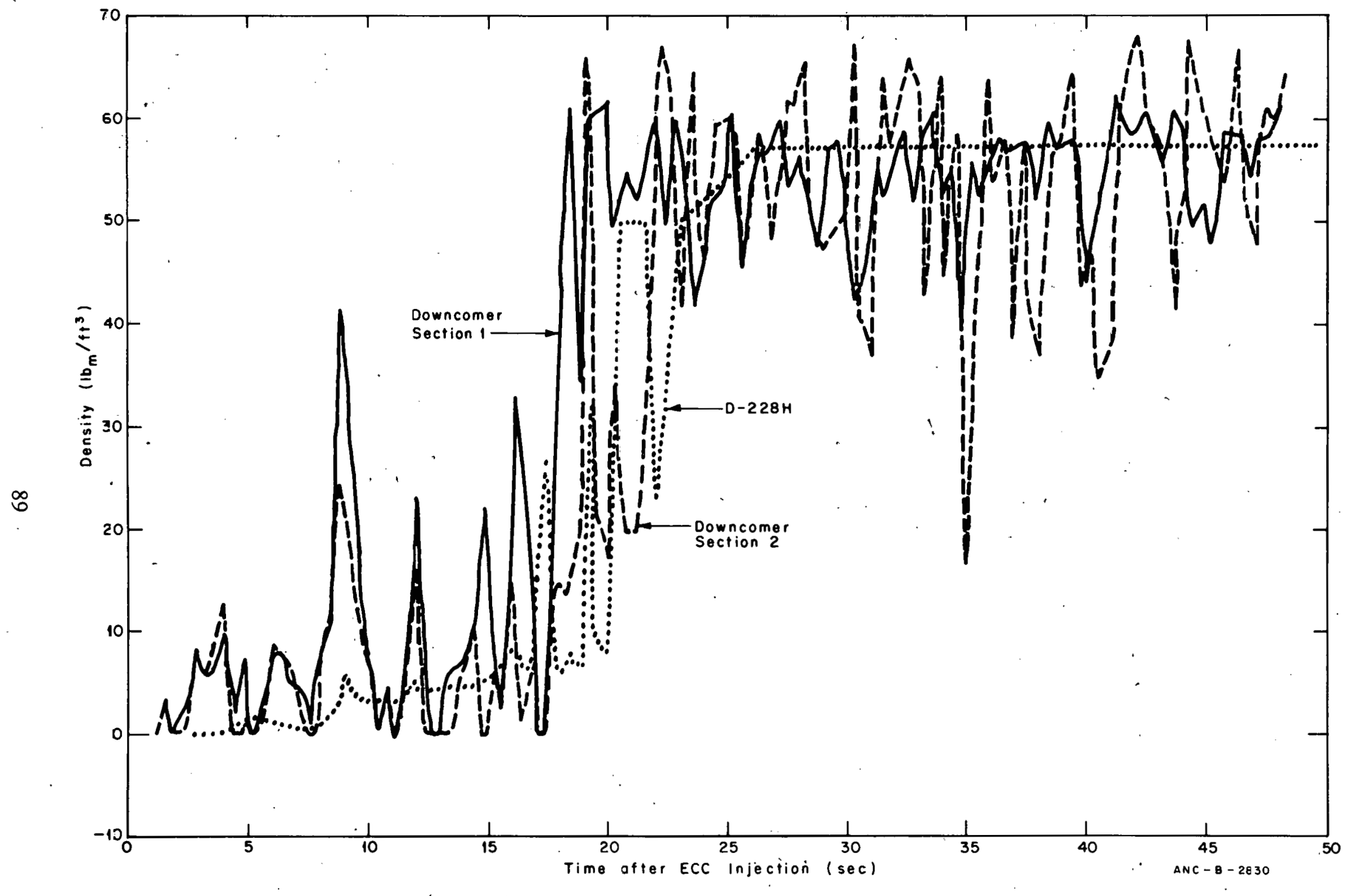

Fig. 66 Densities in the downcomer during ECC injection for hot-wall Test 15.3. 
The thermocouples used for measuring metal temperatures in the vessel filler piece and the core barrel were inserted in small, unsealed holes in these components. The unsealed thermocouple holes penetrating the metal appeared to be filled with water and the thermocouple appeared to be indicating the temperature of the water during the initial portion of the blowdown. Measurement of fluid temperature rather than metal temperature early in blowdown will cause some error in the heat flux calculations. Initial heat fluxes will be too high until the thermocouple hole dries out. After the thermocouple hole dries out the calculated heat flux is expected to approach the correct heat flux.

The preceding comment regarding the possible measurement of fluid temperatures rather than metal temperatures does not apply to isothermal blowdown Tests 1011 and 1009 and the hot-wall tests. During Tests 1011 and 1009, the thermocouples measuring the metal temperatures could not be wetted because they were not surrounded by water. During the hot-wall tests the thermocouple holes were initially dry and appear to have remained dry over the portion of the test that was of interest.

Figure 67 shows the downcomer surface heat fluxes calculated at several different locations for the vessel wall for Tests 1009 and 1011 and for the vessel filler piece for Test 1008. Tests 1008 and 1009 were initiated by $100 \%$ breaks and ECC was injected at about the same time and rate for both tests. Test 1011 was initiated by an $80 \%$ break and ECC was not injected. As previously discussed, the heat fluxes for Test 1008 may not be correct over the blowdown period, and the accuracy of these heat fluxes cannot be ascertained. A comparison of the calculated heat fluxes indicates a considerable difference between the heat fluxes for the different tests. The heat fluxes at equivalent locations from Tests 1008 and 1009 are generally higher than the heat fluxes from Test 1011 because the ECC injected during Tests 1008 and 1009 lowered the quality of the fluid in the downcomer, thereby increasing the heat transfer and because the more rapid depressurization that results from the larger break sizes and ECC injection during Tests 1008 and 1009 cause larger downcomer wall-to-fluid temperature differences which also cause more heat transfer.

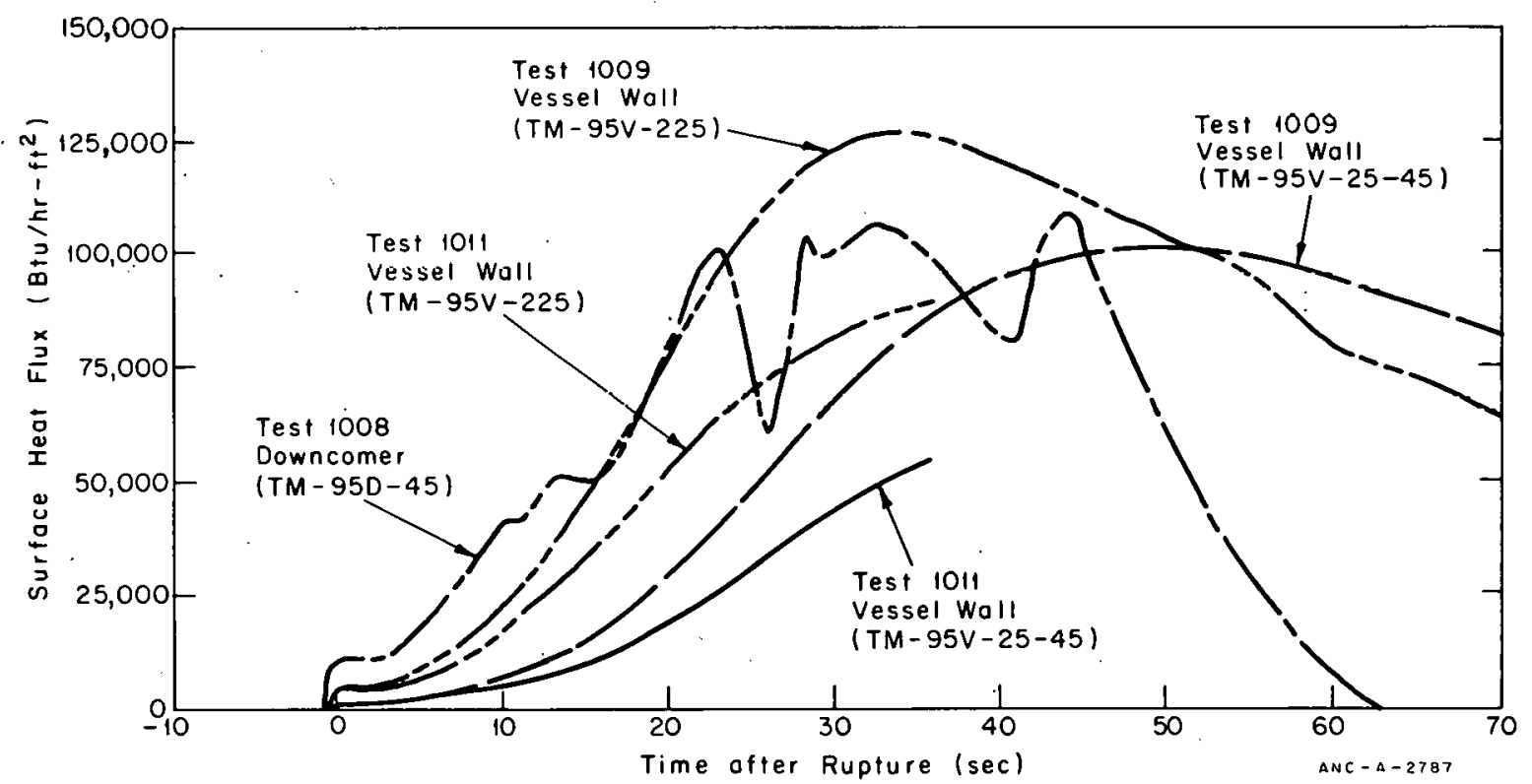

Fig. 67 Downcomer surface heat fluxes calculated by INVERS. 
Eonsiderable differences exist even between calculated heat fluxes at different axial locations from the same test. The surface heat fluxes and heat transfer coefficients are presented for Test 1.011 in Figures 68 and 69. Also included for comparison are calculated values from RELAP4 and a calculated heat flux using Thom's flow boiling correlation [11] used in a conduction model with measured fluid temperature as a boundary condition. Considerable axial and azimuthal variations in energy transfer are indicated by the data

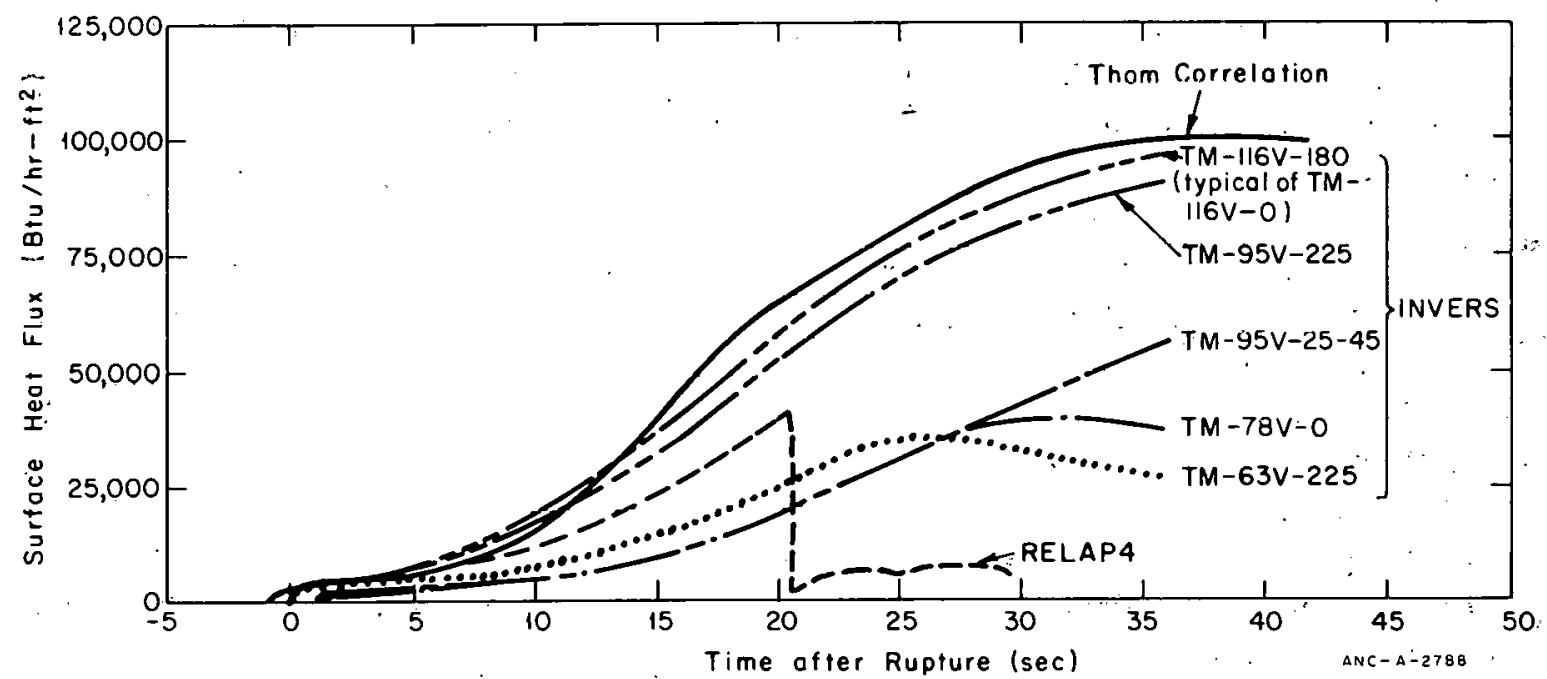

Fig. 68 Calculated downcomer surface heat fluxes for Test 1011 :

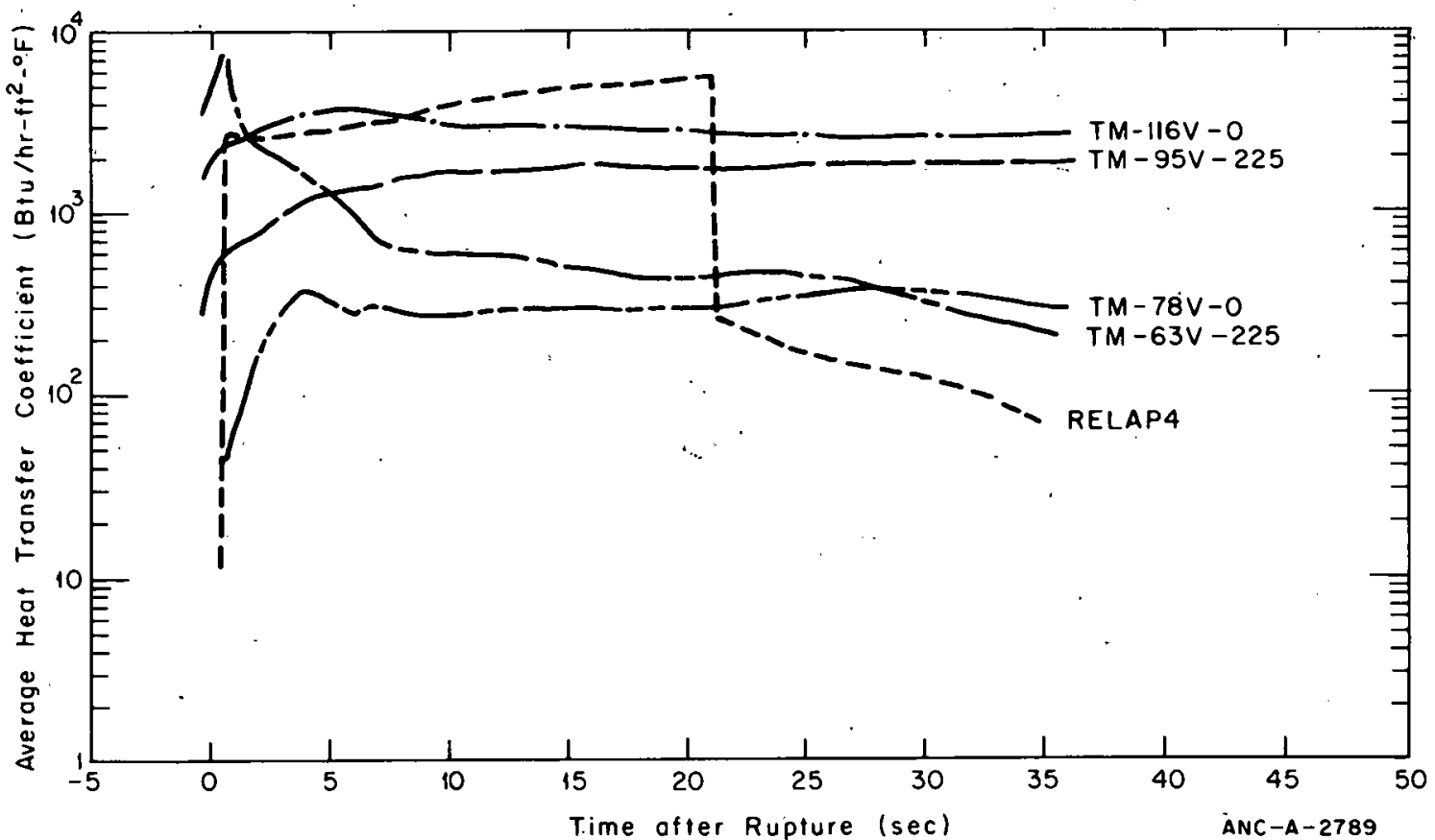

Fig. 69 Calculated downcomer heat transter coefficients for 'l'est 1011. 
during the test. The larger heat fluxes occurring near the bottom of the vessel $(116 \mathrm{~V}$ and $95 \mathrm{~V}$ locations) may result from nucleate boiling which is caused by the tendency of water to collect in the lower regions of the vessel. The nucleate boiling mechanism may become suppressed at the higher downcomer regions due to higher fluid quality in these regions with a lower energy transfer resulting from convective vaporization and a drying out process. The azimuthal variation in energy transfer is seen to exist at the location for TM-95V-225 and TM-95V-25-45. The calculated wall heat flux for TM-95V-255 is about twice the heat flux on the opposite side of the vessel. This large difference in heat fluxes at the $95 \mathrm{~V}$ locations was also noted for Test 1009 for which the same temperature measurements were used. No thermal or hydraulic explanation can presently be given for the large azimuthal variation in heat flux at this location.

The RELAP4 calculation for Test 1011 (Figure 68) during the first 20 seconds stays above the transient heat flux calculated by INVERS for the upper region of the downcomer, and below the INVERS calculation for the lower region. At approximately 20.5 seconds, RELAP4 switches from the Thom flow boiling correlation to a convective vaporization correlation and the RELAP4 calculated heat fluxes fall well below those determined from the data. The INVERS calculation using downcomer fluid data and the Thom flow boiling correlation provide a fair estimate of the heat transfer rate from the vessel wall in the lower part of the downcomer as would be expected if the heat transfer was from a nucleate boiling process.

Figures 70 and 71 show the calculated surface heat flux and heat transfer coefficients for axial positions in the downcomer for Test 1009 during which ECC was injected at about 17 seconds following rupture. As for Test 1011, the calculated heat fluxes evaluated from Test 1009 data in the upper region of the downcomer are the same magnitude, and the heat fluxes for positions in the lower region of the downcomer are significantly higher than the heat fluxes calculated for the upper positions.

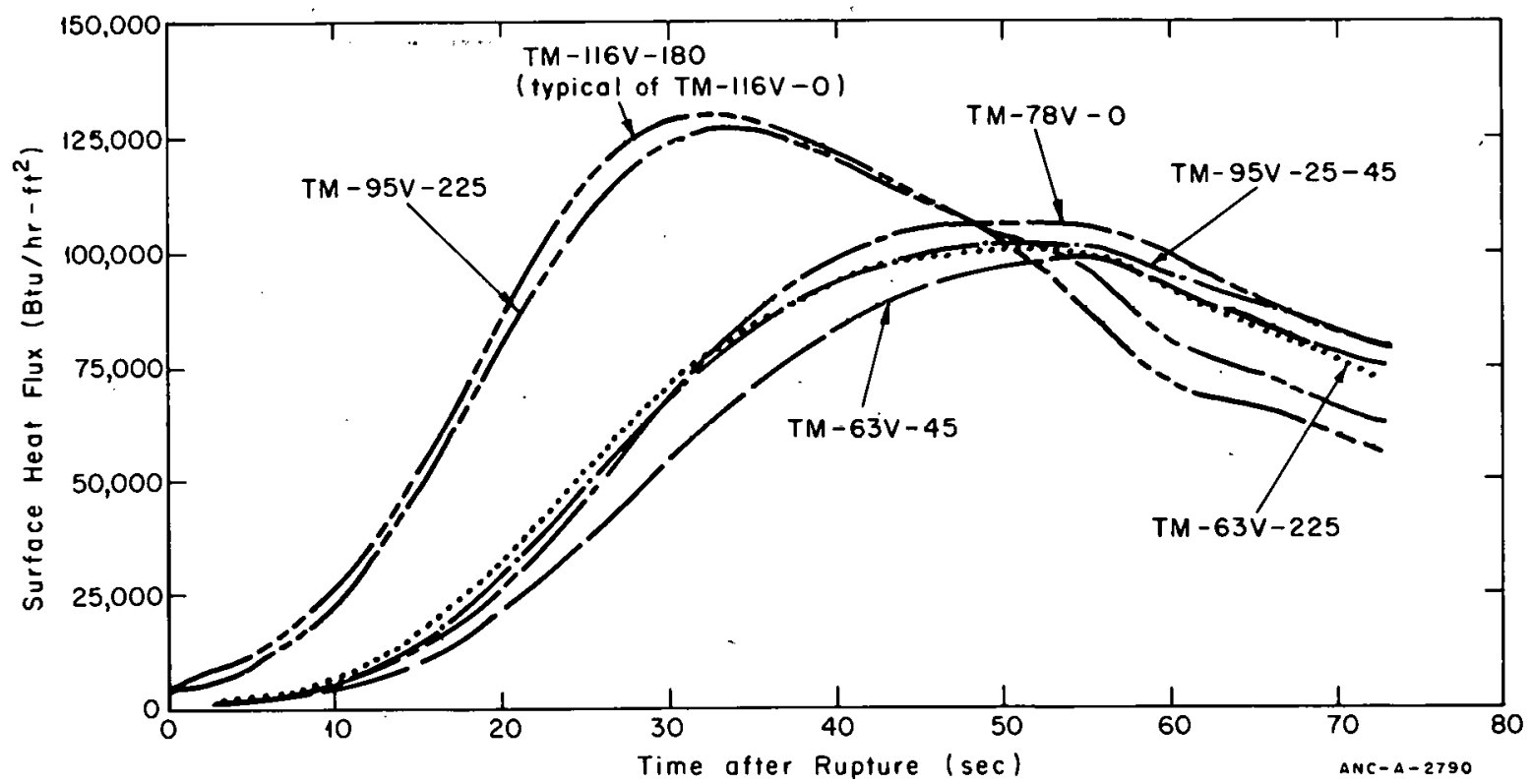

Fig. 70 Calculated downcomer surface heat fluxes for Test 1009. 


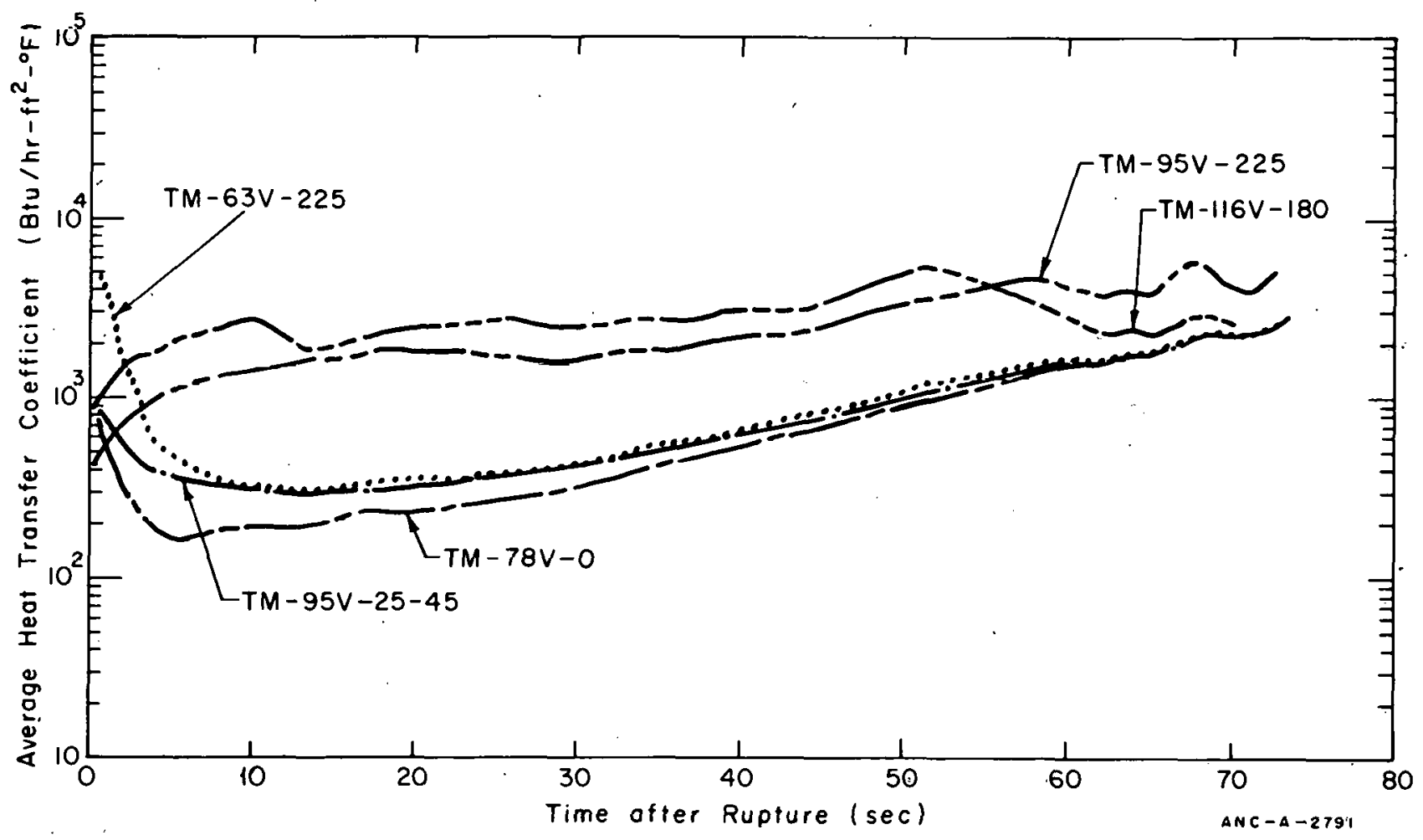

Fig. 71 Calculated downcomer heat transfer coefficients for Test 1009.

Early in the blowdown, the calculated heat transfer coefficients for Test 1009 exhibit a large spread between positions in the upper portion of the downcomer (TM-63V-225, TM-78V-0, and TM-95V-25-45) and positions in the lower portion of the downcomer (TM-95V-225, TM-116V-180). The heat transfer coefficients at the lower positions have about the same magnitude as typical nucleate boiling heat transfer coefficients whereas the heat transfer coefficients at the upper positions are more representative of transition boiling or convective vaporization heat transfer coefficients. As the blowdown progresses, the heat transfer coefficients at the upper positions approach the heat transfer coefficients at the lower positions indicating that the injected ECC decreases the quality of the fluid at the upper positions which improves the heat transfer mode. This trend of the heat transfer coefficients at the upper positions increasing as the blowdown progresses is not observed for Test 1011 (Figure 69) because Test 1011 did not include ECC injection.

Wall heat fluxes were calculated for the isothermal Test Series 15 hot-wall tests. Figures 72 and 73 show the calculated heat fluxes at various axial downcomer locations during Test 15.1. The results presented in Figure 72 show the calculated heat fluxes at locations that are either vertically in line with the intact loop cold leg inlet or 45 degrees clockwise from the cold leg, and the results presented in Figure 73 show the calculated heat fluxes at locations that are either vertically in line with the simulated broken leg or 45 degrees clockwise from the cold leg. For positions immediately below the intact loop cold leg (TM-48D-0), Figure 72 shows an immediate increase in heat flux whereas at the lower positions heat fluxes remain low. A short time after the increase in heat flux is indicated at 


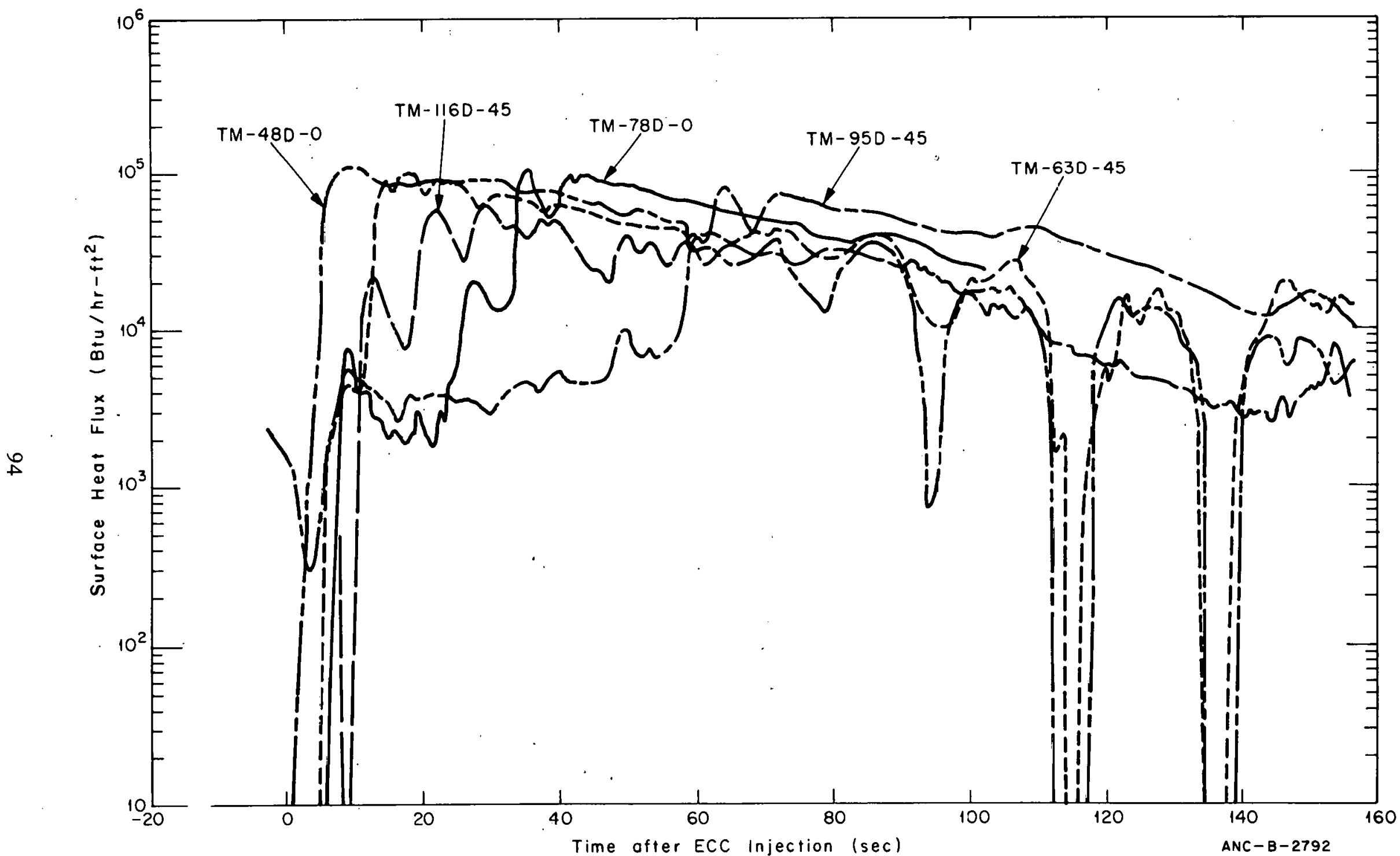

Fig. 72 Calculated surface heat fluxes from the intact loop side of the downcomer during hot-wall Test 15.1. 


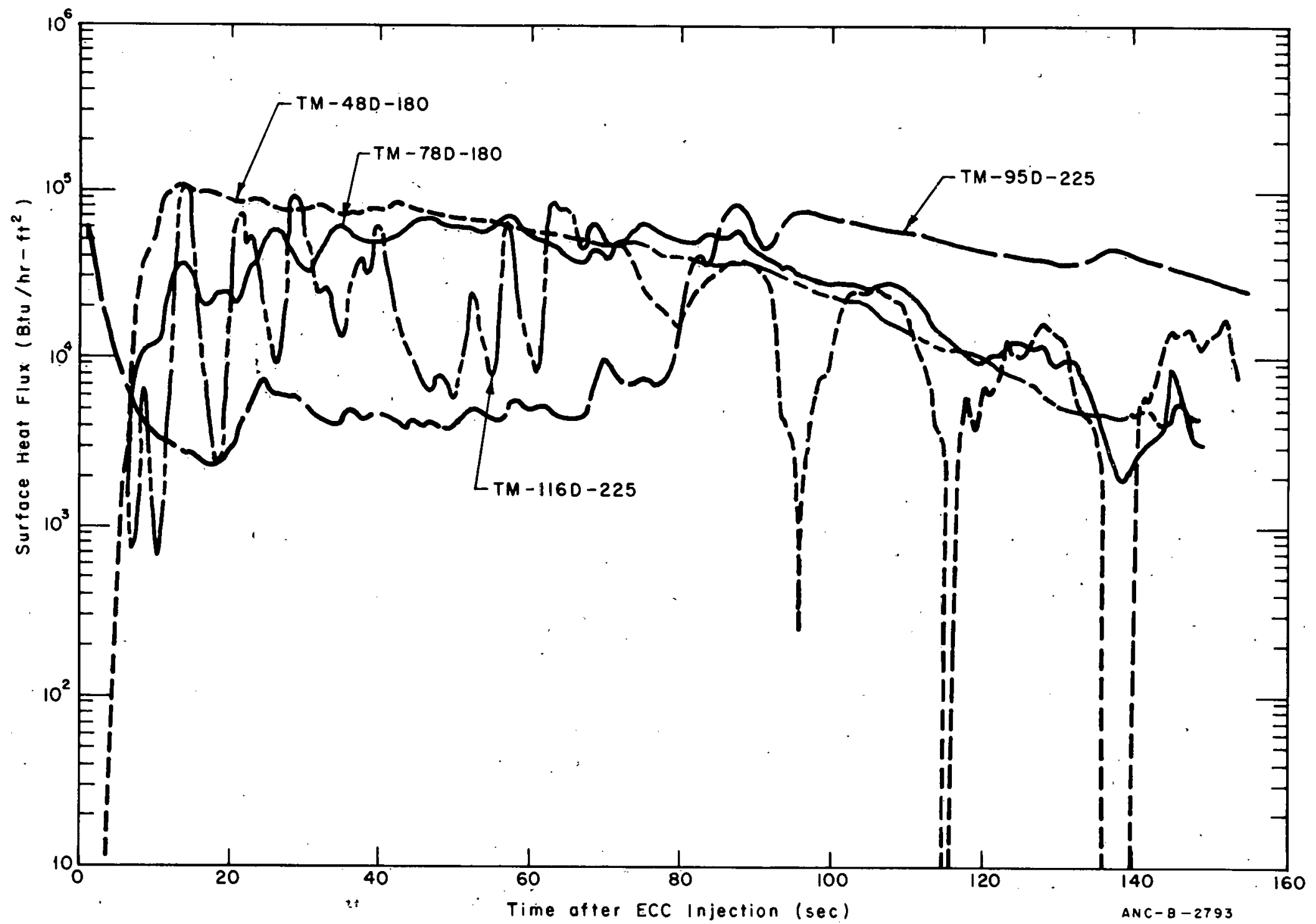

Fig. 73 Calculated surface heat fluxes from the broken loop side of the downcomer during hot-wall Test 15.1. 
the upper position an increase is evidenced at the next lower position (TM-63D-45). The trend of the upper positions in the downcomer cooling before the lower positions indicates that a wetting front progressed down the axial length of the downcomer causing progressive cooling. This trend of a progressing wetting or cooling front is not indicated as strongly in the wall heat fluxes calculated for positions below the broken loop cold leg and presented in Figure 73. At the middle and lower axial positions the results are more nearly typical of the wall being alternately wetted and dried. The alternate wetting and drying is considered to result from chugging of the water which the calculated densities of Section III-3.2 indicated was occurring during the hot-wall tests. The differences observed in the behavior of the opposite sides of the downcomer indicate that more water is available for cooling the wall opposite the intact loop cold leg and, therefore, that the flow of water in the downcomer region is not equally distributed axially or radially.

For hot-wall tests with larger downcomer radial gaps, the data indicate that the possibility of a progressive wetting front controlling the time at which the lower positions wet is diminished. The calculated heat fluxes for the hot-wall test (Test 15.4) with the largest downcomer gap (1.69 inches) tested are shown in Figure 74. A comparison of the calculated heat fluxes from different axial positions indicates that all axial locations exhibit

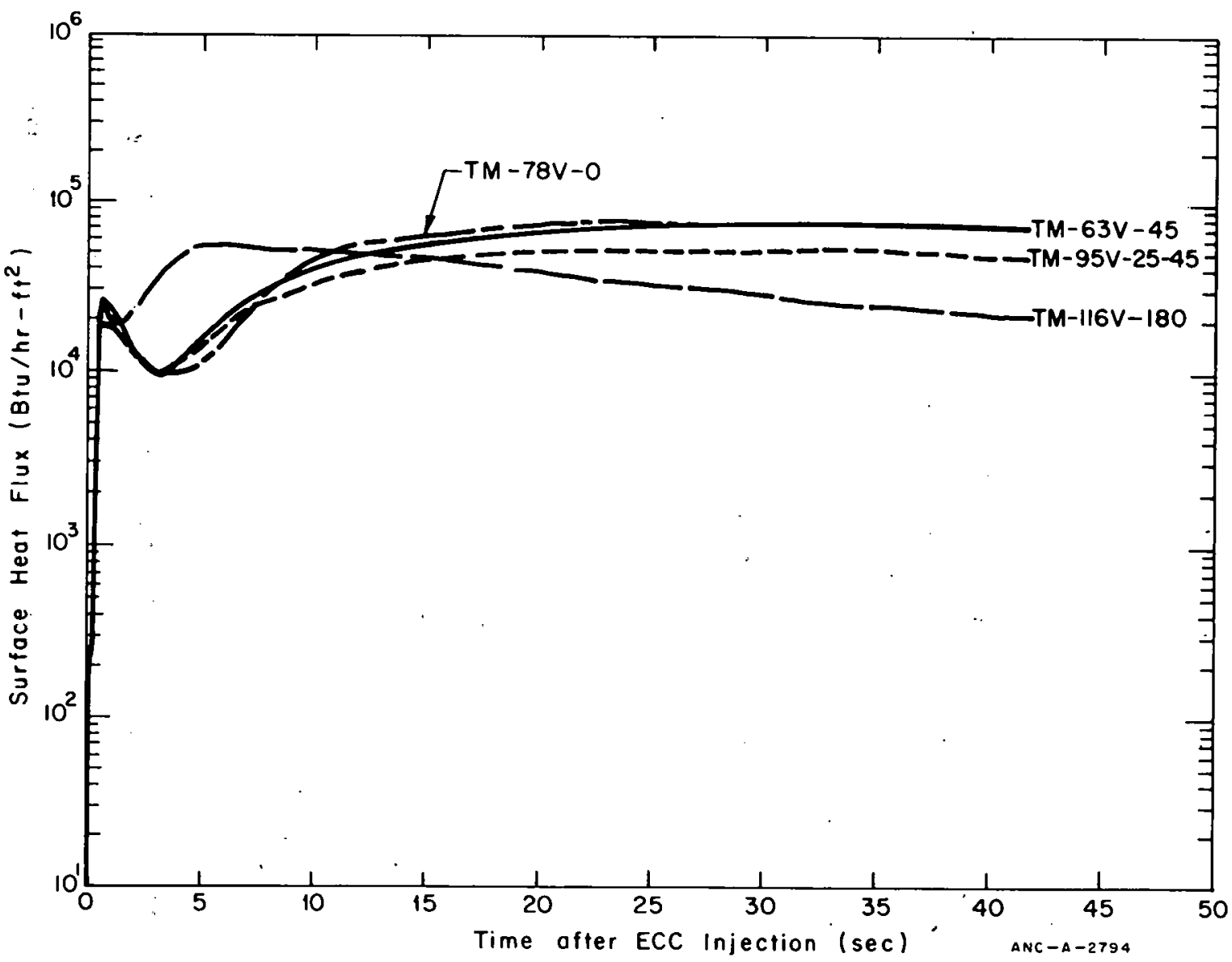

Fig. 74 Calculated surface heat fluxes for hot-wall test (Test 15.4) with the largest downcomer gap (1.69 in.). 
high heat fluxes almost simultaneously and, therefore, must have all wetted at about the same time. Figure 75 shows the calculated heat flux near the axial center of the downcomer for four Test Series 15 hot-wall tests. Comparison of the heat fluxes from Tests 15.2 and 15.3 shows this axial position wets much carlier for Test 15.3 which has a larger downcomer gap but the same ECC injection rate as Test 15.2. Comparison of the heat fluxes from Tests 15.1 and 15.2 shows this axial position wets much earlier for Test 15.2 which had a large injection rate but the same downcomer gap size as Test 15.1. The trends of earlier wetting of an axial position with increasing gap size and increasing ECC injection rate are consistent with the trends in the observed delay in ECC delivery to the lower plenum for the hot-wall tests discussed in the following section.

Figure 76 shows the heat transfer coefficients calculated using the heat fluxes shown in Figure 75 and the temperature difference between the calculated surface temperature and the bulk fluid temperature. The heat transfer coefficients for the period after the water has wetted this axial location are in the range 1000 to $2000 \mathrm{Btu} / \mathrm{hr}-\mathrm{ft}^{2}{ }^{\circ} \mathrm{F}$. This range of heat transfer coefficients is typical of the range of heat transfer coefficients observed at other axial locations.

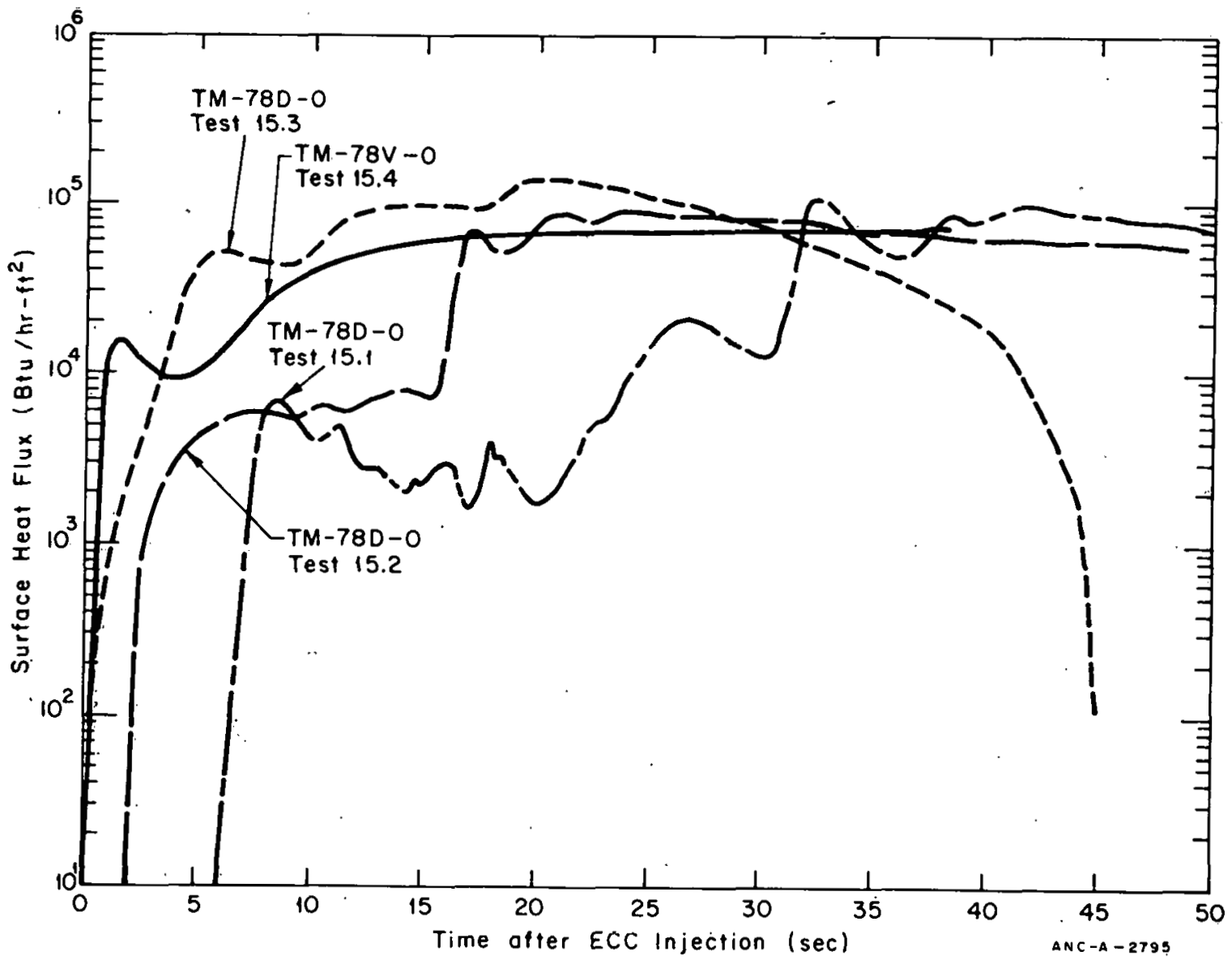

Fig. 75 Calculated surface heat fluxes near the axial center of the downcomer during hot-wall tests. 


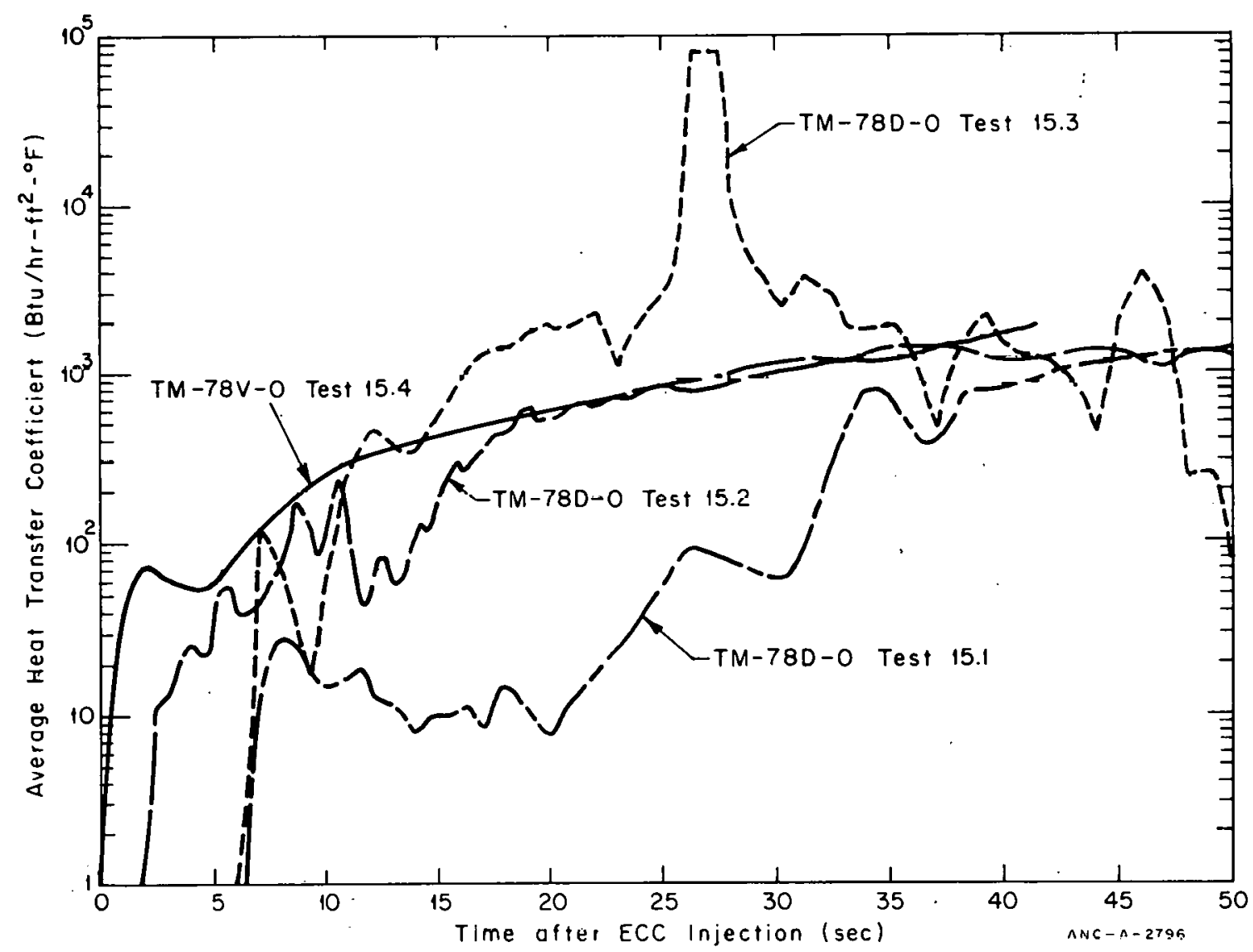

Fig. 76 Calculated heat transfer coefficients near the axial center of the downcomer during hot-wall tests.

\subsection{Hot-Wall Effects on ECC Delivery}

As discussed previously, the effects of hot downcomer walls are exaggerated in the semiscale geometry. The heat fluxes from the downcomer walls can generate steam which increases the quality and consequently the velocity of the fluid in the downcomer. The complex interaction between ECC and blowdown fluids, together with the steam generated at the downcomer walls, may prevent the ECC fluid from entering the downcomer immediately and thereby delay the delivery of water to the lower plenum. In order to investigate the effect of hot walls on ECC delivery to the lower plenum in the semiscale system, three different types of tests were conducted. The results from these tests are presented in Table VII. The delay in ECC delivery to the lower plenum was taken to be the difference between the time of ECC injection and the time at which a significant amount of water $(>5 \mathrm{gpm})$ was delivered to the lower plenum. 
A test with the system at ambient temperature (about $70^{\circ} \mathrm{F}$ ) was conducted in the absence of countercurrent flow to determine the delay in ECC delivery to the lower plenum associated with the transit time from the intact loop cold leg injection point to the lower plenum. This test was conducted in the isothermal system with an injection rate of $20 \mathrm{gpm}$ and with the intact loop pump running at $2900 \mathrm{rpm}$. Figure 77 shows the measured temperatures in the lower plenum as well as the measured lower plenum density from the gamma attenuation density measurement that measures the density along a diagonal path from the top of the lower plenum to a position about 3 inches from the bottom of the lower plenum. The temperature measurements in the lower plenum (TF-260-4) and near the bottom of the downcomer (TF-95D-225) exhibit some cooling at about 2 seconds after the start of ECC injection indicating small amounts of water reached the lower plenum at this time. Since the density of the fluid remains constant over the time period of the test, the diagonal density measurement shows a gradual increase in the water in the lower plenum between 4 and 7 seconds and then a rapid filling of the lower plenum after 7 seconds. The

\section{TABLE VII}

ECC DELAY TIMES FOR VARYING INJECITION RATES AND GAP SIZES

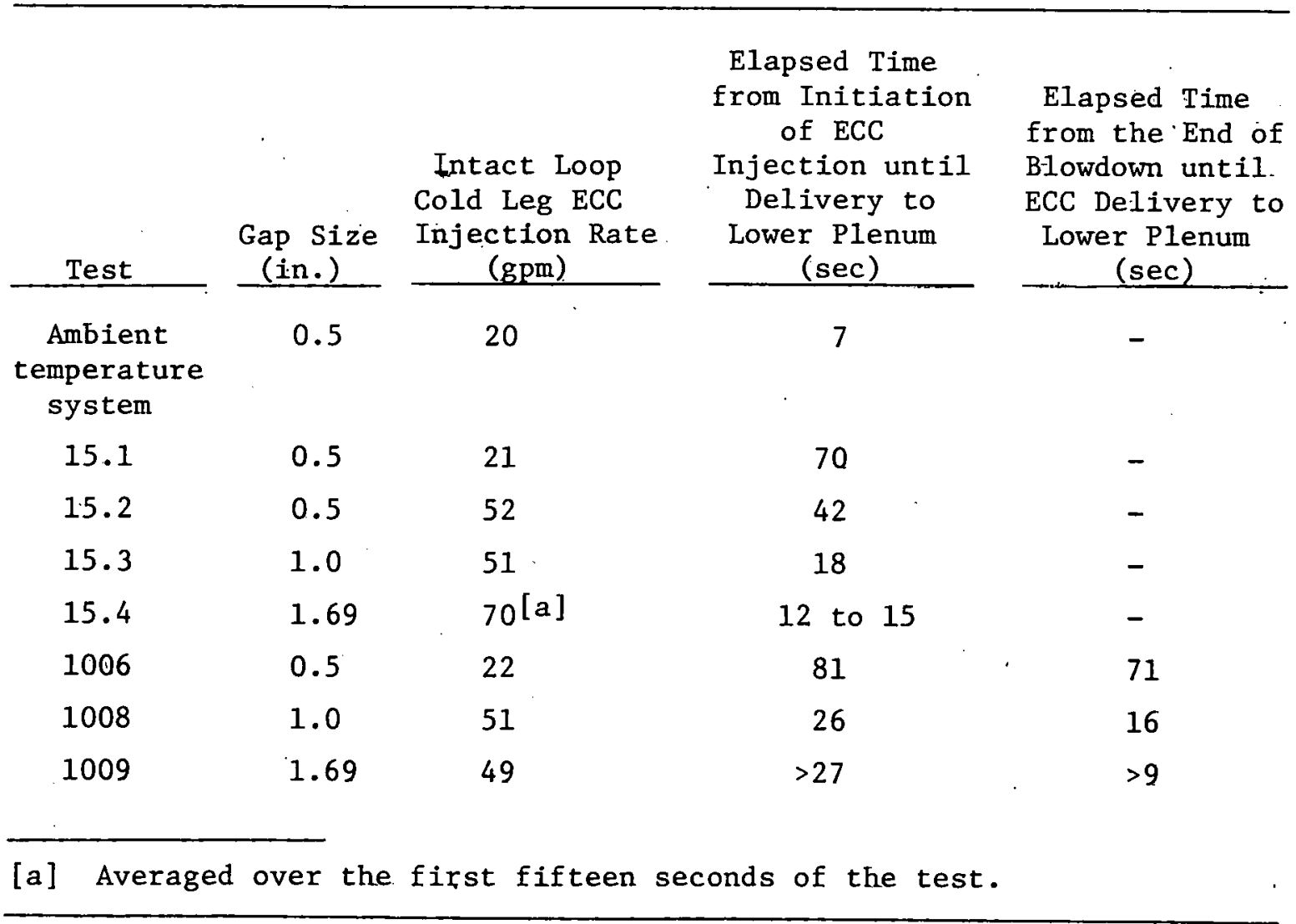




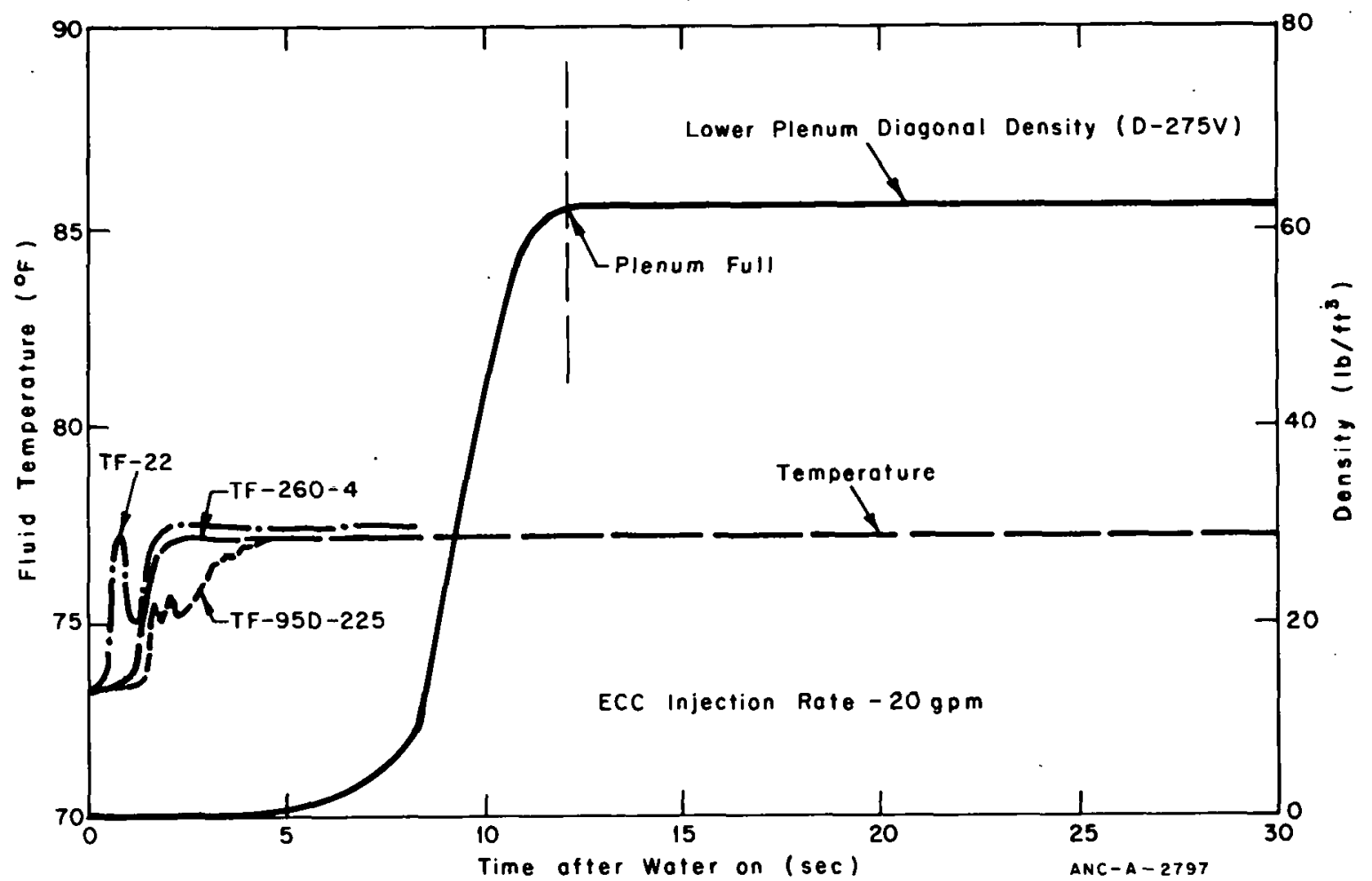

Fig. 77 Measured temperatures and density in lower plenum during ambient temperature test.

delay of about 7 seconds until the delivery of a significant amount of water to the lower plenum was used as a basis for judging the additional delay in lower plenum delivery caused by hot walls in the absence of blowdown.

A series of transient hot-wall tests was conducted in the absence of blowdown to determine the effect of steam generation at the walls on the delay in delivery of ECC to the lower plenum. As previously mentioned, when ECC is injected into the intact loop cold leg, the piping and upper annulus wall heat fluxes are not high enough to generate significant amounts of steam as long as the ECC fluid is substantially subcooled, but, as shown previously in Table VI, they are high enough to result in loss of some of the subcooling of the ECC water. The most significant effect of delay time for the hot-wall tests appears to be due to steam generated in the downcomer. The ratio of surface area to flow area for the semiscale vessel downcomer is such that a relatively low wall heat flux can generate sufficient steam to prevent significant amounts of ECC fluid from flowing to the lower plenum.

Downcomer heat fluxes calculated for hot-wall Test 15.3 were used to calculate the steam generation rate and the volumetric fluxes that result from the transfer of heat from the downcomer walls to the fluid. The downcomer volumetric fluxes that resulted from steam generation during Test 15.3 are presented in Figure 78 . These volumetric fluxes can 


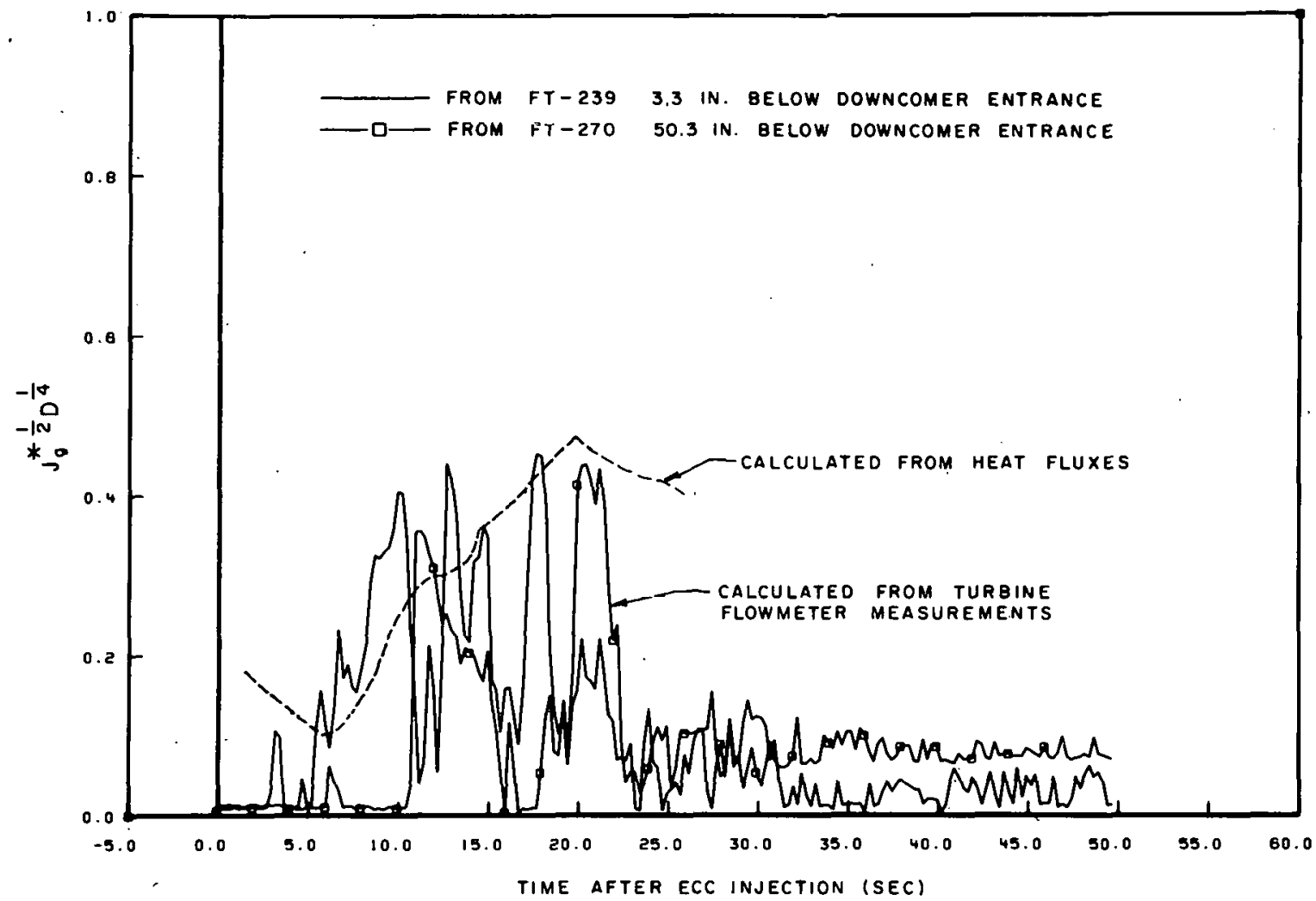

Fig. 78. Downcomer dimensioned volumetric flux resulting from steam generation during hot-wall Test 15.3.

be compared with the volumetric fluxes calculated from the turbine flowmeter data and presented in Figure 65. The volumetric fluxes from the turbine flowmeter data indicate fluctuating flow whereas the volumetric fluxes calculated from the heat transfer data do not show these same fluctuations. Some of the fluctuations indicated by the turbine flowmeters are probably due to water alternately reaching and leaving the turbine flowmeter location.

Although the initial temperatures of the downcomer walls were not exactly the same for these two tests, a qualitative examination of the effect on the delay in ECC delivery to the lower plenum of increasing the ECC injection rate can be made by comparing the results of hot-wall Tests 15.1 and 15.2. When the transit time determined from the results of the ambient temperature tests is taken into account, the delay in ECC delivery decreases by about $60 \%$ for an increase in injection rate of about $240 \%$. Since the measured temperature near the top of the downcomer indicated saturated fluid over most of the time for both tests and since the calculated upper annulus temperature presented in Table VI indicated much more subcooling in the upper annulus for Test 15.2 than Test 15.1, the increased upper annulus subcooling of Test 15.2 appears to result in much more steam being condensed near the top of the downcomer, thereby allowing more water to enter the downcomer and to cool the downcomer walls more rapidly. The trend of more rapid cooling of the downcomer walls with increased injection rate is consistent with the downcomer heat fluxes presented in Figure 75 for Tests 15.1 and 15.2. At the midpoint of the downcomer, significant cooling appears to occur earlier for Test 15.2 than for Test 15.1. 
Although the initial temperature of the downcomer walls was not exactly the same for Tests 15.2 and 15.3, a qualitative examination of the effect on the delay in ECC delivery to the lower plenum of increasing the downcomer gap size can be made by comparing the results of these two tests. When the downcomer gap size was doubled (Test 15.3), consequently increasing the downcomer area by a factor of about 2.17 , the delay in ECC delivery decreased to about $40 \%$ of the small downcomer gap ECC delay time. This decrease in delay time appears to result from the increase in the amount of countercurrent steam flow that would be necessary to limit the amount of water flowing into the larger downcomer. Since downcomer steam flow is generated by energy transfer from the downcomer walls and since only a limited amount of energy is available for removal from the walls, the larger steam flow (necessary to maintain countercurrent Mow) in the larger downcomer gaps causes the downcomer walls to quench more rapidly than for smaller downcomer gaps. If the walls quench more rapidly, $\mathrm{ECC}$ will reach the lower plenum in a shorter time. The trend of a more rapid cooling of the downcomer walls with an increase in downcomer gap size is consistent with the data presented in Figure 75 for Tests 15.2 and 15.3. In this figure the midpoint of the downcomer exhibits significant cooling earlier in time for the test with the larger downcomer gap (Test 15.3).

The results from the isothermal blowdown tests with ECC injection provide insight into the effect of hot walls on the time of delivery of ECC to the lower plenum both during and following blowdown. Comparison of the elapsed time from the initiation of ECC injection until delivery to the lower plenum for similar blowdown and hot-wall tests (Tests 1006 and 15.1, Tests 1008 and 15.3, and Tests 1009 and 15.4) indicates that blowdown causes an additional delay in the time at which ECC reached the lower plenum in the semiscale geometry. Comparison between the elapsed time from the end of blowdown until ECC was delivered to the lower plenum for the blowdown tests and the elapsed time from the initiation of ECC injection until delivery to the lower plenum for hot-wall (nonblowdown) tests shows these two times are about the same for similar blowdown and hot-wall tests indicating that the blowdown delays the flow of water to the downcomer until near the end of blowdown thereby delaying the initiation of the hot-wall phenomena. The delay in water delivery to the downcomer that is caused by the blowdown is consistent with the results presented in Section III-3.2 which indicate that the downcomer countercurrent flow dimensioned fluxes that occurred during the blowdown portion of Test 1008 were high enough to limit the flow of water into the downcomer until near the end of blowdown.

\section{LOWER PLENUM PHENOMEN $\Lambda$}

The amount of water remaining in the lower plenum toward the end of blowdown determines the time required for the ECC water to fill the lower plenum and initiate core reflooding. Several different mechanisms exist that cause mass to be lost from the lower plenum during blowdown. If the lower plenum was not closely coupled to the downcomer and core inlet regions, the major mechanisms for removal of water from the lower plenum would be flashing of the saturated water to steam that results from pressure decreases and the flow of this steam from the lower plenum, and boil off of the lower plenum water 
resulting from heat transfer from the lower plenum walls. Since the lower plenum is closely coupled to the downcomer and core inlet regions, additional lower plenum mass loss can result from other mechanisms, such as entrainment of lower plenum fluid in the downcomer flow when the swell of the lower plenum fluid forces the fluid into the downcomer or sweepout of lower plenum fluid by reverse core flow.

The phenomena occurring in the lower plenum during the isothermal test series have been investigated and are reported in detail in other semiscale system reports ${ }^{[18]}$. The lower plenum results presented herein are limited to the following areas of interest: (a) the effect of cold leg ECC injection on the amount of water remaining in the lower plenum; (b) the effect on system response of ECC injection directly to the lower plenum; and (c) the effect of hot walls on the delivery rate of water to the lower plenum for cold leg ECC injection.

\subsection{Effect on Lower Plenum Mass Due to Cold Leg ECC Injection}

Figure 79 shows the fraction of the initial lower plenum mass that remained in the lower plenum during isothermal Tests 1008 and 1010. Also included is the calculated fraction of the initial mass that would remain in the lower plenum during Test 1010 if the only mechanism for mass loss from the lower plenum was the flashing of the fluid that results from the pressure changes during blowdown. Comparison of the measured response of the lower plenum and the calculated response resulting from only flashing for Test 1010 indicates the effect of mechanisms other than flashing on the amount of mass in the lower plenum. During about the first 12 seconds of blowdown the amount of mass remaining in the lower plenum is about the same as would remain if only flashing was causing the removal of mass from the lower plenum. Differences between the measured lower plenum response and the response for flashing only during the first 12 seconds could result from sume mass being forced out of the lower plenum when voids form in the lower plenum liquid and swell the volume of this liquid. From about 12 to 15 seconds after rupture the measured mass in the lower plenum decreases rapidly. The mechanisms that cause this rapid decrease in the lower plenum mass are not clear but the decrease occurs over about the same period of time that the average velocity in the downcomer reverses and flow begins upward (Section III-3.22 illustrates this behavior for isothermal Test 1010). From about 15 seconds after rupture until the end of blowdown, the measured lower plenum response indicates that mass is being added to the lower plenum faster than flashing of the fluid in the lower plenum can remove mass. Mass addition to the lower plenum over this period of time is probably due to liquid draining down through the core and downcomer regions.

The major difference between Tests 1008 and 1010 was the injection of ECC into the cold leg for Test 1008. As discussed in Section III-1.2, and illustrated in Figure 16, the injection of ECC in the cold leg piping during the isothermal blowdowns increased the reverse flow through the core region. Apparently the large reverse core flow during Test 1008 aided in removal of a significant amount of water from the lower plenum as demonstrated by a comparison between the Test 1008 and Test 1010 results presented in Figure 79. The fraction of the initial lower plenum water mass that remained in the lower plenum during isothermal Tests 1006 and 1008 is shown in Figure 80 The core flow results presented in Figure 18 indicate that the velocity of the reverse core flow for Test 1008 was 


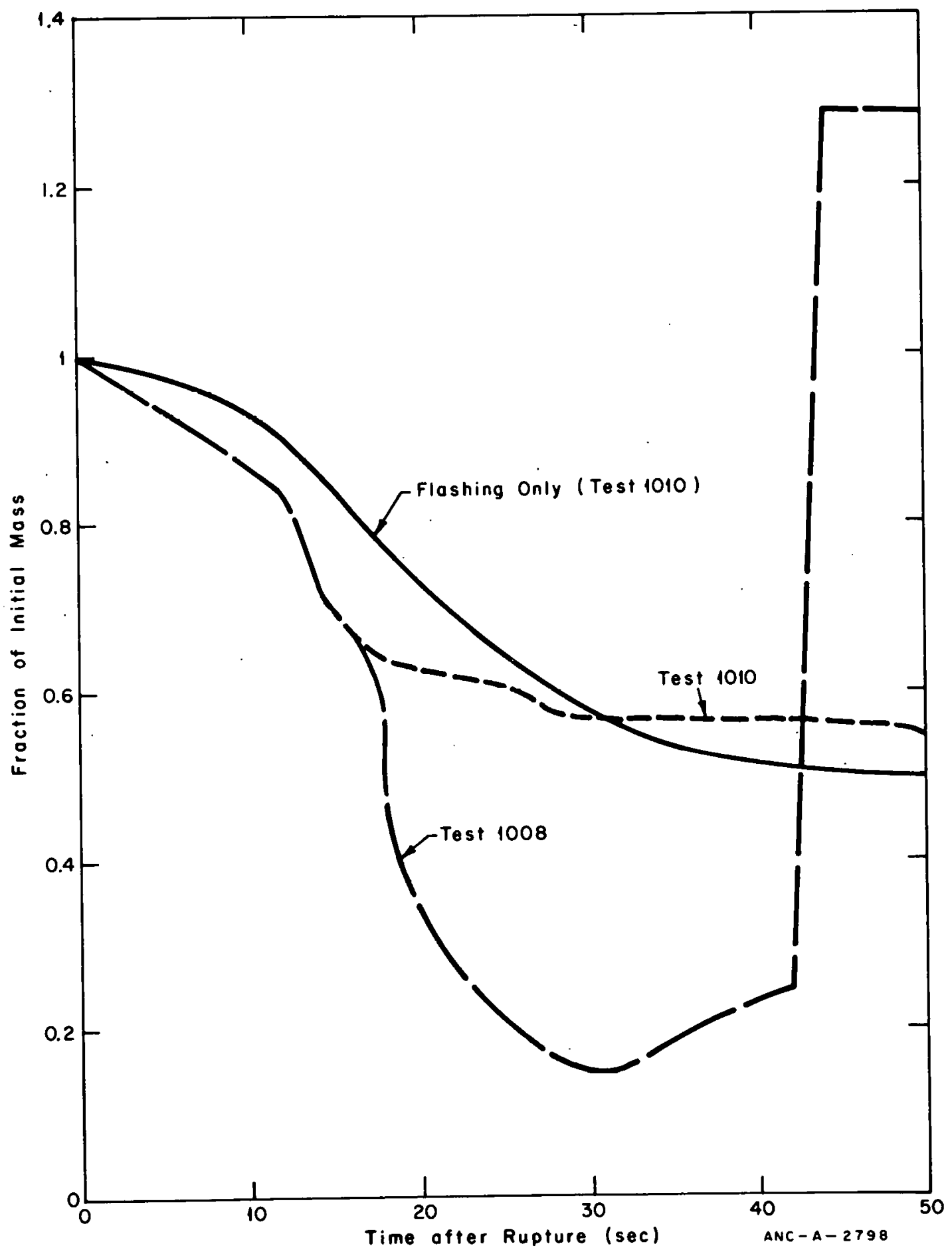

Fig. 79 Fraction of initial lower plenum mass remaining in the lower plenum during isothermal Tests 1008 and 1010. 
greater than the velocity of the reverse core flow for Test 1006 and the results presented in Figure 80 show that the amount of waler remaining in the lower plenum for Test 1008 is less than for Test 1006.

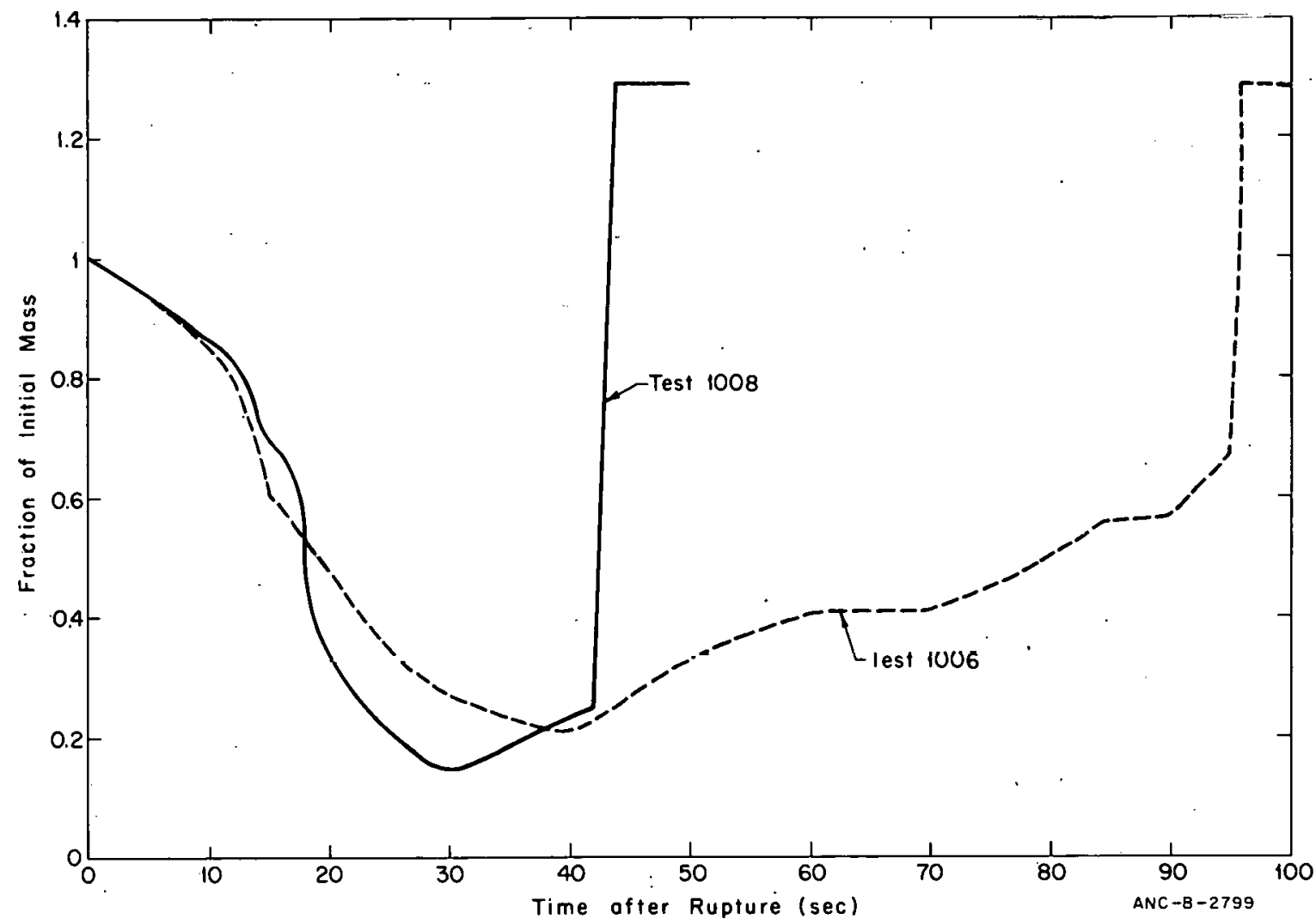

Fig. 80 Fraction of initial lower plenum mass remaining in the lower plenum during isothermal Tests 1006 and 1008.

The exact mechanism of water removal from the lower plenum by reverse flow is not known but it may be similar to the mechanism of removal of water from the lower plenum of the transparent vessel during a series of lower plenum voiding tests. These tests were conducted by forcing relatively high velocity air flows to enter the lower plenum which was initially full of water. In these lower plenum voiding tests, entrainment of the lower plenum water by the high velocity downcomer flow was the mechanism for removing lower plenum water from the system. The lower plenum water was observed to reach the downcomer in two different ways. During the initial portion of the tests the air jetting into the lower plenum was observed to cause the lower plenum water surface to become bowl shaped and to force some of the lower plenum water up into the downcomer where the high velocity flows entrained some of this lower plenum water and carried it out of the system. As water was entrained in the downcomer and carried out of the vessel, the lower plenum water level receded away from the bottom of the core barrel. When the lower plenum water had receded some distance from the bottom of the core barrel, the velocity of the air could no longer support a bowl shape with sufficient depth to force water into the downcomer region. In this situation, the air jetting into the lower plenum forced the water surface to become unstable and the water sloshed from side to side. Each time the water met the downcomer wall, some water was splashed up into the downcomer region and entrained in 
the downcomer gas flow. The level swell that would have occurred during the isothermal tests would also force some lower plenum fluid into the downcomer region where it could be carried out of the system.

A comparison between blowdown tests with similar system flow rates and equivalent ECC injection rates but with different downcomer gap sizes would be expected to indicate whether the fluid velocity in the downcomer does influence the mass remaining in the lower plenum. The effect of downcomer fluid velocity on the mass remaining in the lower plenum can be determined from results of Tests 1008 and 1009 because the volumetric flow rates at the measurement locations close to the downcomer were about the same for these two tests, whereas the downcomer gap for Test 1009 was larger than the downcomer gap for Test 1008. Since the volumetric flows near the downcomer were about the same for both tests, the downcomer velocities near the lower plenum for Test 1009 would have been about $78 \%$ lower than the velocities during Test 1008 based on the difference in the areas of the downcomer. Figure 81 shows the fraction of the initial lower plenum mass that remained in the lower plenum during isothermal blowdown Tests 1008 and 1009. ECC was initiated about 16 and 17 seconds after rupture for Tests 1008 and 1009 , respectively, and the results from both tests indicate that the fraction of the initial mass decreased more rapidly after ECC injection. The results also indicate that as the blowdown progressed, a greater fraction of the initial mass in the lower plenum remained during Test 1009 than remained during Test 1008. The greater fraction of the initial lower plenum mass that remained in the lower plenum during Test 1009 is attributed to lower downcomer velocities which entrained less of the lower plenum fluid that was forced into the downcomer.

\subsection{ECC Injection. into the Lower Plenum}

During one isothermal test (Test 1004), ECC was injected directly into the bottom of the lower plenum. A volumetrically scaled injection rate was initiated when the isothermal system pressure reached 200 psig which occurred about 21 seconds after rupture. Injection was continued until the lower plenum was full of water, which took about 5 seconds.

One of the purposes of injecting water into the lower plenum during Test 1004 was to provide data on system response for system conditions similar to those which resulted in all ECC being expelled from the lower plenum during semiscale single-loop lower plenum injection Tests $848-849^{[19]}$. In the single-loop tests, the geometry of the lower plenum entrance and exit flow paths and of the flow paths to the break was not typical of that of a PWR. Apparently the single-loop system flows following ECC injection, combined with the atypical system geometry, caused or amplified system pressure oscillations which forced the ECC injected from the lower plenum out the simulated brcak. Little water remained in the lower plenum after the single-loop tests as a result of this atypical system behavior.

The isothermal system had flow paths and system geometry that were more nearly typical of a PWR than was the single-loop geometry and flow paths. In contrast to the results of the single-loop tests, isothermal data indicate that the water injected directly into the lower plenum was not expelled but accumulated and remained in the lower plenum. Figure 82 shows the response of the thermocouples vertically spaced at intervals. on the 


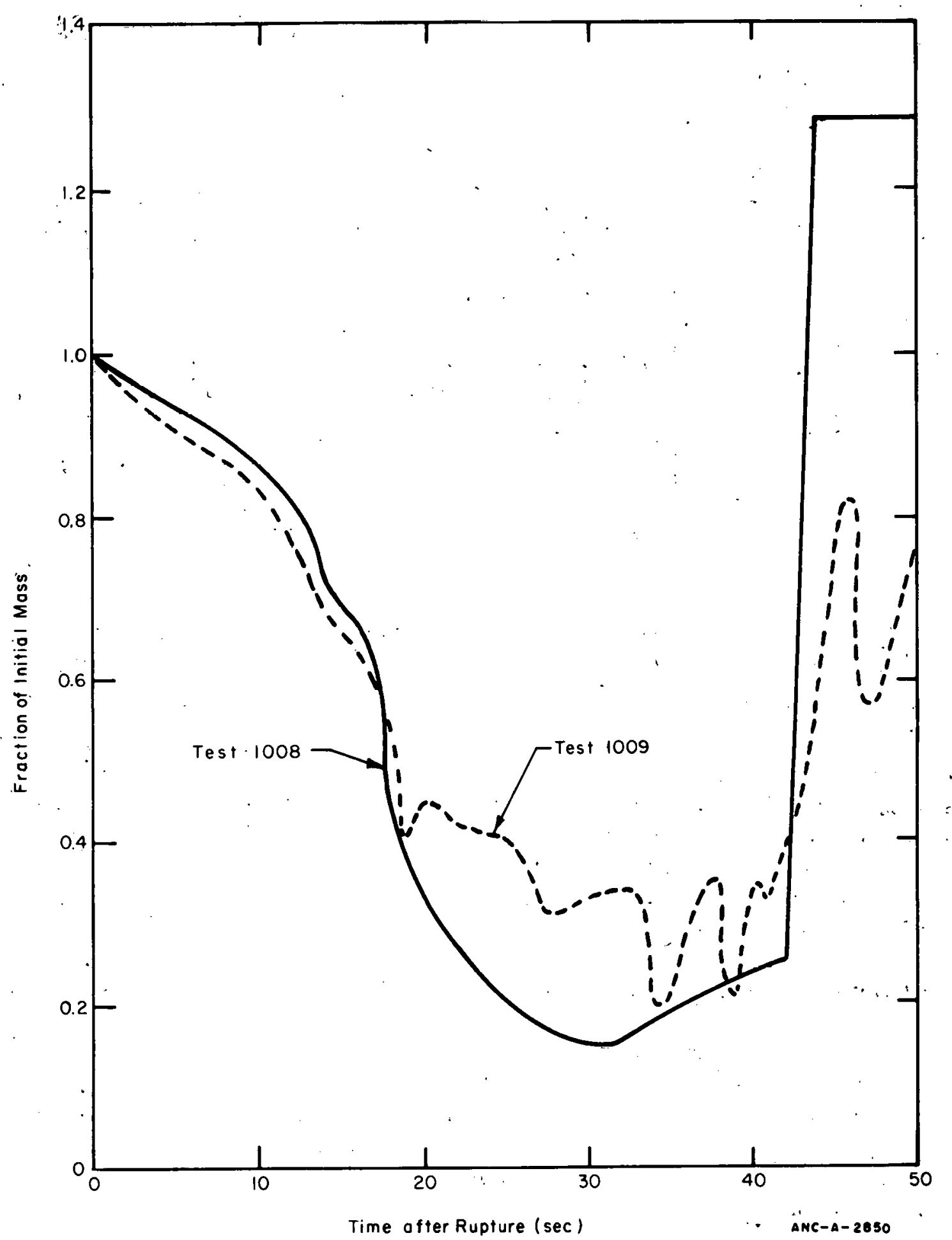

Fig. 81 Fraction of lower plenum mass remaining in the. lnwer plenum during isothermal Tests 1008 and $1009 . \quad-$ 


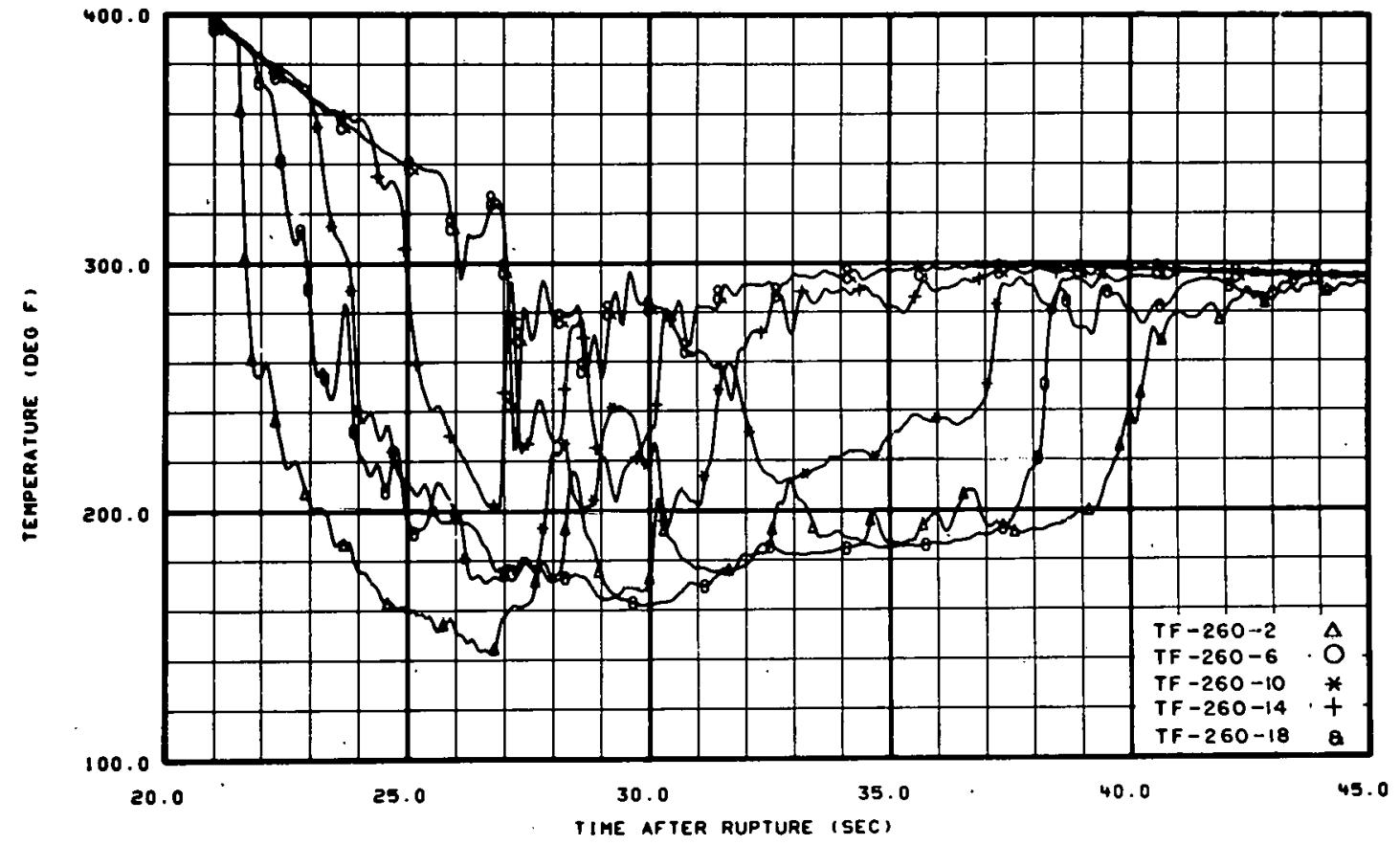

Fig. 82 Thermocouple response exhibiting progressive rise of subcooled water in lower plenum during lower plenum ECC injection -- Test 1004.

lower plenum thermocouple rack. These data show the progressive rise of the level of subcooled water in the lower plenum following ECC injection. Figure 57 of Section III-3.21 shows the density as measured by the gamma densitometer that directed a beam across the top of the lower plenum. The data indicate the lower plenum is filled about 3 seconds after initiation of ECC injection and remains full until the lower plenum is drained about 37 seconds after rupture.

\subsection{Hot-Wall Effects on Rate of Delivery to Lower Plenum}

The isothermal system Test Series 15 hot-wall tests were conducted following several of the isothermal blowdown tests which did not include cold leg ECC injection. Following the blowdown tests, the lower plenum was drained so that the lower plenum was empty at the beginning of the hot-wall tests. The lower plenum horizontal and diagonal density measurements were used to obtain an indication of the time and rate of water delivery to the lower plenum for these tests.

The horizontal density measurement at the top of the lower plenum (D-228H) is shown in Figure 83 for Tests 15.1 and 15.2 and in Figure 84 for Tests 15.3 and 15.4. The increase in measured density that occurs shortly after the initiation of cold leg ECC injection indicates that water is falling through the region of the measurement and that the amount of water that is falling into the lower plenum increases with time. 


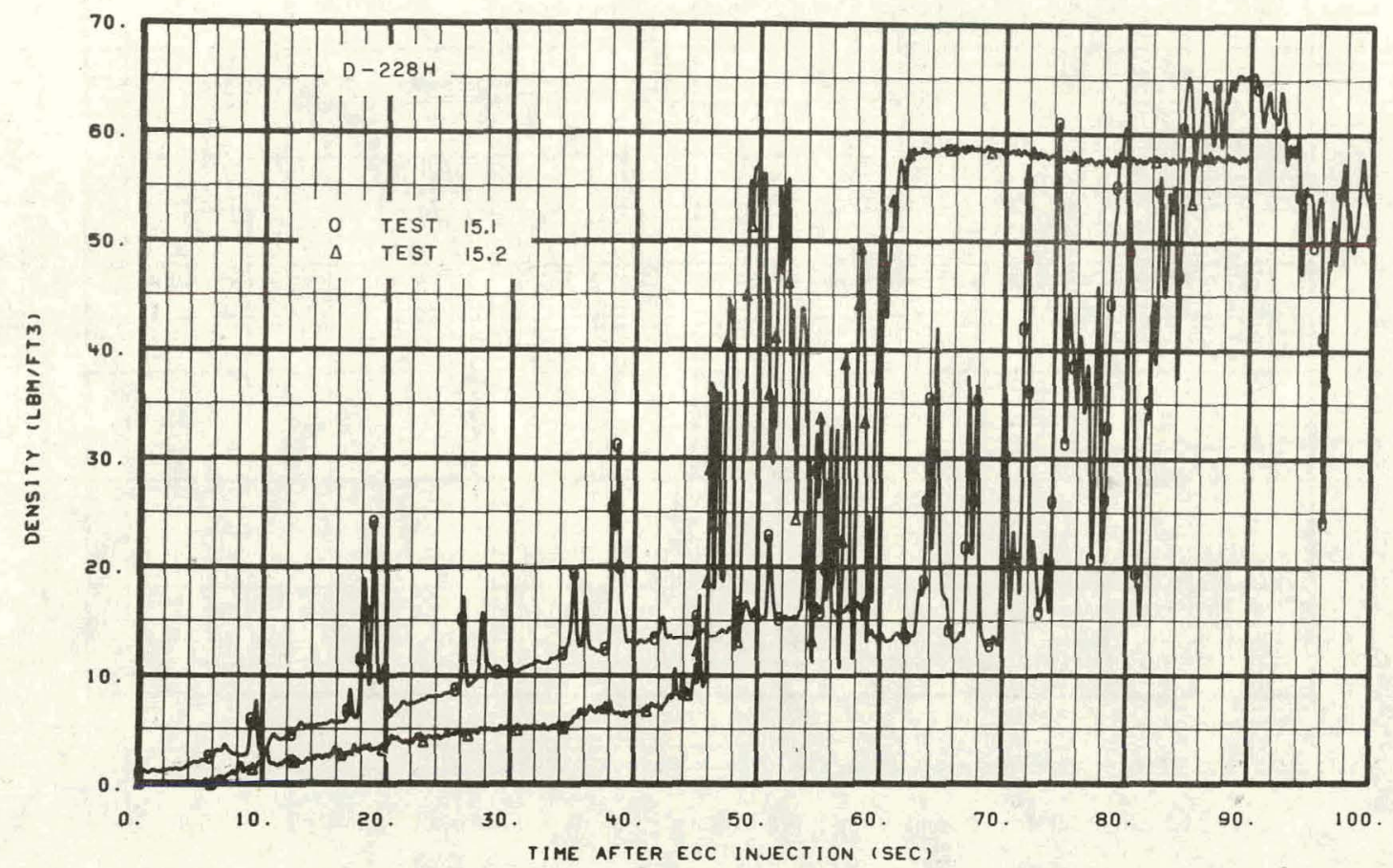

Fig. 83 Horizontal density measurement in lower plenum during hot-wall Tests 15.1 and 15.2.

The lower plenum diagonal density measurement (D-275V) is shown in Figure 85 for Tests 15.2, 15.3, and 15.4 (this measurement failed during Test 15.1). The diagonal density measurement provides an indication of the amount of mass in the lower plenum and the rate of change of this measurement provides an indication of the rate of fill of the lower plenum. The amount of mass in the lower plenum is essentially equal to the measured density at any time multiplied by the volume of the lower plenum, which was about $0.26 \mathrm{ft}^{3}$. The rate at which the diagonal density measurement would change for an input to the lower plenum of $5 \mathrm{gpm}$ is noted by the solid line in the lower right hand corner of Figure 85 to provide an indication of the rate the lower plenum is filling. In all tests shown, the lower plenum filled slowly during the initial portion of the test, but rapidly as the injected water reached the lower plenum. 


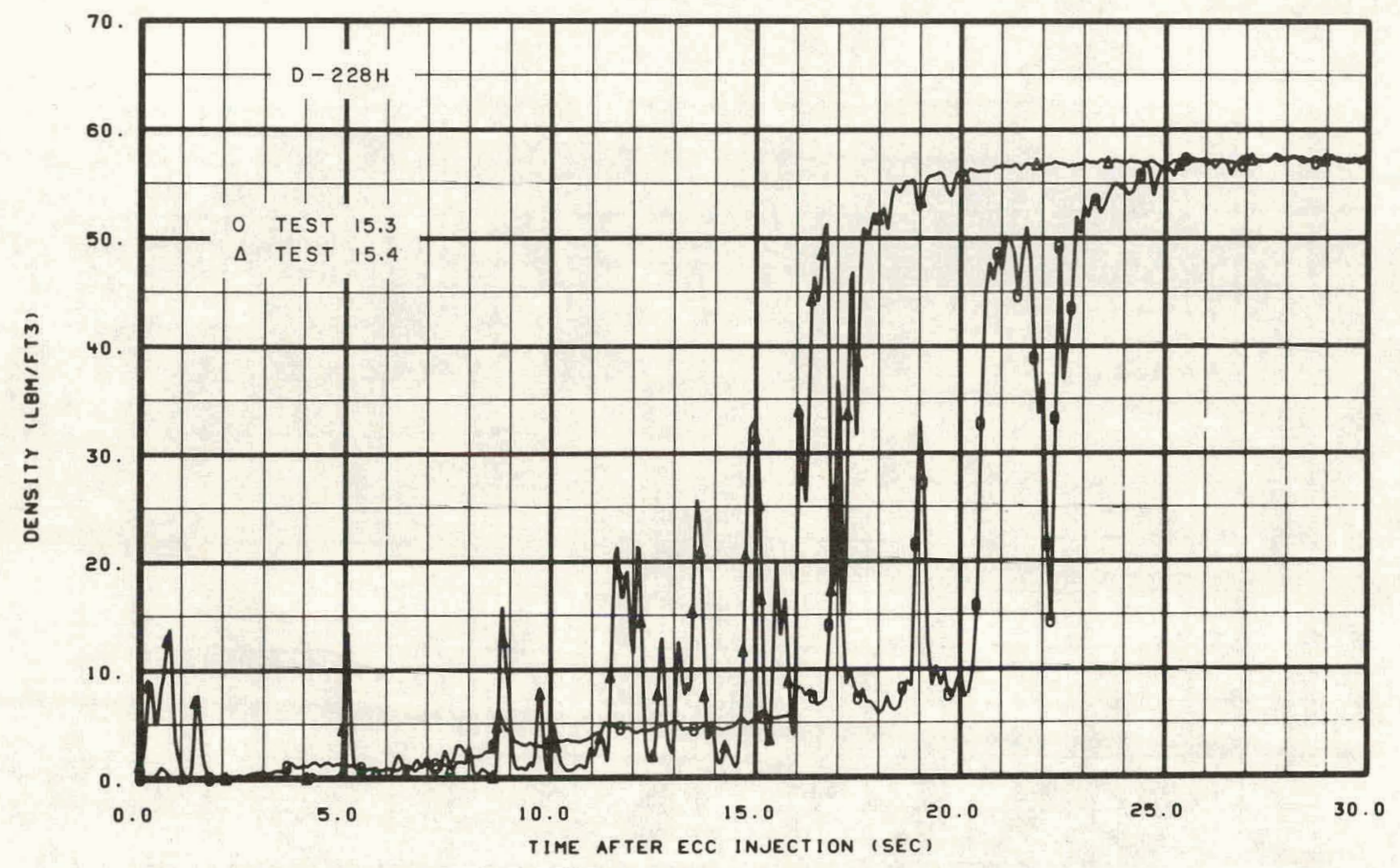

Fig. 84. Horizontal density measurement in lower plenum during hot-wall Tests 15.3 and 15.4.

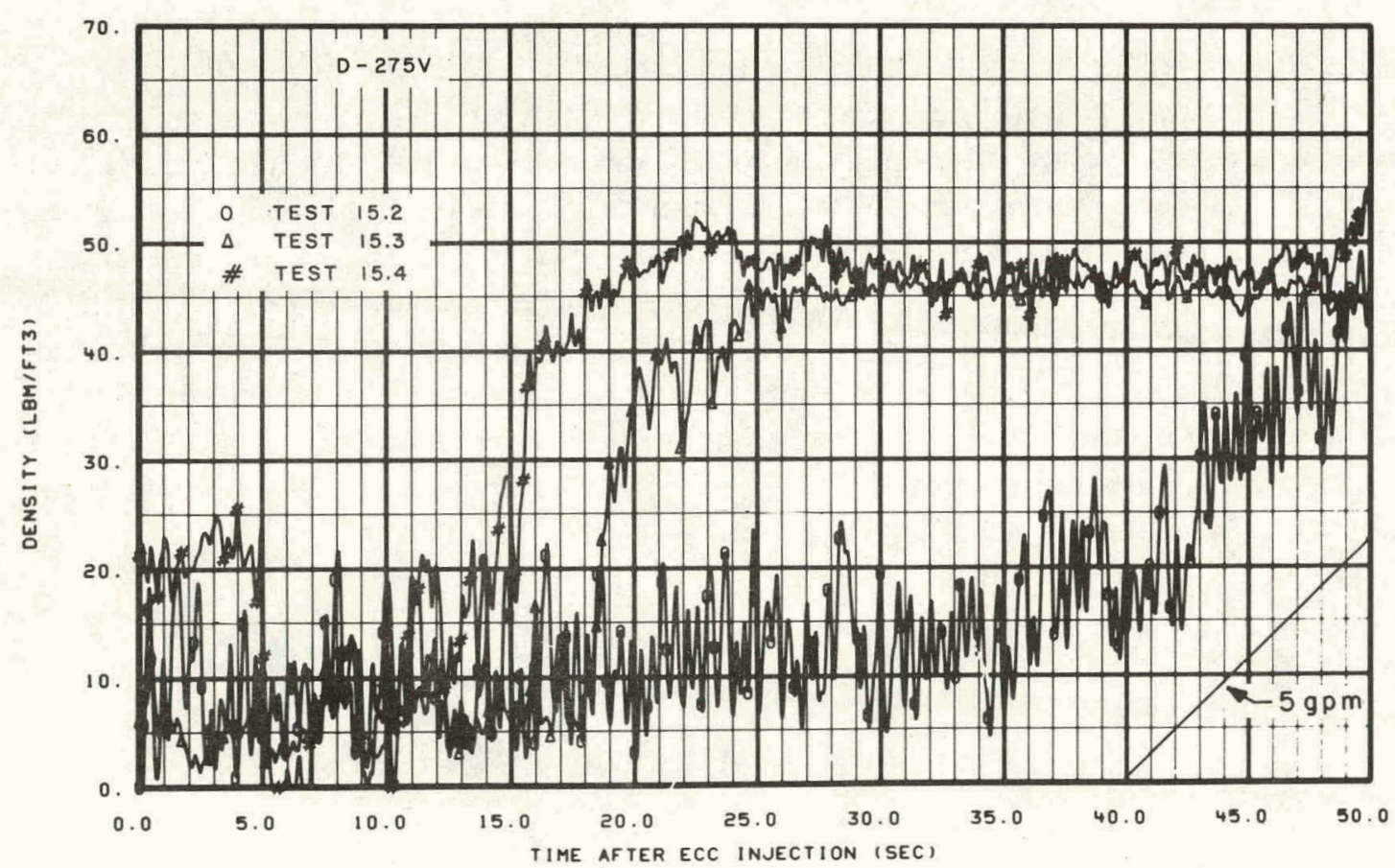

Fig. 85 Diagonal density measurements in lower plenum exhibiting lower plenum mass changes during hot-wall tests. 


\section{HOT.WALL COUNTERCURRENT FLOW PREDICTIVE METHOD}

As discussed in Section III-3, the effect of hot downcomer walls is accentuated in the semiscale geometry. Steam generated at the downcomer walls may increase the steam velocity in the downcomer sufficiently that the resulting countercurrent flow limits the flow of ECC to the lower plenum. Since the delay in delivery of ECC to the lower plenum can be long in the semiscale system, a predictive method was developed to aid in the prediction and interpretation of this delay during semiscale tests employing ECC ${ }^{[a]}$.

Development of the predictive method for the delay of ECC delivery utilized results from the three coordinated experimental programs performed in the semiscale geometry. The phenomena that were observed to occur in the downcomer and upper annulus regions during the isothermal system hot-wall tests were modeled using the results of previous tests including the transparent vessel tests and the semiscale system countercurrent flow tests. The predictive method was extended to blowdown tests by utilizing the isothermal system blowdown test results.

The predictive method assumes that most of the water entering the upper annulus is restricted from falling down the downcomer by the countercurrent flow of steam in the downcomer. The steam in the downcomer comes either from steam generation at the downcomer walls or from steam entering the downcomer from the lower plenum. The water which enters the downcomer is assumed to progress down the wall in a falling film with the amount of heat transfer to the film from the downcomer walls being determined by the position of the falling film and the appropriate downcomer boundary conditions. The position of the falling film is determined by the amount of water entering the downcomer and the amount of steam flow that is necessary to cause some restriction to the water entering the downcomer. The process is then self-limiting because an increase in flow to the downcomer increases the rate of fall of the falling film which increases the downcomer heat transfer rate which in turn increases the downcomer steam generation rate and produces higher steam velocities that cause a decrease in the amount of water entering the downcomer.

A description of the predictive method is presented in the following sections. The upper annulus and the downcomer portions of the predictive method are discussed separately. A sensitivity study of the variables which most strongly influence the delay in delivery of the ECC is presented and the results from the predictive method are compared with actual test results. The results from applying the predictive method to larger geometries are also presented, although the applicability of this predictive method to geometries larger than the semiscale geometry is unverified and the accuracy of the results is consequently unknown.

\section{PREDICTIVE METHOD FOR UPPER ANNULUS}

The following assumptions are made in the predictive method to describe the upper annulus phenomena:

[a] A simple empirical hot-wall data correlation predictive method which works well for the semiscale geometry was developed early in the test program and is documented in Appendix D. 
(1) All injected ECC immediately reaches the upper annulus

(2) The temperature of the water in the upper annulus can be determined by a gross energy balance on the upper annulus region.

The results of the mass balance presented in Section III-2.1 indicate: (a) that during blowdown the initial momentum of the blowdown fluid permitted the injected ECC to be carried toward the upper annulus; (b) that, after the end of blowdown, the ECC continued to flow toward the upper annulus at a relatively steady rate; and (c) following the end of blowdown only slight flow back toward the pump occurred. During the hot-wall tests the ECC appeared to fill a portion of the cold leg, but the pump forced the injected ECC toward the upper annulus. On the basis of these results, the assumption that all the injected ECC enters the upper annulus over the entire period of ECC injection appears to be reasonable although not totally accurate. An adjustment to the calculated delay in lower plenum delivery was made by accounting for the transit time determined from the ambient temperature test results presented in Section III-3.4 for those cases in which the transit time is significant compared to the delay in lower plenum delivery.

A gross energy balance, shown in Section III-2.2, provided a reasonable estimate of the water temperature in the upper annulus. For the hot-wall predictive method, the temperature of the water entering the downcomer was assumed to be equal to the temperature of the water in the upper annulus as calculated through use of Equation (8). The temperature of the water entering the upper annulus from the cold leg as a function of time was input to the calculation. The flow of steam from the downcomer and the flow of water into the downcomer were calculated by the downcomer portion of the predictive method.

\section{PREDICTIVE METHOD FOR TIIE DOWNCOMER}

The downcomer portion of the predictive method consisted of two separate parts, a countercurrent flow portion and a heat transfer portion. The countercurrent flow portion of the predictive method was used to determine the amount of water which will start down the downcomer as a function of the upward countercurrent flow of steam. The heat transfer portion used a heat conduction model of the downcomer in conjunction with the amount of water starting down the downcomer to calculate the amount of steam generated on the hot downcomer walls and the delivery of water to the lower plenum as a function of time.

\subsection{Countercurrent Flow}

The countercurrent flow portion of the downcomer model is based on the results presented in Section III-3.1 on downcomer phenomena. The assumption was made that the controlling mechanism for the restriction of ECC delivery to the downcomer is

countercurrent steam-water flow. The controlling point for the countercurrent flow was 
assumed to be at the narrowest point near the top of the downcomer because steam generation in the downcomer causes the steam flow rate and, therefore, the steam velocity to be a maximum near the top of the downcomer. The dimensioned form of the Wallis countercurrent flow correlation [Equation (11)] was used to calculate the amount of ECC water that starts down the downcomer. An effective volumetric gas flux based on an effective gas velocity at the top of the downcomer was used in place of the volumetric gas flux in the countercurrent flow correlation. The effective superficial volumetric flux was calculated from a steady state mass balance on the gas phase in the downcomer. The mass flow in the downcomer, $\dot{\mathrm{m}}_{\mathrm{eff}}$, is given by

$$
\dot{\mathrm{m}}_{\mathrm{eff}}=\dot{\mathrm{m}}_{\mathrm{LP}}+\dot{\mathrm{m}}_{\mathrm{WS}} \text {. }
$$

The last term, $\dot{m}_{W S}$, is the mass that is either added to the mass flow entering the downcomer from the lower plenum, $\dot{\mathrm{m}}_{\mathrm{LP}}$, as a result of steam generation at the hot downcomer walls or subtracted from the lower plenum mass flow as a result of net condensation in the downcomer. By assuming sufficient heat is available to increase the temperature of the water entering the downcomer to saturation temperature, the term mWS can be evaluated from a steady state mass and energy balance on the water in the downcomer. That is,

$$
\dot{\mathrm{m}}_{\mathrm{WS}} \mathrm{h}_{\mathrm{fg}}=\int^{A} \mathrm{q}^{\prime \prime} \mathrm{dA}-\dot{\mathrm{m}}_{\ell}\left(\mathrm{h}_{\mathrm{f}}-\mathrm{h}_{\mathrm{in}}\right)
$$

where

$$
\begin{aligned}
& \mathrm{h}_{\mathrm{fg}} \quad=\quad \text { the latent heat of vaporization of the water }\left(\mathrm{Btu} / \mathrm{lb}_{\mathrm{m}}\right) \\
& \int \mathrm{A}_{\mathrm{q}} \mathrm{dA}=\quad \begin{array}{l}
\text { the total amount of energy that is transferred from the } \\
\text { downcomer walls to the fluid in the downcomer }(\mathrm{Btu} / \mathrm{sec})
\end{array} \\
& \dot{\mathrm{m}}_{\ell} \quad=\quad \text { the water flow that enters the top of the downcomer calculated } \\
& \text { by the countercurrent flow equation }\left(\mathrm{lb}_{\mathrm{m}} / \mathrm{sec}\right) \\
& \mathrm{h}_{\mathrm{f}}=\quad \text { the saturated water enthalpy }\left(\mathrm{Btu} / \mathrm{lb}_{\mathrm{m}}\right) \\
& \mathrm{h}_{\mathrm{in}}=\text { the enthalpy of the water entering the downcomer from the } \\
& \text { upper annulus (Btu/lb } \mathrm{m} \text { ). }
\end{aligned}
$$

The effective superficial velocity, $\mathrm{J}_{\text {eff }}$, was then calculated by substituting Equation (21) into Equation (20) and using the relationship between velocity and mass flow rate to obtain

$$
J_{\text {eff }}=J_{L P}+\frac{\int_{q^{\prime}}^{A} q^{\prime \prime} d A}{h_{f g} \rho_{g} A_{c}}-J_{\ell}\left(\frac{\rho_{f}}{\rho_{g}}\right)\left(\frac{h_{f}-h_{\text {in }}}{h_{f g}}\right)
$$


where

$$
\begin{aligned}
& \mathrm{J}_{\mathrm{LP}}=\quad \begin{array}{l}
\text { the superficial velocity of the steam entering the lower plenum from the } \\
\text { downcomer }(\mathrm{ft} / \mathrm{sec})
\end{array} \\
& \rho=\text { the density }\left(\mathrm{lb}_{\mathrm{m}} / \mathrm{ft}^{3}\right) \\
& \mathrm{A}_{\mathrm{cs}}=\text { the cross-sectional area of the downcomer }\left(\mathrm{ft}^{2}\right) \\
& \mathrm{J}_{\ell}=\text { the superficial velocity of the water entering the downcomer from the }
\end{aligned}
$$

and the subscripts $\mathrm{f}$ and $\mathrm{g}$ refer to saturated water and steam conditions, respectively.

The capability of this equation to predict accurately the steady state semiscale system countercurrent flow data cannot be checked directly because the small filler gap makes an accurate determination of the amount of heat that reaches the larger gap impossible. However, the trends predicted by Equation (22) are observed in the countercurrent flow test results. Equation (22) predicts that with increasing heat flux and constant inlet subcooling, the effective velocity at the top of the downcomer increases, and according to the dimensioned form of the Wallis correlation the water delivery to the lower plenum consequently decreases. This trend is somewhat evident in the data presented in Figure 51 of Section III-3.16 for higher gas flow rates but not so evident for lower gas flow rates. Equation (22) also predicts that with increasing subcooling of the water entering the downcomer, the effective velocity at the top of the downcomer decreases and the water delivery to the lower plenum consequently increases. This trend is seen to occur in the data in that small amounts of subcooling at the downcomer entrance allowed large quantities of water to penetrate the downcomer.

\subsection{Downcomer Heat Transfer Model}

A heat transfer model of the downcomer was developed to calculate the total amount of heat transferred from the downcomer walls to the liquid in the downcomer. This heat transfer was calculated and input to Equation (22) so that an effective gas velocity in the downcomer could be determined. Calculation of the downcomer heat transfer was performed by utilizing a two-dimensional heat conduction computer code, SIMIR, to calculate the downcomer wall temperature, and a simplified technique, based on the hot-wall test results, was used to determine the heat transfer coefficients that were applied axially at the wall-liquid interface.

A two-dimensional heat conduction computer code was used to calculate the downcomer wall surface temperature as a function of time. Core barrel, downcomer filler pieces, vessel walls, vessel outside insulation as well as appropriate spaces were all part of the nodalized radial heat conduction path. The axial downcomer length and the walls of the lower plenum were also nodalized. 
The basic assumption of the heat transfer coefficient portion of the downcomer model is that either following blowdown or from the beginning of a hot-wall test, a falling film of water progressively wets the downcomer surface from top to bottom and the heat transfer coefficient is high above, and very low below, the wetting front. The concept of a progressive wetting front is supported by some of the data presented in Section III-3.3, although the predictive method is not sufficiently detailed to model the flow oscillations that are seen to alternately fill, and discharge water from, portions of the downcomer. By assuming that a falling film progressively covers the downcomer walls, the position of the water in the downcomer, and consequently the downcomer heat transfer coefficients as a function of axial position, was determined.

The high heat transfer coefficient applied above the wetting front could be calculated from an appropriate heat transfer correlation. The analysis of the data presented in Section III-3.3 indicates that following the end of blowdown, the heat transfer coefficients for locations above the wetted portion of the downcomer are typically greater than 1000 $\mathrm{Btu} / \mathrm{hr}-\mathrm{ft}^{2}{ }^{2}{ }^{\circ} \mathrm{F}$. Several different approaches, including the Thom correlation and empirical heat transfer correlations derived from semiscale data, were tried in calculating the semiscale downcomer hèat transfer coefficient. A discussion of the sensitivity of the predictive method"to the heat transfer coefficient is presented in Section IV-4:

Below the wetting front, a steam-only environment was assumed to exist and the heat transfer coefficient was assumed to be typical of a convective steam environment. A convective heat transfer correlation could be used to determine this heat transfer coefficient although a low constant value was used for semiscale calculations. The data indicate that the heat transfer coefficient at a position well below the wetting front is very low but as the wetting front approaches a given position, the heat transfer coefficient can be increased more than a factor of 20 .

The axial position of the wetting front on the downcomer walls was determined by assuming that all the water that enters the downcomer is distributed on the downcomer walls and is boiled off. Since the core barrel side of the downcomer can cool at a different rate than the vessel side, an individual wetting front position was calculated for each side. The flow into the downcomer was assumed to be distributed to the core barrel and vessel walls on the basis of the fraction of the total downcomer wetted perimeter that is associated with each wall. The axial position of the wetting front on each wall was then determined by assuming that all the water that is distributed on a wall during an interval of time must either be all boiled off or, if the water is not boiled off, some water is delivered to the lower plenum. The heat transfer model accomplishes this calculation by sequentually advancing the wetting front down the wall until sufficient heat transfer occurs over the wall to boil off all the water distributed to the wall during that time period. If the wetting front reaches the bottom of the downcomer before sufficient heat transfer occurs to boil off all the water, the excess water is assumed to be delivered to the lower plenum.

An assumption was made that the fluid temperature in the downcomer is predominantly the saturation temperature. The amount of heat transferred from each wall 
of the downcomer was then calculated using the appropriate heat transfer coefficients over the corresponding areas, the calculated wall surface temperatures, and the fluid saturation temperature. The heat transferred from both walls was summed to provide the necessary input to Equation (22).

The downcomer flow rates and heat transfer coefficients could not be determined accurately during blowdown by using the method just described. Therefore, the blowdown calculations relied on input from blowdown data or blowdown computer calculations for both the heat transfer coefficients and the $J_{L P}$ term in Equation (22) which, for the blowdown, is taken to be the flow at the top of the downcomer. Calculation of the amount of heat transferred during blowdown was necessary because the wall temperatures and heat transfer rates near the end of blowdown influence the effective volumetric flux equation, Equation (22), which determines the calculated amount of ECC that begins flowing down in to the downcomer.

\subsection{Summary of Predictive Method Equations}

The mathematical equations used to predict the delay in simulated ECC delivery to the semiscale lower plenum are summarized in the following discussion.

The equation describing the effective gas velocity at the top of the downcomer is

$$
J_{\text {eff }}=J_{L P}+\frac{\int_{h_{f g} \rho_{g} A_{c}}^{A}}{h_{\ell}}-J_{\ell}\left(\frac{\rho_{f}}{\rho_{g}}\right)\left(\frac{h_{f}-h_{i n}}{h_{f g}}\right) \text {. }
$$

The equation that describes the countercurrent flow in the downcomer, using $\mathrm{J}_{\text {eff }}$ in place of $\mathrm{J}_{\mathrm{g}}$, is

$$
\left[J_{\text {eff }}\left(\frac{\rho_{g}}{g\left(\rho_{\ell}-\rho_{g}\right.}\right)^{1 / 2}\right]^{1 / 2}+m\left[J_{\ell}\left(\frac{\rho_{\ell}}{g\left(\rho_{\ell}-\rho_{g}\right.}\right)^{1 / 2}\right]^{1 / 2}=c \text {. }
$$

The equation that is used to calculate the enthalpy of the water entering the downcomer is

$$
h_{\text {in }}=h_{U A}-\frac{\dot{\mathrm{m}}_{22} h_{22}+\dot{\mathrm{m}}_{\mathrm{dg}} \mathrm{h}_{\mathrm{g}}+\mathrm{Q}_{\mathrm{UA}}}{\dot{\mathrm{m}}_{\mathrm{r} n}+\dot{\mathrm{m}}_{\mathrm{r}}}
$$

where $\dot{\mathrm{m}}_{\mathrm{dg}}$ would be equal to the effective mass flow corresponding to $\mathrm{J}_{\text {eff }}$ and $\dot{\mathrm{m}}_{\mathrm{d}}$ would be equal to the water flow corresponding to $\mathrm{J}_{\ell}$.

The equation that describes the heat transfer from the downcomer walls is

$$
\dot{\mathrm{q}}^{\prime \prime}=\mathrm{h}_{\mathrm{d}}\left(\mathrm{T}_{\text {wa11 }}-\mathrm{T}_{\text {sat }}\right) \text {. }
$$

The value of the heat transfer coefficient depends on the axial position on the wall that is of interest. Above the calculated falling film position, the heat transfer coefficient is assumed to be a high constant value. Below the falling film position the heat transfer coefficient is assumed to be a low, constant value. The position of the falling film is calculated as 
described in the previous section. The wall surface temperature is calculated from the wall conduction heat transfer calculation and the saturation temperature is an input to the problem.

The solution of the preceding four equations gives a fourth-order polynomial in $\mathrm{J}_{\ell}$. The method of solving this fourth-order equation, as well as the method of coupling this solution with the wall condution heat transfer solutions, is described in Appendix E.

\section{COMPARISON OF PREDICTIVE METHOD RESULTS WITH TEST DATA}

The hot-wall countercurrent flow predictive method is based on assumptions that cannot be verified individually for correctness and sensitivity using the present data. However, data are available that can be compared with the calculated results from the predictive method. The experimentally determined time delay from the initiation of ECC until a significant amount of water reaches the lower plenum includes the time for the.water to reach the upper annulus through the cold leg piping. Therefore, the delay times from the data are larger than the time attributed only to the hot-wall effect. So, the predicted delay times were adjusted, as necessary, by adding this extra delay time in the cold leg to the predicted hot-wall time. A time of about 7 seconds was measured for the ECC to reach the lower plenum with cold downcomer walls and an ECC flow rate of 20 gpm (Section III-3.4). A proportional time was used for the higher ECC flow rates. The semiscale system transient countercurrent flow Tests 10 and 12 data indicated that a time of 5 seconds would be about the most reasonable adjustment that could be made, and for the blowdown Tests 1006 and 1008 the time was estimated to be less than a second.

A comparison between predictive method results and experimental data is shown in Figure 86 as a plot of predicted time delay of ECC delivery to the lower plenum versus the actual delay in delivery taken from the data. Perfect agreement between the data and the calculated delay time implies that the test points lie on the dashed 45 -degree line. The calculations for the longer delay times tend to be slightly above the perfect agreement line and the calculations for shorter delay times generally fall below the line. The success of the falling film model for predicting the delay in delivery for the largest downcomer gap size (1.69 inches for Tests 15.4 and 1009) may be fortuitous because a falling film was not indicated by the data from these tests.

The test results presented on Figure 86 cover a range of different test conditions including variations in downcomer gap size, ECC flow rate, and initial axial wall temperature profile. Tests 15.2 and 15.3 were conducted with gap sizes of 0.5 and 1 inch, respectively, and the results for these tests are a good example of the capability of the predictive method to predict the results of tests with different gap sizes, Tests 15.1 and 15.2 were conducted with ECC flow rates of about 21 and $52 \mathrm{gpm}$, respectively, and are a good example of the capability of the predictive method to predict the results of tests with different ECC flow rates, but with the same gap size. Tests 1006,1008 , and 1009 , which were isothermal blowdown tests with ECC injection during blowdown, were conducted with gap sizes of 0.5 , 1 , and 1.69 inches, respectively. As shown by Figure 86, the predictive method is reasonably accurate for the semiscale isothermal blowdown tests. 


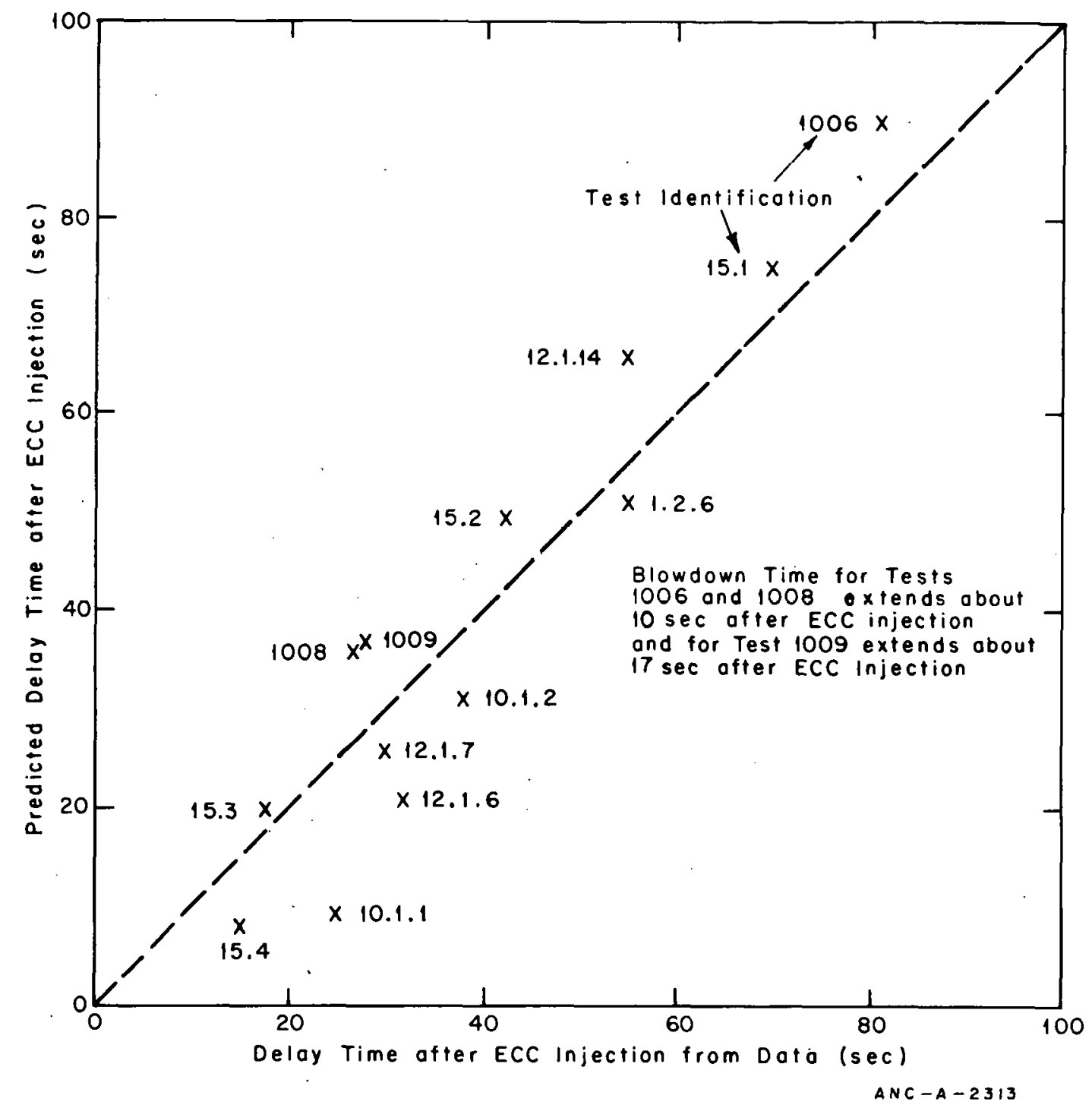

Fig. 86 Comparison of predieted delay times with data.

\section{SENSITIVITY STUDY}

A study was performed for the semiscale system to investigate the sensitivity of the predictive method to several variables of interest. The variables studied were downcomer wall material, downcomer gap size, initial pressure, initial wall temperature, ECC inlet temperature, ECC flow rate, downcomer length, wall thickness, heat transfer coefficients, the countercurrent flow correlation ordinate intercept constant $\mathrm{C}$, flow entering the downcomer from the lower plenum, and the fraction of wall generated steam which escaped the system without flowing up through the downcomer annulus. Each variable was changed from a selected nominal condition and the delay in lower plenum water delivery was noted. The nominal conditions used in the study are presented in Table VIII. 
NOMINAL SYSTEM VARIABLES FOR THE PREDICTIVE

METHOD SENSITIVITY STUDY

\begin{tabular}{ll}
\hline \multicolumn{1}{c}{ Variable } & \multicolumn{1}{c}{ Value } \\
\hline Wall material & Carbon steel \\
Downcomer gap & $1 \mathrm{in}$. \\
Initial system pressure & $60 \mathrm{psia}$ \\
Initial wall temperature & $500^{\circ} \mathrm{F}$ \\
ECC temperature & $120^{\circ} \mathrm{F}$ \\
ECC flow rate & $30 \mathrm{gpm}$ \\
Downcomer length & $85 \mathrm{in}$. \\
Wall thickness: core barrel & $0.75 \mathrm{in}$. \\
& $1.75 \mathrm{in}$. \\
Heat transfer coefficient & $3000 \mathrm{Btu} / \mathrm{hr}-\mathrm{ft}^{2}{ }^{\circ} \mathrm{F}$ \\
Countercurrent flow correlation & 0.495 \\
Constant, C & 0 \\
Flow from lower plenum & 0 \\
Fraction reverse flow & \\
\hline
\end{tabular}

The results of the predictive method sensitivity study are summarized in Table IX. The results for each of the variables are presented to indicate the predicted trends that result from changing the variables for the modeled semiscale geometry. Although the trends of the effect on the delay in lower plenum delivery of changing a variable would be the same, the relative magnitude of the change in the delay would not necessarily be the same in a system other than semiscale. Therefore, care should be taken in projecting the magnitude of the effect on the delay in lower plenum delivery of changing a variable from the semiscale geometry to a larger geometry.

The delay in lower plenum delivery for the nominal system variables is seen, from the results presented in Table IX, to be 23 seconds. A change in the wall material from carbon steel to stainless steel decreases the delay in delivery because the stainless steel has a lower thermal diffusivity which causes the surface temperatures, and consequently the surface 
TABLE IX

RESULTS OF PREDICTIVE METHOD SENSITIVITY STUDY ${ }^{\text {[a] }}$

\begin{tabular}{|c|c|c|}
\hline Variable & $\begin{array}{l}\text { Value of } \\
\text { Variable }\end{array}$ & $\begin{array}{l}\text { Delay in Lower Plenum } \\
\text { Delivery (sec) }\end{array}$ \\
\hline Downcomer wall material & $\begin{array}{c}{[\mathrm{a}] \text { Carbon steel }} \\
\text { Stainless } \\
\text { steel }\end{array}$ & $\begin{array}{l}23 \\
16\end{array}$ \\
\hline Downcomer gap size (in.) & [a] $]_{1.0}^{0.5}$ & $\begin{array}{l}65 \\
23\end{array}$ \\
\hline Pressure (psia) & 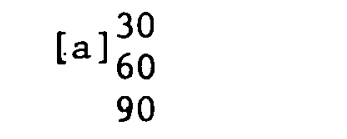 & $\begin{array}{l}40 \\
23 \\
15\end{array}$ \\
\hline Initial wall temperature $\left({ }^{\circ} \mathrm{F}\right)$ & {$[a]_{500}^{400}$} & $\begin{array}{r}8 \\
23 \\
40\end{array}$ \\
\hline ECC inlet temperature $\left({ }^{\circ} \mathrm{F}\right)$ & {$[\dot{a}] \begin{array}{r}60 \\
120 \\
180\end{array}$} & $\begin{array}{l}21 \\
23 \\
25\end{array}$ \\
\hline ECC flow rate (gpm) & {$[\mathrm{a}] \begin{array}{r}5 \\
30 \\
60\end{array}$} & $\begin{array}{l}36 \\
23 \\
21\end{array}$ \\
\hline Downcomer length (in.) & $\begin{array}{r}{[a]^{40}} \\
85 \\
160\end{array}$ & $\begin{array}{r}8 \\
23 \\
48\end{array}$ \\
\hline Wall thickness, (in.) & [a] $\begin{array}{c}0.125 \\
\text { thick }\end{array}$ & $\begin{array}{r}6 \\
23\end{array}$ \\
\hline $\begin{array}{l}\text { Heat transfer coefficient } \\
\left(\text { Btu } / \mathrm{hr}-\mathrm{ft} \mathrm{t}^{2}-{ }^{\circ} \mathrm{F}\right)\end{array}$ & 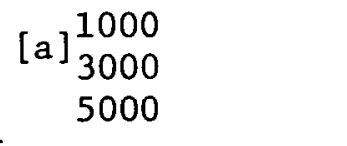 & $\begin{array}{l}17 \\
23 \\
24\end{array}$ \\
\hline $\begin{array}{l}\text { Countercurrent flow correlation } \\
\text { constant, } C\end{array}$ & $\begin{array}{r}0.300 \\
0.495 \\
0.700\end{array}$ & $\begin{array}{l}75 \\
23 \\
10\end{array}$ \\
\hline $\begin{array}{l}\text { Lower plenum steam flow } \\
(\mathrm{ft} / \mathrm{sec})\end{array}$ & $\begin{array}{r}{[\mathrm{a}] 0} \\
10 \\
15\end{array}$ & $\begin{array}{l}23 \\
45 \\
75\end{array}$ \\
\hline Fraction reverse flow & $\begin{array}{l}{[\mathrm{a}]} \\
0 \\
0.2 \\
0.4\end{array}$ & $\begin{array}{l}23 \\
17 \\
11\end{array}$ \\
\hline
\end{tabular}

[a] Indicates standard reference case. 
heat fluxes in the downcomer to be lower as a function of time. By decreasing the downcomer gap size, the amount of steam that must be generated on the walls to restrict the downward flow of water is decreased and the walls cool at a slower rate. The slower cooling of the walls results in the longer delay in delivery, as indicated.

The amount of energy that is available for removal from the downcomer walls is dependent on the initial wall temperature, and for the predictive method, the saturation temperature. Since the initial wall temperature must be a certain number of degrees above the saturation temperature to cause enough heat transfer to delay lower plenum delivery, any attempt to simply predict trends in delay in delivery that result from changes in wall temperature or saturation temperature would have to account for the difference between the initial wall temperature and the minimum wall temperature that will cause a delay in delivery. From the changes made in the saturation temperature through varying pressure and the changes made in the wall temperature, the delay in delivery is shown to be a function of the amount of energy that must be removed from the wall to cool most of the wall to within about 40 to $50^{\circ} \mathrm{F}$ of the saturation temperature.

Both the ECC injection temperature and the ECC injection rate affect the temperature of the fluid in the upper annulus and the temperature of the fluid entering the downcomer. The results from the sensitivity study indicate that changes in the inlet temperature do not result in big changes in the delay of delivery to the lower plenum even though the range of temperature changes resulted in a factor of two change in the amount of subcooling of the inlet water. Variations in the inlet flow indicate that the delay in delivery is not very sensitive to the amount of subcooling caused by increased flow but is sensitive to whether sufficient flow is present to result in subcooled water entering the downcomer rather than saturated water. With the low inlet flow rate of $5 \mathrm{gpm}$, no subcooling occurs and the resulting delay in delivery is much longer than for the cases for which subcooling occurs. For inlet flow rates between 30 and 60 gpm, the amount of subcooling of the water in the upper annulus is roughly doubled but the delay in delivery changes very little.

The results of the sensitivity study indicate that the downcomer length has a strong influence on delay in delivery. The delay in delivery for the longest downcomer is about six times longer than that for the shortest downcomer. The delay in delivery does not change in a manner that is directly proportional to an increase in length because the total rate of heat transfer from a wall is not directly proportional to a change in length owing to continued heat transfer from portions of the wall covered early in time.

The downcomer wall thickness determines the amount of stored energy that is available to generate steam and influences the rate of energy removal from the walls. Since a thin metal wall insulated from the downcomer wall by steam is being considered for future semiscale programs, a 0.125 -inch-thick metal wall was investigated. The results indicate that the thinner wall allows the water to reach the lower plenum much earlier because of the decreased energy available to generate steam.

The heat transfer coefficient input to the predictive method determines the amount of wall that must be covered by the falling film to generate the steam necessary to restrict the 
water flow into the downcomer. If the heat transfer coefficient is low, the wall will cover rapidly and water will be delivered to the lower plenum early. As the heat transfer coefficient increases, the delay increases because the falling film does not need to cover as much wall to generate the steam necessary to restrict the downcomer water flow. When the heat transfer coefficient becomes large the heat flux will approach a conduction-limited situation in which the heat flux will become relatively insensitive to an increase in the heat transfer coefficient. The increase in delay and the effect of conduction limiting are observed in the sensitivity study results.

The constant $\mathrm{C}$ in the dimensioned form of the countercurrent flow correlation, Equation (23), determines the amount of steam flow which will restrict all water from flowing in the downcomer. A low value of this constant would indicate that a small amount of steam flow would stop water flow to the lower plenum and, therefore; the falling film would only need to progress slowly to produce this amount of steam. Conversely, a high value of $\mathrm{C}$ would indicate that large amounts of steam flow would be necessary to greatly restrict the downcomer water flow, and therefore, the falling film would progress rapidly and the water would reach the lower plenum in a short time. This behavior is indicated in the variation of $C$ in the sensitivity study.

If fluid is entering the downcomer from the lower plenum, the velocity in the downcomer will be increased and the amount of steam generation on the walls that is necessary to cause a restriction of water flow into the downcomer will be decreased. Since the steam generation will be decreased, the falling film will progress more slowly and the delay in delivery to the lower plenum will be increased. If some of the steam generated in the downcomer flows downward, rather than upward, the amount of steam generation necessary to restrict the flow of water into the downcomer will be increased and the delay time decreased. These trends are observed in the results to the sensitivity study.

\section{APPLICATION OF PREDICTIVE METHOD TO LARGER SYSTEMS}

The hot-wall countercurrent flow predictive method described in the previous sections was developed for the semiscale system strictly from semiscale data. This method has not been tested against data from geometries larger than the semiscale system, and therefore, the accuracy of the method for estimating the hot-wall effect on delivery of ECC to the lower plenum in a larger geometry has not been determined.

Since the isothermal blowdown tests produced downcomer wall temperatures between 400 and $500^{\circ} \mathrm{F}$ at the end of the blowdown, hot-wall (nonblowdown) calculations of the delay in delivery to the lower plenum for two geometries larger than the semiscale geometry were made with each of these initial wall temperatures to provide an indication of what the delay in delivery might be. A hot-wall calculation for the Loss-of-Fluid Test (LOFT) geometry with an ECC injection rate of 726 gpm gave hot-wall delay times of 4 and 12 seconds for initial downcomer wall temperatures of 400 and $500^{\circ} \mathrm{F}$, respectively. A similar hot-wall calculation for a 4.5-inch downcomer gap width with the downcomer outside 
diameter of 164 inches, an ECC injection rale of $34,500 \mathrm{gpm}$, and an initial wall temperature of 400 and $500^{\circ} \mathrm{F}$ indicate the delay in delivery to the lower plenum would be about 0.3 and 1.7 seconds, respectively, for the two temperatures. 


\section{CONCLUSIONS}

The ECC-related phenomena in the semiscale geometry have been investigated through the means of several coordinated test programs. The results from these tests have led to an increased understanding of the heat transfer and flow processes that are occurring in the intact loop cold leg, upper annulus, downcomer, and lower plenum regions. The results from tests in the semiscale geometry cannot be related directly to the ECC-associated phenomena in a PWR because of scaling compromises in the semiscale system. However, the semiscale ECC performance data are valuable for evaluating the adequacy and improving the predictive capability of analytical models developed to predict system response and ECC behavior during an LOCA.

The authors have reached a number of conclusions from the results of the semiscale data analysis. Following is a summary of these conclusions.

\section{INTACT LOOP COLD LEG}

Cold leg piping surface heat fluxes and heat transfer coefficients near the ECC injection port were calculated from pipe wall temperature measurements. The calculated wall heat fluxes and heat transfer coefficients were predicted well by single-phase heat transfer correlations indicating that boiling at the pipe walls was suppressed. The suppression of the boiling mechanism appears to result because the ECC flowing in the cold leg pipe retained a relatively large amount of subcooling.

Measurements made at the pump discharge and near the vessel inlet were used to determine the distribution of the ECC in the cold leg pipe during and following blowdown. During blowdown, the measurements near the vessel inlet showed single-phase subcooled water flow entering the vessel, whereas measurements near the pump discharge showed high quality fluid flowing toward the injection port. The momentum of the fluid in the cold leg pipe during blowdown appears to force the ECC toward the vessel. Near the end of blowdown and following the completion of blowdown, some ECC periodically flowed back to near the pump discharge but the active pump forced this flow away from the pump discharge.

The temperature of the ECC flowing in the cold leg pipe was influenced by condensation of high quality blowdown fluid and by piping heat transfer with condensation being the strongest influence. Density measurements about 16 inches downstream of the injection port indicated that condensation was complete by the time the ECC reached this position. The amount of condensation that occurred in the cold leg was nearly the same over a range of ECC injection rates from a near volumetrically scaled injection rate to about 2.4 times the volumetrically scaled injection rate. 
The pressure fluctuations in the semiscale cold leg piping during blowdown that are caused by subcooled water injection into the high quality blowdown fluid are about \pm 2 psi which is of lower amplitude than the pressure fluctuations observed in the Combustion Engineering Inc. steam-water mixing tests. Following the end of blowdown, the amplitude of the pressure fluctuations in the semiscale system increase but are seldom larger than 10 psi. Some of the Combustion Engineering Inc. data show similar pressure fluctuations whereas other data show much larger pressure fluctuations than those observed in semiscale following blowdown.

\section{UPPER ANNULUS}

An upper annulus mass balance, using instrumentation at the intact loop and broken loop cold legs, was used to calculate the mass flow at the downcomer entrance. This mass balance indicated much later flow reversal than the downcomer turbine flowmeter velocity measurements, indicating the possibility of fluid draining down the sides of the downcomer after the flow in the center of the downcomer had reversed. A RELAP4 calculation showed earlier flow reversal at the downcomer entrance than the flow calculated from this mass balance.

A simplified energy balance on the upper annulus appears to be accurate enough to calculate an approximate upper annulus bulk fluid temperature. This energy balance indicated that a large percentage of the energy transferred to the injected ECC came from condensation in the upper annulus region. The condensation occurring in the upper annulus appears to cause pressure suppression in this region when the ECC injection rate is above about 2.4 times the volumetrically scaled injection rate.

\section{DOWNCOMER}

The effect of countercurrent flow on delivery of water to the lower plenum was investigated in the semiscale geometry. The form of the Wallis countercurrent flow correlation was shown to correlate the air-water countercurrent flow data in the semiscale geometry for individual downcomer gap sizes but would not correlate the data from a range of gap sizes to a single line. The density term in the Wallis correlation correlated countercurrent flow data for pressures ranging from 20 to 42 psia. Removal of the geometric factor (the hydraulic diameter term) from the form of the Wallis correlation allowed the resulting dimensional parameters to correlate to a single line the data from downcomer gap sizes ranging from 0.5 to 1.58 inches. A dimensionless parameter was found which also correlated the air-water data and has the capability of correlating countercurrent flow data taken for different types of fluids.

Countercurrent flow in the semiscale size downcomer controlled the water delivery to the lower plenum for air flow rates above a volumetric flux of $\mathrm{J}_{\mathrm{g}}^{* 1 / 2}=0.33$. Below this value, whether countercurrent flow controlled or not depended on the water flow rate. If the water flow rate was sufficiently large, the gas velocity was forced to be high enough to 
cause countercurrent flow and some restriction of the flow to the lower plenum. If the water flow was not high enough, buoyancy forces and flow sweeping in the semiscale upper annulus appeared to control the delivery to the lower plenum.

The effect on countercurrent flow in the semiscale geometry of upper annulus geometry, two-phase mixtures entering the upper annulus from the cold leg, and downcomer length were investigated in air-water tests. The effect on the countercurrent flow in the semiscale downcomer of upper annulus geometry variations and of a two-phase mixture entering the upper annulus were negligible. The effect on countercurrent flow of shortening the semiscale downcomer was negligible for all but the shortest length downcomer. For the shortest length downcomer investigated, the velocity of the fluid entering from the cold leg appeared to influence the delivery to the lower plenum. When the fluid velocity was low, asymmetric flow occurred with most of the water flowing down one side of the downcomer and most of the air flowing up the other side. When the fluid velocity was increased, the water was more evenly distributed around the downcomer and symmetric countercurrent flow in the downcomer occurred.

Steam-water countercurrent flow investigations were conducted in the semiscale geometry. The steam-water countercurrent flows were influenced strongly by condensation and evaporation. When the countercurrent steam flow was not sufficiently high to raise the water that reached the entrance to the downcomer to saturation temperature, condensation in the downcomer completely condensed the countercurrent steam flow and all of the water entering the vessel fell to the lower plenum. Energy entering the downcomer from the downcomer walls evaporated some of the water in the downcomer causing an increased countercurrent steam velocity in the downcomer and thereby caused less water to be delivered to the lower plenum.

Differential pressure and velocity measurements in the downcomer as well as flow and density measurements at the boundaries to the downcomer were used to aid in an interpretation of the phenomena occurring in the downcomer during blowdown. The differential pressure measurements provided an indication of the density of the fluid in the downcomer over the first 15 to 20 seconds of the blowdown period. This calculated density indicates axial density differences in the downcomer after about the first 7 seconds of the blowdown. The velocity measurements in the downcomer were used with saturation densities to calculate a countercurrent flow dimensional flux during blowdown. These calculated dimensional fluxes are sufficiently high during blowdown to restrict most countercurrent flow of water according to the steady state countercurrent flow correlations derived from air-water and steam-water data. The calculated downcomer densities indicate that the density in the downcomer remains low until the dimensioned volumetric flux drops below a threshold value. Therefore, little water appears to have entered the semiscale downcomer until the completion of blowdown.

The effects of hot downcomer walls on the delivery of ECC to the lower plenum of the semiscale system are exaggerated compared to the effects of hot downcomer walls on lower plenum delivery in a PWR, because the downcomer surface-area-to-volume ratio in the semiscale system is about a factor of ten higher than this ratio in a PWR. This large 
difference in downcomer surface-area-to-volume ratio results because of compromises necessary in scaling a small systcm from a much larger system. The disproportionate downcomer surface area in the vessel used for the semiscale system countercurrent flow tests and the isothermal system tests allowed sufficient amounts of heat to be transferred to the downcomer fluid to restrict the water flow to the lower plenum for long periods of time. The restriction of water flow into the downcomer appears to result from steam generation at the downcomer walls raising the downcomer steam velocity sufficiently to cause countercurrent flow. The isothermal test results indicated that increasing the ECC injection rate or increasing the downcomer gap size decreased the delay in delivery to the lower plenum that resulted because of hot downcomer walls.

\section{LOWER PLENUM}

The amount of mass that remained in the lower plenum during blowdown was generally less than that which would have remained if only the mechanisms of flashing and lower plenum heat transfer had affected the lower plenum mass. The large reverse core flow that resulted when ECC was injected caused significant lower plenum mass loss over that which occurred during non-ECC tests. The postulated mechanisms of lower plenum water loss that occurred during ECC injection tests included level swell and liquid surface oscillations in the lower plenum which forced water into the downcomer where the downcomer flow velocity was high enough to result in entrainment and subsequent removal from the system.

ECC was injected directly into the lower plenum during one isothermal blowdown test. In contrast to the semiscale single-loop lower plenum ECC injection tests, the ECC injected directly into the lower plenum during the isothermal tests was not expelled but accumulated and remained in the lower plenum.

\section{HOT.WALL PREDICTIVE METHOD}

A predictive method was developed for the semiscale system to predict the delay in delivery of water to the lower plenum that was caused by the hot downcomer walls. This method is based on the results from the coordinated test program to investigate the ECC performance in the semiscale geometry. The method predicts the delay in lower plenum delivery in the semiscale system with reasonable accuracy. 


\section{REFERENCES}

1. K. V. Moore and W. H. Rettig, RELAP4 - A Computer Program for Transient Thermal-Hydraulic Analysis, ANCR-1 127 (December 1973).

2. S. A. Naff, R. S. Alder, P. A. Pinson, Experiment Data Report for Semiscale System Countercurrent Flow Tests, ANCR-1151 (June 1974).

3. S. A. Naff and P. A. Pinson, 1-1/2-Loop Semiscale Isothermal Test Program - Program and System Description in Support of Experiment Data Reports, ANCR-1143 (February 1974).

4. R. S. Alder, E. M. Feldman, D. J. Olson, P. A. Pinson, Experiment Data Report for 1-1/2-Loop Semiscale System Isothermal Tests 1001, 1002, and 1003, ANCR-1 148 (May 1974).

5. R. S. Alder, E. M. Feldman, P. A. Pinson, Experiment Data Report for 1-1/2-Loop Semiscale System Isothermal Tests 1004 and 1006, ANCR-1144 (March 1974).

6. R. S. Alder, E. M. Feldman, P. A. Pinson, Experiment Data Report for 1-1/2-Loop Semiscale System Isothermal Tests 1008 and 1010, ANCR-1145 (March 1974).

7. R. S. Alder, E. M. Feldman, P. A. Pinson, Experiment Data Report for 1-1/2-Loop Semiscale System Isothermal Test 1011, ANCR-1146 (March 1974).

8. E. M. Feldman and P. A. Pinson, Experiment Data Report for 1-1/2-Loop Semiscale System Isothermal Test 1014, ANCR-1 147 (March 1974).

9. E. M. Feldman, Experiment Data Report for 1-1/2-Loop Semiscale System Isothermal Test 1009, ANCR-1152 (June 1974).

10. E. M. Feldman and P. A. Pinson, Experiment Data Report for Semiscale Isothermal Test Program Hot-Wall Tests, ANCR-1 149 (May 1974).

11. J. R. S. Thom et al, "Boiling in Subcooled Water During Flow Up Heated Tubes or Annuli”, Proc. Instn. Mech. Engrs., Vol. 180, Part 3C, (1966) pp 226-246.

12. M. Jakub, Heat Transfer, Vol. 1, New York, Wiley and Sons (1957).

13. J. C. Chen, "A Correlation for Boiling Heat Transfer to Saturated Fluids in Convective Flow", I\&EC Process Design and Development, Vol. 5 No. 3 (July 1966) p 322.

14. W. E. Burchill, P. A. Lowe, J. R. Brodrick, Steam-Water Mixing Test Program, 1/3 Scale Loop, Combustion Engineering, Inc., CENPD-101 (October 1973). 
15. J. R. Brodrick, W. E. Burchill, P. A. Lowe, $1 / \overline{5}$ Scale Intact Loop Post-LOCA Steam Relief Tests, Combustion Engineering, Inc., CENPD-63 Revision 1 (March 1973).

16. W. H. Westendorf and W. F. Brown, Stability of Intermixing of High-Velocity Vapor with Its Subcooled Liquid in Concurrent Streams, NASA TN D-3553 (October 1966).

17. G. B. Wallis, One-Dimensional Two-Phase Flow, McGraw-Hill (1969).

18. R. W. Shumway, D. L. Caraher, G. G. Loomis, G. E. McCreery, Thermal-Hydraulic Response During Semiscale Isothermal Blowdown Experiments, ANCR-1162 (August 1974).

19. D. J. Olson, Semiscale Blowdown and Emergency Core Cooling (ECC) Project Test Report - Tests 848, 819, and 850 (ECC Irijection), ANCR-1036 (July 1972). 


\section{THIS PAGE}

\section{WAS INTENTIONALLY \\ LEFT BLANK}




\section{APPENDIX A \\ ERROR ANALYSIS OF THE INVERS DATA REDUCTIOON METHOD AS APPLIED TO SEMISCALE}




\section{THIS PAGE}

\section{WAS INTENTIONALLY LEFT BLANK}




\section{APPENDIX A \\ ERROR ANALYSIS OF THE INVERS DATA REDUCTION \\ $<$ METHOD AS APPLIED TO SEMISCALE}

Heat fluxes to the primary coolant loop of the semiscale system have been estimated using temperature measurements obtained from thermocouples located within the metal walls (usually $1 / 16$ to $1 / 8$ inch from the inside surface). These measurements were obtained at locations within the wall in order to maintain the integrity of the wall and to preclude flow disturbance.

The problem of determining wall temperatures and surface heat fluxes from internal temperature histories is generally termed the inverse heat conduction problem. This conduction problem is presently solved through use of the computer program INVERS, which utilizes an explicit finite difference procedure described by Beck ${ }^{[\mathrm{A}-1]}$. This procedure is used to solve the nonlinear, one-dimensional, conduction problem with temperature variant and spatially variant thermal properties.

The INVERS code is generalized and can be used for many different geometrical configurations. The key assumption in INVERS is that only one-dimensional heat conduction is occurring. Possible errors in the results are dependent on (a) the validity of this assumption, (b) the sensitivity of the code to the manner in which the input actually models the system and controls the running of the code, and (c) the uncertainties in the initial tempcrature conditions and in the transient temperature measurements. Errors resulting from the sensitivity of the code to input parameters can be minimized, to the extent practical consistent with the desired running time of the problem, by optimizing certain input parameters. The errors resulting from uncertainties in the temperature conditions can be determined by estimating the amount of uncertainty in the temperature data. The applicability and accuracy of INVERS for use in estimating the heat fluxes in the semiscale primary coolant loop has been determined through use of an empirical approach as outlined in the following sections.

\section{INPUT OPTIMIZATION FOR SEMISCALE}

As with most heat transfer computer codes, the results (calculated heat fluxes and surface temperatures) obtained from INVERS are sensitive to the size of the nodes used in the modeling of the geometry and to the size of the time steps used in the calculations. The calculated heat fluxes and surface temperatures at a point in time are also sensitive to the amount of data from future times that is used in the calculations. 
A study was made to aid in minimizing the calculational error while at the same time optimizing the code running time for different node sizes, time steps, and advanced time steps. A brief description of this study follows.

\section{$1.1 \quad$ Nodalization Studies}

In order to determine the probable error in typical applications of INVERS, calculations were performed for a conduction problem having a known analytical solution. The problem considered was for an infinite solid with a uniform initial temperature $\mathrm{T}_{\mathrm{i}}$ and a surface temperature $T_{s}$ imposed at zero seconds. The solution may be obtained from any basic conduction heat transfer text and is given by

$$
T=T_{s}+\left(T_{i}-T_{s}\right) \operatorname{erf}(x / 2 \sqrt{\alpha t})
$$

or in terms of surface heat flux by

$$
q^{\prime \prime}=k\left(T_{i}-T_{s}\right) / \sqrt{\pi \alpha t} \quad
$$

INVERS was run with constant thermal properties (typical of stainless steel) and with equal size nodes near the surface and with nodes of increasing size away from the surface of the solid in order to simulate a very thick wall with a limited number of nodes. Table A-I presents the error in the INVERS calculations for node sizes near the surface of $1 / 32$ and $1 / 128$ inch. Except for the first second, the results from INVERS for the $1 / 32$-inch nodes agree to within $4 \%$ with the known analy tical solutions for the surface heat fluxes and internal temperatures; the results from the $1 / 128$-inch nodes agree to within $2 \%$. The agreement attained through use of 1/32-inch nodes appears to be adequate for reduction of semiscale data.

The effect of node size was also investigated for conditions of rapidly varying pipe wall heat flux (at Spool Piece 19 during hot-wall Test 15.1) to provide a comparison of INVERS results for various radial node sizes. The error in the heat flux (relative to results for a reference 1/256-inch node size) at various times is listed in Table A-II for three different node sizes. The percent error decreases substantially with decreasing radial node size. The times at which the results are presented correspond to the occurrence of minimum and maximum values of the reference heat flux, and for the most part, represent the maximum error for the larger node sizes investigated. A node size of $1 / 32$ inch resulted in a reasonable balance between accuracy and computation time; thus this node size was used for reduction of the semiscale data.

\subsection{Time Step Size Studies}

A series of INVERS calculations was performed for a pipe wall typical of the semiscale intact loop piping to determine the effect of varying the size of the time step. The 
TABLE A-I

ERROR IN INVERS CALCULATIONS RELATIVE TO KNOWN

ANALYTICAL SOLUTION FOR SEMI-INFINITE SOLID

\begin{tabular}{|c|c|c|c|c|}
\hline \multirow[b]{2}{*}{$\begin{array}{l}\text { Time } \\
(\mathrm{sec}) \\
\end{array}$} & \multicolumn{2}{|c|}{$\begin{array}{c}\text { Percent Error } \\
\text { (1/32-in. nodes) }\end{array}$} & \multicolumn{2}{|c|}{$\begin{array}{c}\text { Percent Error } \\
(1 / 128-i n . \text { nodes })\end{array}$} \\
\hline & $\begin{array}{l}\text { Surface } \\
\text { Heat Flux } \\
\end{array}$ & $\begin{array}{l}\text { Temperature } \\
1 / 4 \text { in. from } \\
\text { surface } \\
\end{array}$ & $\begin{array}{l}\text { Surface. } \\
\text { Heat Flux } \\
\end{array}$ & $\begin{array}{l}\text { Temperature } \\
1 / 4 \text { in. from } \\
\text { surface } \\
\end{array}$ \\
\hline 0.3 & -8.3 & 0 & -16.7 & 0 \\
\hline 0.7 & -5.3 & 0.2 & -7.6 & 0.2 \\
\hline 1.0 & -2.6 & 0.8 & -6.4 & 0.5 \\
\hline 2.0 & 0.4 & 2.7 & 1.1 & 0.5 \\
\hline 3.0 & 2.0 & 3.5 & 1.7 & 1.2 \\
\hline 4.0 & 3.1 & 3.7 & 1.6 & 1.2 \\
\hline 5.0 & 1.6 & 3.3 & 1.7 & 1.. 0 \\
\hline 7.0 & 3.5 & 2.5 & 1.2 & 0.8 \\
\hline 9.0 & 3.1 & 2.0 & 1.2 & 0.9 \\
\hline 12.0 & 1.9 & 1.3 & 0.4 & 0.7 \\
\hline
\end{tabular}

TABLE A-II

INVERS HEAT FLUX ERROR FOR VARIOUS RADIAL NODE SIZES

FOR TEST 15.1, SPOOL PIECE 19

\begin{tabular}{|c|c|c|c|}
\hline \multirow[b]{2}{*}{ Time (sec) } & \multicolumn{3}{|c|}{$\begin{array}{l}\text { Percent Error in Heat Flux Relative to } \\
\text { Results for } 1 / 256-\text { in. Node Size }\end{array}$} \\
\hline & 1/16-in. node & 1/32-in. node & 1/64-in. node \\
\hline 1.87 & 17.5 & 11.8 & 2.9 \\
\hline 4.27 & 14.3 & 8.2 & 4.1 \\
\hline .6 .67 & 11.5 & 0.8 & 0.1 \\
\hline 9.07 & 0.8 & 0.2 & 0 \\
\hline 11.47 & 1.5 & 0.5 & 0.1 \\
\hline .16 .27 & 2.0 & 1.0 & 0.3 \\
\hline 21.07 & 6.9 & 2.6 & 0.8 \\
\hline 25.87 & 2.4 & 1.0 & 0.2 \\
\hline
\end{tabular}


results indicate that the accuracy of INVERS is dependent on the capability of a given step size to represent adequately the input temperature data. That is, if the results are to predict adequately the heat transfer, the time step size must be sufficiently small that fluctuations in the data arc not skipped. The effect of time step size is shown in Figure A-1 for two différent time step sizes. The curves are offset slightly for clarity. For a time step of 0.24 second, the predicted surface temperature appears smooth because the major fluctuations in the input temperature are well represented. For a time step size of 0.96 second, the predicted surface temperature shows sharp changes in magnitude which result when some of the major fluctuations in the input data are skipped over because the time step is too large. The time step used for reduction of the semiscale data was less than 0.5 second because fluctuations in the semiscale data were on a larger time scale than 0.5 second.

\subsection{Time Advance Studies}

The unique feature of INVERS is the use of nonlinear estimation techniques to determine surface conditions, at a given time, from the initial radial temperature profile and future internal temperature changes. From the physics of the problem, the further the input temperatures are from the surface, the more future information is needed to estimate the present surface conditions. If insufficient future information is included at each time step, the computation procedure yields severe changes over short periods, and the surface fluctuations are overestimated. Conversely, if too much future information is included, the computation procedure yields slight changes over long periods and the surface fluctuations are underestimated. Thus, determination of the necessary time advance is based on engineering judgment. From numerous comparisons, the best advance times were found to be 2,3 , and 4 seconds for input temperature data from locations $1 / 16,1 / 8$, and $1 / 4$ inch from the surface, respectively. (These advance times are for Type 316 stainless steel; the requirements will change somewhat for materials of different thermal properties.) The results for three different time advances are shown in Figure A-2. The curves have been displaced slightly for clarity. The measured internal temperature profile is included for comparison. The result for the time advance selected for semiscale data reduction (1.96 seconds) exhibits nearly the same fluctuations as the measured internal profile, whereas the result for the 3.6-second time advance exhibits fluctuations of much smaller amplitude and the result for the 1.2-second time advance exhibits fluctuations of larger amplitude.

\section{ERRORS RESULTING FROM UNCERTAINTIES IN TEMPERATURE CONDITIONS}

Errors in the calculated surface heat fluxes and temperatures can result from uncertainties in the initial temperature conditions of the experimental system which are input to INVERS. Uncertainties in the initial temperature distribution in the metal surrounding the temperature measurement location can affect the INVERS results, as can errors in the initial and transient temperature measurements themselves. The following sections give an estimation of thie error that results from the uncertainties in the initial measured temperature distribution and the measured temperatures. 


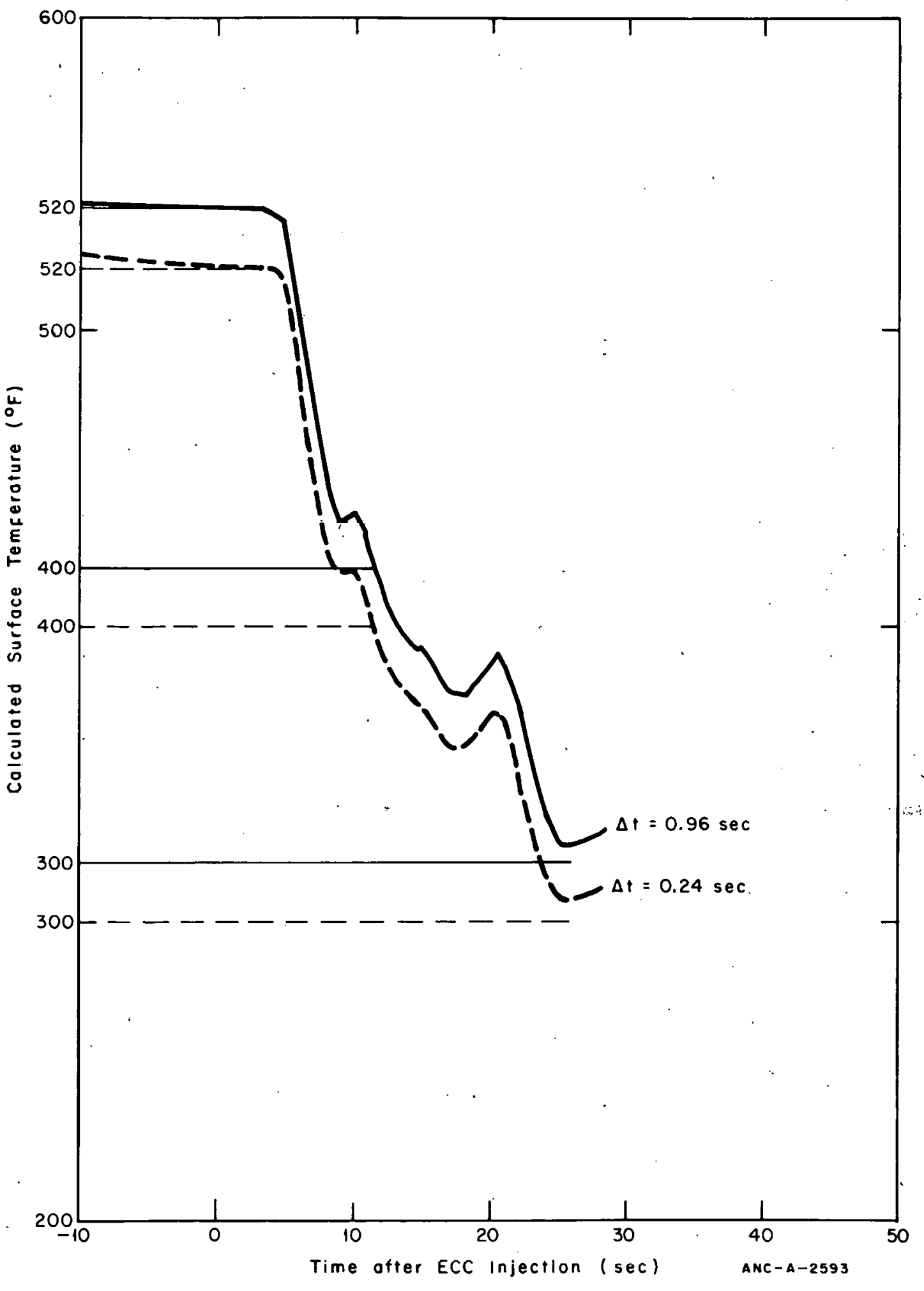

Fig. A-1 Comparison of INVERS surface temperature solutions for two time-step sizes. 


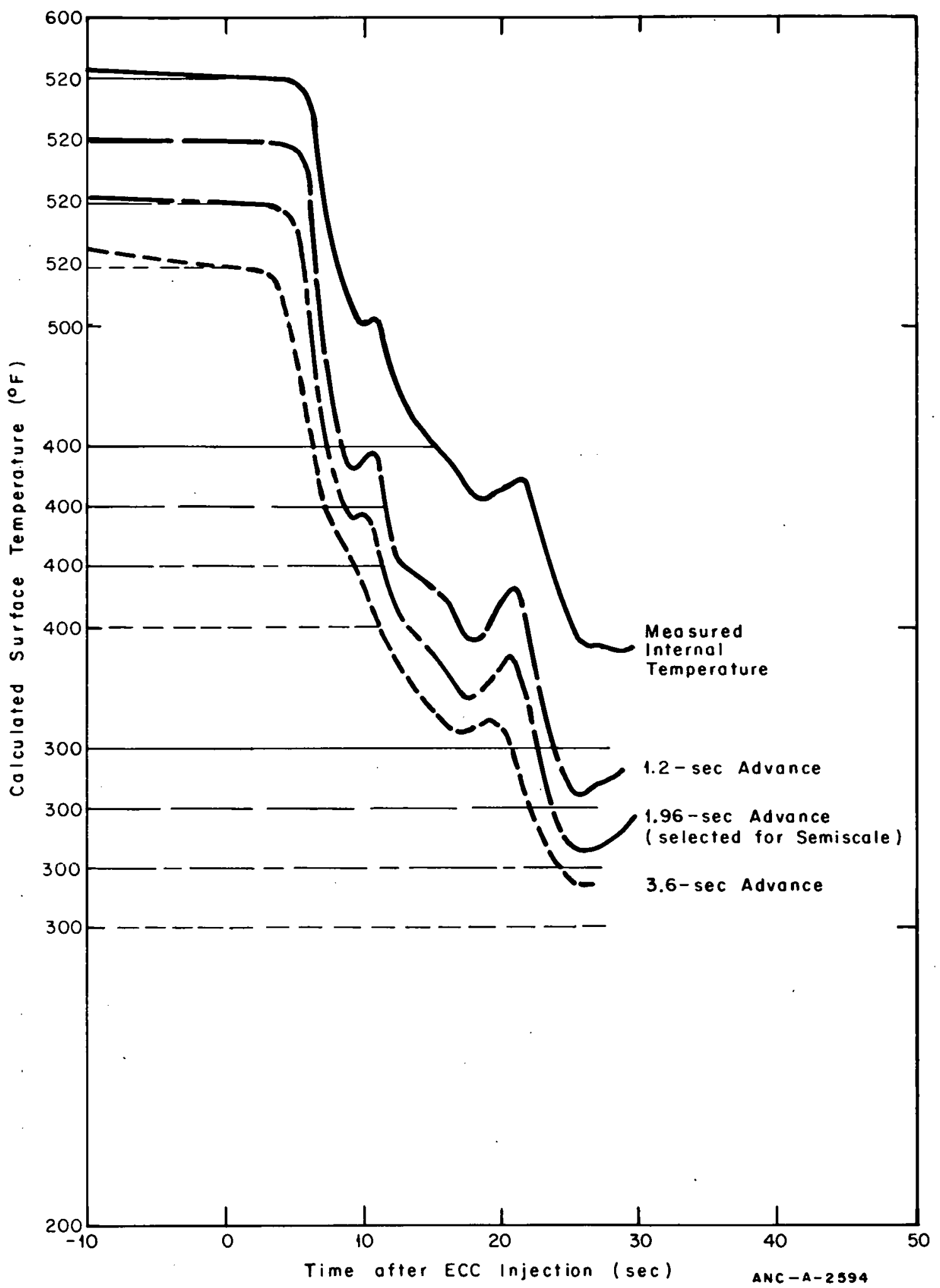

Fig. A-2 INVERS surface temperature solutions for three time advances compared to the internal temperature data. 


\subsection{Initial Temperature Distribulion}

For the conditions of the isothermal tests, thermal equilibrium is fairly well established at the start of each test so that an assumption of a constant wall temperature is fairly accurate. However, the INVERS solution is quite sensitive to the initial temperature distribution and for a short time during the initial portion of the transient, it may exhibit substantial error even for a very small initial temperature error. The error due to uncertainty in the initial temperature distribution was approximated by considering the case in which the initial temperature distribution. is in error by a constant value, $\Delta \mathrm{T}$. By considering the metal to be a semi-infinite solid with a suddenly imposed temperature change at the boundary, the heat flux per unit area, $q^{\prime \prime}$, that results from the $\Delta T$ uncertainty and that would be fictitiously imposed on the actual heat flux can be approximated by

$$
\mathrm{q}^{\prime \prime}=\mathrm{k} \Delta \mathrm{T} / \sqrt{\pi \alpha t} \text {. }
$$

From the semiscale data, the temperature distribution error, $\Delta T$, near the inside surface of the intact loop cold leg pipe was estimated to be about $2^{\circ} \mathrm{F}$. For a stainless steel wall, with a $2^{\circ} \mathrm{F}$ temperature error, the fictitious heat flux will have decayed to 1600 $\mathrm{Btu} / \mathrm{hr}-\mathrm{ft}^{2}$ after 1.0 second and for typical heat fluxes during blowdown or ECC injection (heat fluxes on the order of $10,000 \mathrm{Btu} / \mathrm{hr}^{-\mathrm{ft}^{2}}{ }^{2}$ ), the INVERS results can be expected to be accurate to within $10 \%$ for $t \geqslant 3$ seconds.

\subsection{Thermocouple Temperature Uncertainty}

The uncertainty in the temperature measurement in the wall is composed of three quantities. The first and largest uncertainty is due to the uncertainty in the measurement itself which has been estimated as $\pm 6^{\circ} \mathrm{F}$. The second is due to the uncertainty in the radial position of the thermocouple. For the manufacturing tolerances $( \pm 0.005$ inch) and for typical temperature gradients, the resulting uncertainty in temperature is $\pm 5^{\circ} \mathrm{F}$. The third error in temperature is due to nonuniformities in the pipe. (In some cases, instrumentation bosses were added quite close to the location of the thermocouple.) An estimation of the error in temperature due to nonuniformities in the pipe was made as follows.

The temperature gradient, tangential to the surface, was estimated by considering the wall temperature for a semi-infinite solid (a pipe wall with a very large boss attached) with typical ECC boundary conditions. This solution is compared to the predicted wall temperature for the actual pipe wall with no instrumentation bosses within close proximity. The difference between the two idealizations is a rough approximation of the temperature gradient due to the attached bosses. For the thermocouples located on the side of the pipe, this tangential temperature gradient resulted in an error of about $\pm 4^{\circ} \mathrm{F}$, but for the thermocouples located at the top of the pipe (used only for purposes of comparison in Figures A-3 and A-4 and not for the results presented for the semiscale tests) the error is estimated to be $\pm 25^{\circ} \mathrm{F}$. (This estimated difference is consistent with the difference in surface temperature prediction of about $25^{\circ} \mathrm{F}$ toward the end of Test 15.1 for the 
top-mounted thermocouple, TM-22M, compared to that for the side-mounted thermocouple, TM-22H.) The total uncertainty in the measured temperature is the square root of the sum of the squares of the separate uncertainties and is about $9^{\circ} \mathrm{F}$. The uncertainty in the calculated wall surface temperature would be about the same as the uncertainty in the measured temperature.

The uncertainty in the heat flux is not simply related to the uncertainty in the temperature measurement because the heat flux calculation depends on the time variation of the temperature and not on the absolute value. The uncertainty in the heat flux is, therefore, partially dependent on how well the temperature variation can be measured. The uncertainty can be approximated for the ideal case of a semi-infinite solid with a sudden change in surface temperature where the surface heat flux is related to the imposed temperature change by the equation

$$
q^{\prime \prime}=\left(T_{i}-T_{s}\right) \sqrt{k \rho c_{p} \pi t} .
$$

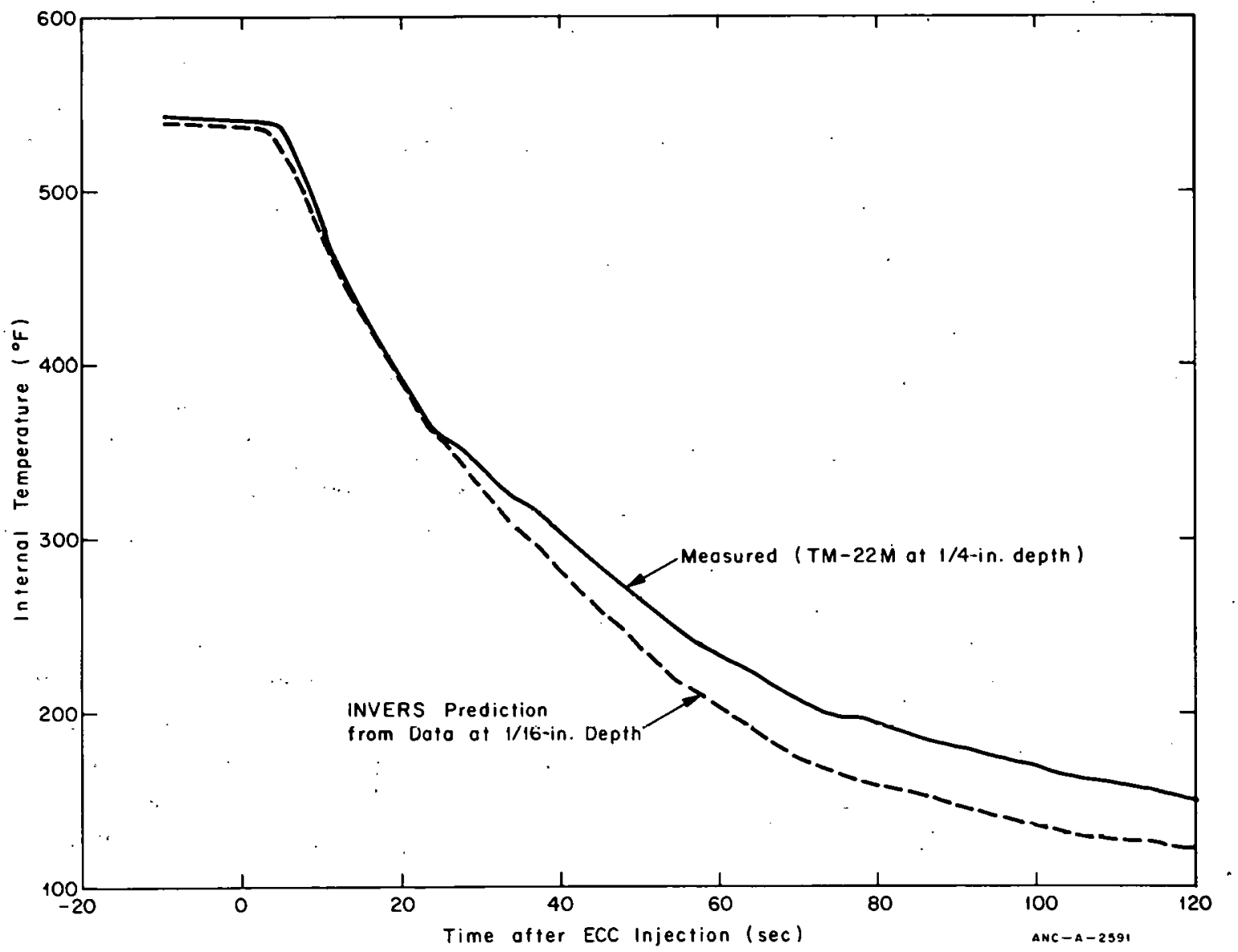

Fig. A-3 Internal temperature calculated by INVERS compared to measured internal temperature. 


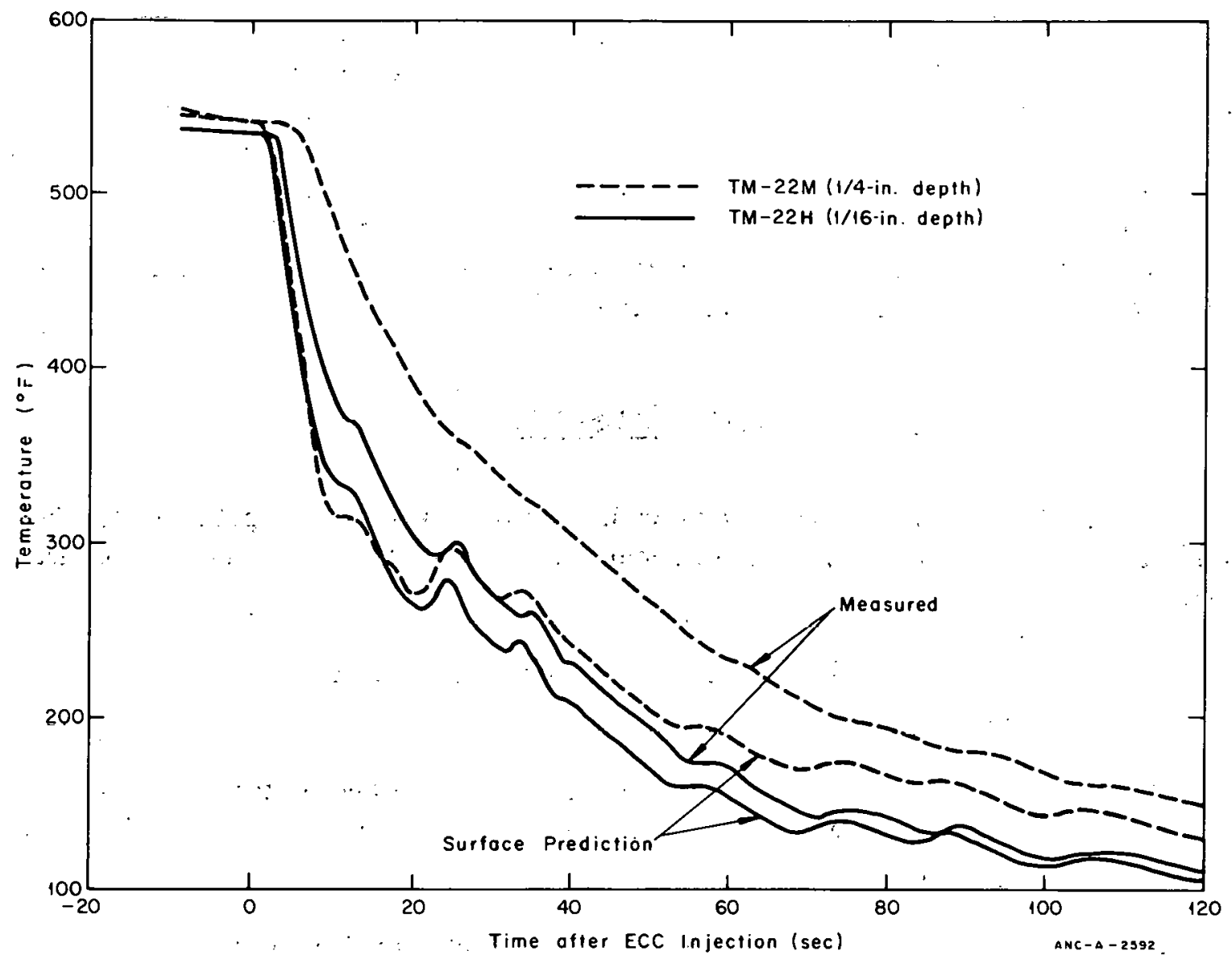

Fig. A-4 Surface temperatures calculated by INVERS compared to measured internal temperatures input to INVERS for two radial locations.

Since the uncertainties in time and density are relatively small, the uncertainty in heat flux, $\Delta \mathrm{q}_{\mathrm{S}}^{\prime \prime}$, is given by

$$
\Delta q_{s}^{\prime \prime} / q_{s}^{\prime \prime}=\sqrt{\left(\frac{\Delta T}{T_{i}-T_{s}}\right)^{2}+\left(\frac{1}{2} \frac{\Delta k}{k}\right)^{2}+\left(\frac{1}{2} \cdot \frac{\Delta c_{p}}{c_{p}}\right)^{2}} .
$$

The $\Delta \mathrm{T}$ shown in the preceding equation is the uncertainty in the time variation of the temperature, which can be affected by the data processing equipment. For the short duration of a test (about one minute), the sensitivity of the data processing equipment was assumed to be constant. This assumption was confirmed by a comparison of calibration signals taken before and after testing. Thus, the variation in output for a given thermocouple was considered to be only a function of the thermocouple sensitivity (known to within $\pm 1 \%$ ) and the calibration accuracy (estimated to be within $\pm 1 \%$ of the temperature variation plus $\pm 0.1^{\circ} \mathrm{F}$ due to signal noise). For a temperature variation greater than $5^{\circ} \mathrm{F}$, the total uncertainty is estimated to be less than $2 \%$ of the temperature change. For the thermocouples located. $1 / 16$ inch from the surface, the temperature at the thermocouple is 
very close to that at the surface (except for large heat fluxes) so the uncertainty in the surface temperature has nearly the same uncertainty as that at the thermocouple and, therefore, the uncertainty in the time variation of the surface temperature would be about the same as the uncertainty of the time variation at the thermocouple. The thermal properties of the wall material are estimated to be known to within $4 \%$. Thus, the total uncertainty in heat flux resulting from uncertainties in the time variation of temperature and in the thermal properties is estimated as $3.5 \%$.

\section{CONCLUSIONS}

The INVERS data reduction routine has been shown to be applicable to the conditions of the present experiment. The component errors in the calculated heat flux have been estimated as:

(1) $<10 \%$ for $t>3$ seconds, due to the error in initial temperature distribution

(2) $<4 \%$, due to uncertainties in the thermal properties of the material and the uncertainty in the measured temperature variation

(3) $<12 \%$, due to the numerical approximations for sharp changes in heat flux with considerably better agreement obtained for gradual changes in heat flux (Table A-II).

Since these errors can be assumed to be independent, the total uncertainty in heat flux is estimated to be $\pm 16 \%$.

The uncertainty in the surface temperature calculation was estimated to be $\pm 9^{\circ} \mathrm{F}$ and the wall-to-bulk temperature difference was estimated to be $\pm 10^{\circ} \mathrm{F}$. The uncertainty in wall-to-bulk temperature difference does not account for the error in the bulk fluid temperature measurements that result from radiation from the wall, which can become significant at high qualities and low velocities. These conditions occur as the fluid temperature approaches the wall temperature, which only happens near the end of the semiscale tests.

\section{REFERENCE}

A-1. J. V. Beck, "Nonlinear Estimation Applied to the Nonlinear .Inverse Heat Conduction Problem", Int. J. Heat Mass. Trans., 13, (1970) pp 703-716. 


\begin{abstract}
APPENDIX B
RELAP4, MODEL USED FOR THE INVESTIGATION OF ECC PERFORMANCE IN THE SEMISCALE GEOMETRY
\end{abstract}


THIS PAGE

\section{WAS INTENTIONALLY LEFT BLANK}




\section{APPENDIX B \\ RELAP4 MODEL USED FOR THE INVESTIGATION OF ECC PERFORMANCE IN THE SEMISCALE GEOMETRY}

The RELAP4 computer program is designed to calculate the thermal-hydraulic response of a system which is undergoing a depressurization. The program is generalized such that a variety of system configurations and operating conditions can be modeled. The system to be modeled is divided into interconnecting control volumes with the number of control volumes depending on the geometric and thermodynamic features of the system. The geometric features that are necessary to describe the control volumes include: fluid volume, elevation, flow area, flow resistance, surface areas within the volume when heat transfer between the metal and fluid can occur, and the volume of the material that can exchange heat with the fluid. Thermodynamic features that are necessary to describe the features of the control volume are: power generation in the material that is part of the control volume, thermal properties of the material in the control volume, and state properties of the fluid. Specialized input to RELAP4 is required to describe a pump if the pump is present in the system being modeled. Other input specifies the heat transfer correlations to be used for the heat transfer surfaces and the choked flow model to be used. Given the geometric, thermodynamic, and other specialized input, as well as the initial conditions of the system, RELAP4 solves an integral form of the momentum, energy, and mass conservation equations for each control volume to calculate the flow rates, pressure, enthalpy, quality, and energy transfer rates throughout the system at each time step.

The isothermal blowdown system was modeled using the RELAP4 computer code. The basic computer model, shown in Figure B-1, included 45 control volumes with 49 junctions interconnecting the volumes and connecting the ECC system to the appropriate volumes. The size and location of the control volumes were specified to give a reasonable representation of the system geometry while at the same time providing information at the approximate location of the experimental measurements.

The two-phase degraded pump model was used for the investigation of ECC performance in the isothermal system. This pump model accounts for the reduced or degraded capability of the pump to generate head by reducing the single-phase pump head according to the void fraction of the two-phase mixture at the pump. The single-phase homologous curves for the semiscale pump which were used to calculate the pump head for single-phase flow and the void fraction dependent multiplier that degraded the single-phase pump head according to the two-phase flow conditions were derived from tests performed on the semiscale pump.

Heat transfer from the metal surfaces was included in all RELAP4 computer runs used for the investigation of ECC behavior in the isothermal system. The Dittus-Boelter 


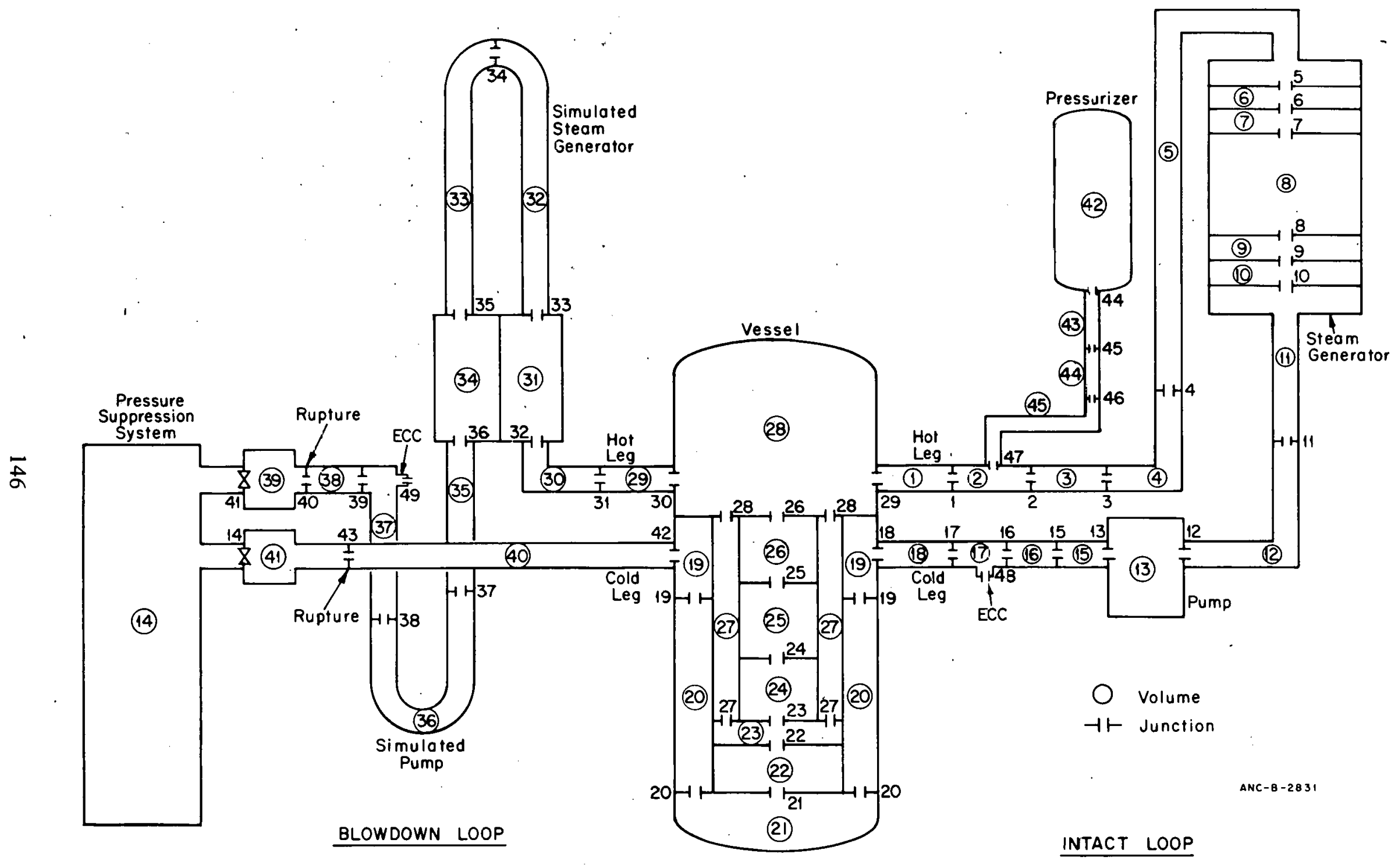

Fig. B-1 RELAP4 model of the isothermal system. 
correlation was used to calculate the heat transfer coefficient during single-phase water and steam flow. The Thom correlation was used to calculate flow boiling heat transfer coefficients and a form of the Schrock-Grossman correlation was used to calculate heat transfer coefficients in the transition between flow boiling and single-phase steam heat transfer. The use of these correlations is documented in the RELAP4 computer program description $[\mathrm{B}-1]$.

The flow at the break nozzles was calculated by the Moody critical flow model with an area multiplier of 0.6 . The 0.6 multiplier was found to be appropriate from past experiments performed in semiscale.

\section{REFERENCE}

B-1. K. V. Moore and W. H. Rettig, RELAP4 - A Computer Program for Transient Thermal-Hydraulic Analysis, ANCR-1 127 (December 1973). 


\section{THIS PAGE}

\section{WAS INTENTIONALLY \\ LEFT BLANK}


APPENDIX C

FILLER GAP FLOW ANALYSIS 
THIS PAGE

\section{WAS INTENTIONALLY \\ LEFT BLANK}




\section{APPENDIX C}

\section{FILLER GAP FLOW ANALYSIS}

Differences between the transparent vessel and semiscale system test results led to the conclusion that a flow path in addition to that through the downcomer annulus may have influenced the amount of water delivered to the lower plenum. An investigation led to the conclusion that a gap of approximately 0.05 inch existed between the filler piece and the vessel inside wall. This small filler gap resulted in a second flow path to the lower plenum during tests with the semiscale system. Only the single flow path through the downcomer annulus existed during the transparent vessel tests because the filler gap was sealed.

An analysis was performed to obtain an understanding of the effect on the overall flooding characteristics of the possible flow through the filler gap. As a first approximation, the water flow down the filler gap was calculated strictly on the basis of single-phase hydrodynamic resistance relationships. The amount determined was a significant portion $(\sim 18 \mathrm{gpm})$ of the vessel inlet flow and indicated that a two-phase analysis was warranted. A two-phase flooding curve for this gap was developed which was as consistent as possible with previous data obtained for small gap sizes. In a similar manner, a flooding curve was alsø developed for the downcomer annulus. The values of the constants for the filler gap flooding curves were obtained by trial and error, such that an overall mass balance was achieved for the lower plenum, that is, the water flowing down each gap (according to the flooding curves) added to give the total water measured out the lower plenum. In this manner, the effects of the small gap on the downcomer flooding characteristics were determined.

\section{APPROXIMATION OF SINGLE-PHASE FLOW DOWN FILLER GAP}

The flow down the filler gap was approximated through use of Streeter's expression for single-phase water flow through an annulus under a gravity head $[\mathrm{C}-1]$ :

$$
Q=-\frac{\pi}{8 \mu} \frac{d}{d 1}(p+\gamma h)\left[a^{4}-b^{4}-\frac{\left(a^{2}-b^{2}\right)^{2}}{\ln a / b}\right]
$$

where

$$
\begin{aligned}
\mu & =\text { absolute viscosity }\left(\mathrm{lb}_{\mathrm{f}}-\mathrm{sec} / \mathrm{ft}^{2}\right) \\
1 & =\operatorname{length}(\mathrm{ft}) \\
\mathrm{p} & =\operatorname{pressure}(\mathrm{psia})
\end{aligned}
$$




$$
\begin{aligned}
& \gamma=\text { specific weight }\left(\mathrm{lb}_{\mathrm{f}} / \mathrm{ft}^{3}\right) \\
& \mathrm{h}=\text { height of hydrostatic head }(\mathrm{ft}) \\
& \mathrm{a}=\text { filler gap outside radius }(\mathrm{ft}) \\
& \mathrm{b}=\text { filler gap inside radius }(\mathrm{ft})
\end{aligned}
$$

The following assumptions were applied to Equation (C-1):

(1) The flow is laminar

(2) The pressure term is small in comparison with the gravity term

(3) The height of the hydrostatic head is approximately equal to the length of the annulus.

Then, for standard pressure and temperature conditions (specific weight, $\gamma$, of 62.4 $\mathrm{lb}_{\mathrm{f}} / \mathrm{ft}^{3}$ and absolute viscosity, $\mu$, of $2.05 \times 10^{-5} \mathrm{lb}_{\mathrm{f}}-\mathrm{sec} / \mathrm{ft}^{2}$ ), for the semiscale filler gap of outside radius, a, equal to 4.305 inches $(0.35874 \mathrm{ft})$ and inside radius, $b$, of 4.255 inches $(0.35458 \mathrm{ft})$

$$
\begin{aligned}
\mathrm{Q} & =0.04109 \mathrm{ft}^{3} / \mathrm{sec} \\
& =18.44 \mathrm{gpm} \\
& =2.56 \mathrm{lb} \mathrm{m} / \mathrm{sec}
\end{aligned}
$$

This volumetric flow rate represents the amount of water that would flow down a 0.050-inch annular gap under a gravity head. This estimation indicated that the actual flow in the semiscale filler gap could be a significant portion of the vessel inlet flow and that a more comprehensive two-phase analysis was warranted.

\section{FLOW SPLIT CALCULATIONS}

The percentage of the total water flow going down the semiscale filler gap was determined by equating the pressure drop along the filler gap to that along the downcomer gap. Then the mass flow rate down the filler gap can be derived in terms of the total mass flow rate, $\dot{\mathrm{m}}_{\mathrm{T}}$, out the lower plenum; that is,

$$
\dot{\mathrm{m}}_{\mathrm{T}}=\dot{\mathrm{m}}_{1}+\dot{\mathrm{m}}_{2}
$$


where the subscripts 1 and 2 , in this and subsequent equations, refer to the filler gap and downcomer gap, respectively.

From basic fluid dynamics, the head loss is given by

$$
\frac{\Delta \mathrm{P}}{\gamma}=\left(\mathrm{k}+\mathrm{f} \frac{\mathrm{L}}{\mathrm{D}}\right) \frac{\mathrm{V}^{2}}{2 \mathrm{~g}}
$$

where

$$
\begin{aligned}
& \mathrm{P}=\text { pressure }(\mathrm{psfa}) \\
& \gamma \quad=\text { specific weight }\left(\mathrm{lb}_{\mathrm{f}} / \mathrm{ft}^{2}\right) \\
& \mathrm{k}=\text { minor friction loss coefficient } \\
& \mathrm{f}=\text { friction factor } \\
& \mathrm{L}=\text { length }(\mathrm{ft}) \\
& \mathrm{D}=\text { hydraulic diameter }(\mathrm{ft}) \\
& \mathrm{V} \quad=\quad \text { bulk velocity }(\mathrm{ft} / \mathrm{sec}) \\
& \mathrm{g} \quad=\quad \text { gravitational acceleration }\left(\mathrm{ft} / \mathrm{sec}^{2}\right) .
\end{aligned}
$$

The minor friction loss coefficient is the sum of the expansion and entrance losses, $k_{\text {exp }}$ and $\mathrm{k}_{\text {ent }}$, respectiv̀ely.

Since

$$
v^{2}=\frac{\dot{m}^{2}}{\rho^{2} A^{2}}
$$

where

$$
\begin{aligned}
\dot{\mathrm{m}} & =\text { mass flow rate }\left(\mathrm{lb}_{\mathrm{m}} / \mathrm{sec}\right) \\
\rho & =\text { density }\left(1 \mathrm{lb}_{\mathrm{m}} / \mathrm{ft}^{3}\right)
\end{aligned}
$$

$A=$ cross-sectional area $\left(\mathrm{ft}^{2}\right)$

Equation (C-3) can be written as

$$
\Delta P=\dot{P}\left(k+f \frac{L}{D}\right) \frac{\dot{m}^{2}}{2 g \rho^{2} A^{2}}
$$


The basic fluid dynamic system represented by the two gaps is a parallel network in which the head loss $(\Delta \mathrm{P} / \gamma)$ for each gap length must be the same. That is,

$$
\Delta \mathrm{P}_{\text {gap }}=\Delta \mathrm{P}_{\text {downcomer }}
$$

Application of the pressure drop equation to each gap gives

$$
\gamma_{1}\left(\mathrm{k}_{1}+\mathrm{f}_{1} \frac{\mathrm{L}_{1}}{\mathrm{D}_{1}}\right) \frac{\dot{\mathrm{m}}_{1}^{2}}{\rho_{1}^{2} \mathrm{~A}_{1}^{2} \mathrm{~g}}=\gamma_{2}\left(\mathrm{k}_{2}+\mathrm{f}_{2} \frac{\mathrm{L}_{2}}{\mathrm{D}_{2}}\right) \frac{\dot{\mathrm{m}}_{2}^{2}}{\rho_{2}^{2} \mathrm{~A}_{2}^{2} \mathrm{~g}}
$$

or

$$
\dot{\mathrm{m}}_{2}=\dot{\mathrm{m}}_{1} \frac{\mathrm{A}_{2} \rho_{2}}{\mathrm{~A}_{1} \rho_{1}}\left[\frac{\mathrm{k}_{1}+\mathrm{f}_{1} \frac{\mathrm{L}_{1}}{\mathrm{D}_{1}}}{\mathrm{k}_{2}+\mathrm{f}_{2} \frac{\mathrm{L}_{2}}{\mathrm{D}_{2}}}\right]^{1 / 2} \sqrt{\frac{\gamma_{1}}{\gamma_{2}}} .
$$

Through use of the mass balance represented by Equation (C-2), $\dot{\mathrm{m}}_{2}$ is expressed in terms of the total mass flow and $\dot{\mathrm{m}}_{1}$ as

$$
\dot{\mathrm{m}}_{\mathrm{T}}-\dot{\mathrm{m}}_{1}=\mathrm{m}_{1} \frac{\mathrm{A}_{2} \rho_{2}}{\mathrm{~A}_{1} \rho_{1}}\left[\frac{\mathrm{k}_{1}+\mathrm{f}_{1} \frac{\mathrm{L}_{1}}{\mathrm{D}_{1}}}{\mathrm{k}_{2}+\mathrm{f}_{2} \frac{\mathrm{L}_{2}}{\mathrm{D}_{2}}}\right]^{1 / 2} \sqrt{\frac{\gamma_{1}}{\gamma_{2}}} .
$$

Equation (C-9) is then solved for $\dot{\mathrm{m}}_{1}$ in terms of the total phase flow rate

$$
\dot{\mathrm{m}}_{1}=\frac{\dot{\mathrm{m}}_{\mathrm{T}}}{1+\frac{\mathrm{A}_{2} \rho_{2}}{\mathrm{~A}_{1} \rho_{1}}\left[\frac{\mathrm{k}_{1}+\mathrm{f}_{1} \frac{\mathrm{L}_{1}}{\mathrm{D}_{1}}}{\mathrm{k}_{2}+\mathrm{f}_{2} \frac{\mathrm{L}_{2}}{\mathrm{D}_{2}}}\right]^{1 / 2} \cdot \sqrt{\frac{\mathrm{r}_{1}}{\mathrm{r}_{2}}}}
$$

But

$$
\gamma=\frac{\rho g}{g_{c}}
$$


where $\mathrm{g}_{\mathrm{c}}$ is a conversion constant in $. \mathrm{lb}_{\mathrm{m}}-\mathrm{ft} / \mathrm{sec}^{2}-\mathrm{lb}_{\mathrm{f}}$. Hence, Equation (C-10) becomes

$$
\dot{\mathrm{m}}_{1}=\frac{\dot{\mathrm{m}}_{\mathrm{T}}}{\left.1+\frac{\mathrm{A}_{2}}{\mathrm{~A}_{1}}\left[\left(\frac{\rho_{2}}{\rho_{1}}\right)\left(\frac{\mathrm{k}_{1}+\mathrm{f}_{1} \frac{\mathrm{L}_{1}}{\mathrm{D}_{1}}}{\mathrm{k}_{2}+\mathrm{f}_{2} \frac{\mathrm{L}_{2}}{\mathrm{D}_{2}}}\right)\right]\right]^{1 / 2}} .
$$

This equation represents the mass flow rate of water flowing down the filler gap in terms of the total mass flow rate out the lower plenum.

The percentage of the total flow going down the filler gap for a $1 / 2$-inch downcomer gap in the semiscale system was determined using the following system dimensions and loss coefficients:

Dimensions

Core barrel outside diameter

Filler piece inside diameter

Filler gap outside radius

Filler gap inside radius

Downcomer gap and filler gap lengths

Downcomer hydraulic diameter

Filler gap hydraulic diameter

Downcomer gap cross-sectional area.

Filler gap cross-sectional area

\subsection{2 in.}

$6.25 \mathrm{in.}$

$0.35874 \mathrm{ft}$

$0.35458 \mathrm{ft}$

76 in.

$1.0 \mathrm{in}$.

$0.1 \mathrm{in}$.

$0.0644 \mathrm{ft}^{2}$

$0.00932 \mathrm{ft}^{2}$

\section{Loss Coefficients}

Downcomer

$\mathrm{k}_{\mathrm{l}_{\mathrm{exp}}}=1.0$

$\mathrm{k}_{\mathrm{l}_{\text {ent }}}=0.5$

$f_{1}=0.05$ $\underline{\text { Filler }}$

$\mathrm{k}_{2 \exp }=1.0$

$\mathrm{k}_{2_{\text {ent }}}=0.5$

$f_{2}=0.02$ 
If the fluid densities $\rho_{1}$ and $\rho_{2}$ are assumed equal, application of the preceding dimensions and loss coefficients to Equation (C-12) results in

$$
\dot{\mathrm{m}}_{1}=0.04 \dot{\mathrm{m}}_{\mathrm{T}} \text {. }
$$

For the 1/2-inch downcomer gap in the semiscale vessel, the flow rate down the filler gap represents approximately $4 \%$ of the total flow. The percentage flow down the filler gap was also calculated for the 1-inch downcomer gap that was also used for tests in the semiscale system. For this downcomer gap size, the flow down the filler was $0.0159 \dot{\mathrm{m}}_{\mathrm{T}}$. These results show that the influence of the filler gap is greater for a $1 / 2$-inch downcomer gap than for the 1 -inch downcomer gap in the semiscale system.

The preceding calculations were based on an average filler gap of 0.05 inch. When tolerances for all surfaces are taken into account, the gap could be as large as 0.100 inch or nonexistent. The actual gap existing within the assembled system was probably closer to an integrated average of these gaps which would be larger than 0.05 inch.

\section{DETERMINATION OF FLOODING CURVES USING STEADY STATE DATA}

Flooding curves were developed for the filler and downcomer gaps through use of the previous calculations for the $1 / 2$-inch downcomer gap. The generalized flooding curve is $[\mathrm{C}-2]$

$$
\mathrm{J}_{\mathrm{g}}^{*^{1 / 2}} \mathrm{D}^{1 / 4}+\mathrm{BJ}_{\ell}^{*} 1 / 2 \mathrm{D}^{1 / 4}=\mathrm{C}
$$

where

$$
\begin{aligned}
\mathrm{J}_{\mathrm{g}}^{*} & =\text { gas volumetric flux }=\frac{\mathrm{J}_{\mathrm{g}}}{\sqrt{\mathrm{gD}}}\left(\frac{\rho_{\mathrm{g}}}{\rho_{\ell}-\rho_{\mathrm{g}}}\right)^{1 / 2} \\
\mathrm{~J}_{\ell}^{*} & =\text { liquid volumetric flux }=\frac{\mathrm{J}_{\ell}}{\sqrt{\mathrm{gD}}}\left(\frac{\rho_{\ell}}{\rho_{\ell}-\rho_{\mathrm{g}}}\right)^{1 / 2} \\
\mathrm{D} . & =\text { hydraulic diameter }(\mathrm{ft}) \\
\mathrm{B}, \mathrm{C} & =\quad \text { constants dependent on geometry. }
\end{aligned}
$$

The constants $B$ and $C$ were initially estimated through use of published data. The following expressions resulted:

\section{$\underline{\text { Filler gap }}$}

$$
\mathrm{J}_{\mathrm{g}}^{*^{1 / 2}} \mathrm{D}^{1 / 4}+0.68 \mathrm{~J}_{\ell}^{\mathrm{K}^{1 / 2}} \mathrm{D}^{1 / 4}=0.405
$$




\section{Downcömer gap}

$$
\mathrm{J}_{\mathrm{g}}^{\mathrm{I}^{1 / 2}} \mathrm{D}^{1 / 4}+0.74 \mathrm{~J}_{\ell}^{*^{1 / 2}} \mathrm{D}^{1 / 4}=0.485
$$

A typical steady state test conducted in the semiscale system, was used as a basis for calculation. For this test, the mass flow rates of gas in the hot leg $\left(\dot{\mathrm{m}}_{\mathrm{g}}\right)$, filler gap $\left(\dot{\mathrm{m}}_{\mathrm{g}_{1}}\right)$, and downcomer gap $\left(\dot{\mathrm{m}}_{\mathrm{g}_{2}}\right)$ are

$$
\begin{aligned}
& \dot{\mathrm{m}}_{\mathrm{g}}=0.13891 \mathrm{~b}_{\mathrm{m}} / \mathrm{sec} \\
& \dot{\mathrm{m}}_{\dot{\mathrm{g}}_{1}}=0.04 \dot{\mathrm{m}}_{\mathrm{g}}=0.005556 \cdot 1 \mathrm{~b}_{\mathrm{m}} / \mathrm{sec} \\
& \dot{\mathrm{m}}_{\mathrm{g}_{2}}=\dot{\mathrm{m}}_{\mathrm{g}}-\dot{\mathrm{m}}_{\mathrm{g}_{1}}=0.133341 \mathrm{~b}_{\mathrm{m}} / \mathrm{sec}
\end{aligned}
$$

Through use of the continuity equation, $\mathrm{J}_{\mathrm{g}}=\frac{\dot{\mathrm{m}}_{\mathrm{g}}}{\rho \mathrm{A}}$, and $\rho_{\mathrm{g}_{1}}=\rho_{\mathrm{g}_{2}}=0.416 \mathrm{lb} \mathrm{m} / \mathrm{ft}^{3}$

$$
\mathrm{J}_{\mathrm{g}_{1}}=\frac{\dot{\mathrm{m}}_{\mathrm{g}_{1}}}{{ }_{\rho_{\mathrm{g}_{1}} \mathrm{~A}_{1}}}=4.2010 \mathrm{ft} / \mathrm{sec}
$$

and

$$
\mathrm{J}_{\mathrm{g}_{2}}=\frac{\dot{\mathrm{m}}_{\mathrm{g}_{2}}}{\rho_{\mathrm{g}_{2}} A_{2}}=14.6226 \mathrm{ft} / \mathrm{sec}
$$

Then for $\rho_{\ell}=57.3311 \mathrm{lb} / \mathrm{m}^{3}$,

$$
\mathrm{J}_{\mathrm{g}_{1}}^{1 / 2} \mathrm{D}_{1}^{1 / 4}=\frac{\mathrm{J}_{\mathrm{g}_{1}}{ }^{1 / 2}\left(\frac{\rho_{\mathrm{g}}}{\rho_{\ell}-\rho_{\mathrm{g}}}\right)^{1 / 4}}{(\mathrm{~g})^{1 / 4}}=0.1919
$$

and similarly

$$
\mathrm{J}_{\mathrm{g}_{2}}^{* 1 / 2} \mathrm{D}^{1 / 4}=0.3581
$$

Use of these values in the filler gap and downcomer flooding curves [Equations (C-14) and (C-15)] results in: 
Filler Gap

$$
\mathrm{J}_{\ell_{1}}^{* 1 / 2} \mathrm{D}_{1}^{1 / 4}=0.3134
$$

$J_{l_{1}}=\left[\frac{\left(\mathrm{J}_{l_{1}^{*}}^{1 / 2} \mathrm{D}_{1}^{1 / 4}\right) \mathrm{g}^{1 / 4}}{\left(\frac{\rho_{\ell}}{\rho_{\ell}-\rho_{\mathrm{g}}}\right)^{1 / 4}}\right]^{2}=0.5567$
Downcomer Gap

$$
\mathrm{J}_{\ell_{1}}^{* 1 / 2} \mathrm{D}^{1 / 4}=0.1715
$$

$$
\mathrm{J}_{\ell_{2}}=0.1667
$$

The flows to the lower plenum from the filler gap and downcomer gap were calculated to be:

Filler Gap

$$
\overline{\dot{\mathrm{m}}_{\mathrm{L}_{1}}}=\mathrm{J}_{\ell_{1}} \rho_{\ell} \mathrm{A}_{1}=0.29811 \mathrm{~b}_{\mathrm{m}} / \mathrm{sec}
$$

Downcomer Gap

$$
\overline{\dot{\mathrm{m}}_{2}}=\mathrm{J}_{\ell_{2}} \rho_{\ell} \mathrm{A}_{2}=0.6154 \mathrm{1b} / \mathrm{sec}
$$

The total calculated mass flow rate to the lower plenum is $0.9135 \mathrm{lb} \mathrm{m} / \mathrm{sec}$, which agrees to within $6 \%$ with the total measured flow rate of $0.980 \mathrm{lb}_{\mathrm{m}} / \mathrm{sec}$.

The $6 \%$ difference indicates that the constants for the two flooding curves are not exactly correct. Trial and error solutions were tried for obtaining the values of the constants which gave an optimum mass balance. The total mass balance was quite sensitive to the value of the constant $C$ used for each flooding curve. The eventual flooding curves with their respective constants are as follows:

Filler Gap

$\mathrm{J}_{\mathrm{g}}^{*^{1 / 2}} \mathrm{D}^{1 / 4}+0.68 \mathrm{~J}_{\ell}^{* 1 / 2} \mathrm{D}^{1 / 4}=0.410$
Downcomer Gap

$$
\mathrm{J}_{\mathrm{g}}^{* 1 / 2} \mathrm{D}^{1 / 4}+0.74 \mathrm{~J}_{\ell}^{* 1 / 2} \mathrm{D}^{1 / 4}=0.490
$$

\section{REFERENCES}

C-1. V. L. Streeter, Fluid Mechanics, McGraw-Hill Book Company (1971) p 243.

C-2. G. B. Wallis, One-Dimensional Two-Phase Flow, McGraw-Hill Book Company (1969) p 339. 


\section{$\therefore$}

APPENDIX D

DATA CORRELATION PREDICTIVE METHOD 
THIS PAGE

\section{WAS INTENTIONALLY \\ LEFT BLANK}




\section{APPFNDIX D}

\section{DATA CORRELATION PREDICTIVE METHOD}

An empirical data correlation was developed early in the isothermal test program to predict the delay in ECC delivery to the semiscale lower plenum that results from hot downcomer walls. This correlation, which is based on a downcomer energy exchange process, is written as:

$$
\mathrm{t}_{\mathrm{d}}=\frac{\left(1+\mathrm{b} \rho_{\mathrm{g}} \mathrm{j}^{2}\right)\left[_{\mathrm{w}} \mathrm{C}_{\mathrm{p}} \mathrm{k} \int_{\mathrm{A}}\left(\mathrm{T}_{\mathrm{wi}}-\mathrm{T}_{\mathrm{sat}}\right) \mathrm{dA}_{\mathrm{s}}\right]}{\dot{\mathrm{m}}_{\mathrm{ECC}} \overline{\mathrm{h}}\left(\mathrm{T}_{\mathrm{sat}}-\mathrm{T}_{\ell}\right)}
$$

where

$$
\begin{aligned}
& t_{\mathrm{d}}=- \text { delay in ECC delivery to the lower plenum (sec) } \\
& \mathrm{b}=\text { constant } \\
& \rho_{\mathrm{g}}=\text { steam density }\left(\mathrm{lb}_{\mathrm{m}} / \mathrm{ft}^{3}\right) \\
& \mathrm{j}=\text { superficial velocity of the steam entering the downcomer from the } \\
& \text { lower plenum (ft/sec) } \\
& \rho_{\mathrm{w}}=\text { downcomer wall material density }\left(\mathrm{lb}_{\mathrm{m}} / \mathrm{ft}^{3}\right) \\
& C_{\dot{p}}=\text { wall specific heat }\left(B t u / l b_{m}\right) \\
& \mathrm{k}=\text { wall thermal conductivity }\left(\mathrm{Btu} / \mathrm{hr}-\mathrm{ft}-{ }^{\circ} \mathrm{F}\right) \\
& A_{S}=\text { downcomer wall surface area }\left(\mathrm{ft}^{2}\right) \\
& \mathrm{T}_{\text {wi }}=\text { initial downcomer wall temperature }\left({ }^{\circ} \mathrm{F}\right) \\
& \mathrm{T}_{\text {sat }}=\quad \text { saturation temperature }\left({ }^{\circ} \mathrm{F}\right) \\
& \mathrm{m}_{\mathrm{ECC}}=\text { emergency core cooling flow rate }\left(\mathrm{lb}_{\mathrm{m}} / \mathrm{sec}\right) \\
& \overline{\mathrm{h}}=\text { overall heat transfer coefficient (Btu/hr-ft }{ }^{2}-{ }^{\circ} \mathrm{F} \text { ) } \\
& \mathrm{T}_{\ell}=\text { temperature of water entering the upper annulus region }\left({ }^{\circ} \mathrm{F}\right) .
\end{aligned}
$$


was assumed to be the average value over the period of time delay and was found to be equal to $177 \mathrm{Btu} / \mathrm{hr}_{-} \mathrm{ft}^{2}{ }^{2} \mathrm{O}_{\mathrm{F}}$ from a test with no steam entering the downcomer from the lower plenum (Test 1.2.6). This value of $\bar{h}$ was then used with the data from a test with steam flow from the lower plenum to evaluate the constant $b$. A value for $b$ of 0.0446 sec- $\mathrm{ft}^{2} / \mathrm{lb} \mathrm{m}$ was derived from Test 12.1.6. These values for $\hat{h}$ and $b$ were then used in evaluating the delay in delivery for other tests.

The delay in ECC delivery to the semiscale lower plenum calculated by the data correlation predictive method is compared in Figure D-1 to the measured delay times for a number of different tests. For some tests the different measurements in the lower plenum indicated different ECC delay times as reflected by the span of the data on the figure. Included in this figure are delay times for semiscale system transient countercurrent flow tests, isothermal system hot-wall tests, and isothermal system blowdown tests. The delay in ECC delivery for the blowdown tests was considered to result from countercurrent flow during blowdown and hot-wall effects after blowdown. Since all ECC was assumed to bypass the downcomer during the blowdown period, the delay in ECC delivery during the blowdown tests was the sum of the elapsed time from the initiation of ECC injection to the end of blowdown and the predicted delay time due to hot walls following the end of blowdown. The delay time due to the hot walls was determined from Equation (D-1) by using the downcomer wall temperatures, either measured or calculated, at the end of blowdown.

The delays in ECC delivery to the lower plenum calculated by the data correlation method are seen in Figure D-1 to agree well with the measured semiscale delay times. For all but a few tests, the delay times calculated by this simple method are within $\pm 20 \%$ of the measured values. However, since this method used data from the semiscale system to determine the unknown constants, $\overline{\mathrm{h}}$ and $\mathrm{b}$, and since the semiscale system tends to accentuate hot-wall phenomena, this method may not be directly applicable to other geometries. 


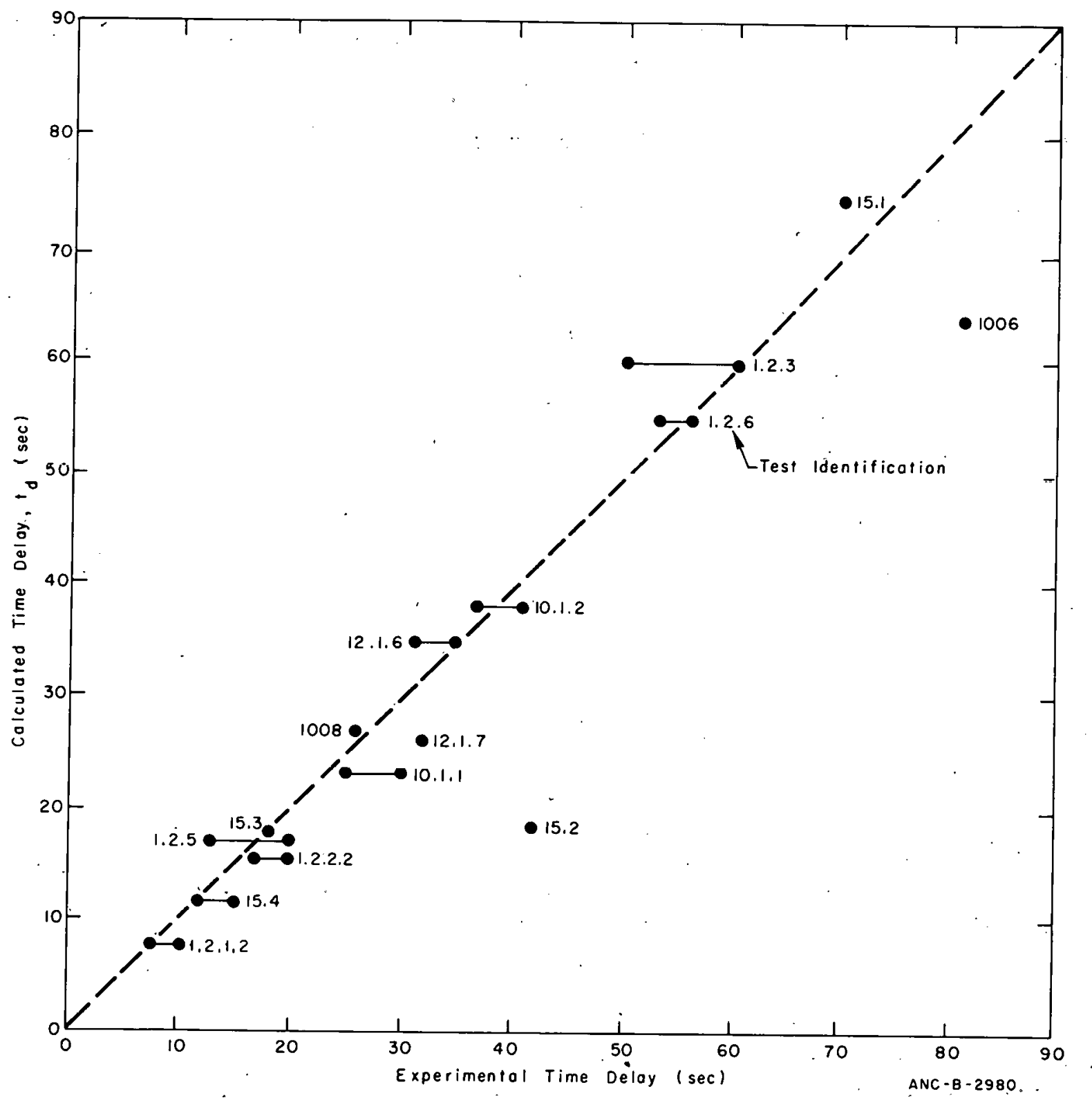

Fig. D-1 Comparison between delay time calculated by the data correlation method and that obtained experimentally. 


\section{THIS PAGE}

\section{WAS INTENTIONALLY \\ LEFT BLANK}




\section{APPENDIX E}

SOLUTION TO MATHEMATICAL EQUATIONS EMPLOYED IN THE HÓT-WALL COUNTERCURRENT FLOW PREDICTIVE MODEL 


\section{APPENDIX E \\ SOLUTION TO MATHEMATICAL EQUATIONS EMPLOYED IN THE}

HOT-WALL COUNTERCURRENT FLOW PREDICTIVE MODEL

The effect of hot downcomer walls on simulated ECC flow to the lower plenum is accentuated in the semiscale geometry. High velocity steam generated at the uninsulated downcomer walls restricts the downward flow of ECC. Since the delay in delivery of ECC to the lower plenum can be large in the semiscale system, a predictive model has been developed to aid in the prediction and interpretation of this delay during semiscale tests employing ECC.

Results from three related semiscale experimental programs were utilized in the development of the predictive model for the delay of ECC delivery to the lower plenum. The phenomena that were observed to occur in the downcomer and upper annulus regions during the semiscale system hot-wall tests were modeled using the results of the transparent vessel tests and the semiscale system countercurrent flow tests. The predictive model was then extended to blowdown tests by utilizing the isothermal system test results.

This appendix summarizes the assumptions on which the predictive model is based and the input required for application of the model.The method of solution of the mathematical equations used in the model is described.

\section{ASSUMPTIONS BASIC TO PREDICTIVE MODEL}

The predictive model assumes that most of the water entering the upper annulus is restricted from falling down the downcomer by the countercurrent flow of steam in the downcomer. The steam in the downcomer is that generated at the downcomer walls or that which has entered from the lower plenum. The water which enters the downcomer is assumed to progress down the downcomer walls in a falling film with the amount of heat transfer in the downcomer being determined by the position of the falling film, and the appropriate downcomer boundary conditions. The position of the falling film is determined by the amount of water entering the downcomer and the amount of steam flow that is necessary to cause some restriciton of the amount of water entering the downcomer. The process is then self-limiting because an increase in flow to the downcomer increases the rate of fall of the film and the downcomer heat transfer rate which. in turn increases the downcomer steam generation rate resulting in higher steam velocities and an accompanying decrease in the amount of water entering the downcomer. The specific major assumptions on which the model is based are as follows: 
(1) The countercurrent flow processes are controlled by conditions at the top of the downcomer filler piece (or at the top of the narrowest restriction in the annulus below the cold leg entrance) and the dimensional form of the Wallis countercurrent flow correlation applies at the control point.

(2) The enthalpy of water flow down the downcomer annulus past the control point can be calculated for thermal equilibrium steam-water mixing in the upper annulus with no mass or energy storage.

(3) The downcomer walls below the control point are independent of each other in that the water on the inner and outer walls below the control point does not interact. The water flowing down the downcomer annulus is divided between the two walls on the basis of wetted perimeter such that each wall has a uniform film of the same thickness.

(4) The effective steam volumetric flux is the same for both walls and countercurrent flow affects both walls in the same manner.

\section{INPUT TO PREDICTIVE MODEL}

The input information required by the predictive model is as follows:

(1) Node-dependent initial temperatures for conduction materials in the heat transfer model

(2) Boundary conditions for the inside of the core barrel and the outside of the insulation on the exterior of the vessel

(3) System pressure as a function of time

(4) The volumetric flux of steam entering the lower plenum from the core as a function of time

(5) Blowdown heat transfer coefficients as a function of time

(6) Enthalpy of the ECC at the cold leg entrance as a function of time

(7) Outside and inside diameters of the downcomer annulus, and other geometric information

(8) Water density as a constant 
(9) Modified Wallis countercurrent flow correlation constants

(10) System pressure at which ECC is initiated during blowdown

(11) Thermal properties as functions of temperature.

\section{METHOD OF SOLUTION}

The overall predictive method employs a mathematical model containing a set of equations and a computer program, SIMIR. The mathematical model and the computer program are coupled to provide a coupled solution for the entire method. The model and computer program are coupled as shown in Figure E-1. The model consists of three main sections - flooding, heat transfer coefficients, and conduction. SIMIR, a two-dimensional conduction heat transfer computer program, forms the nucleus of the entire computer model. The remainder of the model parts are programmed as subroutines to SIMIR. The solid flow lines show the coupling that would be used for a solution using iterative numerical techniques. Unfortunately, to iterate through the heat conduction portion of the SIMIR program is not possible and an alternate approximation must be used. This approximation is shown by the dashed lines in Figure E-1 and consists of an estimation of the integrated wall heat flux that will be calculated by the conduction portion during the next time advancement and an iteration around the heat conduction portion until the rest of the problem converges. The method of estimating the integrated heat flux utilizes the previous time step results and estimations to provide a new estimation which is altered until results and estimations converge. This method works well as long as the rate of transient heat transfer does not change too rapidly, and generally acceptable results have been obtained. 


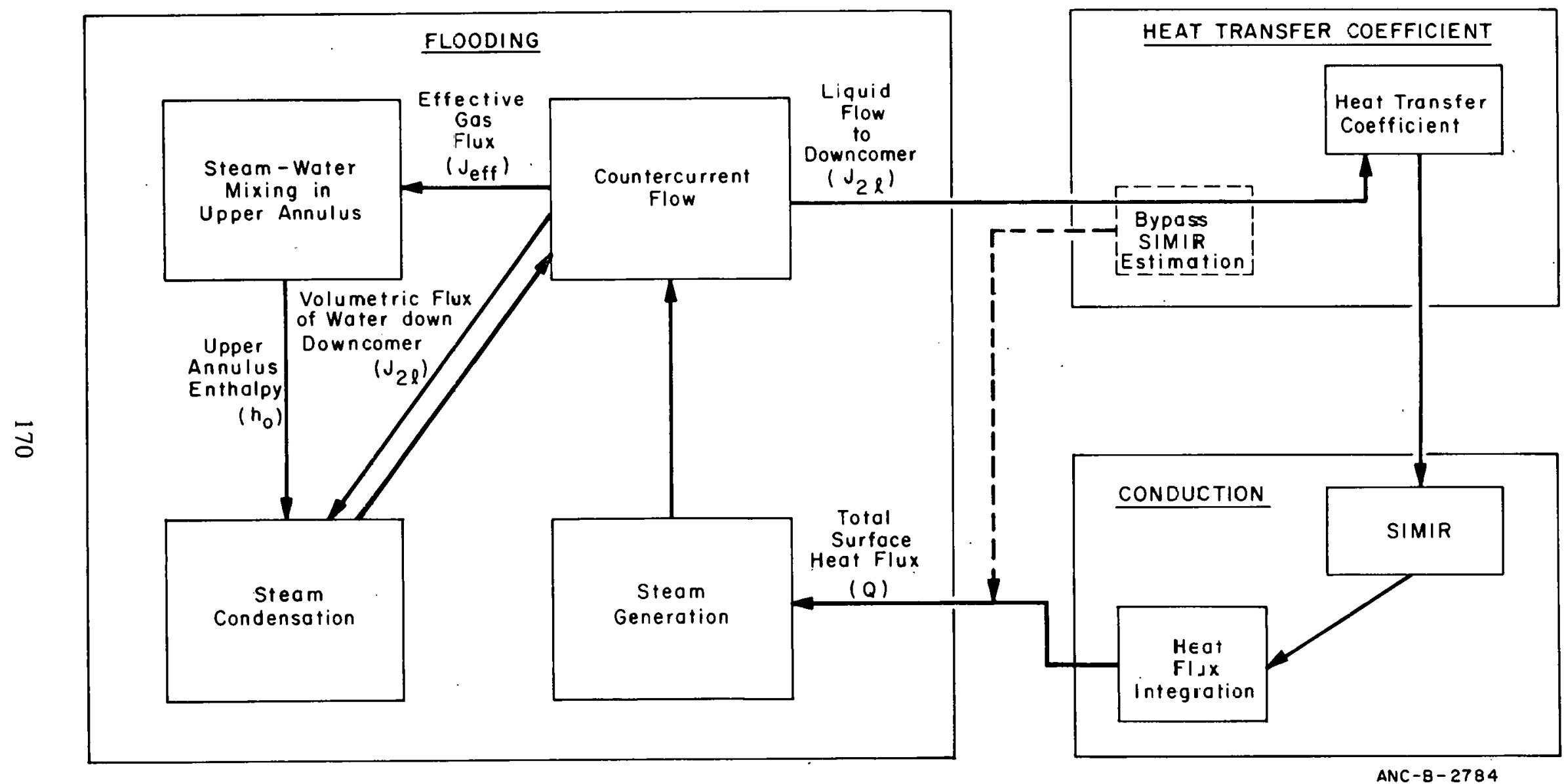

Fig. E-1 Model flow diagram. 


\section{SPECIFIC SOLUTIONS}

The hot-wall predictive model is solved in two major steps. First, the tlooding model in Figure E-1 is solved to obtain the volumetric flux of water flowing down the downcomer past the control point, $\mathrm{J}_{2}$, for a given integrated wall heat flux, $\mathrm{Q}$. The second step is to solve for $\mathrm{Q}$.

\subsection{Flooding Model}

The solutions of the flooding model requires the solution of the following equations:

$$
\mathrm{Jeff}^{*}{ }^{1 / 2}+\mathrm{B}_{2 \ell} \mathrm{J}_{2}^{* 1 / 2}=\mathrm{C}_{2}
$$

where

$$
\begin{aligned}
J_{\text {eff }}^{*} & =J_{\text {eff }}\left[\frac{\rho_{g}}{g\left(\rho_{\ell}-\rho_{g}\right)}\right]^{1 / 2},\left(\mathrm{ft}^{1 / 4}\right) \\
J_{2 \ell}^{*} & =J_{2 \ell}\left[\frac{\rho_{g}}{g\left(\rho_{\ell} \rho_{g}\right)}\right]^{1 / 2},\left(\mathrm{ft}^{1 / 4}\right) \\
\mathrm{B}_{2} & =0.72 \\
\mathrm{C}_{2} & =0.495 \\
\mathrm{~J} & =\text { the superficial velocity of the phase } \\
g & =\text { the acceleration due to gravity } \\
\rho & =\text { the phase density }
\end{aligned}
$$

and the subscripts eff, $2 \ell, \ell$, and $g$ refer, respectively, to the effective gas superficial velocity, the water, the saturated water properties, and the saturated steam properties.

The superficial velocity of the phase can be expressed as

$$
J_{\text {eff }}=J_{L P}+\frac{Q}{h_{f g} \rho_{g} A_{C S}}-J_{2 \ell}\left(\frac{\rho_{f}}{\rho_{g}}\right)\left(\frac{h_{f}-h_{o}}{h_{f g}}\right)
$$

where

$$
\begin{aligned}
& \mathrm{J}_{\mathrm{LP}}=\text { the volumetric flux rate of steam entering the lower plenum from the core } \\
& \mathrm{Q}=\text { the total energy per unit time transferred to the downcomer by heat } \\
& \text { transfer from the hot downcomer walls }
\end{aligned}
$$

$\mathrm{A}_{\mathrm{CS}}=$ the downcomer cross-sectional area 


$$
\begin{aligned}
& \mathrm{h}_{\mathrm{o}}=\begin{array}{l}
\text { the enthalpy of the water flowing into the downcomer. from the upper } \\
\text { annulus }
\end{array} \\
& \mathrm{h}_{\mathrm{f}}=\text { the saturated water enthalpy } \\
& \mathrm{h}_{\mathrm{fg}}=\text { the heat of vaporization for saturation conditions. }
\end{aligned}
$$

and

$$
h_{o}=\frac{m_{C L} h_{C L}+\rho_{g} J_{\text {eff }} A_{C S} h_{g}+Q_{\text {ua }}}{m_{C L}+\rho_{g} J_{\text {eff }} \Lambda_{C S}}
$$

where

$$
\begin{aligned}
& \mathrm{m}_{\mathrm{CL}}=\quad \text { the mass flow rate of injected ECC into the upper annulus through the cold } \\
& \mathrm{h}_{\mathrm{CL}}=\text { the enthalpy of the ECC water flow entering the upper annulus } \\
& \mathrm{Q}_{\mathrm{ua}}=\text { the rate of energy input to the upper annulus by heat transfer from the } \\
& \mathrm{h}_{\mathrm{g}}=\text { upper annulus walls }
\end{aligned}
$$

Combining these three equations into a single equation yields a fourth-order equation in $\mathrm{J}_{\mathrm{eff}}$ which has two mathematical real solutions and two imaginary solutions. The fourth-order equation is not solved directly, but rather a numerical approach is applied to two quadratic equations [Equation (E-1) and the combined Equations (E-2) and E-3)]. The forms of these two quadratic equations are shown in Figure E-2.

The countercurrent flow correlation, Equation (E-1), is shown as a straight line and the combined Equations (E-2) and (E-3) are shown as the curved lines labeled $A_{1}, A_{2}, A_{3}$, and $\mathrm{A}_{4}$ for four different magnitudes for the sum of the steam generated and lower plenum volumetric fluxes. Some of the mathematical real solutions are shown in this figure; the imaginary solutions are in the other quadrants and are not shown. The mathematical real solutions to the two quadratic equations are those points which the two equations have in common. Equation (E-1) is physically discontinuous at its intersection with both axes and follows the axes to infinity so that when the quadratic formed by the combined Equations (E-2) and (E-3) intersects an axis at a greater magnitude than the point of discontinuity of Equation (E-1), a mathematical real solution exists at this intersection.

The mathematic real solutions shown in Figure $E-2$ are labeled $S_{1}, S_{2}, S_{3}, S_{4}$, and $S_{5}$. Line $\mathrm{A}_{3}$ has only one mathematical real solution and line $\mathrm{A}_{4}$ does not have any. Where two mathematical solutions exist, the solutions which describe the physical phenomenon were 


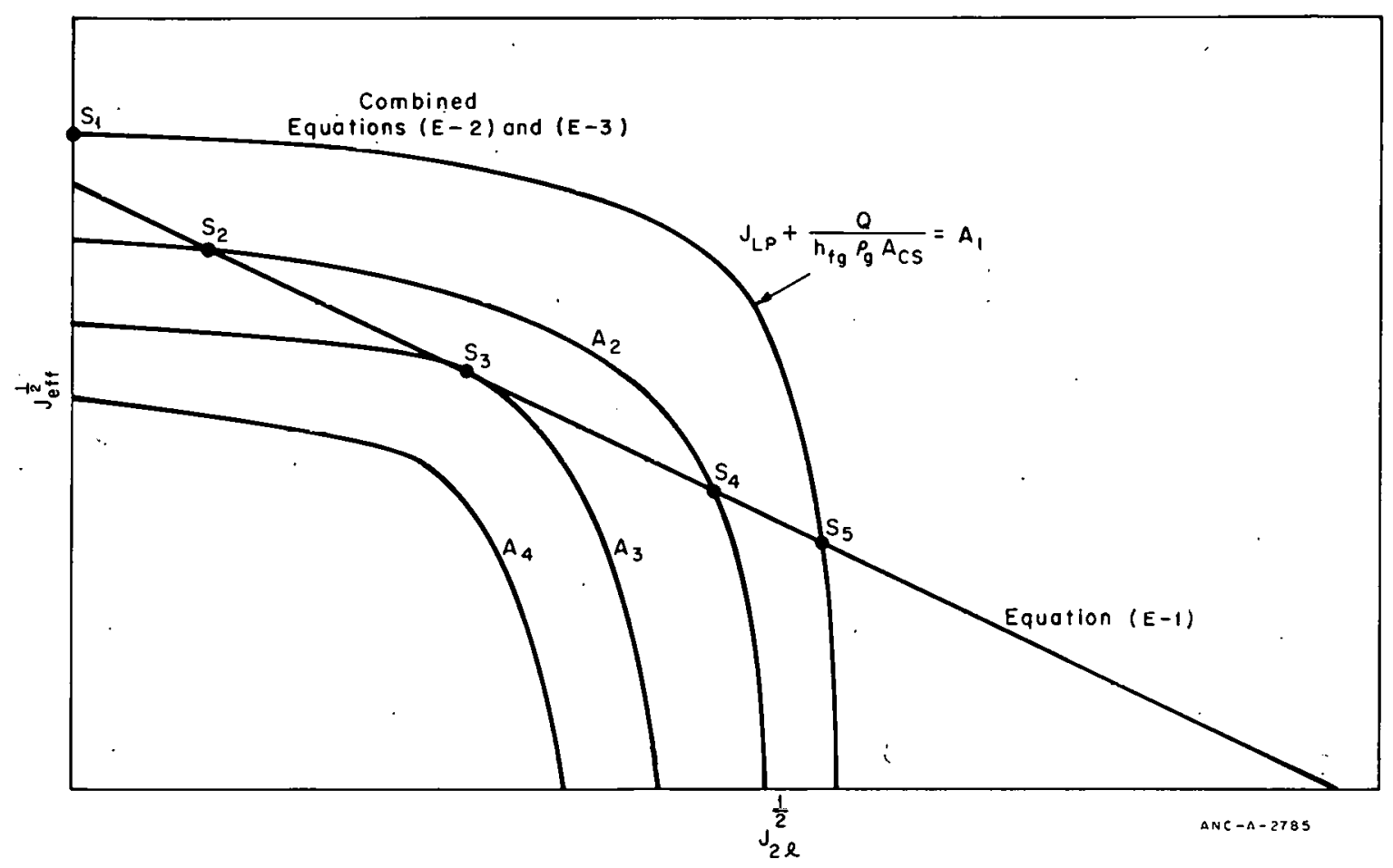

Fig. E-2 Flooding model solutions.

chosen by comparing the solution to experimental data. Experimentally, $\mathrm{J}_{2 \ell}$ is known to increase with decreasing $J_{\text {eff }}$, as is illustrated by Solutions $S_{1}, S_{2}$, and $S_{3}$ for decreasing magnitude of $A$. Solutions $S_{4}$ and $S_{5}$ show a decreasing $J_{2 \ell}$ with decreasing $A$, which is contradictory to experimentally observed data. When the magnitude of the volumetric flux is equal to that of line $A_{1}$, the water is being completely held up by the steam. As the steam volumetric Mux decreases to that of line $A_{2}$, solution $S_{2}$ shows the water being partially heldup; that is, some water flows down the wall. When the steam is further reduced to that of Line $A_{3}$, solution $S_{3}$ indicates the minimum steam flow which will hold up water. For any volumetric flux below that of line $A_{3}$, all water flows down.

\subsection{Integrated Heat Flux Solution}

The integrated heat flux $Q$ is calculated by applying a numerical iteration procedure to the flooding model that was solved in the previous section. These solutions are shown in Figure E-3 which is the solid line plot of $\mathrm{J}_{2 \ell}$ versus the value of $\mathrm{Q}$ input into the flooding model. As seen in the figure, a large $Q$ will result in the water flow down the annulus being completely shut off. As $\mathrm{Q}$ decreases from the shutoff point, $\mathrm{J}_{2 \ell}$ gradually increases until the flooding model reaches and passes the solution $S_{3}$ (Figure E-2), in which case $\mathrm{J}_{2 \ell}$ immediately goes to its maximum value determined by the inlet ECC flow rate. Two specific solutions are demonstrated in Figure E-3, one steady state and one oscillatory. The correct value of $Q$ is delermined through an energy balance which indicates that the integrated energy is equal to the energy necessary to remove the subcooling from the water flowing down the annulus and the energy to boil the water into steam. This energy balance is shown by the dotted lines in Figure E-3. The solutions for $Q$ are those points at which the dotted lines intersect the solid line. In the case of the steady state solution, water flows 


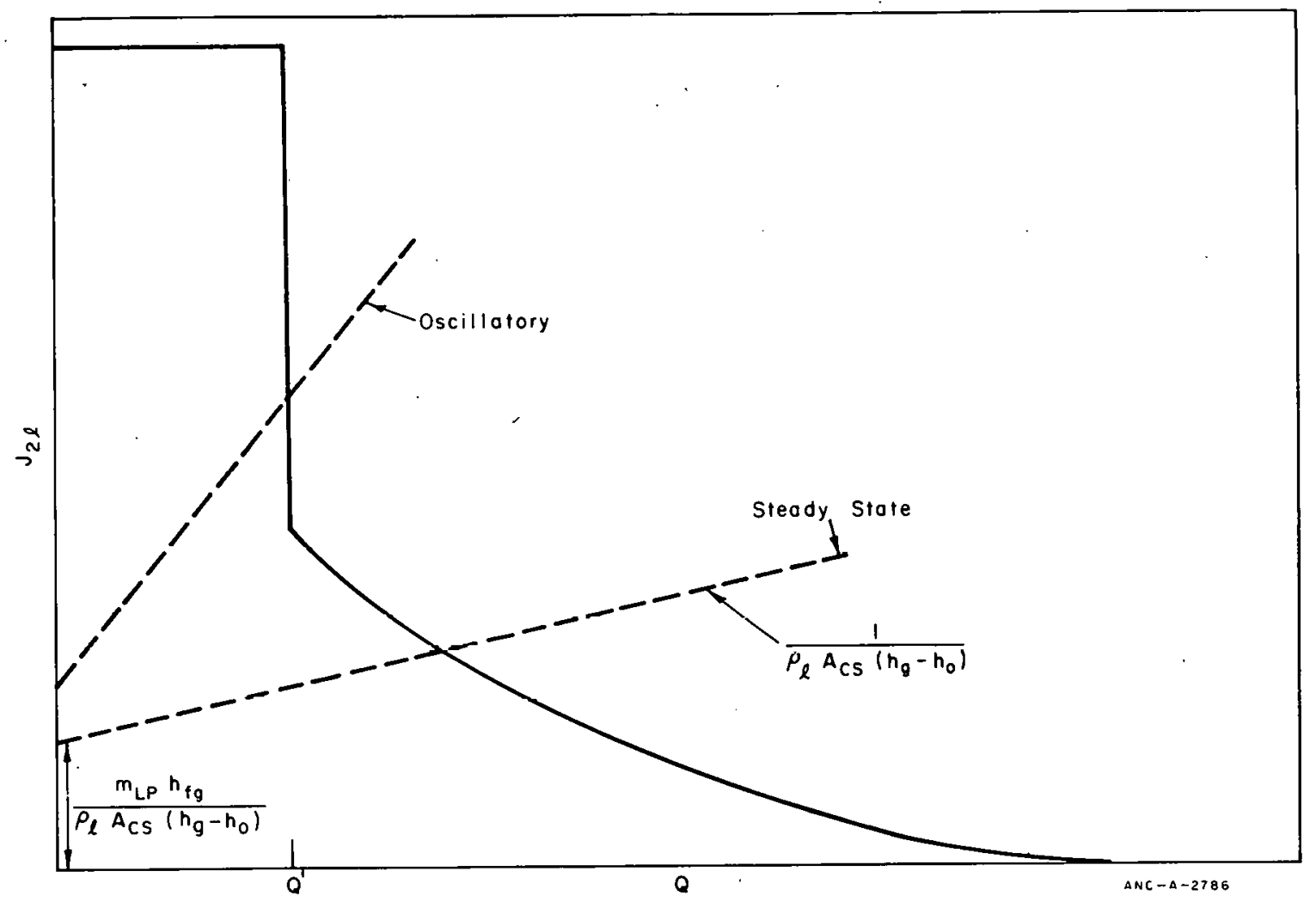

Fig. E-3 Flooding mode dependence on the integrated flux.

continuously down and is boiled into steam which flows back up the annulus. If the input conditions are constant for the ECC flow rate, the ECC enthalpy, the pressure, and the upper annulus heat transfer, then the rate of energy removal from the downcomer annulus is constant. For the oscillatory solution the dotted lines intersects the solid line along the vertical portion of the solid line, where $J_{2 \ell}$ goes to its maximum value. When $Q$ is equal to $Q^{\prime}$, no specific $J_{2 \ell}$ lies on the solid line. For any value of $Q$ greater than $Q^{\prime}$, water is held up and $\mathrm{J}_{2 \ell}$ has a specific value; and for any $\mathrm{Q}$ less than $\mathrm{Q}^{\prime}, \mathrm{J}_{2 \ell}$ has its maximum value. In terms of physical phenomena, if $Q$ is greater than $Q^{\prime}$ then sufficient water will flow down the annulus to generate the steam to hold up the water. Therefore, the steam flow will decrease with decreasing $Q$ and increasing water flow until $Q$ decreased below $Q^{\prime}$ and all the water is allowed to flow down. However, when all the water flows down, more water will come into contact with the hot walls thereby increasing the steam generation rate until $Q$ becomes greater than $Q^{\prime}$ and an oscillation has been completed. This solution mathematically shows a slug of water flowing into the annulus and generating steam which stops the water flow until the steam disperses or is condensed and lets another slug of water flow downward.

The position of the vertical portion of the solid line depends mainly on the value of the downcomer inlet enthalpy, which is dependent on pressure, ECC conditions, and upper annulus heat transfer. As $h_{\text {in }}$ approaches $h_{g}$, the vertical portion moves to the left and converges with the ordinate. 
The oscillatory solution needs a model which will be able to calculate such items as the frequency of oscillation, and the fraction of the cycle in which water or steam or both are in contact with the wall. Data are lacking in this area and:a model is not available. As a first try at determining an effective $Q$ for the oscillatory solution, $Q$ is assumed equal to $Q^{\prime}$ since $Q^{\prime}$ is somewhere close to the center of the oscillation. The reality of this assumption can only be evaluated.by how well the results from the model agree with existing data, and such agreement has been found to be reasonably good.

Finally; the nonflooding solution, which is a trivial solution, is that solution for which the maximum energy input capable by the downcomer annulus is less than $Q$ or the amount needed to hold up the water. In this case, the solution is that $\mathrm{J}_{2 \ell}$ is equal to its maximum value and water holdup does not occur.

The water flowing down the downcomer is divided between the two walls so that each wall can act independent of the other such that the total integrated energy of both walls is equal to Q. Since the walls have different dimensions, one wall will cool faster than the other; usually the core barrel wall will cool faster. When the core barrel becomes completely covered with water, some water will flow from the core barrel into the lower plenum. Shortly. after the core barrel becomes completely covered with water, the heat flux will begin to decrease, which will require the filler piece wall to contribute a larger fraction of the energy necessary for the generation of steam. A larger flow of water into the annulus is necessary so that additional water will be flowing on the filler wall to generate the extra steam. The end result is water holdup with some water being delivered to the lower plenum until the filler wall is quenched. 
